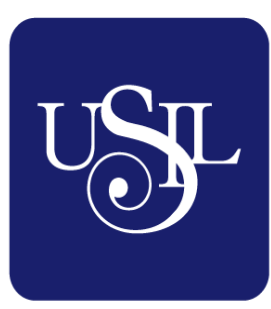

UNIVERSIDAD

SAN IGNACIO

DE LOYOLA

FACULTAD DE CIENCIAS EMPRESARIALES

Carrera de International Business

\title{
RELACIÓN ENTRE LA GESTIÓN DE CALIDAD TOTAL Y EL DESEMPEÑO EXPORTADOR DE MYPES EXPORTADORAS PERUANAS DE CACAO EN GRANO 2020
}

Tesis para optar el Título de Licenciado en International Business

JOHANA EVANELL JUÁREZ SÁNCHEZ (0000-00025986-0035)

Asesor:

MAG. JIMMY ELIAS SANCHEZ GOMEZ (000-0002-04256404)

Lima - Perú 


\section{Dedicatoria}

Este trabajo va dedicado con todo mi amor a mi familia; de manera especial a mi mamá; quien siempre confía en mí y me ayudó a cumplir un objetivo más en mi vida. 


\section{Agradecimiento}

En primer lugar, a Dios por mantenerme con salud y fortaleza, también hago extenso este reconocimiento a mi mamá, tía, hermanos, abuelo y a las personas que me permitieron lograr mis objetivos trazados. 


\section{Resumen}

El objetivo de la presente investigación fue sondear la relación entre la gestión de calidad total y el desempeño exportador de las empresas exportadoras peruanas MYPE en el Perú para el año 2020. De esta forma, se buscó contribuir a las empresas brindándoles información que puede ser de apoyo para el proceso de mejora de su producto de exportación logrando obtener una mayor cantidad de exportaciones generando estrategias de éxito a largo plazo para que el cliente y el empleado estén satisfechos llegando a tener una calidad de producto en todas sus etapas produciendo innovaciones continuas para alcanzar y posicionarse en el mercado internacional.

Por otro lado, el método que se utilizo fue el de análisis cuantitativo con un tipo de investigación correlacional y un diseño no experimental transversal, con una muestra de 50 empresas exportadoras de cacao en grano en el Perú. El instrumento de medición que se usó fue cuestionario, para mediar las variables gestión de calidad total y desempeño exportador se utilizó el cuestionario de los autores Imran, Hamid y Aziz (2018).

Los resultados alcanzados en la presente investigación validaron que la gestión de calidad total si se relaciona con el desempeño exportador de las empresas MYPES exportadoras peruanas de cacao en grano 2020.

\section{Palabras claves: Gestión de calidad total, Desempeño Exportador.}




\begin{abstract}
The objective of this research was to probe the relationship between total quality management and the export performance of Peruvian MYPE exporting companies in Peru for the year 2020. In this way, it was sought to contribute companies by providing them information that can be support for the process of improving their export product, achieving a greater quantity of exports, generating long-term strategies for success so that the client and the employee are satisfied, achieving success, and positioning in the international market.

On the other hand, the method used was quantitative analysis with a correlational time of research and a non-experimental and transversal design, with a sample of 50 companies exporting cocoa beans in Peru. The measurement instrument used was a questionnaire, to mesure the variables total quality management and export performance, the questionnaire of the authors Imran, Hamid and Aziz (2018) was used.
\end{abstract}

The results achieved in the present investigation validated that total quality management is related to the export performance of MYPES companies that export Peruvian cocoa beans 2020 .

Keywords: Total quality management, Export Performance. 


\section{Índice}

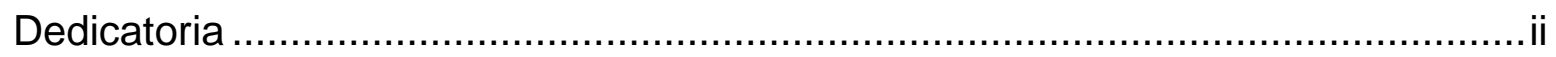

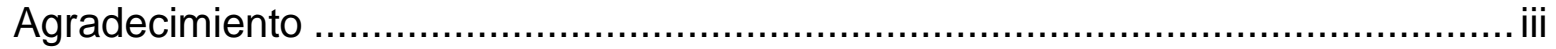

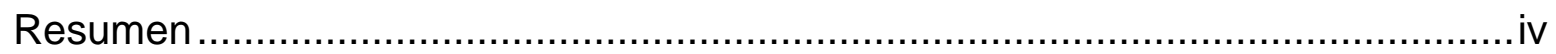

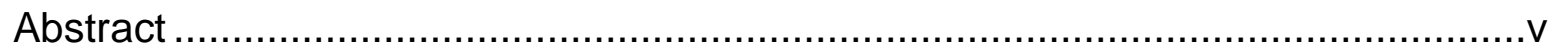

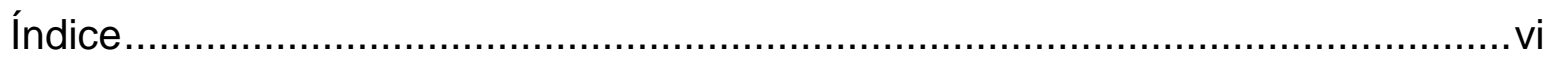

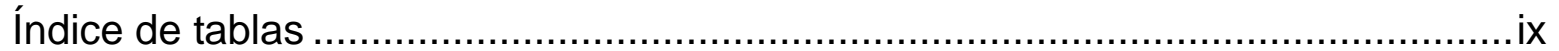

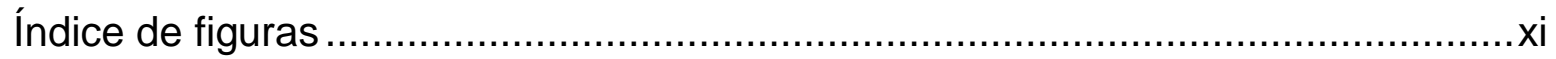

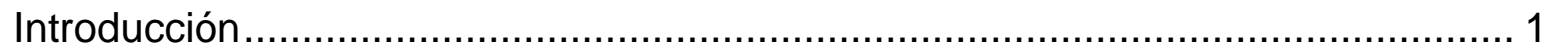

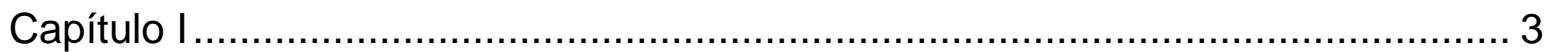

1.1. Problema de investigación ............................................................. 3

1.1.1. Planteamiento del problema. ........................................................ 3

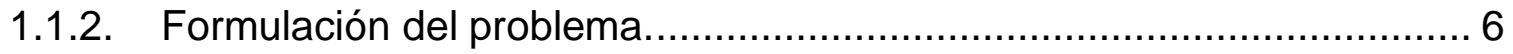

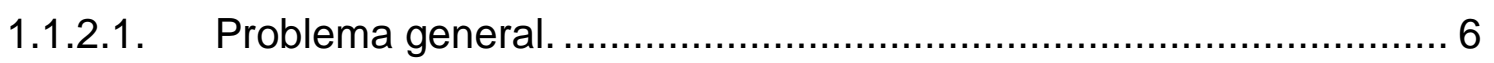

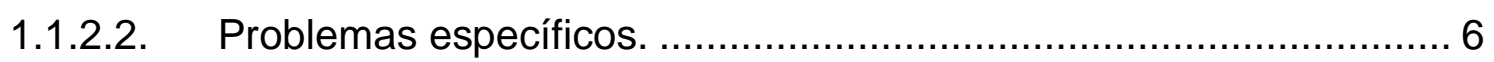

1.1.3. Justificación de la investigación..................................................... 6

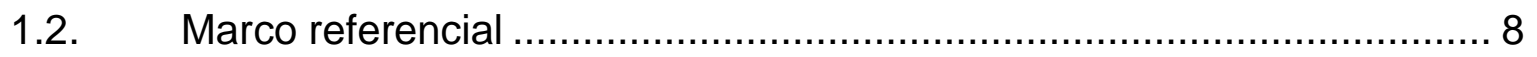

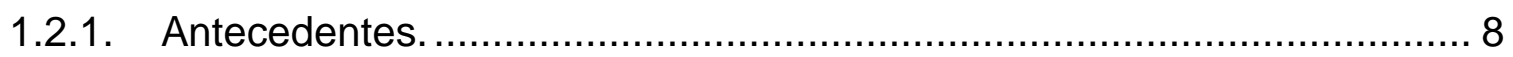

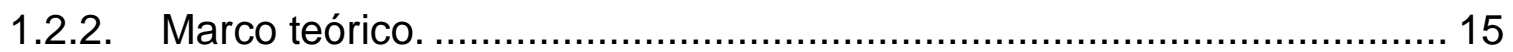

1.2.2.1. Gestión de calidad total......................................................... 15

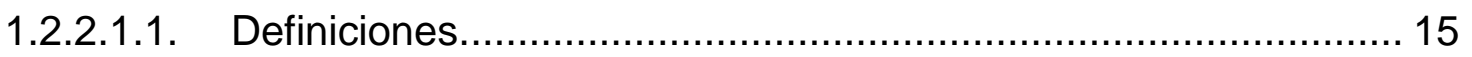

1.2.2.1.2. Principios de la gestión de calidad total. ................................... 16

1.2.2.1.3. Dimensiones de gestión de calidad total................................... 18

1.2.2.1.4. Teorías de la gestión de calidad total........................................ 19

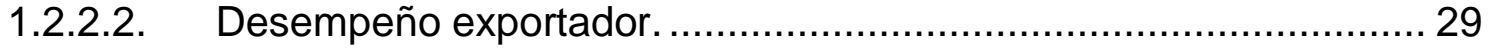

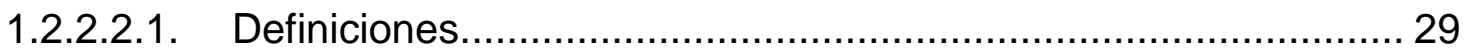

1.2.2.2.2. Características del desempeño exportador ................................ 30

1.2.2.2.3. Dimensiones del desempeño exportador.................................... 31

1.2.2.2.4. Teorías del desempeño exportador. ......................................... 32

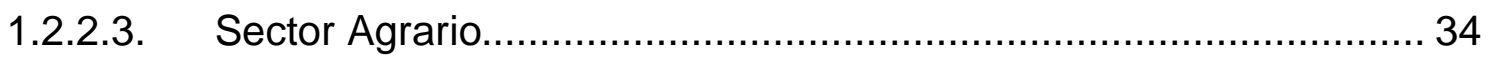




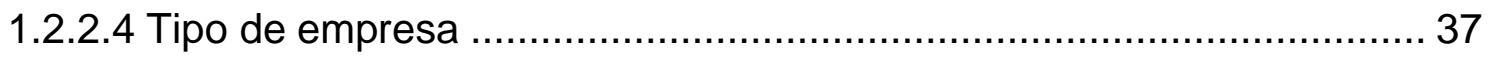

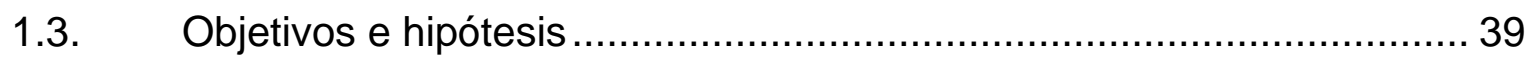

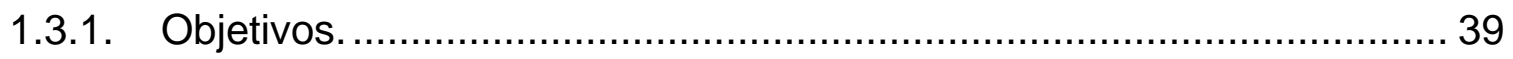

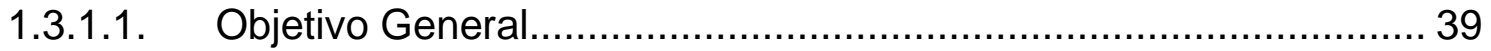

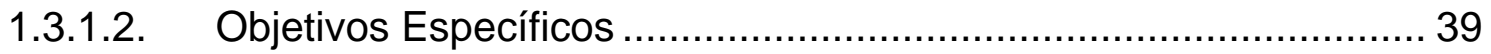

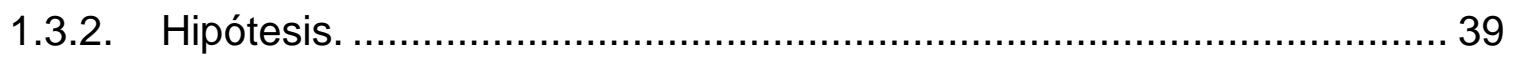

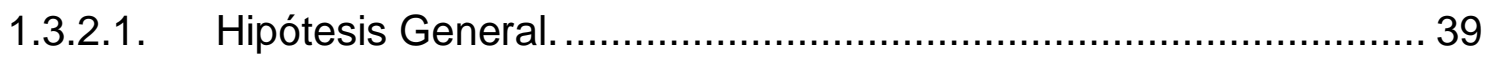

1.3.2.2. Hipótesis Específicas. ............................................................. 40

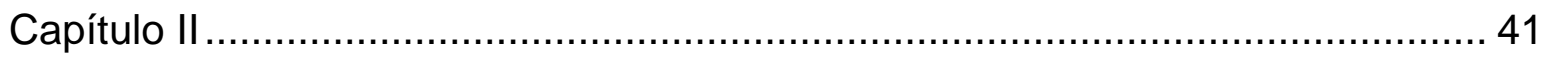

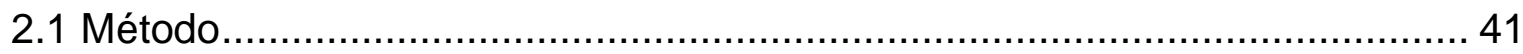

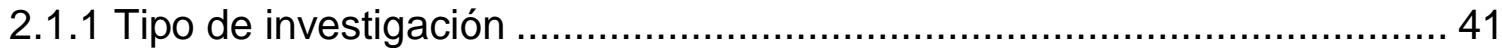

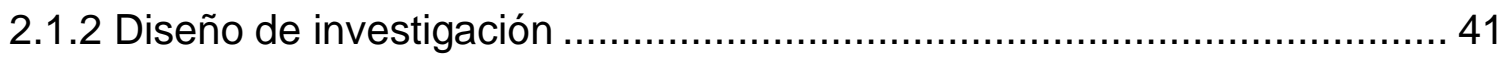

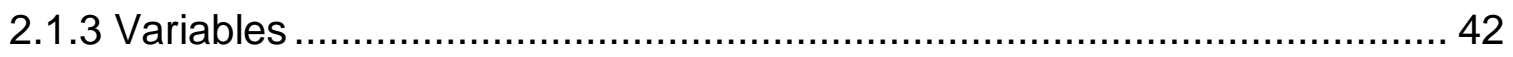

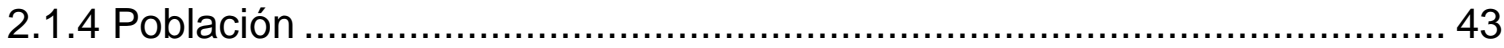

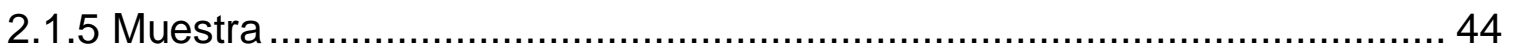

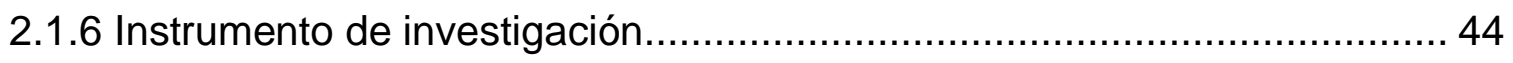

2.1.7 Procedimiento de recolección de datos .............................................. 46

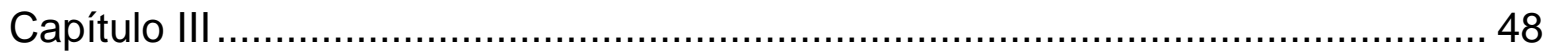

3.1. Análisis de los resultados de los cuestionarios .................................. 48

3.1.1. Análisis las encuestas de Gestión de calidad total.............................. 48

3.1.2. Análisis de las encuestas de Desempeño exportador.......................... 78

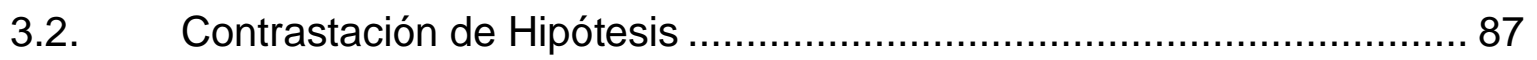

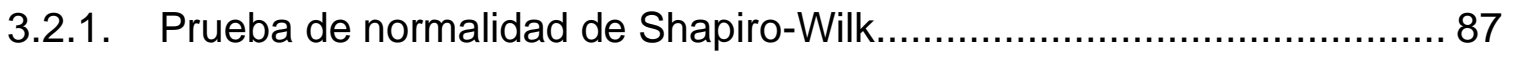

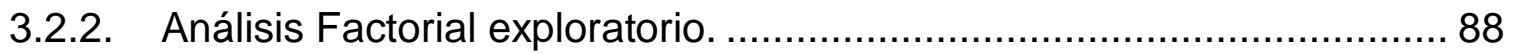

3.2.3. Correlaciones Rho Spearman....................................................... 95

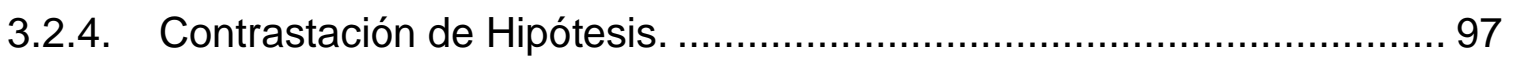

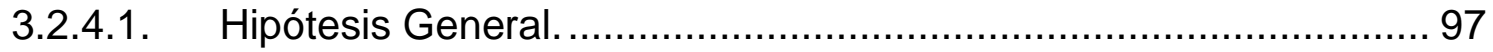

3.2.4.2. Primera Hipótesis Especifica.................................................... 98

3.2.4.3. Segunda Hipótesis Especifica. ...................................................... 99

3.2.4.4. Tercera Hipótesis Especifica.................................................... 100

3.2.4.5. Cuarta Hipótesis Especifica......................................................... 101 
3.2.4.6. Quinta Hipótesis Especifica................................................ 102

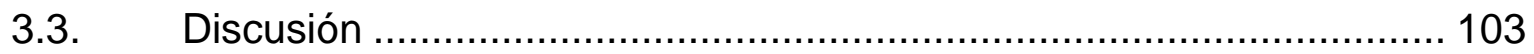

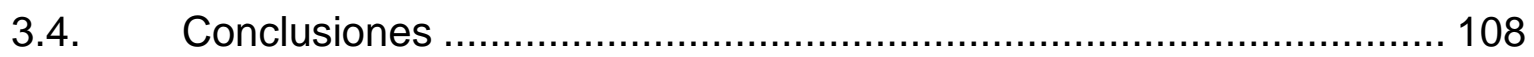

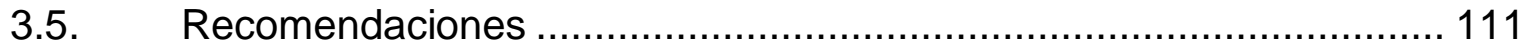

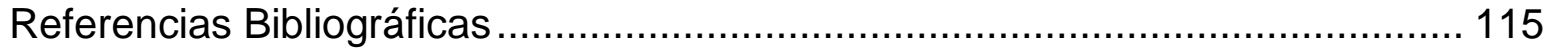

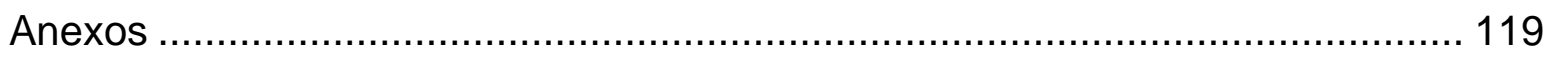

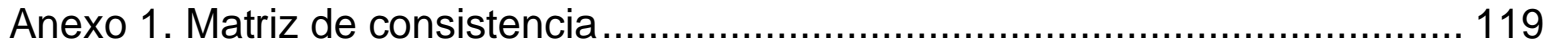

Anexo 2. Cuestionario de Gestión de calidad total y desempeño exportador ..... 121

Anexo 3. Prueba de Shapiro-Wilk-Gestión de calidad total ................................ 126

Anexo 4. Prueba de Shapiro-Wilk-Desempeño exportador ................................. 128

Anexo 5. Alfa de Cronbach........................................................................ 129

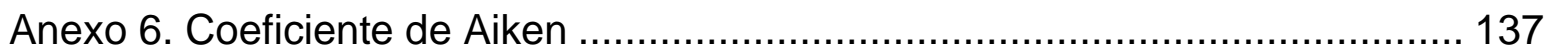

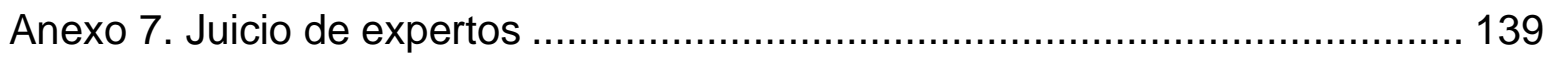




\section{Índice de tablas}

Tabla 1 Dimensiones del desempeño exportador ............................................................ 31

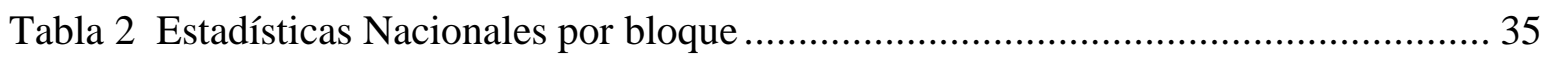

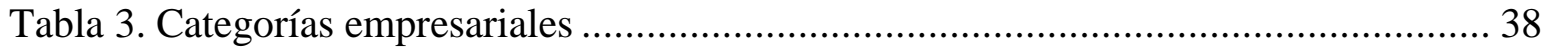

Tabla 4. Ficha Técnica Cuestionario gestión de calidad total ........................................... 45

Tabla 5. Ficha Técnica Cuestionario Desempeño exportador........................................... 46

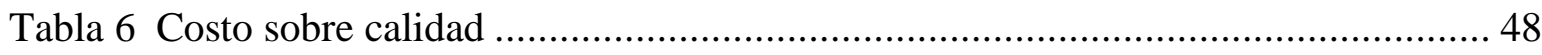

Tabla 7 Gerentes son modelos a seguir........................................................................ 49

Tabla 8 Empleados conocen los planes a largo plazo de la empresa.................................. 50

Tabla 9 Gerentes no desean otorgar a sus empleados decisiones sobre sus trabajos........... 51

Tabla 10 Los gerentes adquieren y actualizan su conocimiento continuamente ................. 52

Tabla 11 Gerentes fomentan y partición en iniciativas de mejora continua ....................... 53

Tabla 12 Opinión de clientes al diseñar nuevos productos ................................................ 54

Tabla 13 Opinión de proveedores en objetivos de la empresa ............................................. 55

Tabla 14 Evaluación y análisis del desempeño de los competidores................................... 56

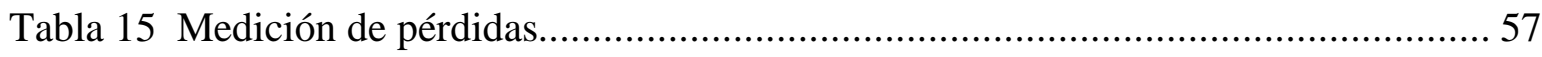

Tabla 16 Captura de información sobre clientes y mercados............................................... 58

Tabla 17 Evaluación del desempeño organizacional contra objetivos y metas...................59

Tabla 18 Procesos formales para conocer opiniones de empleados .................................... 60

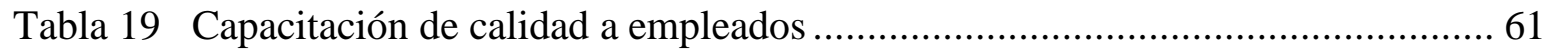

Tabla 20 Actualización de conocimiento y habilidades a empleados.................................. 62

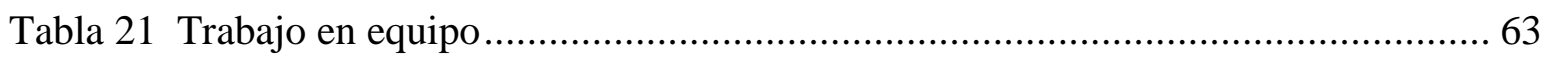

Tabla 22 Fácil acceso para empleados a información relevante ………………………...... 64

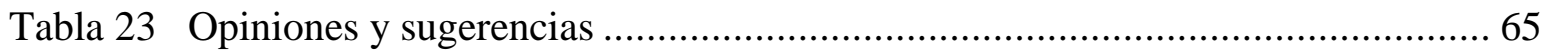

Tabla 24 Asociaciones a largo plazo con la organización .................................................. 66

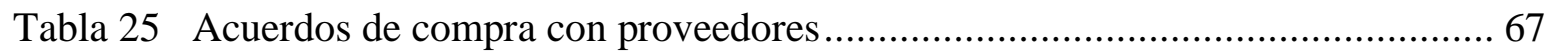

Tabla 26 Evaluación de desempeño de proveedores ........................................................... 68

Tabla 27 Información y recursos actualizados a los empleados.......................................... 69

Tabla 28 Reducción de efectos nocivos en el medio ambiente .......................................... 70

Tabla 29 Procedimientos para diferentes trabajos ......................................................... 71 
Tabla 30 Conocimiento de los parámetros de los diferentes procesos .......................... 72

Tabla 31 Monitoreo del desempeño de los procesos de producción ............................ 73

Tabla 32 Desarrollo y mejora de la empresa ........................................................ 74

Tabla 33 Desarrollo e innovación de los procesos de producción................................ 75

Tabla 34 Producción de acuerdo a especificaciones de diseño ................................... 76

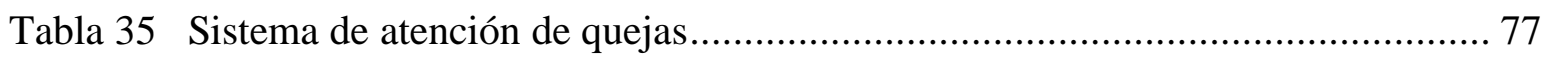

Tabla 36 Firma de exportación rentable............................................................ 78

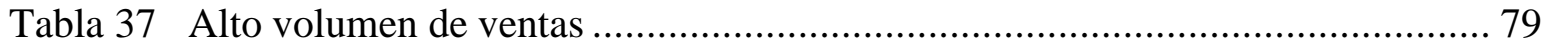

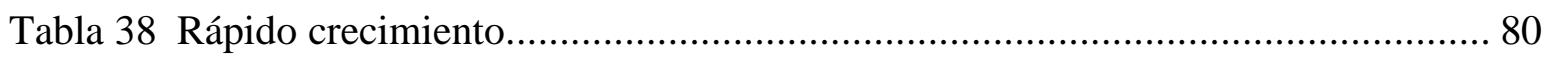

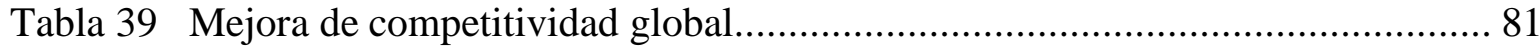

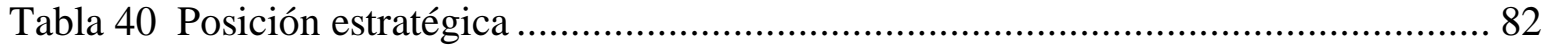

Tabla 41 Aumento de participación en el mercado global........................................ 83

Tabla 42 Desempeño exportador satisfactorio .............................................. 84

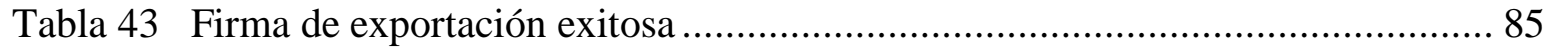

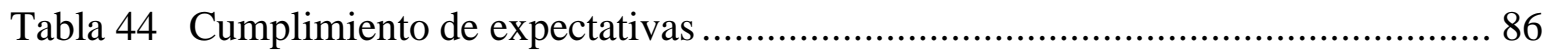

Tabla 45 Prueba de KMO y Bartlett -Gestión de calidad total................................... 89

Tabla 46 Varianza total explicada-Gestión de calidad total...................................... 89

Tabla 47 Matriz de factores rotados-Gestión de calidad total .................................... 90

Tabla 48 Prueba de Bartlett y KMO -Desempeño exportador................................. 93

Tabla 49 Varianza total explicada - Desempeño exportador ................................... 94

Tabla 50 Matrix Factorial-Desempeño exportador............................................... 94

Tabla 51 Correlaciones Rho Spearman para hipótesis general. .................................. 96

Tabla 52 Correlaciones Rho Spearman para hipótesis específicas............................. 96

Tabla 53 Resultado de Rho de Spearman - Hipótesis General ................................... 98

Tabla 54 Resultado de Rho de Spearman - Primera Hipótesis Especifica. .................... 99

Tabla 55 Resultado de Rho de Spearman - Segunda Hipótesis Especifica.................. 100

Tabla 56 Resultado de Rho de Spearman - Tercera Hipótesis Especifica................... 101

Tabla 57 Resultado de Rho de Spearman - Cuarta Hipótesis Especifica..................... 102

Tabla 58 Resultado de Rho de Spearman - Quinta Hipótesis Especifica...................... 103 


\section{Índice de figuras}

Figura 1. Modelo Baldrige para la evaluación de la calidad ............................................ 22

Figura 2. Modelo EFQM para la excelencia ................................................................. 24

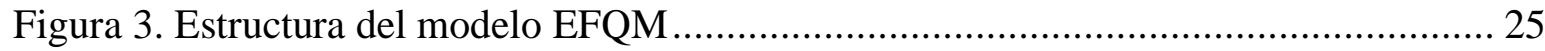

Figura 4. Puntuación de los criterios y subcriterios del modelo EFQM ............................ 26

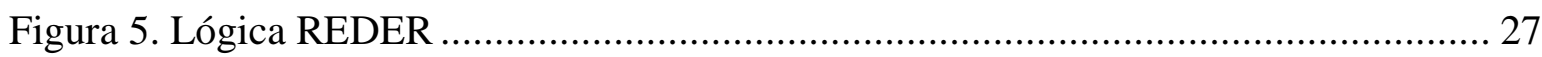

Figura 6. Evolución de las exportaciones de cacao en grano ................................................ 36

Figura 7. Precios mensuales internacionales de cacao en grano ……………………........ 37

Figura 8. Empresas exportadoras de cacao al 2019 ..................................................... 43

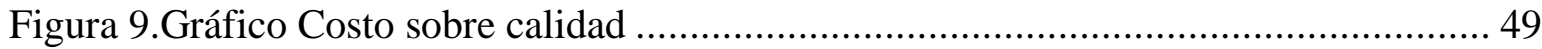

Figura 10.Gráfico Gerentes son modelos a seguir ......................................................... 50

Figura 11. Gráfico Empleados conocen los planes a largo plazo de la empresa .................. 51

Figura 12. Gráfico Gerentes no desean otorgar a sus empleados decisiones sobre sus

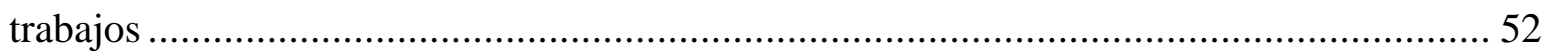

Figura 13. Gráfico Los gerentes adquieren y actualizan su continuamente su conocimiento

Figura 14. Gráfico Gerentes fomentan y partición en iniciativas de mejora continua ......... 54

Figura 15.Gráfico Opinión de clientes al diseñar nuevos productos ................................. 55

Figura 16. Gráfico Opinión de proveedores en objetivos de la empresa .............................. 56

Figura 17.Grafico Evaluación y análisis del desempeño de los competidores .................... 57

Figura 18. Gráfico Medición de pérdidas................................................................... 58

Figura 19. Gráfico Captura de información sobre clientes y mercados................................59

Figura 20. Gráfico Evaluación del desempeño organizacional ............................................. 60

Figura 21. Procesos formales para conocer opiniones de empleados ................................... 61

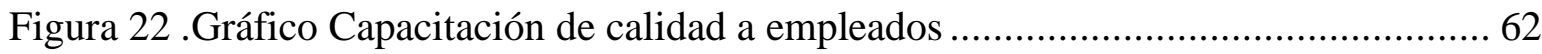

Figura 23 .Grafico Actualización de conocimiento y habilidades a empleados................... 63

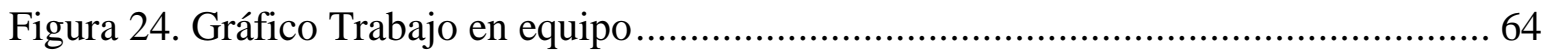

Figura 25.Gráfico Fácil acceso para empleados a información relevante ............................ 65

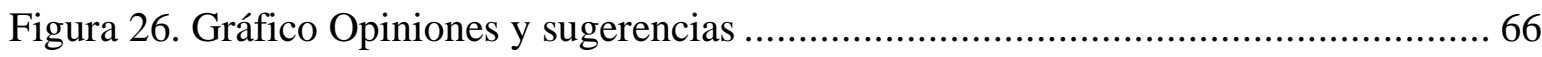


Figura 27.Gráfico Asociaciones a largo plazo con la organización ..................................... 67

Figura 28.Gráfico Acuerdos de compra con proveedores............................................... 68

Figura 29. Gráfico Evaluación de desempeño de proveedores ............................................ 69

Figura 30. Gráfico Información y recursos actualizados a los empleados........................... 70

Figura 31.Gráfico Reducción de efectos nocivos en el medio ambiente .............................. 71

Figura 32. Gráfico Procedimientos para diferentes trabajos ............................................... 72

Figura 33. Conocimiento de los parámetros de los diferentes procesos .............................. 73

Figura 34. Gráfico Monitoreo del desempeño de los procesos de producción .................... 74

Figura 35. Desarrollo y mejora de la empresa............................................................... 75

Figura 36.Gráfico Desarrollo e innovación de los procesos de producción........................... 76

Figura 37.Gráfico Producción de acuerdo a especificaciones de diseño .............................. 77

Figura 38. Gráfico Sistema de atención de quejas.......................................................... 78

Figura 39. Gráfico Firma de exportación rentable............................................................ 79

Figura 40. Gráfico Alto volumen en ventas ................................................................... 80

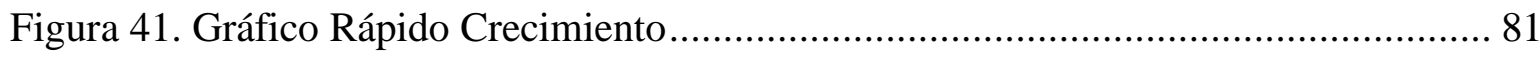

Figura 42.Gráfico Mejora de competitividad global .................................................... 82

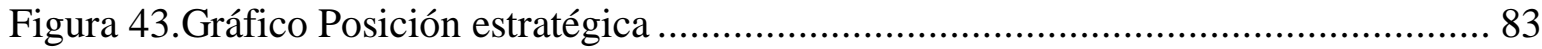

Figura 44 . Gráfico Aumento de participación en el mercado global.................................. 84

Figura 45. Gráfico Desempeño exportador satisfactorio ................................................ 85

Figura 46.Gráfico Firma de exportación exitosa ............................................................ 86

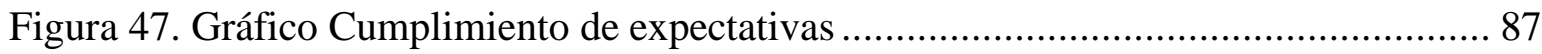




\section{Introducción}

La gestión de la calidad total es una estrategia de gestión orientada a crear una conciencia de calidad en todos los procesos que se realicen en cualquier tipo de organización. Se pretende que la calidad no sea responsabilidad únicamente de un departamento específicamente en una empresa, sino que se hace partícipe de esta responsabilidad a todos los integrantes de la organización. No se trata solamente de la calidad del producto o del servicio que ofrece la organización, va más allá al referirse a la calidad integral de los procesos y sistemas. Es decir, se reconoce que para lograr un producto o servicio final de calidad los procesos y sistemas empleados en la ejecución de los mismos deben ser de gran calidad y todos los niveles de la organización se involucran hasta conseguir que todos los integrantes de la empresa se empeñen en un logro colectivo y global de la máxima calidad.

Las MYPES deben entender que la gestión de calidad total es un factor clave para conseguir ventajas competitivas y poder regirse a las exigencias del mercado con el fin de lograr una efectiva conexión entre la gestión de calidad total y el desempeño exportador, en tal sentido, la presente investigación determina la relación que existe entre la capacidad de innovación y el desempeño exportador de empresas MYPE peruanas exportadoras de cacao en grano.

En el capítulo I se expone el problema de investigación y luego de ello se plantea, fórmula y justifica el problema. Posteriormente, se mencionan los antecedentes de estudios empíricos de investigadores internacionales seguidamente se expresan los objetivos e hipótesis de la presente investigación.

En el desarrollo del capítulo II se puntualiza la metodología aplicada y se define el tipo de investigación, diseño y variables a considerar. Posteriormente, se determina la muestra de investigación al igual que el instrumento utilizado como apoyo en la recolección de datos precisos y concretos.

El capítulo III inicia con la interpretación de los resultados obtenidos de cada pregunta del cuestionario brindado a los representantes de las empresas exportadoras MYPE de cacao en grano; además ,se realizó un análisis estadístico mediante el coeficiente Rho de Spearman a 
través del programa SPSS 26.Los resultados obtenidos de este análisis se compararon con los de otros investigadores permitiendo realizar una discusión sobre las similitudes encontradas pudiendo así llegar a las conclusiones y recomendaciones del presente estudio.

Se finalizó la investigación con la mención de las referencias bibliográficas las cuales fueron utilizadas para poder desarrollar la presente investigación de igual manera que con los anexos, las encuestas realizadas, la validación de expertos y la matriz de consistencia siendo estos necesarios para poder obtener la información que requeríamos. 


\section{Capítulo I}

\subsection{Problema de investigación}

\subsubsection{Planteamiento del problema.}

El Perú es un exportador de cacao, siendo este el octavo producto de mayor envío al exterior, y el segundo en la agroindustria, luego del café, con unas 150 mil hectáreas a nivel nacional siendo Europa el principal mercado de destino. Se tiene proyectado que para el 2020 las exportaciones de cacao tengan una reducción ya que, a partir del 1 de enero del 2019 se establecerá un límite máximo de cadmio a los productos derivados de cacao según lo publicado en el diario Gestión. Es por ello que es importante considerar y estudiar los suelos en los que se cosechan ya que actualmente hay más países que vienen poniendo restricciones y reglamentos al respecto, lo cual influye en la exportación.

Se tiene conocimiento que el cacao peruano está utilizando actualmente una tecnología de nivel medio en su producción logrando integrarse a la cadena producto internación además de que más del $50 \%$ de sus ventas han sido dirigidas a Europa logrando satisfacer su demanda debido la calidad de producto que tiene su cosecha según el Centro de Investigación de Economía y Negocios Globales (2019).

La Unión Europea en agosto del 2019 indicó que el problema del alto porcentaje de cadmio en los frutos de cacao afectaba a la salud ya que, según la OMS, el cadmio tiene efectos tóxicos en los riñones y en los sistemas óseos y respiratorios; además de estar clasificado como carcinógeno para los seres humanos. Luis Mendoza (2019), gerente de la Asociación Peruana de Productores de Cacao (APPCACAO) señala para el diario Gestión que la barrera comercial que se presenta es que los compradores de cacao de Europa van a exigir que el contenido de cadmio en el grano sea bajo, en base al reglamento, y de no llegar a un límite aceptable, no van a comprar o van a exigir un precio más bajo llegando a afectar las exportaciones por lo que debe haber una correcta gestión de calidad del grano en las cosechas. La producción de cacao genera 11 millones de jornales por año y un valor de US\$ 266 millones en exportaciones principalmente para el mercado europeo. Para el año 2018, los envíos de cacao en grano ascendieron a 85,000 toneladas los cuales fueron valorizadas en 
unos US\$ $187^{\prime} 000,000$ representando un crecimiento de un $18 \%$ con respecto a las exportaciones del 2017 (72,000 toneladas), de acuerdo con APPCACAO. Para el año 2020 el gremio de cacaotero espera que los envíos lleguen a ser de 90,000 toneladas representando un crecimiento del $6 \%$ respecto al año 2018. Esta reducción en la tasa de crecimiento se debe al impacto que tendrá según Mendoza.

Según informó el presidente Juan Varilias de la Asociación de Exportadores (ADEX, 2019) las MYPES (micro y pequeñas empresas ) dejaron de exportar en el primer trimestre del 2019 respecto al periodo anterior reflejando su creciente urgencia por fortalecer sus políticas de apoyo a su internacionalización ya que son varias las causas por falta de un plan de negocios en el ámbito de metas y propósitos como también el capital suficiente para poder sobrevivir en el mediano y largo plazo porque la mayoría de las empresas destinan sus recursos a pagos de créditos personales, inexperiencia, ausencia de una política de apoyo y la incapacidad para acceder a nuevos mercados

Según Rankin (2018), esta limitación impuesta por la Unión Europea a través del Reglamento 488/2014 aplicable desde el 1 de enero de 2019 bloqueará inmediatamente parte de las exportaciones de cacao de la zona Andina, lo que tendrá un fuerte impacto negativo sobre la cadena de producción de cacao, además de repercusiones económicas y sociales, teniendo en cuenta que la producción de cacao proviene, por lo general, de pequeños productores con mínimos ingresos. De acuerdo al Ministerio de Agricultura y Riego (Minagri) existe actualmente 100,000 familias, principalmente de agricultura familiar se dedican al cultivo del cacao en 16 de las 24 regiones del país.

Los niveles de cadmio en los granos de cacao dependen de una serie de factores, entre ellos: características químicas y biológicas físicas del suelo; el origen del material del suelo (la geología); la contaminación por uso de fertilizantes o el agua de riego con alto contenido de cadmio; y las capacidades de asimilación de los árboles de cacao, influenciadas por su origen genético (Rankin,2018).Al tener la cosecha este ingreso alto en químicos el producto final que es en este caso el grano del cacao llega a contaminarse teniendo una alta perdida de ventas en caso se desee exportar a la Unión Europea. Desde el año 2011 se estudiaba que otra principal fuente de contaminación de cadmio son los fertilizantes provenientes de roca 
fosfórica. Es por estas razones que es necesario determinar cuál es la condición actual de los suelos y de algunos productos agrícolas que por su alto consumo podrían representar un peligro para la salud humana. (Huamaní, 2011). Por otro lado, es importante resaltar que existen genotipos de cacao (variedades de la especies) que presentan una mayor absorción de Cadmio en la planta que otras; lo cual se debe tener en cuenta para estudiar cuales son las que deben mejorar y poder ser propagadas (D,Kadow., 2015).

Se tiene conocimiento que el cacao se cultiva en la parte baja de la selva peruana en la parte baja de la vertiente occidental de los andes, entre los 300 y 900 metros sobre el nivel del mar en 16 de los 24 departamentos de nuestro país siendo las principales zonas de producción los departamentos de San Martín, Junín, Ucayali, Cusco, Huánuco, Amazonas y Ayacucho representando el 93\% del total de la producción nacional. En el año 2018 la producción nacional fue de 135,000 toneladas a lo largo de 160,000 hectáreas siendo nuestro país propietario del $60 \%$ de las variedades del cacao.

El presidente de la Asociación de Exportadores (ADEX), Juan Varilias Velásquez destacó que, en los primeros siete meses del 2018, las presentaciones de cacao que lograron los mayores crecimientos fueron las de manteca de cacao (72\%), chocolate $(55 \%)$ y el cacao en grano (49\%) gracias a su alta calidad y excelente valoración en el extranjero.

En el Perú, el sector agrícola es uno de los más competitivos. En el 2017, se consolidó como el segundo generador de divisas para la nación; lo cual resaltó un impacto positivo para la economía (MINAGRI, 2018). Este resultado se dio gracias al incremento de las agro exportaciones peruanas, en primera instancia. Aún en medio de tanta crisis política, fenómenos naturales y problemas sociales; el sector continuó indicando alzas.

Es por ello que se procede a analizar la relación entre la relación de la gestión de calidad total y el desempeño exportador de las empresas MYPE peruanas exportadoras de cacao en grano 2020. 


\subsubsection{Formulación del problema.}

Para la formulación del problema se tomará en cuenta las dimensiones que definen gestión de calidad total con la variable desempeño exportador de los autores Imran, Hamid y Aziz (2018)

\subsubsection{Problema general.}

¿Cuál es la relación entre la gestión de calidad total y el desempeño exportador de empresas MYPE exportadoras peruanas de cacao en grano 2020?

\subsubsection{Problemas específicos.}

- ¿Existe relación entre el liderazgo y el desempeño exportador?

- ¿Existe relación entre la estrategia y el desempeño exportador?

- ¿Existe relación entre las personas y el desempeño exportador?

- ¿Existe relación entre los recursos y el desempeño exportador?

- ¿Existe relación entre los procesos y el desempeño exportador?

\subsubsection{Justificación de la investigación.}

La presente investigación tiene como objetivo principal determinar la relación que existe entre las dimensiones de gestión de calidad total y desempeño exportador de MYPES exportadoras peruanas de cacao en grano en el Perú. Es importante mencionar que el aporte de la variable "gestión de calidad total" representa un factor muy importante para el correcto desarrollo de esta investigación, ya que su aplicación permite a las empresas transformar el producto en lo que el mercado internacional demande con el correcto estándar de calidad requerido y tal cual el cliente final lo desea, lo cual influiría positivamente en la variable “Desempeño Exportador".

Si se enfoca la información recopilada, se podrá evaluar y demostrar el estado actual en términos de gestión de calidad total de las MYPES exportadoras de cacao en grano. El estudio 
brindará la oportunidad de conocer el escenario en el que actualmente operan dichas empresas y en qué magnitud se relaciona la gestión de calidad total con el desempeño exportador.

Considerando el enfoque comercial y empresarial de la presente investigación, los que se benefician directamente son los dueños y gerentes de MYPES exportadoras de cacao en grano ya que, brindándole un mayor énfasis a la gestión de calidad total de sus empresas, podrán brindar productos de nivel internacional haciendo posible que la oferta y la demanda se enlacen de manera positiva incrementando su productividad y su competencia a nivel global.

Indirectamente, los beneficiados serán los clientes internacionales y el estado propio. Los clientes internacionales se verán beneficiados ya que las empresas exportadoras de cacao en grano, al mejorar su producción, su operativa e incrementando su calidad exportadora lograran ofrecer productos de alta calidad con lo justo y necesario que el cliente busca, obteniendo que estos reciban la eficacia del servicio que requieren.

Por otro lado, el país se beneficiaría con la mejora del sector agrario, ya que este representa un elemento estratégico para la economía del Perú al ser la segunda fuente generadora de divisas después de la minería debido al crecimiento sostenido de las agroexportaciones, informó el Ministerio de Agricultura y Riego (Minagri). Asimismo, se detalló que las exportaciones agrarias tradicionales alcanzaron los 599 millones de dólares, concentrando el $13 \%$ del total de las agro exportaciones. Los hallazgos de esta investigación servirán también para sectores afines, así como referencia para futuras investigaciones.

Según cifras estimadas del INEI, en el año 2006 la participación del sector agropecuario sobre el PBI fue del 8.3\%; en relación a la importancia relativa del sector agropecuario en la economía nacional, se calculó que el 31.6\% (8.1 millones de habitantes) de la población nacional vive de la actividad agropecuaria, y que el sector agricultura emplea al 31.2\% (2.8 millones de personas) del total de la PEA ocupada nacional.

Se busca con el planteamiento de la investigación que los exportadores de cacao sean los más beneficiados al fomentar la competitividad y crecimiento de su participación en los 
mercados internaciones beneficiando al sector agrario por las mejores en cuanto al volumen de las exportaciones. Además de ello el beneficio directo es para los gerentes y trabajadores al convertirse en una empresa competitiva en un mercado internacional adquiriendo mayor rentabilidad y utilidad y por ultimo todos los peruanos son los beneficiados indirectamente ya que ayudara a mejorar la exportación logrando tener una mejor calidad de producto para exportar incrementando el porcentaje de exportación y por consecuencia de ello el PBI.

\subsection{Marco referencial}

\subsubsection{Antecedentes.}

Se realizó investigación literaria respecto a las variables gestión de calidad total y desempeño exportador a nivel internacional. Se obtuvo variedad de estudios; sin embargo, los más resaltantes se presentan a continuación.

El artículo "The Role of Quality in Determining Export Success" Bruce Barringer,S. Thomas Foster Jr. \& Granger Macy (1999). Para las empresas de esta muestra existe una relación positiva significativa entre la calidad del producto de exportación y el éxito de la exportación. Este problema es importante para los gerentes de operaciones, que deben priorizar los recursos de su empresa para lograr los mejores resultados al ingresar a los mercados extranjeros. La relación calidad del producto de exportación-éxito de exportación parece ser bastante sólida. Mientras se controla estadísticamente el tamaño de la empresa, la experiencia de exportación y las estrategias de mercado de la fijación de precios, promoción y distribución, se encontró una relación positiva entre la calidad del producto de exportación y el rendimiento de la exportación. La importancia de este resultado es convincente y los gerentes de producto tienen el desafío de desarrollar estrategias para competir en mercados de exportación desconocidos. El desarrollo de productos de alta calidad es un antecedente importante para el éxito de las exportaciones. 
El artículo "Service Quality and Export Performance of Business-to-Business Service Providers: The Role of Service Employee- and Customer-Oriented Quality Control Initiatives" Christina Sichtmann, Maren von Selasinsky, Adamantios Diamantopoulos (2011).Utilizando el marco de instalaciones-transformación-uso de la provisión de servicios y basándose en la teoría del control, los autores desarrollan un modelo teórico que examina la influencia de diferentes iniciativas de control de calidad en la calidad relativa del servicio en un entorno de empresa a empresa y, en consecuencia, en la exportación. Consideran explícitamente las iniciativas de control de calidad que abordan el desempeño de los empleados de servicio y la coproducción de los clientes, así como las características seleccionadas de la empresa como antecedentes de tales iniciativas. Se ponen a prueba el modelo propuesto en datos extraídos de una encuesta de exportación de proveedores de servicios y los resultados muestran que la capacitación orientada al cliente de exportación, las instrucciones de coproducción del cliente y la estandarización del proceso de trabajo tienen una influencia positiva en la calidad relativa del servicio, lo que a su vez afecta positivamente el desempeño de la exportación. Sin embargo, La adaptación a la competencia y motivación de coproducción de los clientes de exportación tiene una influencia positiva en la calidad relativa del servicio solo cuando la integración del cliente en la prestación del servicio es alta. Los autores concluyen considerando las implicaciones para la gestión del proceso de prestación de servicios en un entorno de exportación e identificando futuras direcciones de investigación.

El artículo "TQM and performance: Is the relationship so obvious?" Corredor \& Goñi (2011). Este estudio explora la relación entre la gestión de calidad total (TQM) y el desempeño de la empresa, tomando la gestión de calidad total como un sistema de prácticas internamente consistente. El estudio prueba el vínculo entre las dos variables utilizando el enfoque universal, analiza si las empresas más competitivas son las que adoptan gestión de calidad total y prueba un efecto igual en otras empresas. El estudio utiliza una muestra de empresas españolas que han recibido premios de gestión de calidad total a nivel nacional o regional entre 1997 y 2003 y una muestra de control para comparar. Los resultados indican que, en ausencia de evidencia para confirmar la hipótesis universal, los pioneros de la gestión de calidad experimentan ganancias de rendimiento, debido a la implementación temprana del 
sistema; sin embargo, los adoptadores tardíos no experimentan resultados similares. Por otro lado, las empresas que usan un sistema de gestión de calidad total no son necesariamente mejores que sus contrapartes, antes de poner el sistema en acción. El estudio utiliza datos de panel que tienen en cuenta la heterogeneidad no observable entre individuos y la dinámica de las variables financieras de las empresas.

El estudio "The effect of information, communication and technology (ICT) and quality management to export performance of Malaysian's SME in manufacturing sector" Journal of Scientific Research and Development 2 (2015). Este documento tiene como objetivo explorar la influencia de las ICT y la gestión de la calidad en el rendimiento de las exportaciones en el Valle de Klang, Malasia. Mediante el uso del método cuantitativo de un total de 416 encuestas, fueron retornados 200 cuestionarios lo que hace que la tasa de respuesta de este estudio sea del 50\%. Los datos se analizaron utilizando diversos análisis descriptivos, de validez, confiabilidad y correlación. Los hallazgos discuten estadísticas descriptivas de los datos, incluidos datos demográficos de los encuestados, confiabilidad y análisis de correlación. Se espera que los resultados brinden una breve visión del desempeño de las exportaciones en Malasia en la perspectiva de la información, comunicación y tecnología con la gestión de la calidad. Como resultado se obtuvo que uso de las TIC en las empresas fue exitoso en cuanto a la utilización de aplicaciones y software en sus sistemas de negocio y de gestión con el fin de realizar sus actividades sin problemas. Por otro lado, casi todos los encuestados creen que la aplicación de gestión de la calidad trajo beneficio a sus empresas y productos, especialmente en la atracción de clientes extranjeros. Los responsables políticos deberían beneficiarse de estos hallazgos para una mejor política que se adapte a la dinámica de la demanda internacional en el futuro. El gobierno de Malasia se beneficia de estos hallazgos al considerar la posibilidad de proporcionar más asistencia financiera a las PYME en Malasia para implementar las TIC y la gestión de calidad en sus negocios, de modo que puedan competir con el dinámico mercado internacional.

$\mathrm{El}$ artículo "The relationship between innovation and total quality management and the innovation effects on organizational performance" Marina Godinho Antunes, Joaquín Texeira Quirós, Maria do Rosário Fernandes Justino (2017).El propósito de este documento 
es analizar la relación entre la innovación y la gestión de calidad total (TQM), y también identificar los efectos de la innovación en el desempeño organizacional. Los datos se obtuvieron a través de un cuestionario en línea, enviado a pequeñas y medianas empresas portuguesas, después de haber realizado el estudio con base en las respuestas recibidas de 287 cuestionarios válidos y utilizando un análisis estadístico multivariado para el desarrollo estadístico se obtuvieron 3 resultados importantes ; el primero es que las empresas que adoptan estrategias de innovación de procesos obtienen mejoras en su desempeño, tanto operacional como financieramente, mientras que la innovación de productos solo proporciona mejoras en el desempeño financiero de las organizaciones. Como segundo resultado se descubrió que las prácticas de gestión de calidad total fomentan la definición de estrategias de innovación de productos y procesos. Tercero, se encontró que solo las empresas que adoptan estrategias de innovación de sus procesos promueven la adopción de prácticas de gestión de calidad total, y existe una relación estadísticamente significativa entre la innovación de productos y la implementación de prácticas de gestión de calidad total.

En el artículo académico "The Impact of Total Quality Management Practices on Export Performance of Apparel Exporters in Sri Lanka" Abeykoon y Alwis (2016) el propósito de este estudio fue examinar el impacto de las prácticas de gestión de calidad total en el desempeño exportador de indumentaria de Sri Lanka. Este estudio propuso que la orientación al mercado de exportación pueda proporcionar una comprensión clara de la gestión de calidad total y la relación de rendimiento de exportación de la empresa. La metodología que se utilizo fue un cuestionario de escala Likert de cinco puntos como instrumento clave para la recopilación de datos obteniendo datos de 65 exportadores de indumentaria en Sri Lanka. Se utilizaron ocho dimensiones para medir la gestión de calidad total, incluyendo liderazgo, capacitación, gestión de empleados, información y análisis, gestión de proveedores, gestión de procesos, enfoque al cliente y mejora continua. El análisis de regresión y correlación se utilizó para examinar el impacto de la gestión de calidad total en el desempeño de exportador y la relación entre la gestión de calidad total en el desempeño de exportador. Los resultados del estudio dieron por resultado que todas las dimensiones, excepto información y análisis, se correlacionaron significativamente con el desempeño exportador. Además, el enfoque en el cliente, la mejora continua y la gestión de proveedores 
se encontraron como las dimensiones más importantes que impactan en el desempeño exportador.

El artículo "The Effects of Total Quality Management and Market Orientation on Business Performance of Small and Medium Enterprises in Pakistan" Gamal Abdualmajed Ali ,Haim hilman Abdullah,Abdullahi Hassan Gorondutse (2017). Las pequeñas y medianas empresas desempeñan un papel importante en el desarrollo económico y progreso del país. Hay varios factores que contribuyen al éxito de las pequeñas y medianas empresas. Este estudio investiga los efectos de la gestión de calidad total, la orientación al mercado en los negocios desempeño de pequeñas y medianas empresas en Pakistán. La población objetivo del estudio fue pequeñas y medianas empresas, el tamaño de la muestra fue de 183 empresas que operan en Rawalpindi / Islamabad mediante un cuestionario. Se utilizó el protocolo para recopilar los datos. Se utilizó el software SPSS 20 para el análisis. El argumento de que tanto la gestión de calidad como la orientación de mercado generan un mayor rendimiento empresarial. Los resultados también indicaron que es crucial que las PYME implementen estrategias como la gestión de calidad como la orientación de mercado ya que estas actuarían como un sistema de apoyo para responder al entorno competitivo y luego puede conducir a mayor rendimiento. Esto se puede hacer ofreciendo productos de calidad o nuevos productos mejorados en el mercado utilizando los recursos disponibles en el mercado. Esta investigación contribuye a la literatura existente sobre resultados positivos de la gestión de calidad como la orientación de mercado y relación de desempeño comercial en el contexto de las PYME del país en desarrollo, Pakistán. Los resultados de este documento sugieren que los propietarios / gerentes deberían adoptar un enfoque más dinámico hacia la implementación de la gestión de calidad y la orientación de mercado para preparar a sus empresas para enfrentar los desafíos futuros. Ellos deberían actualizarse y equiparse con los conocimientos, habilidades y capacidades actuales que podrían beneficiar a su firma.

El artículo "Total Quality Management, Export Market Orientation and Firm Export Performance: A Conceptual Framework" Imran, Norasyikin ,Hamid y Aziz (2017). Este estudio propone que la orientación al mercado de exportación pueda 
proporcionar una comprensión clara de gestión de calidad total con la firme relación de resultados de exportación. La relación usada para producir la proposición que explica cómo la gestión de calidad total interactúa con la orientación de mercado y el rendimiento de exportación en el mercado internacional. El objetivo principal de este estudio es mejorar la comprensión acerca de la relación entre la gestión de la calidad total y el rendimiento de las exportaciones mediante la introducción de la orientación al mercado de exportación como mediador entre dos variables. Investigaciones previas sugieren que la gestión de la calidad total (Joiner, 2007), la orientación al mercado de exportación (Singh y Mahmood, 2013) y la firma de los resultados de exportación (Shoham, Brencic, Virant, y Ruvio, 2008) son construcciones unidimensionales. Esto se debe a las diferentes dimensiones de la orientación de calidad total y la exportación de mercado pueden tener una influencia diferente sobre diferentes aspectos del comportamiento de las exportaciones. De acuerdo con Pfau, (1989) la gestión de calidad total tiene un enfoque integral de la concentración de los objetivos de la organización y gestión de la organización a través de la calidad, la mejora de la productividad, la satisfacción de las necesidades de los clientes y dar una ventaja competitiva ya que el objetivo principal de la gestión de calidad total es proporcionar el producto de calidad y servicio a los clientes aumentando el rendimiento de la organización con bajo costo(Antony, Fergusson, Warwood, y Hing Yee Tsang, 2004). El artículo propone la orientación al mercado de exportación para servir como una variable mediadora entre la gestión de la calidad total y los resultados de exportación encontrándose el efecto mediador de la orientación al mercado en la estrategia y el resultado del desempeño de la empresa (es decir, la satisfacción del cliente, cuota de mercado y la rentabilidad del negocio).Como conclusión se obtuvo que la gestión de la calidad total y la orientación al mercado de exportación están específicamente destinadas a las necesidades del cliente, sus deseos y su satisfacción esperando la gestión de la calidad total y la orientación al mercado de exportación para influir en el comportamiento de las exportaciones firme. Por lo tanto, la gestión de la firma debe considerar la gestión de la calidad total como estrategia principal para manejar las demandas del mercado. Por este motivo, la orientación al mercado de exportación tiene un papel clave para poner en práctica la gestión de calidad total y, alternativamente, puede aumentar el rendimiento de las exportaciones firme también. Por lo tanto, la empresa debe entender estos factores y su efecto sobre el comportamiento de las exportaciones firme. 
En el estudio "The influence of TQM on export performance of SMEs: Empirical evidence from manufacturing sector in Pakistan using PLS-SEM" Imran, Hamid y Aziz (2018). El estudio investiga la influencia de la gestión de calidad total en el desempeño de las exportaciones del sector manufacturero de las pequeñas y medianas empresas de Pakistán. Los datos fueron obtenidos de las Pymes manufactureras que participaban en las exportaciones lográndose recaudar trescientas sesenta y cuatro (364) respuestas las cuales se utilizaron para los análisis estadísticos. El análisis estadístico SEM se desarrolló mediante Smart PLS-3, un software con interfaz gráfica de usuario para el modelado de ecuaciones estructurales basado en varianza utilizando el método de modelado de ruta de mínimos cuadrados parciales. Los resultados que se obtuvieron del estudio muestran que la gestión de calidad total tuvo un papel influyente en el desempeño exportador de las PYME, de ello muestra también que las empresas con la implementación de alto nivel de gestión de calidad total tendrán más éxito en el mercado internacional y podrán lograr un mejor rendimiento de exportación. Además, nos indica que la ausencia de gestión de calidad total puede afectar el desempeño de la empresa en el mercado internacional. El estudio revela que la gestión de calidad total es un recurso intangible valioso y dinámico que puede aumentar el rendimiento de las exportaciones de las PYME. En conclusión, los profesionales y los investigadores podrán tomar una mejor decisión sobre la implementación de gestión de calidad total ya que el estudio actual contribuyó a la literatura del desempeño de las exportaciones de gestión de calidad total y la pequeñas y medianas empresas, empíricamente.

\section{El estudio "The mediating role of total quality management between entrepreneurial} orientation and SMEs export performance" Imran, Aziz, Norasyikin ,Hamid, Muhammad Salman Shabbir, Rabia Salman, Zhaoquan Jian (2018).El propósito de este estudio fue investigar el papel mediador de la gestión de calidad total (TQM) entre la orientación empresarial (OE) y el desempeño exportador de las pequeñas y medianas empresas en el sector manufacturero de Pakistán. Se realizó este estudio ya que solo unos pocos estudios han examinado cómo los recursos intangibles y las capacidades de la empresa, como la orientación empresarial y la gestión de calidad total hacen que las exportaciones de las PYME incrementen. Para el estudio se utilizaron cuestionarios en escala Likert para recopilar los datos y 364 utilizables obteniendo respuestas de los gerentes de las PYME 
exportadoras. Para el análisis de los datos se utilizó el modelado de ecuaciones estructurales de mínimos cuadrados parciales (PLS-SEM). Los resultados que se obtuvieron revelan importantes relaciones entre la orientación empresarial y la gestión de calidad total con el rendimiento de exportación de las pequeñas y medianas empresas. El estudio también tuvo como hallazgo el papel complementario de mediación de la gestión de calidad total entre la orientación empresarial y el desempeño de exportación de las PYME del sector manufacturero de Pakistán. Este estudio tiene implicaciones para los gerentes de las Pymes, ofrece también una mejor comprensión de la implementación de orientación empresarial y gestión de calidad total. Por lo tanto, los propietarios o gerentes de las pequeñas y medianas empresas pueden tomar mejores decisiones para la implementación de las prácticas de la gestión de calidad total.

\subsubsection{Marco teórico.}

En el marco teórico se definen las variables involucradas, la primera variable a estudiar es la gestión de calidad total donde se detalla sus características, dimensiones y principales teorías. Por otro lado, se tiene la segunda variable desempeño exportador, la cual en el presente trabajo es la variable dependiente. Sobre desempeño exportador se identifican las características, dimensiones y principales teorías.

\subsubsection{Gestión de calidad total.}

\subsection{Definiciones.}

Según los autores Foster y Whittle (1988), la gestión de calidad total es un análisis sistemático, la atención se centra en pasar de un proceso impulsado por controles externos a través del cumplimiento y la mejora del procedimiento a un proceso de mejora habitual en el que el control está integrado y es impulsado por la cultura de la organización.

Existen diversas definiciones y estudios sobre gestión de calidad total, algunos investigadores utilizan el término "total quality management "para referirse a un enfoque para mejorar la eficacia y la flexibilidad del negocio en conjunto, es esencialmente una forma 
de organizar e involucrar a toda la organización es decir cada departamento, cada actividad a realizar y cada persona en su área de trabajo (Oakland, 1989).

La gestión de calidad total es un proceso para mejorar los productos, procesos y servicios de la empresa para lograr la satisfacción del cliente a bajo costo (Kanji, 1990).

Atkison (1990), conceptualiza la gestión de calidad total como un enfoque estratégico para producir el mejor producto y servicio posible a través de la innovación constante.

Se define como un método sistemático para gestionar que requiere cambios en los procesos de la organización, prioridades estratégicas, actitudes y comportamientos individuales (Olian y Rynes, 1991).

La gestión de calidad total es un proceso continuo que se enfoca en las personas y que lucha por incrementar la satisfacción de los consumidores al menor coste real (Roberts y Sergesketter, 1993).

En resumen, la gestión de calidad total es una estrategia de éxito a largo plazo para la organización que apunta a la satisfacción del cliente, del empleado, la calidad del producto en todas las etapas y demás de ello produce mejoras e innovaciones continuas de calidad total.

\subsection{Principios de la gestión de calidad total.}

Se encuentra sustento en los principios gerenciales proporcionados por Deming (1986) y Schroeder (1994) sobre los sistemas de gestión de la calidad total en donde se pone énfasis en la necesidad de administrar para el largo plazo sin sacrificar la calidad para obtener ganancias a corto plazo. Los principios gerenciales para el logro sostenido de la calidad a largo plazo son catorce:

1. Crear constancia de propósito hacia el mejoramiento de productos y servicios, con objeto de ser competitivo y permanecer en el negocio a largo plazo 
2. Adoptar la nueva filosofía, rehusándose a permitir niveles comúnmente aceptados de equivocaciones, defectos, retrasos y errores

3. Abandonar la dependencia de inspección en masa, confiando en la obtención de la calidad del producto la primera vez y en medios estadísticos para controlar y mejorar la calidad

4. Desechar la práctica de adjudicar contratos basados exclusivamente en el precio, poniendo énfasis en su lugar la reducción del coste total a largo plazo. Insiste en la selección de proveedores que proporcionen evidencia de control estadístico de procesos

5. Mejorar constantemente, y para siempre, los sistemas de producción, mejorando la calidad, la productividad y los costes

6. Instituir la capacitación en el trabajo, para todos los empleados

7. Instituir el liderazgo para ayudar a los empleados a hacer mejor su trabajo

8. Eliminar el temor de los empleados por los problemas de los sistemas. Fomentar la comunicación bidireccional

9. Romper las barreras entre departamentos, alentando el trabajo en equipos multidisciplinares y multiprocesos

10. Eliminar los lemas, exhortaciones y programas, que soliciten nuevos niveles de productividad sin proporcionar mejores métodos

11. Eliminar cuotas numéricas, estándares de trabajo y objetivos que interfieran con la calidad, utilizando en su lugar el liderazgo y la mejora continua de los procesos de trabajo 12. Eliminar las barreras que impiden a los trabajadores el sentimiento de orgullo hacia el trabajo con calidad

12. Impulsar la educación y la capacitación a largo plazo, para proporcionar la auto mejora de los empleados 
13. Tomar medidas para lograr la transformación, facilitando la puesta en marcha de cada uno de los principios anteriores

\subsection{Dimensiones de gestión de calidad total.}

Según Imran, Hamid y Aziz (2018), existen 5 dimensiones de la gestión de calidad total que hacen más operativo el concepto de calidad de un producto o servicio favoreciendo la comprensión en que la gestión de calidad se puede aplicar en las empresas:

\section{- Liderazgo}

Hace referencia a ser líderes del mercado al igual que brindar una buena imagen para los colaboradores de la empresa. Esta dimensión se enfoca en que el empleado se identifique con la empresa motivándolos a tener un mejor desempeño brindándoles la opción de tomar decisiones sobre sus labores diarias.

- Estrategias

Se realizan estrategias corporativas como la evaluación del desempeño de los competidores, la medición automatizada de pérdidas, tener un sistema de información para obtener clientes y proveedores, la evaluación del desempeño organizacional de acuerdo a las metas y objetivos establecidos y se toma en cuenta la opinión de los clientes ya que es importante para la creación de nuevos productos.

- Personas

Enfatiza en el empleado, encuestas de actitud, información de ellos, capacitaciones sobre calidad, se incentiva al colaborador a actualizarse y capacitarse constantemente, a trabajar en equipo y a puedan dar su opinión en todo momento.

- Recursos

Enfoca su dimensión en tener por ejemplo asociaciones a largo plazo con una empresa, tener acuerdos de compra con sus proveedores con el fin de no afectar la calidad sobre el costo de un producto, se evalúa la manera de no afectar el medio ambiente minimizando el uso de plástico, papel y bolsas., 
- Procesos

Esta dimensión hace referencia a que las empresas establecen procedimientos para cada actividad a realizar, se debe conocer por ejemplo los parámetros de cada procedimiento, en algunos casos se monitorea los procesos de producción y el departamento de investigación y desarrollo trabaja continuamente en la mejora, se debe tener también los sistemas adecuados para atender las quejas de los clientes.

\subsection{Teorías de la gestión de calidad total.}

\section{Teoría Kaizen}

Teoría de mejora contínua desarrollada por Masaaki Imai (1985), es un sistema enfocado en la mejora continua no solo en toda la empresa sino también en sus componentes, de manera proactiva y armónica. Surgió como resultado de sus imperiosas necesidades de superarse a sí mismo de forma tal de poder alcanzar a las potencias industriales en Japón.

El Mejoramiento Continuo, no requiere de inversiones grandes para poder ser implementada, más bien necesita de un esfuerzo permanente y un fuerte compromiso gerencial. La manera de poder mejorar el desarrollo en todos los niveles operativos es utilizando todos los recursos humanos y capital disponible. Esta teoría es de gran ayuda para la gerencia para lograr una mayor competitividad y rentabilidad contribuyendo a mejorar las debilidades y fianzas las fortalezas de la organización permitiendo incrementar su productividad y competitividad en el mercado al cual pertenece la empresa.

El mejoramiento continuo se logra a través de todas las acciones diarias (por pequeñas que éstas sean), Trabajando en que los procesos y la empresa sean más competitivas en la satisfacción de nuestros clientes.

La velocidad del cambio dependerá mucho del número de acciones de mejoramiento que se realicen diariamente y de la efectividad con que éstas se realicen, por lo que es importante que la mejora continua sea una filosofía de trabajo y de vida. 
Uno de los aspectos del Kaizen es que no requiere de técnicas sofisticadas o tecnologías avanzadas.

Según Manuel Suarez en su libro “El Kaizen”: Lo más interesante y práctico del Kaizen a diferencia de la innovación es que no necesita una tecnología complicada, altamente sofisticada, ni siquiera una enorme inversión para implantarlo; sólo se requiere de sistemas, mecanismos y herramientas sencillas, convencionales, que con sentido común son fáciles de aplicar. El verdadero catalizador de su aplicación es el Know-how, es decir, el conocimiento aprendido por los empleados a lo largo de los años, que operando bajo una filosofía Kaizen se vuelve en una estrategia básica de la supervivencia de la organización en los mercados."

Se debe mejorar continuamente los productos o servicios que se ofrecen con el fin de:

- Ser líderes en el mercado

- Mejorar la calidad de vida de los trabajadores

\section{Elementos del Kaizen:}

1. Orientación hacia el proceso, antes que hacía al resultado.

2. Iniciar la puesta en práctica desde arriba e involucrar a todos.

3. Compromiso de los altos niveles gerenciales.

4. Una comunicación vertical y horizontal eficaz y sin trabas.

5. Mejoramiento continuo de los productos y procesos, internos y externos.

6. Constancia de los objetivos y una visión compartida.

7. El cliente manda. (Enfoque al Cliente).

8. La inversión en personal.

9. La gestión de calidad se inicia y concluye con la capacitación.

10. Dos cabezas piensan mejor que una.

11. Participación en la determinación y comunicación de metas. 


\section{Teoría Six Sigma}

Para Pyzdek (2003), Six Sigma es una implementación rigurosa, centrada y muy eficaz de proporcionar principios y técnicas de calidad. Se incorpora muchos elementos de los trabajos realizados por los pioneros de la calidad, usando herramientas estadísticas, métodos y técnicas de mejora para la reducción de la variabilidad en cualquier proceso

Este concepto tiene relación con lo que menciona Evan et al. (2008) quien presenta los principios del Six Sigma como una estrategia general para acelerar las mejoras y alcanzar niveles de desempeño sin precedentes enfocándose en las características críticas por los clientes y la identificación y eliminación de las causas de los errores o defectos en los procesos.

Six Sigma está orientado a ayudar a las organizaciones a obtener más dinero mediante la eficiencia y la mejora de valor para el cliente (Pyzdek ,2003). Es por ello que existe una relación entre calidad y Six Sigma proporcionando una nueva definición de calidad. Se define la calidad de dos maneras, como la calidad potencial y la calidad real; siendo la calidad potencial el valor máximo posible conocido añadido por unidad de insumo y la calidad real como el valor actual agregado por unidad de insumo. En donde la diferencia entre la calidad potencial y real viene a ser el desperdicio.

Six Sigma se enfoca en la mejora de la calidad reduciendo el desperdicio y ayudando a las organizaciones producir productos y servicios mejores, más rápidos y más baratos.

De acuerdo a Evans et al. (2008), indica que six sigma evolucionó desde un simple indicador de calidad hasta convertirse en una estrategia general para acelerar las mejoras y alcanzar los niveles de desempeño, con un enfoque en las características críticas de los clientes y la identificación y eliminación de las causas de los errores o defectos de los procesos. Para el cumplimiento de estas tareas se requiere una implementación eficaz de los principios estadísticos y diversas herramientas para diagnosticar los problemas de calidad y facilitar las mejoras. De acuerdo a Pyzdek (2003) PDCA (Planificar, Hacer, Verificar y Actuar) es una parte integral de Six Sigma que se utiliza para organizar el proyecto de una manera sistemática y esquematizada 


\subsection{Principales Modelos de la Gestión de calidad Total \\ - Modelo Malcolm Baldrige (1987)}

Establece que los líderes de la organización deben estar orientados hacia la dirección estratégica y los clientes. Dirigiendo y haciendo correcciones en base a los resultados que obtenga la empresa. Las estrategias clave deben estar basadas en las medidas e indicadores del conocimiento organizativo.

Los criterios Baldrige para un "desempeño excelente" señalan las prácticas de administración válidas y que pueden ser medidas dentro de una organización. Estos criterios tienen una aceptación internacional y constituyen además una forma común de comunicación entre las compañías con el fin de desarrollar mejores prácticas. Cabe destacar que para las empresas estadounidenses existe el premio Malcolm Baldrige National Quality Award basado en este modelo.

Las áreas de evaluación de estos criterios son 7, las cuales representan las áreas en las que cualquier perfil administrativo debe reflejar excelencia en su entorno, en sus relaciones y en los retos que enfrenta quedando resumidas en el siguiente diagrama:

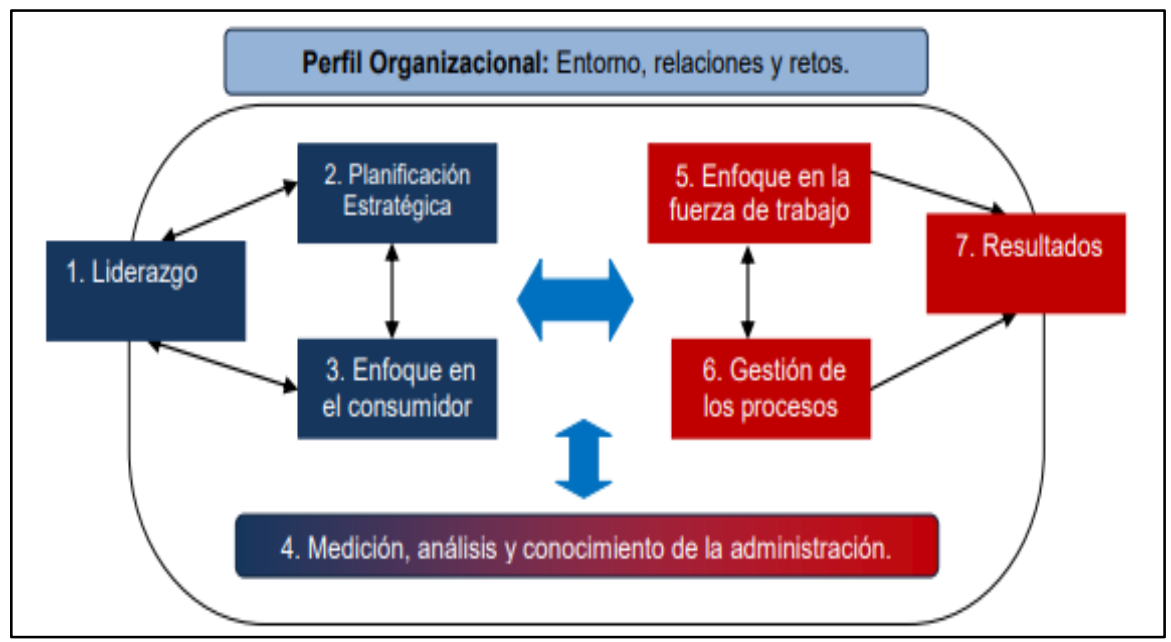

Figura 1. Modelo Baldrige para la evaluación de la calidad

Fuente: The National Quality Program and National Institute of Standards and Technology (2009) 


\section{- Modelo EFQM de Excelencia (1992)}

La EFQM (European Foundation Quality Management) es una organización que pretende desarrollar estrategias para optimizar recursos, reducir los costes y mejorar los resultados con el objetivo de perfeccionar constantemente los procesos productivos.

En 1988 catorce empresas europeas se asociaron para crear la EFQM con el objetivo de tener una ventaja competitiva. Tal y como señalan Bueno, Salmador, Merino y Martín (2006:357), excelencia se entiende como "el modo sobresaliente de gestionar la organización y obtener resultados" mediante la aplicación de ocho conceptos fundamentales:

1. Orientación de los resultados: La organización debe satisfacer las necesidades de todos los grupos de interés.

2. Orientación al cliente: La organización debe satisfacer las necesidades y expectativas de sus clientes, tanto las presentes como las futuras. Los clientes son el árbitro final de la calidad del producto/servicio.

3. Liderazgo y coherencia: El equipo directivo debe estar comprometido e implicado en la cultura de la excelencia, para ello deben tener una visión emprendedora y coherente sobre cómo será la empresa en el futuro.

4. Gestión por procesos y hechos: se trata de analizar los procesos que utiliza la empresa para crear sus productos o servicios.

5. Desarrollo e implicación de las personas: El capital humano es el activo más importante de la organización, hay que inculcarles los valores de la empresa y propiciar un clima de confianza. Para ello hay que desarrollarlos tanto personal como profesionalmente.

6. Proceso continuo de aprendizaje, innovación y mejora continuos: Debe existir una gestión adecuada del conocimiento, las experiencias, la creatividad y la innovación dentro de una cultura orientada a la mejora continua. 
7. Desarrollo de alianzas: la organización debe establecer relaciones de colaboración y cooperación con otras empresas con el fin de que ambas salgan beneficiadas pudiendo compartir conocimientos y así crear valor añadido para el cliente.

8. Responsabilidad social de la organización: la organización debe intentar exceder las expectativas y el marco legal mínimo en el que actúa

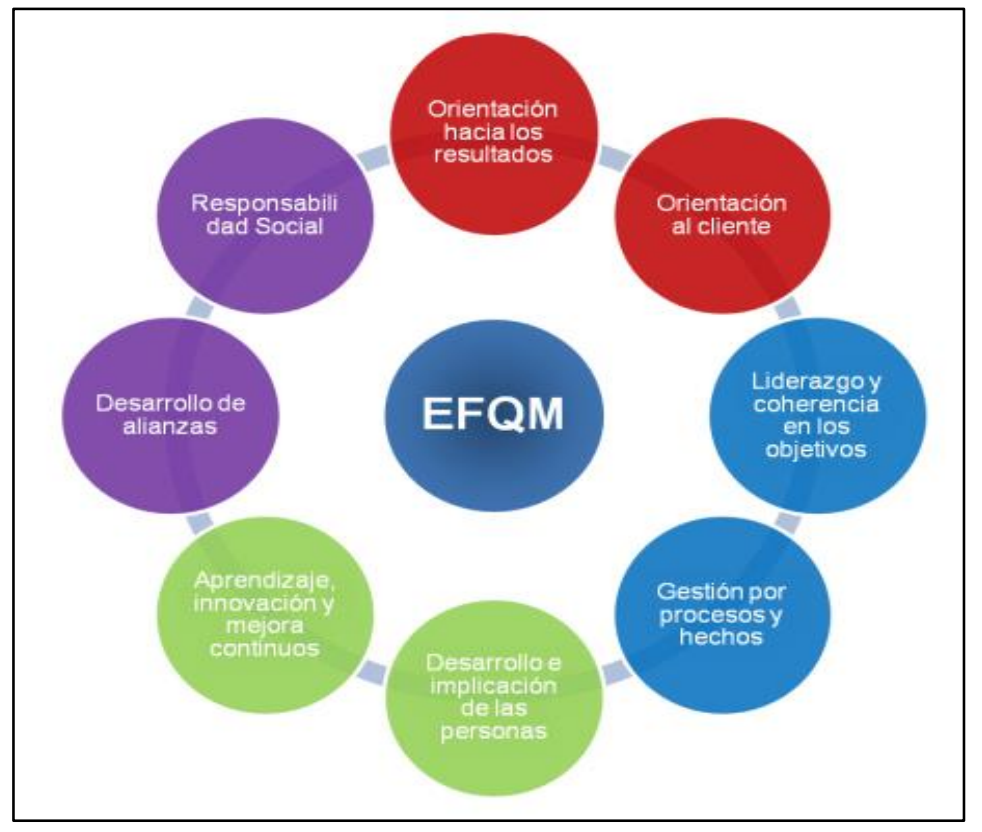

Figura 2. Modelo EFQM para la excelencia

Fuente: Elaboración propia

El modelo EFQM consta de 9 criterios básicos los cuales permiten evaluar el posicionamiento de una organización hacia la excelencia. Cada criterio se subdivide en diferentes subcriterios (32 en total) que deberán considerar en la evaluación. Además, cada subcriterio incluye unas determinadas áreas orientativas a abordar.

Están divididos en agentes facilitadores y resultados:

- Agentes facilitadores: reflejan la manera de actuar de la organización formados por los siguientes criterios: liderazgo, política y estrategia, personas, alianzas y recursos y por último procesos. 
-Resultados: tratan los logros de la organización. Formados por los siguientes criterios: Resultados en los clientes, resultados en las personas, resultados en la sociedad y resultados clave.

Todos estos criterios se relacionan de la siguiente manera:

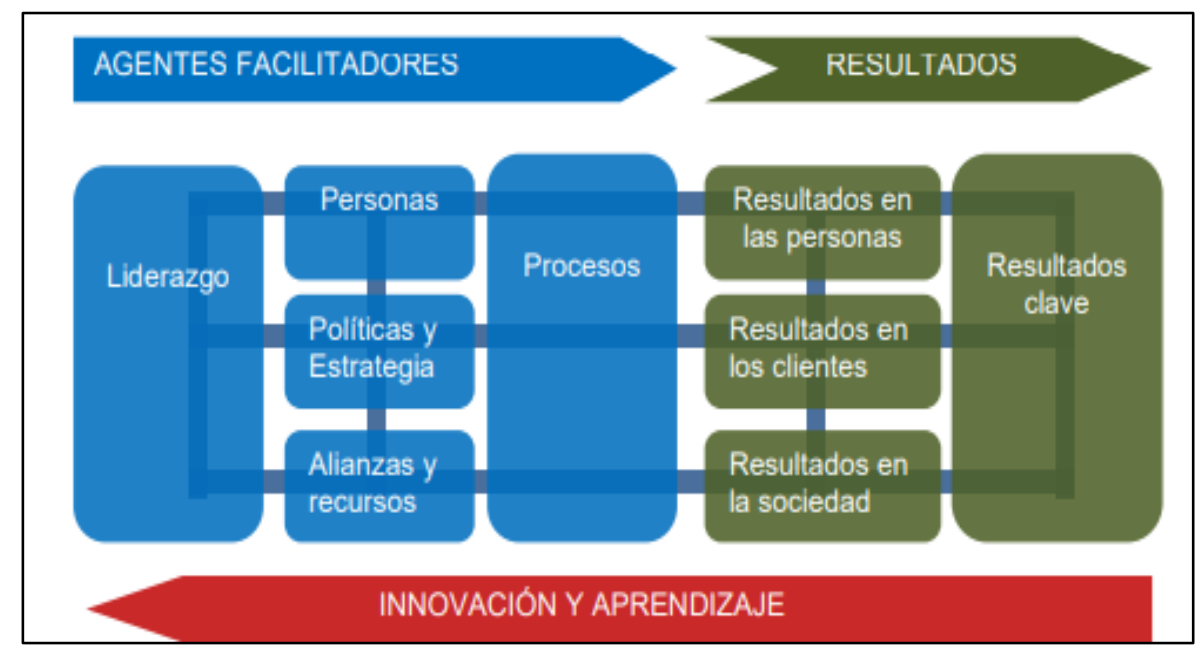

Figura 3. Estructura del modelo EFQM

Fuente: European Foundation for Quality Management. (2011)

Este es un modelo dinámico en donde la innovación y el aprendizaje permiten una retroalimentación que potencia la labor de los agentes facilitadores provocando una mejora en los resultados. Los criterios y subcriterios nombrados anteriormente se utilizan para poner una puntuación a la empresa. Cada uno de los criterios tiene una puntuación 


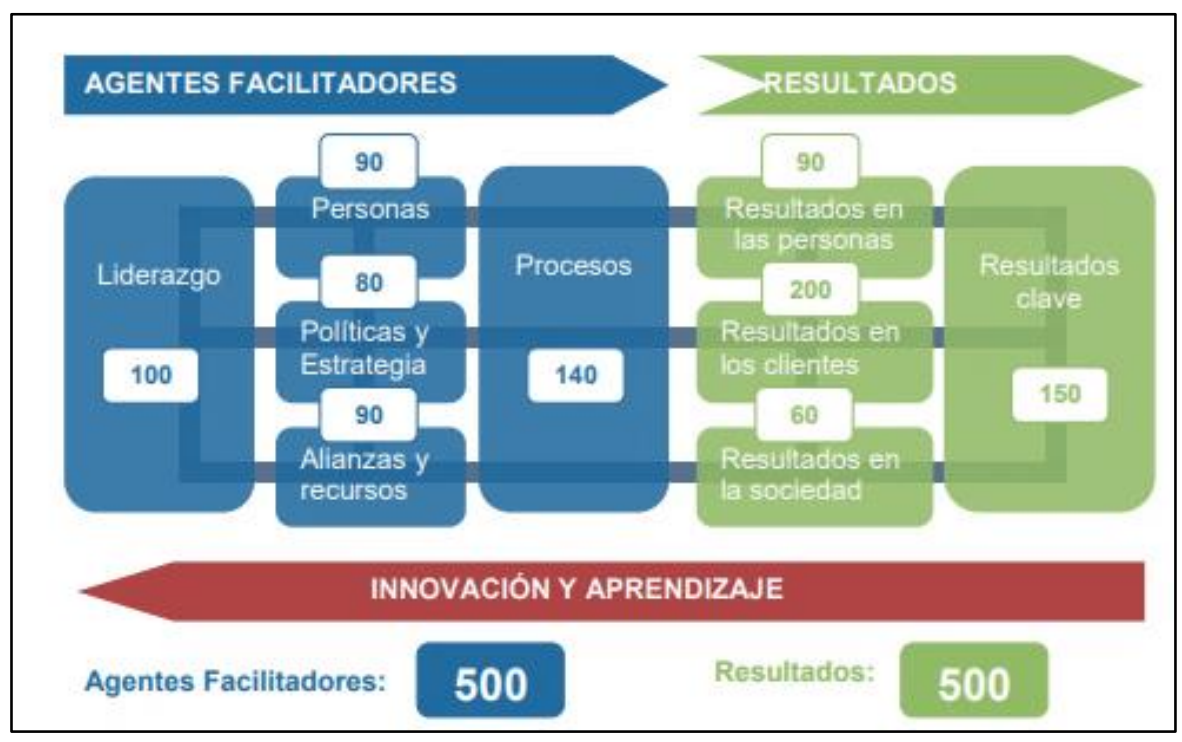

Figura 4. Puntuación de los criterios y subcriterios del modelo EFQM

Fuente: European Foundation for Quality Management. (2011)

Podemos ver que hay un total de 1.000 puntos, lo que equivaldría a un 100\%, la empresa tiene que ver en qué situación está y que puede hacer mejorar, una vez que hayan implantado las medidas que crea necesarias para su mejora, se hará otra vez la evaluación de la empresa, para ver si realmente ha mejorado. Para poder dar una puntuación correcta, hay que saber que cada subcriterio tiene la misma relevancia que el resto de subcriterios dentro de cada criterio. Cada subcriterio se compone además de unas pautas orientativas llamadas áreas, cada una de las cuales obtiene una calificación que se suma.

\section{- La lógica REDER}

Método del modelo EFQM, es usada para cuestionar y evaluar la performance de las organizaciones y puede ser explicada de la siguiente manera:

1. Se planifican los resultados deseados.

2. Se desarrollan enfoques adecuados para alcanzarlos.

3. Se despliegan e implantan los enfoques.

4. Se evalúan los resultados obtenidos, y se revisan los enfoques. 


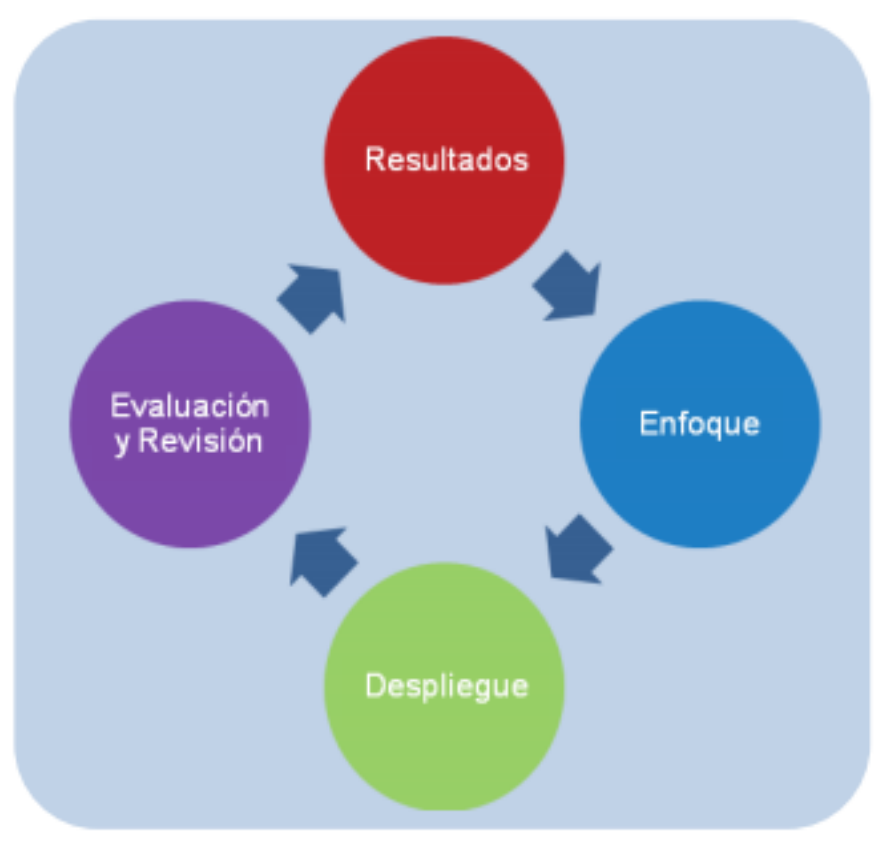

Figura 5. Lógica REDER

Fuente: European Foundation for Quality Management. (2011)

- Modelo ISO (1947)

Estas normas definen los estándares en los sistemas de calidad bajo la premisa de que ciertas características en las prácticas administrativas pueden ser estandarizadas y que un buen diseño, implantación y correcta administración de los sistemas de calidad brindan la confianza de que los resultados lograrán cumplir con las expectativas y requerimientos de los clientes. Estas normas, junto con los modelos para la excelencia EFQM y Baldrige, constituyen los modelos modernos más importantes en relación a la gestión de la calidad como estrategia competitiva.

Una organización que cumple con las normas ISO puede certificarse y con ello tener un documento oficial que ampare el nivel de calidad que ofrece.

Los 8 principios según Evans y Lindsay (2008) para la gestión de la calidad de acuerdo a los ya mencionados estándares son los siguientes:

1- Organización enfocada en los clientes 


\section{2- Liderazgo}

3- Involucramiento de las personas

4- Enfoque en los procesos

5- Enfoque en los sistemas para la administración

6- Mejora continua

7- Toma de decisiones basada en hechos

8- Mutuo beneficio en relación con los proveedores

Como puede apreciarse, varios de estos principios coinciden con los conceptos del modelo EFQM o con los criterios del modelo Baldrige, lo cual significa que el cumplimiento de un modelo no implica quebrantar otro. Por otro lado, son muchas las razones que motivan a las empresas a certificarse bajo los estándares ISO, pero lo más importante es que con ello las organizaciones se someten a procesos planificados de mejora y comienzan a apreciar el trabajo como un sistema de procesos interrelacionados que finalmente los lleva a generar confianza tanto interna como externa de que los requerimientos y especificaciones son cumplidos.

Es cierto que muchas organizaciones ven la certificación ISO como un trámite necesario para poder vender sus productos y competir en mercados más amplios. Sin embargo, los beneficios intrínsecos del cumplimiento de las normas ISO es mucho más amplio incluida la satisfacción y retención de los consumidores, productos de mejor calidad, productividad más elevada, costes reducidos, mayor uso de la información como herramienta de administración de los negocios y revisiones más eficientes. 


\subsubsection{Desempeño exportador.}

\subsection{Definiciones.}

Los autores Katsikeas, Leonidou y Morgan (2000), Sousa (2004) y otros como Diamtopoulos (1999), indicaron que el rendimiento de las exportaciones es un fenómeno complejo multidimensional que debe ser analizado utilizando múltiples medidas; las medidas de rendimiento de las exportaciones deben incorporar medidas económicas y no económicas, así como las medidas objetivas y subjetivas debiendo describirse tanto a las empresas de exportación como al rendimiento a nivel de producto.

Por otro lado, Atabay (2008) refiere que existieron varios estudios que coinciden en que el desempeño se define como el grado de realización del propósito de la empresa de exportación.

Hultman et al. (2009), considera el desempeño del emprendimiento de exportación como un constructo de orden superior que está compuesto del desempeño del mercado, evidenciando los indicadores de comercialización económica sobre las ventas y la participación en el mercado; desempeño financiero, tomando en cuenta la rentabilidad de la empresa y el retorno de la inversión; y el desempeño del cliente, el cual aprovecha la respuesta de la empresa a las necesidades y presiones de los diferentes clientes.

Se define desempeño exportador que está vinculado con el éxito o fracaso de los esfuerzos de una empresa o nación para exportar los distintos bienes y servicios de producción nacional al mercado externo. El desempeño que se obtiene puede ser expresado en términos objetivos, como las ventas, utilidades, o también por medidas subjetivas, como el nivel de satisfacción del cliente, el manejo de las relaciones con los distribuidores, entre otros (Lages y Lages ,2004).

Por último, Leonidou et al. (2002), argumentó que el desempeño exportador se muestra a raíz de la relación causal y unidireccional de tres diferentes factores: gerenciales, organizacionales y fuerzas del entorno. Estos factores se evidencian en la dirección 
exportadora de la empresa y en las decisiones de marketing, afectando el resultado de las exportaciones.

\subsection{Características del desempeño exportador.}

Wheeler, Ibeh, Dimitratos (2008) y Zou y Stan (1998) nos indican que las variables independientes o factores que explican el desempeño exportador son los internos y externos a la empresa.

Los factores externos se componen de las variables del entorno que afectan el accionar de la empresa, se pueden incluir: la acción del Estado, el mercado local y el mercado de exportación. Por otro lado, los factores internos se agrupan en función de las características de la empresa, su capacidad gerencial y su estrategia exportadora.

Dentro de los factores externos se encuentran las características de la industria, la inestabilidad de la industria, las entidades financieras, los avances tecnológicos, las características del mercado de exportación, las características del mercado local, la articulación del mercado local y la industria para acceder al mercado de destino. Dentro de los factores internos tenemos a las características de la empresa, las características gerenciales, las estrategias y el marketing mix. 


\subsection{Dimensiones del desempeño exportador.}

\section{Tabla 1}

Dimensiones del desempeño exportador

\begin{tabular}{ll}
\hline & AUTORES \\
\hline Imran, Hamid y Aziz (2018) & $\begin{array}{l}\text { Diamantopouos y Winklhofer (2001), } \\
\text { Katsikeas et al. (2000);Lages y } \\
\text { Montgomery (2004) }\end{array}$ \\
\hline Finanzas & $\begin{array}{l}\text { La intensidad de la exportación } \\
\text { Estrategias }\end{array}$ \\
Satisfacción & La satisfacción de la exportación \\
\hline Malesi y Aggio(2008) & Zou, Taylor y Osland (1998) \\
\hline Continuidad exportadora & Rentabilidad \\
Diversificación de mercados & Alto volumen de ventas \\
Condiciones de acceso a los mercados & Rápido crecimiento \\
Dinamismo exportador & \\
\hline Favre-Bonte y Giannelonni (2008) & $\begin{array}{l}\text { Brothers y Nakos (2004) y Brouthers et } \\
\text { al.(1999) }\end{array}$ \\
\hline Eficiencia & Crecimiento de ventas \\
Rentabilidad & Volumen de ventas \\
Compromiso continuo para exportar & Rentabilidad anterior a impuestos \\
& Participación de mercado \\
\hline
\end{tabular}

Fuente: Imran, Hamid y Aziz (2018), Diamantopouos y Winklhofer (2001), Katsikeas et al. (2000); Lages y Montgomery (2004), Malesi y Aggio(2008), Zou, Taylor y Osland (1998), Favre-Bonte y Giannelonni (2008), Brothers y Nakos (2004) y Brouthers et al.(1999)

Distintos autores mencionan diferentes dimensiones con respecto a desempeño exportador. Sin embargo, se optó por escoger las dimensiones de Imran, Hamid y Aziz (2018) las cuales se ajustan a la teoría basada en los recursos en donde detallan con claridad la importancia que involucra cada una de estas dimensiones.

Las dimensiones según Imran, Hamid y Aziz (2018) son tres: 
1- Finanzas: Hace referencia a la capacidad de incrementar la inversión por parte de la empresa. El autor indica que a mayor porcentaje de rentabilidad antes de impuesto más rentable es la empresa.

2- Estrategias: Se basa en los volúmenes de exportación realizadas, en las estrategias que las empresas tienen con los estados, los tratados de libre comercio y los volúmenes de ventas.

3- Satisfacción: Se refiere a los montos que traen los volúmenes de ventas de productos o servicios gracias a su crecimiento. De igual manera mide el grado en que el consumidor final está a gusto con lo recibido.

\subsection{Teorías del desempeño exportador.}

\section{La teoría basada en los recursos}

La teoría basada en los recursos o también llamada TBR indica que las capacidades de las empresas y los recursos son trascendentales para diseñar e implementar diversas estrategias orientadas a incrementar la eficiencia y eficacia de la misma generando un mejor desempeño en el mercado interno, externo o de exportación frente a sus competidores (Barney, 1991; Wernerfelt, 1984; Zou \& Stan, 1998; Piercy, Kaleka \& Katsikeas, 1998; Zou, Fang \& Zhao, 2003).

Los recursos de las empresas están puntualizados como activos tangibles e intangibles, y se distribuyen de manera heterogénea en las empresas siendo estos la principal fuente de ventaja competitiva. La combinación de los recursos mencionados para la empresa permite desarrollar estrategias arduas de ser replicadas (Barney, 1991; Barney \& Masterly, 2012; Dhanaraj \& Beamish, 2003; Amit \& Schoemaker, 1993).

Según Acedo, Barroso y Galán (2006), actualmente existen diferentes tendencias que están vinculadas con la TBR destacando entre ellas la teoría del conocimiento y el enfoque relacional. Con respecto al conocimiento, Wiklund y Shepherd (2003),Haahti, Madupu, Yavas y Babakus (2005), Probst, Buchel y Raub (1998),Toften y Olsen (2003); señalaron la 
posible existencia de diversos estudios en donde se muestra que el conocimiento organizacional tiene un impacto positivo en el desempeño de la empresa. (Haahti et al., 2005; Leonidou 23 \& Theodosiou, 2004; Autio, Sapienza \& Almeida, 2000; Yli-Renko, Autio \& Tontti, 2002).

Por último, en el estudio de Haahti et al. (2005), se validó que existe una relación causal positiva entre el grado de conocimiento de las empresas y su desempeño exportador, medición que se realiza en términos de la intensidad exportadora (porcentaje de las exportaciones sobre el total de ventas de la firma) y en el crecimiento exportador (crecimiento porcentual en las ventas de exportaciones de la firma). Así, Lages, Silva y Styles (2009) evidenciaron que las capacidades relacionales, medidas a partir de la calidad de la comunicación, las relaciones a largo plazo, la difusión de información y la implicación del importador con respecto a la firma exportadora, influyen de manera positiva al desempeño relacional y este, a su vez, al desempeño económico, variables que los autores consideran bajo el desempeño exportador.

\section{La teoría de la Organización Industrial}

Señala que el desempeño de la empresa depende de las características de la industria en la cual se encuentra compitiendo ya que la estructura mencionada determina la conducta de la empresa y, por ende, su estrategia (Porter, 1981). Todos los factores externos fijan la estrategia de la empresa, que a su vez incide en el desempeño económico (Zou \& Stan, 1998). Cabe recalcar que todas las industrias tienen distintos potenciales de rentabilidad, siendo de algunas la pertenencia de una empresa a una industria determinada, un factor que explica el desempeño económico superior frente a otras empresas que pertenecen a otras industrias. En dicho sentido, los rendimientos de las empresas, dentro de una industria, serán homogéneos y las diferencias solo existirán entre industrias (Porter, 1981). Por ello, para la prosperidad y supervivencia de la empresa, es necesario que esta se adapte a las presiones del entorno (Zou \& Stan, 1998). En resumen, el enfoque de la organización industrial evidencia que los factores externos influyen en el diseño de la estrategia de la empresa, determinando el desempeño económico, de modo que el entorno externo impone presiones a la empresa, la cual debe adaptarse para sobrevivir y prosperar (Root, 1987; Zou \& Stan, 1981). 


\section{La Teoría de la dependencia de los recursos}

Esta teoría estuvo dispuesta a explicar las diferencias en el resultado de las empresas mediante el manejo de los recursos externos a ella (Prévot, Brulhart \& Gilles, 2010). Es por este motivo que las empresas deben examinar su entorno con el fin de disminuir la incertidumbre pudiendo crear y conservar las relaciones estratégicas con su entorno reduciendo la dependencia (Martins de Matos, 2013; González-Campo, 2010). Martins de Matos (2013), nos indica que las investigaciones académicas han demostrado que las estrategias internas empleadas por las empresas influyen en mayor porcentaje en su rendimiento que el comportamiento del sector al que pertenecen. Además de ello, estas investigaciones nos muestran que las distintas estrategias manejadas por las empresas para ejecutar los recursos externos afectan directamente en el desempeño empresarial. Esto confirma lo indicado por Pfeffer y Salancik (1978), que las empresas dependen del entorno y se las obliga a desarrollar diversas estrategias para intentar neutralizar o contrarrestar estas contingencias.

De acuerdo con Hillman, Whithers y Collins (2009), las adquisiciones, fusiones, joint ventures y otras relaciones interorganizacionales como consejos de administración, la acción política corporativa y la sucesión ejecutiva, se utilizan para gestionar estas dependencias.

\subsubsection{Sector Agrario.}

El cacao tiene significativa relevancia social por ser el sexto cultivo más importante a nivel nacional en términos de cantidad de productores. Más de 138 mil productores tienen cacao en sus unidades agropecuarias en la selva peruana, de los cuales más de 111 mil productores cosecharon cacao en la campaña 2015/2016 según los últimos datos disponibles (ENA 2016). El 67,6\% de los productores cacaoteros conducen una Unidad Agropecuaria que no supera las 10 hectáreas, más de las dos terceras partes de productores de cacao son pequeños y medianos productores agropecuarios. Asimismo, el cacao es un cultivo que requiere un uso intensivo de mano de obra, con lo que se genera alrededor de 10 millones de jornales al año. 
A nivel productivo, el Perú tiene instalado más de 199 mil ha de cacao, de las cuales cosechó en la campaña 2015/2016 143 mil hectáreas (ENA 2016). La producción de cacao en el año 2017 fue de 122 mil t de cacao en grano y el valor bruto de la producción de cacao en grano del año 2017 fue de 614 millones de soles a precios constantes del año base 2007 (MINAGRI). El cacao contribuye con el 3\% del Valor Bruto de la Producción Agrícola y permite el ingreso de divisas por 253 millones de dólares en exportaciones.

A nivel regional, la producción de cacao está distribuida en 16 regiones, 57 provincias y 259 distritos cacaoteros posicionándose en los primeros lugares en varias regiones según los Productos Agrarios Priorizados para el año 2018. El Ministerio de Agricultura y Riego (Minagri) informó hoy que sector agropecuario acumuló una expansión de 3.3\% en el primer semestre (enero-junio) para el año 2019 en comparación al periodo 2018, lo que acredita el buen comportamiento del campo en los últimos meses. En los primeros seis meses del 2019, el subsector agrícola tuvo un crecimiento de $2.7 \%$ obteniendo un buen desempeño del cacao intensificando su producción en un 20\% (mayor superficie en Ucayali, Pasco y Cusco).

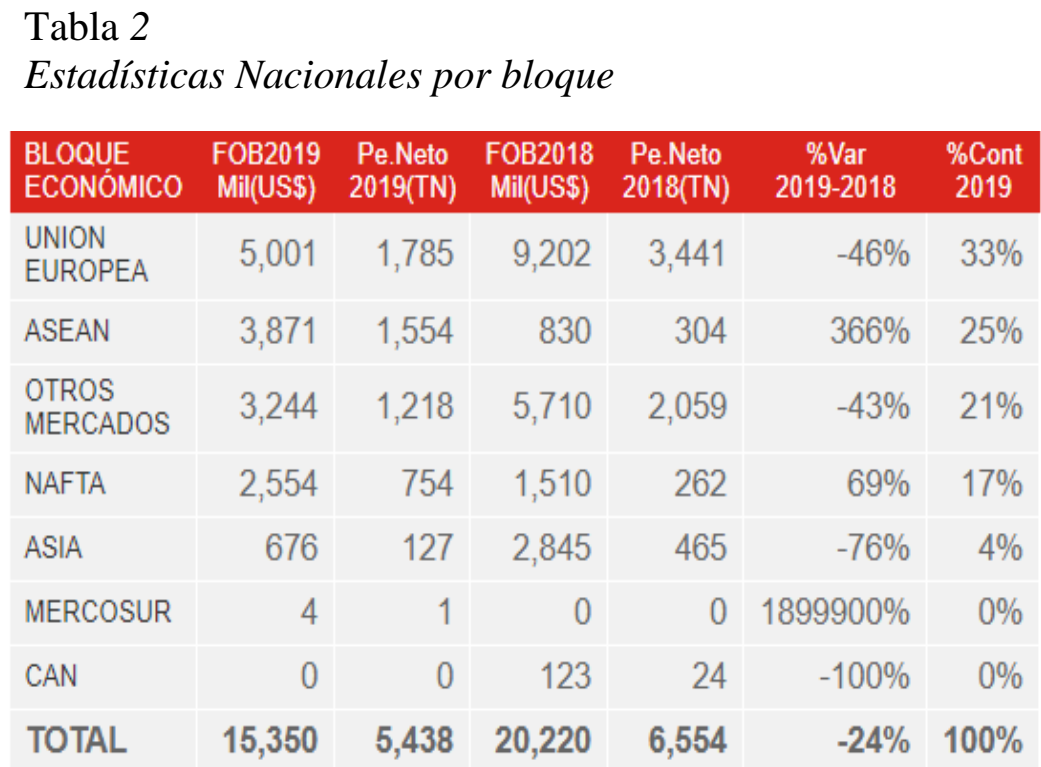

Fuente: SUNAT 
EXPORTACIONES DE CACAO EN GRANO

(2016-2020)

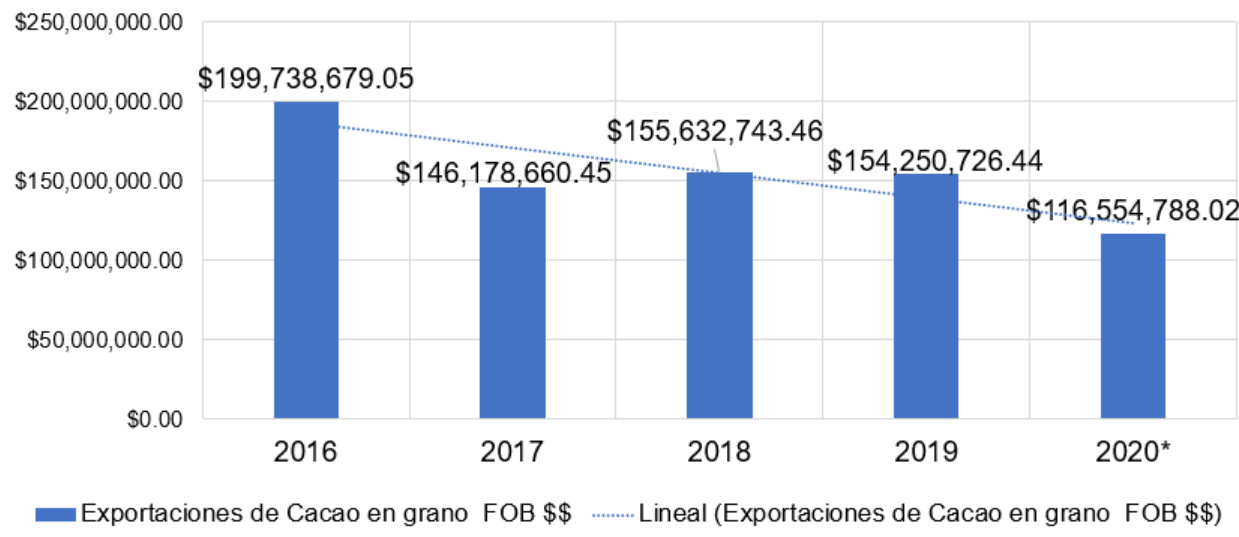

Figura 6. Evolución de las exportaciones de cacao en grano

Fuente: Data Trade

Durante el 2018 los precios del caco en grano se han mejorado a comparación del 2017, alcanzado picos de US\$ 2,660 por tonelada. Los precios diarios del mes de diciembre, muestran una recuperación en el caso del cacao ICCO y las cotizadas en la bolsa de Londres y Nueva York.

Muchos expertos señalan como causantes de tener un mejor precio no solo a las compras realizadas por los Fondos de Inversión, sino al incremento del procesamiento del cacao lo cual aumento la demanda del producto. Según la Organización internacional de cacao (ICCO), para el año 2019 se obtuvo un precio promedio por kilo de 2.34 dólares americanos. Sin embargo, para el 2020, se tiene que el precio promedio por kilo hasta el mes de setiembre es de 2.37 dólares americanos.

Los precios brindados por la ICCO generan que se llegue a la conclusión de que a partir del mes de septiembre los precios ascienden a comparación de los meses de enero a marzo en donde descienden sin tener en cuenta que para abril del 2020 el precio del cacao en grano llego a tener precio de 2.27 dólares el kilo debido a la pandemia mundial en la que estamos atravesando todo en todo el mundo. 


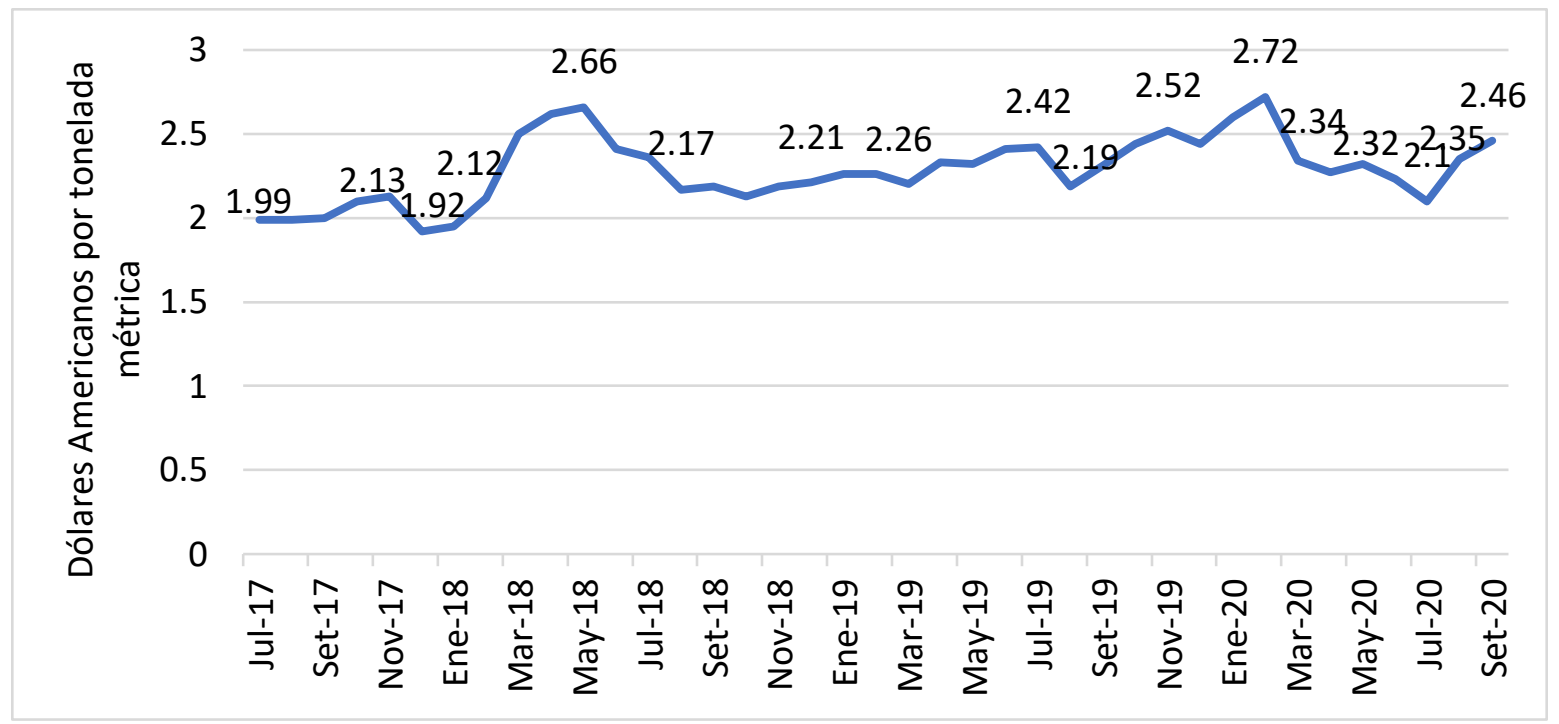

Figura 7. Precios mensuales internacionales de cacao en grano

Fuente: The International Cocoa Organization (ICCO)

La investigación se enfocará en el cacao en grano siendo este uno de los productos más importantes para el Perú (MINCETUR).

\subsubsection{Tipo de empresa}

Para desarrollar el trabajo de investigación se considerará como muestra las micro y pequeñas empresas peruanas exportadoras de cacao en grano.

Según SUNAT, la micro y pequeña empresa son las unidades económicas constituidas por una persona natural o jurídica, bajo cualquier forma de organización o gestión empresarial contemplada en la legislación vigente que tiene como objetivo desarrollar actividades de transformación, producción, comercialización de bienes o prestación de servicios.

Las MYPES en Perú cumplen un rol fundamental en la economía del país. Estas empresas contribuyen al desarrollo socioeconómico de las zonas en las que se ubican además de fomentar la empleabilidad. Según el estudio de la Situación Actual de las Empresas Peruanas realizado por el Ministerio de la Producción en el 2015, las MYPES formaron en ese año el 86\% del empleo en el sector privado y 58.6\% de la PEA (Población Económicamente activa) ocupada en el 2015. Por otro lado, entre los años 2011 a 2015 la economía peruana registró 
un crecimiento promedio anual de $4.3 \%$ y en el 2015 el PBI nacional creció en 3.3\%. No obstante, este comportamiento fue atenuado por la caída de los sectores de construcción y manufactura.

\section{- Características:}

Las MYPES se ubican dentro de las siguientes categorías empresariales de acuerdo a sus niveles de ventas anuales:

Tabla 3. Categorías empresariales

\begin{tabular}{lcc}
\cline { 2 - 3 } & $\begin{array}{c}\text { Trabajadores } \\
\text { (Promedio al año) }\end{array}$ & $\begin{array}{c}\text { Ventas anuales (RUS, } \\
\text { RER Y RG) } \\
\text { UIT 2009 S/.3.550 }\end{array}$ \\
\hline Microempresa & De 1 hasta 10 & $\begin{array}{c}\text { Hasta el monto } \\
\text { máximo 150 UIT } \\
(\text { S/.532,500) }\end{array}$ \\
\hline Pequeña empresa & De 1 hasta 100 & $\begin{array}{c}\text { Hasta S/.1700 UIT } \\
(\text { S/.6,035,000) }\end{array}$ \\
\hline
\end{tabular}

Fuente: PROMPEX

\section{- Beneficios generales}

En el Perú, las MYPES se acogen a ciertos beneficios entre los más destacados se encuentran:

- Cuentan con un mecanismo sencillo para realizar sus exportaciones denominado Exporta Fácil, a cargo de la SUNAT.

- Pueden participar en las contrataciones y adquisiciones del Estado.

- Pueden constituirse como personas jurídicas (empresas), vía internet a través del Portal de Servicios al Ciudadano y Empresas. 
- Se les brinda la opción de asociarse para tener un mayor acceso al mercado privado y a las compras estatales.

- Gozan de facilidades del Estado para participar eventos feriales y exposiciones regionales, nacionales e internacionales.

\subsection{Objetivos e hipótesis}

\subsubsection{Objetivos.}

\subsubsection{Objetivo General.}

Determinar la relación que existe entre la gestión de calidad total y el desempeño exportador de empresas MYPE exportadoras peruanas de cacao en grano.

\subsubsection{Objetivos Específicos}

- Determinar la relación que existe entre liderazgo y el desempeño exportador.

- Analizar la relación que existe entre la estrategia y el desempeño exportador.

- Analizar cómo se relacionan las personas en el desempeño exportador.

- Determinar la relación que existe entre los recursos y el desempeño exportador.

- Determinar la relación que existe entre procesos y el desempeño exportador.

\subsubsection{Hipótesis.}

Para el enfoque cuantitativo de un proceso de investigación, la hipótesis puede surgir de una teoría, de su análisis, de generalizaciones empíricas pertinentes a nuestro problema de investigación y de antecedentes consultados según Hernández, Fernández \& Baptista (2014).

\subsubsection{Hipótesis General.}

La gestión de calidad total tiene relación positiva con el desempeño exportador de las empresas MYPE exportadoras peruanas de cacao en grano 2020. 


\subsubsection{Hipótesis Específicas.}

- El liderazgo se relaciona positivamente con el desempeño exportador.

- La conformidad de estrategia se relaciona de manera efectiva con el desempeño exportador.

- Las personas se relacionan de manera eficiente con el desempeño exportador.

- Los recursos se relacionan positivamente con el desempeño exportador.

- Los procesos se relacionan de manera positiva con el desempeño exportador. 


\section{Capítulo II}

\subsection{Método}

Para la investigación se utilizó un método cuantitativo, en donde la muestra representativa fueron las empresas peruanas exportadoras de cacao en grano, la información se recopiló a través de encuestas con preguntas estandarizadas con la finalidad de que se complementara los objetivos de la investigación mencionada. El método cuantitativo permitió obtener las variables de forma numérica y el resultado de los datos puedo describirse por medio de gráficos, tablas o mediciones estadísticas como promedios, variaciones y correlaciones como análisis de varianza, análisis factorial o análisis de regresión (Befring, 2015).

\subsubsection{Tipo de investigación}

Debido al análisis cuantitativo de la presente investigación, se aplicó el tipo de investigación correlacional. Según Hernández, Fernández \& Baptista (2014) es un estudio que tiene como objetivo evaluar la relación que exista entre dos o más conceptos ,categorías o variables ,los estudios cuantitativos correlacionales miden el grado de relación entre las 2 variables es decir miden cada variable presuntamente relacionada y miden y analizan la correlación expresadas en hipótesis sometidas a prueba El objetivo de la presente investigación radica en argumentar las variables entre sí, para lo cual se medirá el impacto de la variable gestión de calidad total en la variable desempeño exportador.

\subsubsection{Diseño de investigación}

La presente investigación utilizó el diseño de investigación no experimental transversal ya que la relación entre las variables se realiza sin ningún tipo de influencia directa, en este sentido, las relaciones se observan en su contexto natural.

Hernández, Fernández \& Baptista (2014) define la investigación sin manipular voluntariamente variables, y en los que se pueden observar los fenómenos en su ambiente natural, para que sean analizados luego. Agrega también, que el diseño experimental es 
transversal cuando se recolectan datos en un solo momento, en un tiempo único, por lo que el propósito es describir variables y su suceso de interrelación en un momento especifico dado.

\title{
2.1.3 Variables
}

- Variable (X): Gestión de calidad total

Según Imran., hace referencia a la vinculación de todos con las operaciones de la empresa que están involucradas en la mejora continua del producto a ofrecer incluyendo clientes y proveedores si es posible.

Dimensiones (X): Según Imran, Hamid y Aziz (2018) existen 5 dimensiones de la gestión de calidad total que hacen más operativo el concepto de calidad de un producto o servicio:

\author{
X1: Liderazgo \\ X2: Estrategia \\ X3: Personas \\ X4: Recursos \\ X5: Procesos
}

- Variable (Y): Desempeño exportador

El desempeño exportador se define como el grado en el que una empresa logra sus objetivos estratégicos y financieros Imran, Hamid y Aziz (2018).

Dimensiones (X): Según Imran, Hamid y Aziz (2018) existen 3 dimensiones del desempeño exportador que permiten medir el crecimiento de la empresa exportadora los cuales son:

Y1: Finanzas

Y2: Estrategias 


\section{Y3: Satisfacción}

\subsubsection{Población}

Según datos obtenidos mediante la plataforma SIICEX (2019) se registraron 111 empresas exportadoras de Cacao en grano en el Perú de las cuales 56 son MYPES.

\begin{tabular}{|c|c|}
\hline Ruc & Empresa \\
\hline 20525955843 & 'CAES PIURA' \\
\hline 20486142724 & AGROINDUSTRIA SCHULER E.I.R.L. \\
\hline 10011541866 & AGUILAR MESTANZA DIONICIO \\
\hline 20551165711 & AMAZONIA MARAVILLA NATURAL DEL PERU S.A.C. \\
\hline 20535652555 & ARDYSS INTERNATIONAL PERU S.R.L. \\
\hline 20509911054 & ARHUSA TRADING S.A.C. \\
\hline 20133080717 & ARTE PERU S.A.C. \\
\hline 20544631897 & ARUBA LIMA E.I.R.L. \\
\hline 20447604281 & ASOCIACION ARTE AYMARA \\
\hline 10425701580 & BOLLIGER NEUMANN MARK \\
\hline 20539086082 & CABALLERO CARMELO IMPEXP EIRL \\
\hline 10419819561 & CELIS CHUMBILE LEOPOLDO ELIAS \\
\hline 10068219103 & CHUMBIRAY Y PERRY ARMANDO EUGENIO \\
\hline 20307167442 & $\begin{array}{l}\text { COMISION DE PROMOCION DEL PERU PARA LA EXPORTACION Y EL TURISMO - } \\
\text { PROMPERU }\end{array}$ \\
\hline 20539090942 & CONSULTORIA COMERCIAL Y EXPORTACION EMPR \\
\hline 20514323551 & Café Risso Perú SAC \\
\hline 20515732269 & $\begin{array}{l}\text { EMPRESA SOCIO SOSTENIBLE COMERCIALIZADORA DE PRODUCTOS ECOLOGICOS } \\
\text { S.A.C (E.S.S.C.P.E. S.A.C) }\end{array}$ \\
\hline 20541786971 & EXPORTADORA, COMERCIALIZADORA BALLARTE E HIJOS S.A.C. \\
\hline 20503522421 & FITOMUNDO COMERCIAL DE RESPONSABILIDAD LIMITADA \\
\hline 20568517041 & FUNDO LA DOÑA S.A.C. \\
\hline 20519147085 & GRUPO L \& G SAC \\
\hline 20551736211 & HOJA VERDE IMPOREX SOCIEDAD ANONIMA CERR \\
\hline 20549093494 & IMPORTACIONES \& EXPORTACIONES GALLO E. I. R.L. \\
\hline 20550242517 & INTERNATIONAL COMMERCE AND TRADING LATIN \\
\hline 20524772044 & J \& M DESING EXPORT S.A.C. \\
\hline 20550320259 & JACKMAN GOODS E.I.R.L. \\
\hline 20555032731 & MAREMI S.A.C. \\
\hline 10256047816 & MATUK DEL RISCO MARIA ELENA JOSEFA CLOTILDE \\
\hline 20528362711 & MONO COTO TRADE S.R.L. \\
\hline 20494039339 & MONTAÑA ROJA DE SHAMBU EIRL \\
\hline 20526305095 & MUNDO BIO - ORGANICO SOCIEDAD COMERCIAL DE RESPONSABILIDAD LIMITADA \\
\hline 10400438868 & ROMAN FIGUEROA PAUL \\
\hline 20515554654 & TOP TRADE S.A.C. \\
\hline 10256628444 & TORRES BOCANEGRA WILLY AURELIO \\
\hline 10424891415 & VARILLAS BALTAZAR CINTHIA PAOLA \\
\hline 20508989467 & VC LEATHER S.A.C \\
\hline
\end{tabular}

Figura 8. Empresas exportadoras de cacao al 2019

Fuente: SUNAT 


\subsubsection{Muestra}

La muestra se basó en la formula probabilística de la población finita con la finalidad de obtener el subgrupo preciso de la población y como resultado poder tener la representación exacta.

$$
n=\frac{N \cdot Z^{2} \cdot p \cdot(1-p)}{\mathrm{e}^{2} \cdot(N-1)+Z^{2} \cdot p \cdot(1-p)}
$$

Se tomó en cuenta 56 MYPES exportadoras peruanas de cacao en grano. Los datos de las variables se describen a continuación:

- $\quad \mathrm{N}=56$

- $\quad \mathrm{Z}=1.96$

- $\quad \mathrm{P}=0.5$

- $\mathrm{e}=0.05$

Realizando la operación requerida con los datos brindados obtuvimos que el total de la muestra es de 50 empresas MYPE exportadoras de cacao en grano en el Perú.

\subsubsection{Instrumento de investigación}

Los instrumentos de investigación que se utilizaron fueron los cuestionarios validados por expertos, Coeficiente de Aiken (anexo 6) y se verifico también la fiabilidad mediante el alfa de Cronbach (anexo 5). De igual manera, de acuerdo con Hernández, Fernández y Baptista (2014), se realizó la contrastación de las hipótesis mediante la prueba de Spearman para la comprobación de la correlación de más de dos variables ordinales.

Considerando que el coeficiente de Aiken, en donde indica que es una verificación de que la muestra de los ítems que han sido incluidos en el cuestionario, su objetivo es que cubran de una manera efectiva todas las dimensiones que son relevantes de las variables que serán estudiadas. Siendo evaluados cuatro factores: claridad, congruencia, contexto y dominio del constructo. 
Adicionalmente, en el anexo $\mathrm{n}^{\circ} 2$, se encuentra la encuesta la cual fue entregada a gerentes de MYPES exportadoras de cacao en grano en el Perú. La presente encuesta sobre la relación entre la gestión de calidad total y el desempeño exportador contiene 19 preguntas alineadas correctamente con la escala de Likert del 1 al 5, donde 1 es totalmente en desacuerdo, 2 es parcialmente en desacuerdo, 3 es indiferente, 4 parcialmente de acuerdo y 5 es totalmente de acuerdo. El diseño del cuestionario se elaboró en base a las preguntas propuestas por los investigadores Imran., Hamid y Aziz (2018) los cuales aplicaron las variables mencionadas para lograr el cuestionario final.

A continuación, en la tabla 4 y 5 se mostrará la ficha técnica de los instrumentos de investigación de la "Relación entre la gestión de calidad total y el desempeño exportador de las empresas exportadoras peruanas MYPE al 2020”.

Tabla 4.

Ficha Técnica Cuestionario gestión de calidad total

\begin{tabular}{ll}
\hline Cuestionario & $\begin{array}{l}\text { "The influence of TQM on export performance of } \\
\text { SMEs: Empirical evidence from manufacturing } \\
\text { sector in Pakistan using PLS-SEM" }\end{array}$ \\
\hline Autor & Imran, M., Hamid, S y Aziz, A. \\
\hline Año & 2018 \\
\hline Aplicación & Individual \\
\hline Ámbito de aplicación & Perú \\
\hline Universo & $\begin{array}{l}\text { Todas las empresas exportadoras peruanas MYPE } \\
\text { de cacao en grano al 2020 }\end{array}$ \\
\hline Duración & 7 min aproximadamente por representante \\
\hline Objetivo & $\begin{array}{l}\text { Determinar la relación entre la gestión de calidad } \\
\text { total y el desempeño exportador de las empresas } \\
\text { exportadoras peruanas MYPE al 2020 }\end{array}$ \\
\hline Tamaño de la muestra & 50 empresas \\
\hline Técnica & Llamada telefónica y correos \\
\hline Fecha de realización & Junio-Julio 2020 \\
\hline Financiación & Recursos propios \\
\hline Validadores & Carla Arriola Alvarado \\
\hline
\end{tabular}

Elaboración propia 
Tabla 5.

Ficha Técnica Cuestionario Desempeño exportador

"The influence of TQM on export performance of

Cuestionario

SMEs: Empirical evidence from manufacturing sector in Pakistan using PLS-SEM"

\begin{tabular}{ll}
\hline Autor & Imran, M., Hamid, S y Aziz, A. \\
\hline Año & 2018 \\
\hline Aplicación & Individual \\
\hline Ámbito de aplicación & Perú \\
\hline Universo & $\begin{array}{l}\text { Todas las empresas exportadoras peruanas MYPE de } \\
\text { cacao en grano al 2020 }\end{array}$ \\
\hline Duración & 2 min aproximadamente por representante \\
\hline Objetivo & $\begin{array}{l}\text { Determinar la relación entre la gestión de calidad } \\
\text { total y el desempeño exportador de las empresas } \\
\text { exportadoras peruanas MYPE al 2020 }\end{array}$ \\
\hline Tamaño de la muestra & 50 empresas \\
\hline Técnica & Llamada telefónica y correos \\
\hline Fecha de realización & Junio-Julio 2020 \\
\hline Financiación & Recursos propios \\
\hline Validadores & Carla Arriola Alvarado \\
& $\begin{array}{l}\text { Alberto Valdez Barboza } \\
\text { Carlos Pereira Luza }\end{array}$ \\
\hline
\end{tabular}

Elaboración propia

\subsubsection{Procedimiento de recolección de datos}

Para la presente investigación se tomaron en cuenta las encuestas realizadas a los gerentes de las diferentes MYPES exportadoras de cacao en grano, a fin de poder obtener información confiable, precisa y eficaz. Se utilizó una base de datos recolectada de la Asociación de Exportadores del Perú, en la cuales se podrá obtener el directorio con los gerentes de las 50 MYPES exportadoras de cacao en grano.

Con el fin de que se pueda trabajar la información de una manera más rápida se implementó una base de datos en donde se consideró la razón social, la dirección de la empresa ,el teléfono ,el correo y el número de RUC de cada una de las MYPES exportadoras de cacao en grano, con la información obtenida se pudo proceder a contactar a cada uno de 
los representantes vía telefónica y por correo electrónico para facilitar el llenado de las encuestas virtualmente durante el periodo de un mes desde el 10 de Junio del 2020 al 10 de Julio del 2020.

Según Hernández, Fernández \& Baptista indican que los requisitos necesarios que un instrumento de medición debe cubrir para recolectar apropiadamente datos cuantitativos son: confiabilidad, validez y objetividad. Asimismo, se define el concepto de medición y los errores que puedan cometerse al recolectar datos (2014, p.196).

Las herramientas utilizadas para realizar el análisis fueron las siguientes:

- Excel: Diferentes tipos de tabla

- SPSS 26: Se utilizo para tabular las encuestas y realizar las pruebas estadísticas como el alfa de Cronbach, el análisis factorial confirmatorio y la correlación de Spearman (Rho). 


\section{Capítulo III}

\subsection{Análisis de los resultados de los cuestionarios}

Según Hernández., Fernández y Baptista (2014) para el proceso de cualquier investigación existen niveles de errores en el que los más comunes son el $1 \%$ y el 5\%, siendo el 5\% el más común en las ciencias sociales. En esta oportunidad se ha considerado el $5 \%$ con un nivel de confianza de $95 \%$ de confiabilidad, donde no se considera equivocación y el $5 \%$ rechaza una hipótesis nula cuando es verdadera.

\subsubsection{Análisis las encuestas de Gestión de calidad total.}

A continuación, se expondrán los resultados de los 50 cuestionarios desarrollados por los representantes de las empresas MYPE exportadoras de cacao en grano en el Perú, acerca de la relación que tiene la gestión de calidad total y sus dimensiones frente a el desempeño exportador.

Tabla 6

Costo sobre calidad

GCT 1) Los gerentes de nuestra empresa consideran que el costo es más importante en comparación con la calidad de los productos.

\begin{tabular}{llcccc}
\hline & Frequency & Percent & Valid Percent & $\begin{array}{c}\text { Cumulative } \\
\text { Percent }\end{array}$ \\
\hline \multirow{4}{*}{ Valid } & En desacuerdo & 6 & 12.0 & 12.0 & 12.0 \\
& Ni de acuerdo ni en & 15 & 30.0 & 30.0 & 42.0 \\
desacuerdo & & & & \\
& De acuerdo & 19 & 38.0 & 38.0 & 80.0 \\
& Muy de acuerdo & 10 & 20.0 & 20.0 & 100.0 \\
\cline { 2 - 5 } & Total & 50 & 100.0 & 100.0 & \\
\hline
\end{tabular}

Elaboración propia (2020) - Extraído del SPSS 26 


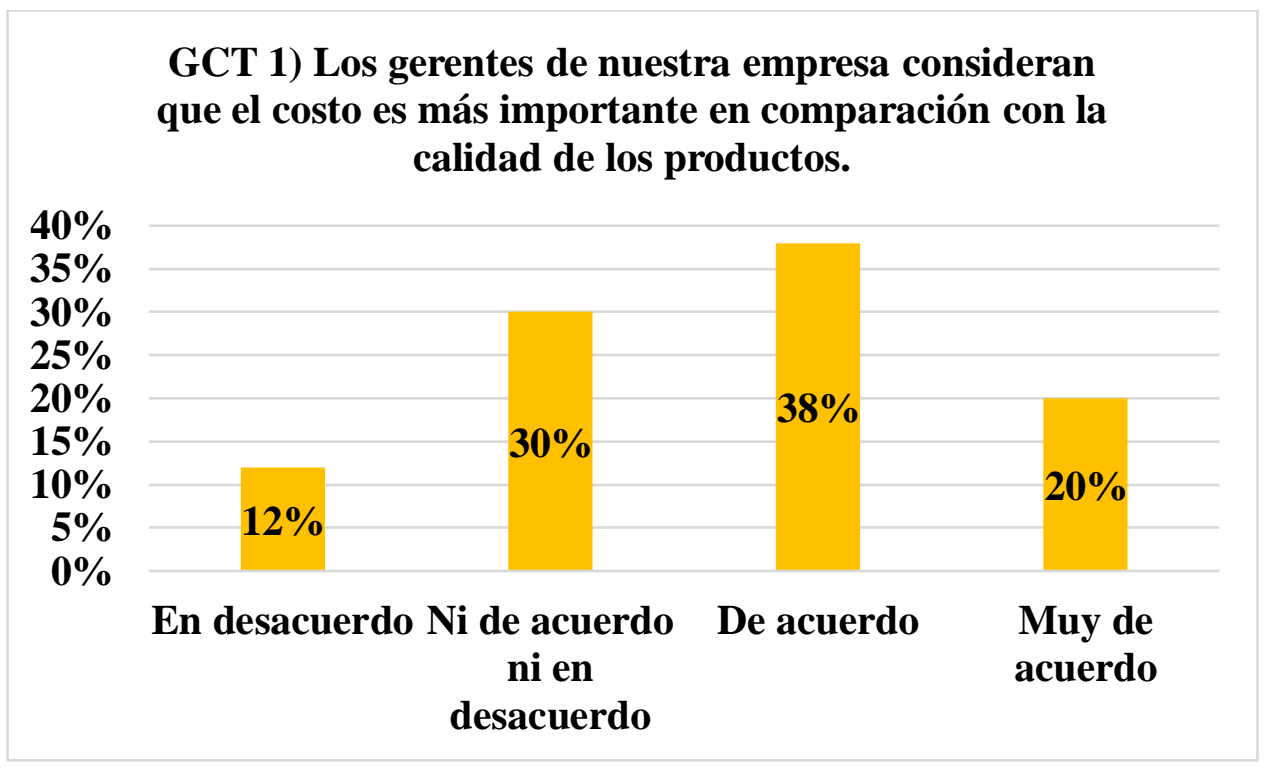

Figura 9.Gráfico Costo sobre calidad

Interpretación:

Como se puede observar en la Tabla 6 , de los 50 representantes de las empresas 6 personas se encuentran en desacuerdo, el $58 \%$ está de acuerdo o muy de acuerdo, pero también hubo un $30 \%$ de representantes de las empresas que se encontraron en una posición neutral frente a esta afirmación, Por ello, podemos concluir que la gran mayoría de los representantes de las empresas consideran que el costo es más importante en comparación con la calidad de los productos.

Tabla 7

Gerentes son modelos a seguir

GCT 2) Los gerentes de nuestra empresa se presentan como modelos a seguir para los empleados.

\begin{tabular}{|c|c|c|c|c|c|}
\hline & & Frequency & Percent & $\begin{array}{c}\text { Valid } \\
\text { Percent }\end{array}$ & $\begin{array}{c}\text { Cumulative } \\
\text { Percent }\end{array}$ \\
\hline \multirow[t]{4}{*}{ Valid } & $\begin{array}{l}\text { Ni de acuerdo ni en } \\
\text { desacuerdo }\end{array}$ & 3 & 6.0 & 6.0 & 6.0 \\
\hline & De acuerdo & 18 & 36.0 & 36.0 & 42.0 \\
\hline & Muy de acuerdo & 29 & 58.0 & 58.0 & 100.0 \\
\hline & Total & 50 & 100 & 100 & \\
\hline
\end{tabular}

Elaboración propia (2020) - Extraído del SPSS 26 


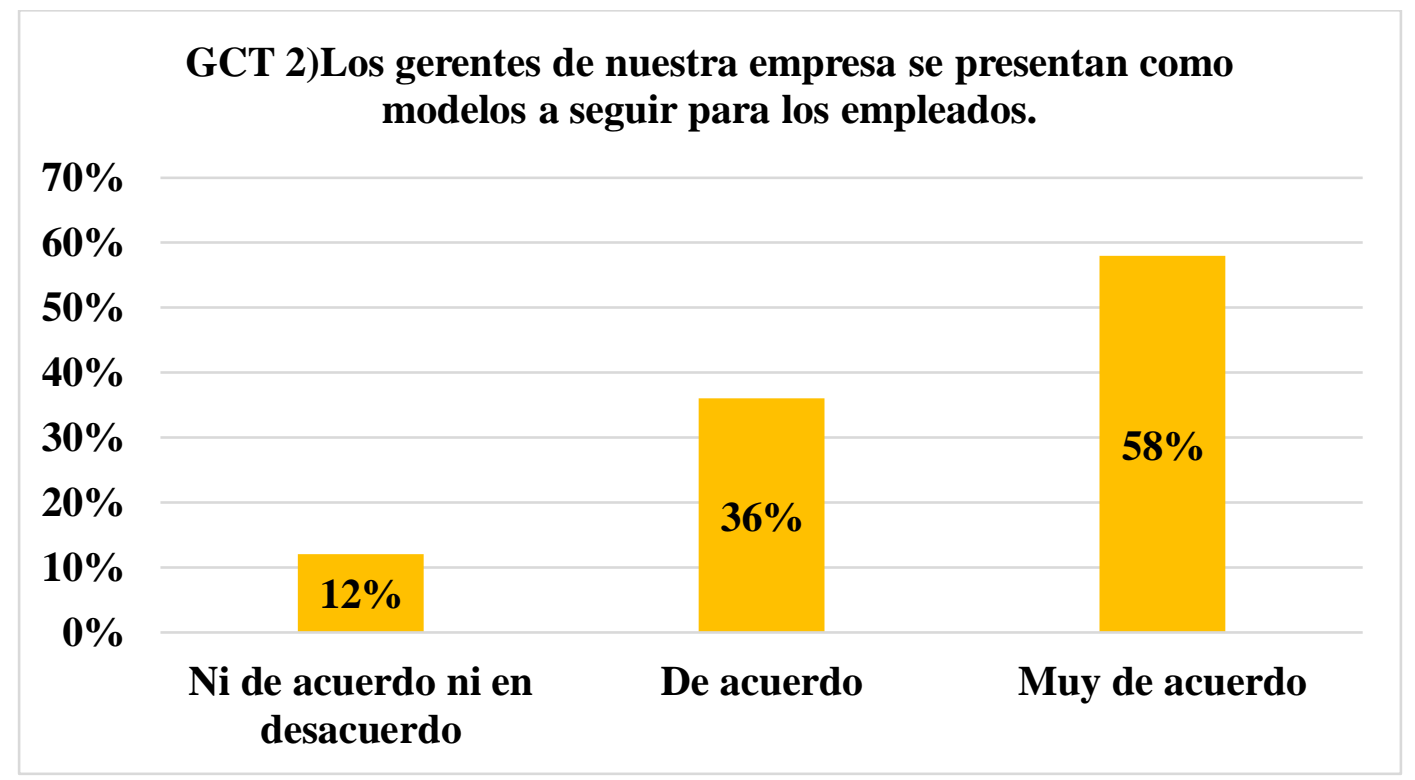

Figura 10.Gráfico Gerentes son modelos a seguir

Interpretación:

Para este caso, de los 50 representantes encuestados obtuvimos como resultado que el $58 \%$ de gerentes o administradores están muy de acuerdo con que los gerentes se presenten como modelos a seguir para sus colaboradores. Además de tener un 36\% o 18 personas que están de acuerdo, existe un $12 \%$ que no se encuentran ni de acuerdo ni en desacuerdo con lo antes mencionado tomando una posición neutral

Tabla 8

Empleados conocen los planes a largo plazo de la empresa

GCT 3) Los gerentes de nuestra empresa se aseguran de que los empleados conozcan los planes a largo plazo de la empresa.

\begin{tabular}{llccc}
\hline & Frequency & Percent & $\begin{array}{c}\text { Valid } \\
\text { Percent }\end{array}$ & $\begin{array}{c}\text { Cumulative } \\
\text { Percent }\end{array}$ \\
\hline En desacuerdo & 8 & 16.0 & 16.0 & 16.0 \\
Ni de acuerdo ni en & 11 & 22.0 & 22.0 & 38.0 \\
Valid desacuerdo & & & & \\
De acuerdo & 15 & 30.0 & 30.0 & 68.0 \\
Muy de acuerdo & 16 & 32.0 & 32.0 & 100.0 \\
\cline { 2 - 5 } & 50 & 100.0 & 100.0 & \\
\hline
\end{tabular}

Elaboración propia (2020) - Extraído del SPSS 26 


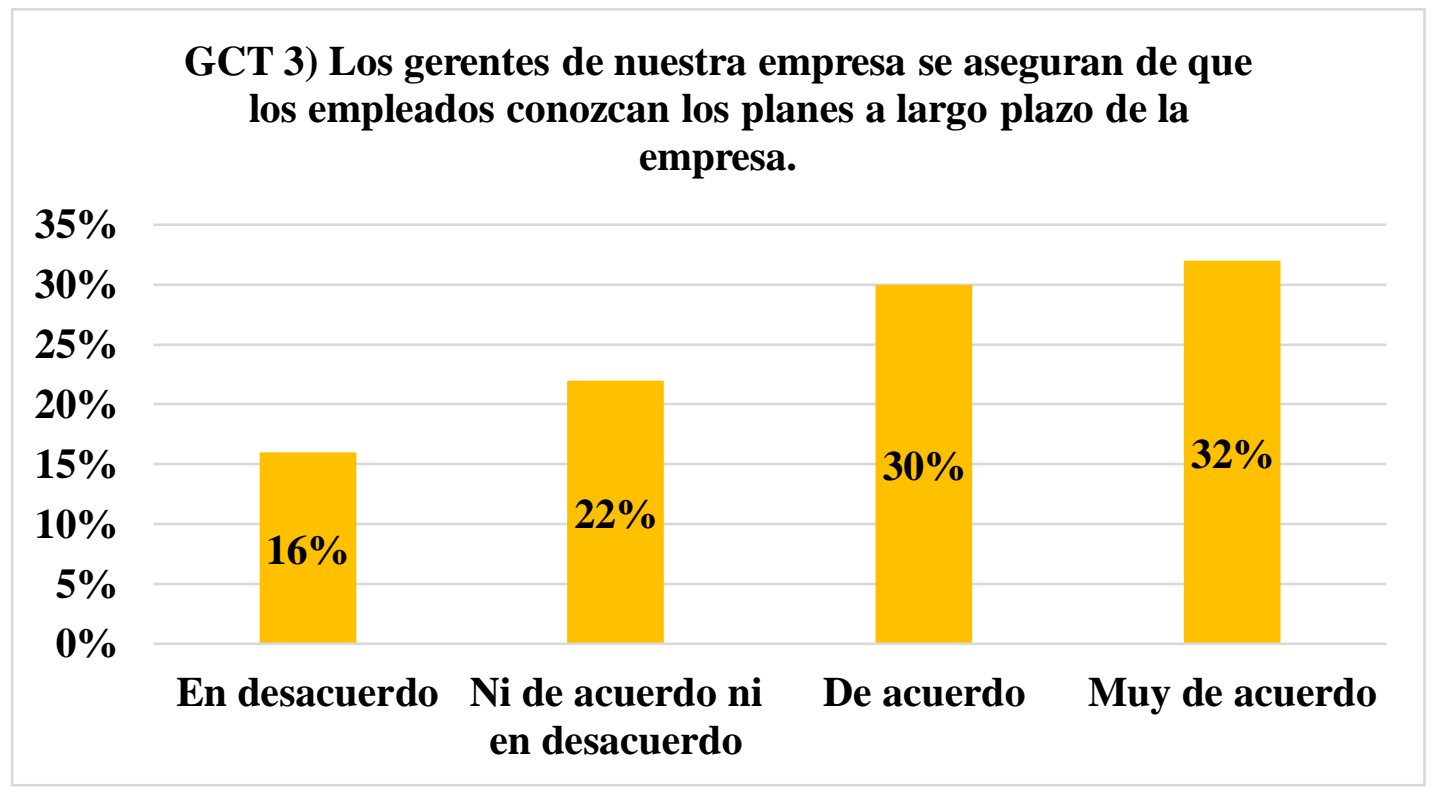

Figura 11. Gráfico Empleados conocen los planes a largo plazo de la empresa Interpretación:

Para la tercera afirmación del cuestionario, el resultado arrojó que, de los 50 representantes, el 22\% tienen una posición neutral donde opinan que están ni de acuerdo ni en desacuerdo con que los empleados conozcan los planes a largo plazo de la empresa y un $16 \%$ que se encuentran en desacuerdo con la afirmación. Por otro lado, obtuvimos un $62 \%$ que están de acuerdo o muy de acuerdo.

\section{Tabla 9}

Gerentes no desean otorgar a sus empleados decisiones sobre sus trabajos

GCT 4) Los gerentes de nuestra empresa no desean otorgar autoridad a los empleados para que tomen decisiones sobre sus trabajos.

\begin{tabular}{|c|c|c|c|c|c|}
\hline & & Frequency & Percent & $\begin{array}{c}\text { Valid } \\
\text { Percent }\end{array}$ & $\begin{array}{c}\text { Cumulative } \\
\text { Percent }\end{array}$ \\
\hline \multirow{6}{*}{ Valid } & En desacuerdo & 6 & 12.0 & 12.0 & 12.0 \\
\hline & Ni de acuerdo ni en & 3 & 6.0 & 6.0 & 18.0 \\
\hline & desacuerdo & & & & \\
\hline & De acuerdo & 23 & 46.0 & 46.0 & 64.0 \\
\hline & Muy de acuerdo & 18 & 36.0 & 36.0 & 100.0 \\
\hline & Total & 50 & 100.0 & 100.0 & \\
\hline
\end{tabular}

Elaboración propia (2020) - Extraído del SPSS 26 


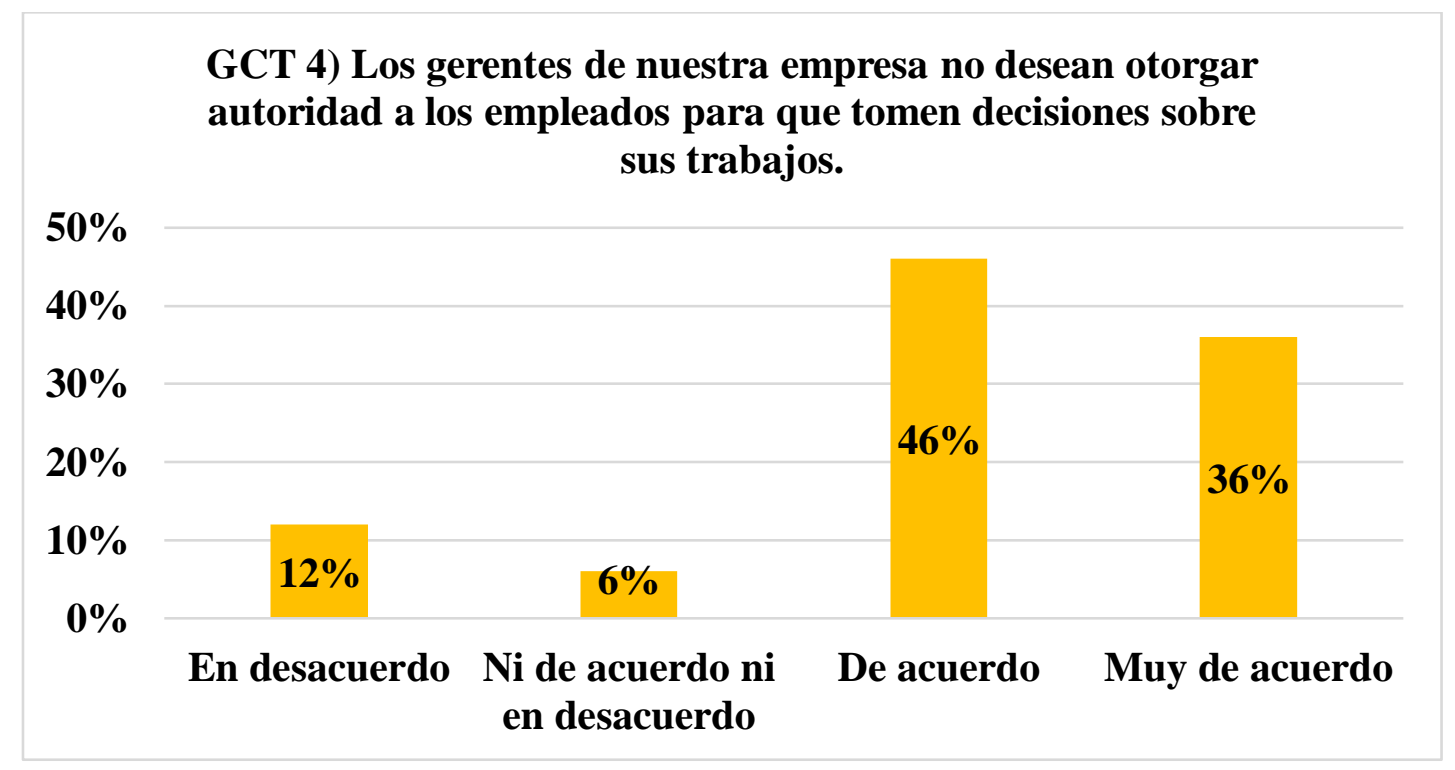

Figura 12. Gráfico Gerentes no desean otorgar a sus empleados decisiones sobre sus trabajos

Interpretación:

Para esta afirmación, 23 de los representantes de las empresas estuvieron de acuerdo y el $36 \%$ de la muestra se encontraron muy de acuerdo afirmando que los gerentes si otorgan autoridad a sus empleados para que tomen decisiones sobre sus trabajos. Por otro lado, hubo solo 6 representantes en desacuerdo que es equivalente solo al 12\% de la muestra y también hay un $6 \%$ de los representantes de empresas que tienen una posición neutral frente a esta afirmación.

Tabla 10

Los gerentes adquieren y actualizan su conocimiento continuamente

GCT 5) Los gerentes de nuestra empresa adquieren y actualizan continuamente su conocimiento que es valioso para la organización.

\begin{tabular}{|c|c|c|c|c|c|}
\hline & & Frequency & Percent & $\begin{array}{c}\text { Valid } \\
\text { Percent }\end{array}$ & $\begin{array}{c}\text { Cumulative } \\
\text { Percent }\end{array}$ \\
\hline \multirow[t]{4}{*}{ Valid } & $\begin{array}{l}\text { Ni de acuerdo ni en } \\
\text { desacuerdo }\end{array}$ & 10 & 20.0 & 20.0 & 20.0 \\
\hline & De acuerdo & 9 & 18.0 & 18.0 & 38.0 \\
\hline & Muy de acuerdo & 31 & 62.0 & 62.0 & 100.0 \\
\hline & Total & 50 & 100.0 & 100.0 & \\
\hline
\end{tabular}

Elaboración propia (2020) - Extraído del SPSS 26 


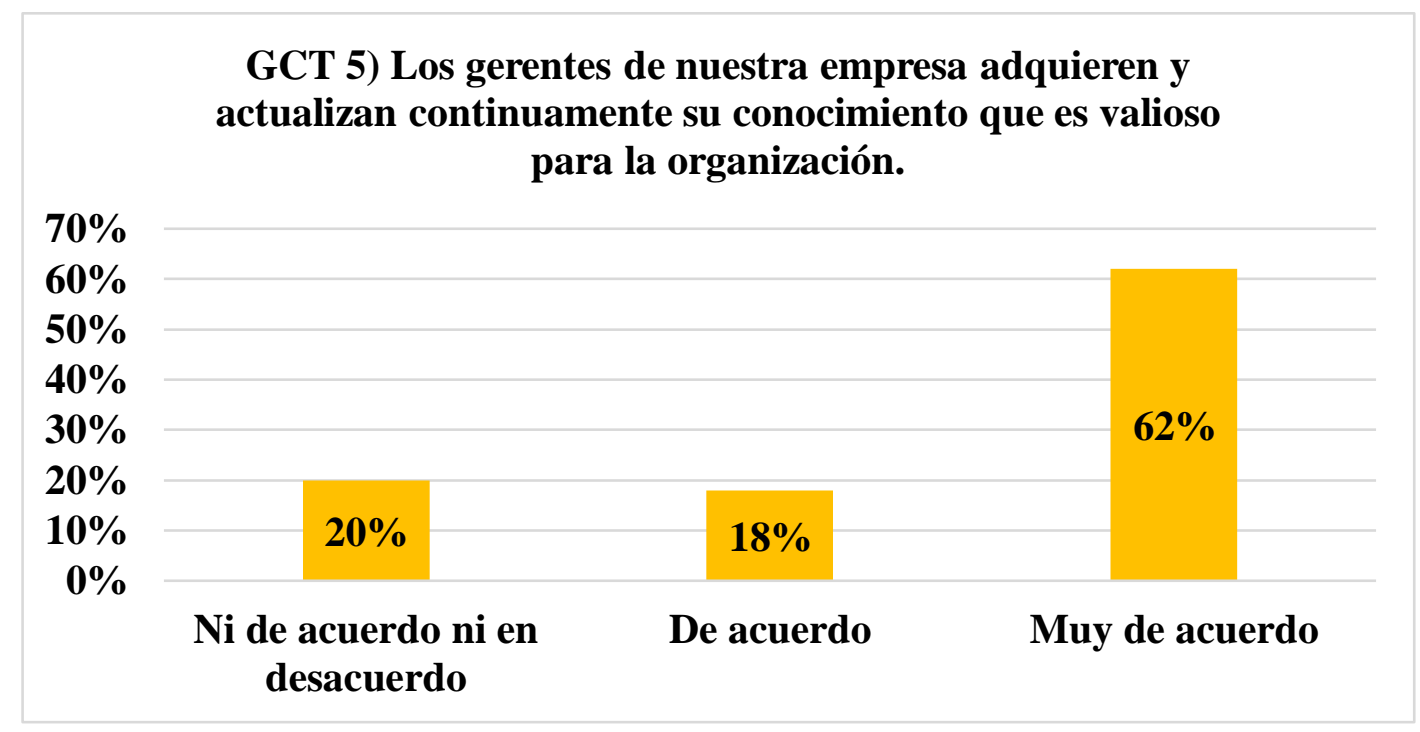

Figura 13. Gráfico Los gerentes adquieren y actualizan su continuamente su conocimiento

Interpretación:

En la quinta afirmación con respecto a la constante actualización de conocimiento de los gerentes al ser este importante para la organización, los resultados obtenidos indican que solo un $20 \%$ de los representantes están ni de acuerdo ni en desacuerdo teniendo una posición neutral. Asimismo, un $80 \%$ de los representantes de las empresas se encuentran muy de acuerdo y de acuerdo indicando que si adquieren y actualizan sus conocimientos con frecuencia porque es valiosos para la organización en general.

\section{Tabla 11}

Gerentes fomentan y partición en iniciativas de mejora continua

GCT 6) Los gerentes de nuestra empresa fomentan y participan en iniciativas de mejora continua.

\begin{tabular}{|c|c|c|c|c|c|}
\hline & & Frequency & Percent & $\begin{array}{c}\text { Valid } \\
\text { Percent }\end{array}$ & $\begin{array}{c}\text { Cumulative } \\
\text { Percent }\end{array}$ \\
\hline \multirow{5}{*}{ Valid } & En desacuerdo & 3 & 6.0 & 6.0 & 6.0 \\
\hline & $\begin{array}{l}\text { Ni de acuerdo ni en } \\
\text { desacuerdo }\end{array}$ & 4 & 8.0 & 8.0 & 14.0 \\
\hline & De acuerdo & 31 & 62.0 & 62.0 & 76.0 \\
\hline & Muy de acuerdo & 12 & 24.0 & 24.0 & 100.0 \\
\hline & Total & 50 & 100.0 & 100.0 & \\
\hline
\end{tabular}

Elaboración propia (2020) - Extraído del SPSS 26 


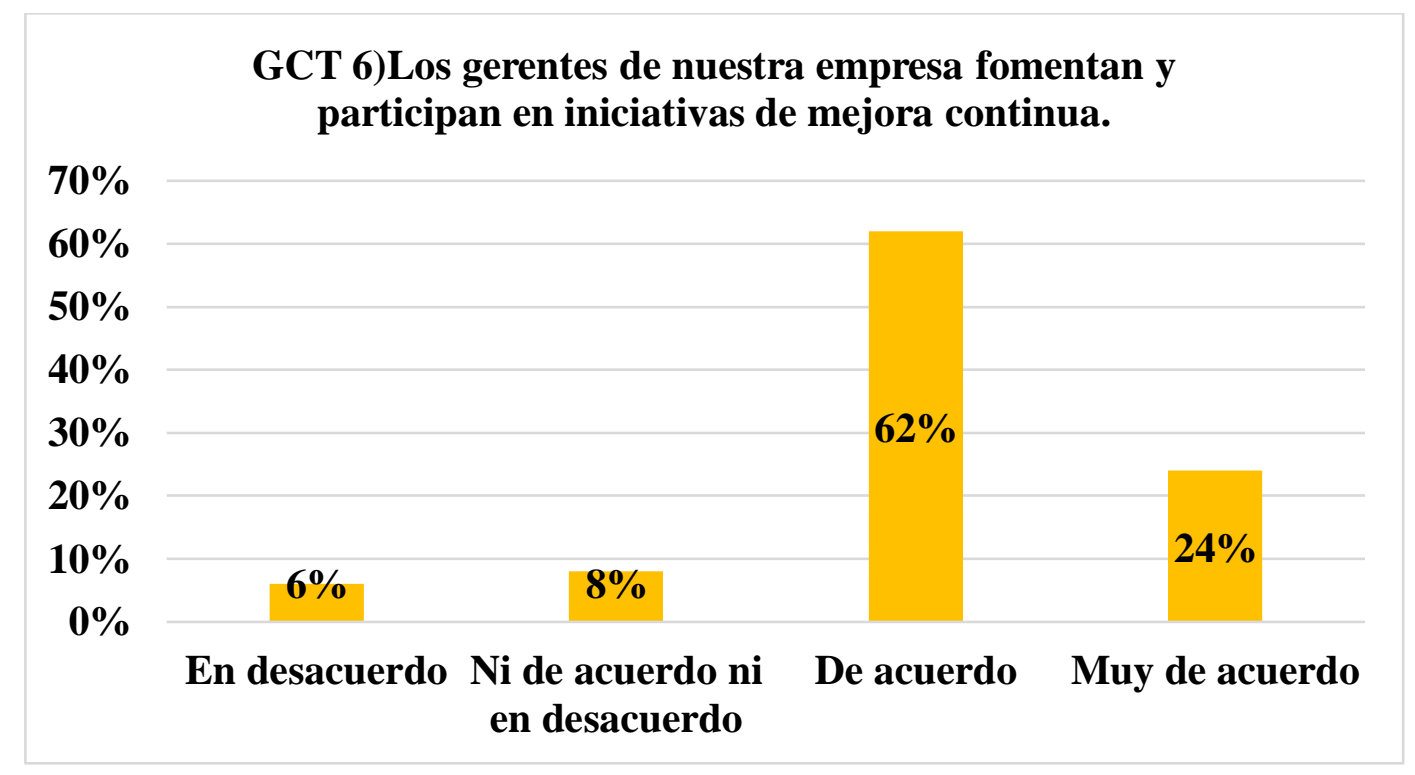

Figura 14. Gráfico Gerentes fomentan y partición en iniciativas de mejora continua

Interpretación:

Para esta afirmación hubo el $8 \%$ de los representantes de las empresas que tuvieron una posición neutral y solo el $6 \%$ de los representantes de las empresas estuvieron en desacuerdo, pero el $86 \%$ de ellos si tuvieron de acuerdo y muy de acuerdo con que los gerentes en la empresa fomenten y participen en iniciativas de mejora continua.

Tabla 12

Opinión de clientes al diseñar nuevos productos

GCT 7) En nuestra empresa, las opiniones de los clientes (las personas / empresas que compran o desean comprar los productos de su empresa) se consideran importantes al diseñar nuevos productos.

\begin{tabular}{|c|c|c|c|c|c|}
\hline & & Frequency & Percent & $\begin{array}{c}\text { Valid } \\
\text { Percent }\end{array}$ & $\begin{array}{c}\text { Cumulative } \\
\text { Percent }\end{array}$ \\
\hline \multirow{5}{*}{ Valid } & En desacuerdo & 1 & 2.0 & 2.0 & 2.0 \\
\hline & $\begin{array}{l}\text { Ni de acuerdo ni en } \\
\text { desacuerdo }\end{array}$ & 5 & 10.0 & 10.0 & 12.0 \\
\hline & De acuerdo & 26 & 52.0 & 52.0 & 64.0 \\
\hline & Muy de acuerdo & 18 & 36.0 & 36.0 & 100.0 \\
\hline & Total & 50 & 100.0 & 100.0 & \\
\hline
\end{tabular}

Elaboración propia (2020) - Extraído del SPSS 26 


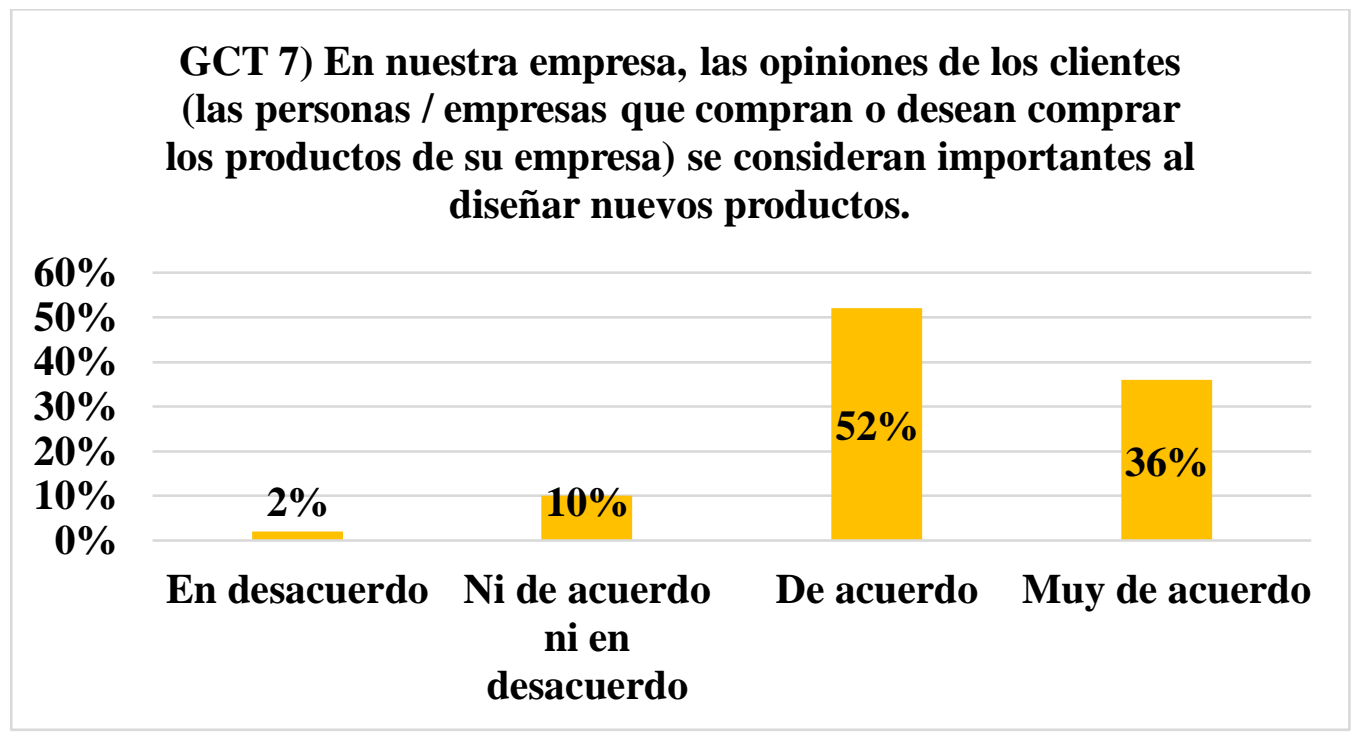

Figura 15.Gráfico Opinión de clientes al diseñar nuevos productos

Interpretación:

En este caso,52\% de los representantes votaron por estar de acuerdo, también hubo un $22.8 \%$ de los representantes de empresas que se encontraban muy de acuerdo. Sin embargo, el $12 \%$ de los representantes de las empresas se encontraron en desacuerdo o en una posición neutral al indicar que los clientes ya sean personas o empresas que compran o desea comprarles se consideran importantes al diseñar nuevos productos.

Tabla 13

Opinión de proveedores en objetivos de la empresa

GCT 8) En nuestra empresa, se consideran las opiniones de los proveedores al configurar los objetivos de la empresa.

\begin{tabular}{|c|c|c|c|c|c|}
\hline & & Frequency & Percent & $\begin{array}{c}\text { Valid } \\
\text { Percent }\end{array}$ & $\begin{array}{c}\text { Cumulative } \\
\text { Percent }\end{array}$ \\
\hline \multirow[t]{4}{*}{ Valid } & $\begin{array}{l}\text { Ni de acuerdo ni en } \\
\text { desacuerdo }\end{array}$ & 2 & 4.0 & 4.0 & 4.0 \\
\hline & De acuerdo & 12 & 24.0 & 24.0 & 28.0 \\
\hline & Muy de acuerdo & 36 & 72.0 & 72.0 & 100.0 \\
\hline & Total & 50 & 100.0 & 100.0 & \\
\hline
\end{tabular}

Elaboración propia (2020) - Extraído del SPSS 26 


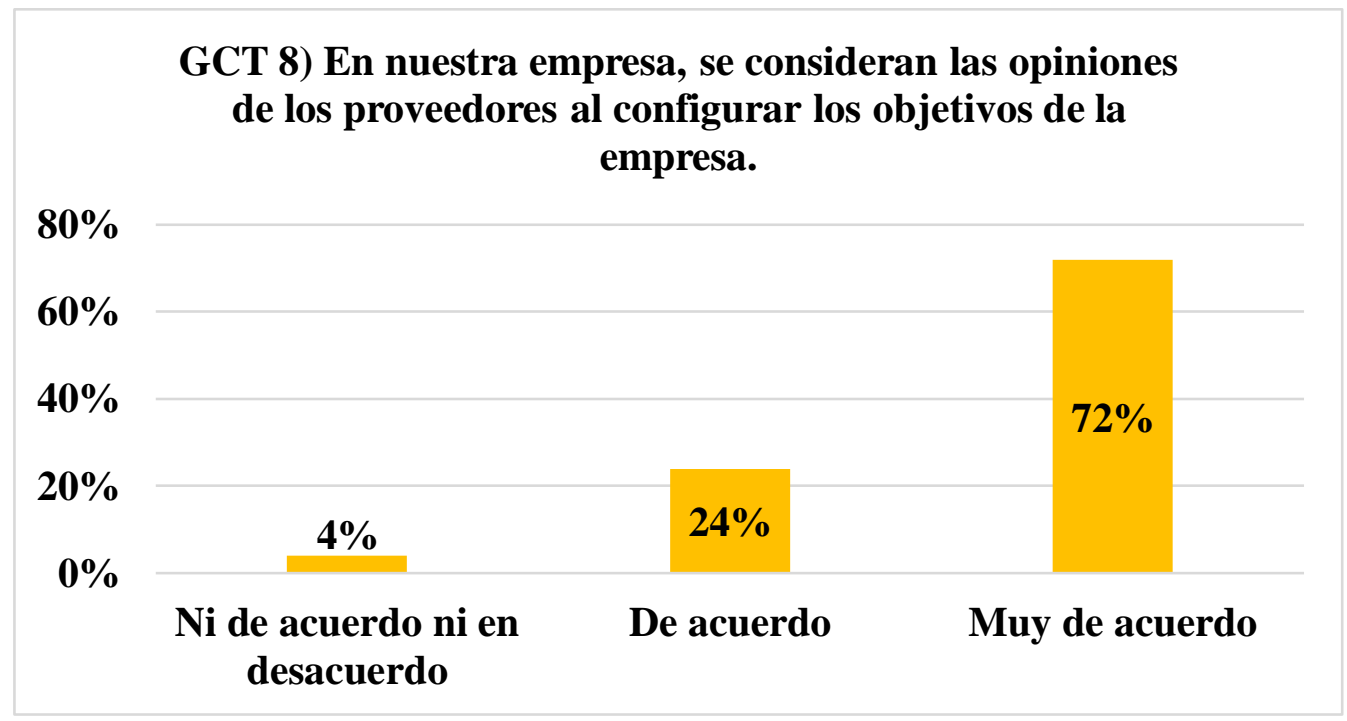

Figura 16. Gráfico Opinión de proveedores en objetivos de la empresa

Interpretación:

Para esta afirmación hubo solo un $4 \%$ de los representantes de las empresas que estuvieron en una posición neutral ya que el $72 \%$ de los representantes de las empresas estuvieron muy de acuerdo con que se considere las opiniones de los proveedores al configurar los objetivos de su empresa. Adicional a ello, un $24 \%$ también estuvo de acuerdo con la afirmación mencionada.

Tabla 14

Evaluación y análisis del desempeño de los competidores

GCT 9) En nuestra empresa, se evalúa y analiza el desempeño de los competidores y las mejores compañías de su clase.

\begin{tabular}{|c|c|c|c|c|c|}
\hline & & Frequency & Percent & $\begin{array}{c}\text { Valid } \\
\text { Percent }\end{array}$ & $\begin{array}{c}\text { Cumulative } \\
\text { Percent }\end{array}$ \\
\hline \multirow[t]{4}{*}{ Valid } & $\begin{array}{l}\text { Ni de acuerdo ni en } \\
\text { desacuerdo }\end{array}$ & 3 & 6.0 & 6.0 & 6.0 \\
\hline & De acuerdo & 9 & 18.0 & 18.0 & 24.0 \\
\hline & Muy de acuerdo & 38 & 76.0 & 76.0 & 100.0 \\
\hline & Total & 50 & 100.0 & 100.0 & \\
\hline
\end{tabular}

Elaboración propia (2020) - Extraído del SPSS 26 


\section{GCT 9)En nuestra empresa, se evalúa y analiza el desempeño de los competidores y las mejores compañías de su clase.}

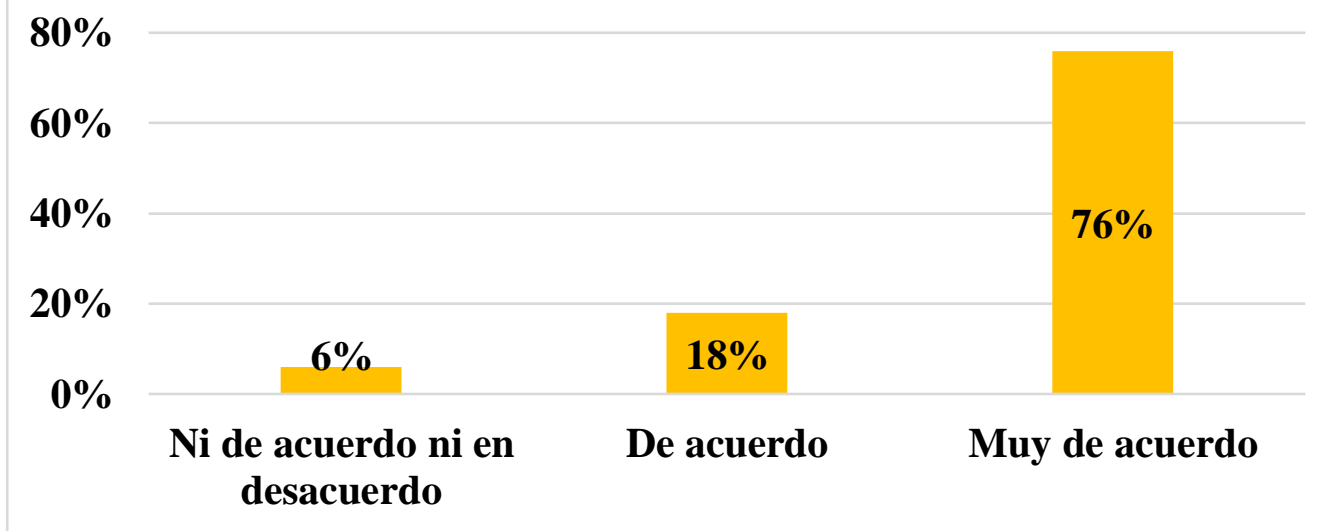

Figura 17.Grafico Evaluación y análisis del desempeño de los competidores

Interpretación:

En este caso, no tuvimos una posición en desacuerdo. Sin embargo, el 6\% de los representantes de las empresas indicaron que no estaban ni de acuerdo ni en desacuerdo por lo que el $94 \%$ indico que se encuentran de acuerdo y muy de acuerdo con que se evalúe y analice el desempeño de los competidores y las mejores compañías de su clase.

Tabla 15

Medición de pérdidas

GCT 10) En nuestra empresa, la medición sistemática de pérdidas (como pérdidas de producción, pérdidas debidas al rechazo de productos terminados, etc) se lleva a cabo.

\begin{tabular}{|c|c|c|c|c|c|}
\hline & & Frequency & Percent & $\begin{array}{c}\text { Valid } \\
\text { Percent }\end{array}$ & $\begin{array}{c}\text { Cumulative } \\
\text { Percent }\end{array}$ \\
\hline \multirow{4}{*}{ Valid } & $\begin{array}{l}\text { Ni de acuerdo ni en } \\
\text { desacuerdo }\end{array}$ & 3 & 6.0 & 6.0 & 6.0 \\
\hline & De acuerdo & 9 & 18.0 & 18.0 & 24.0 \\
\hline & Muy de acuerdo & 38 & 76.0 & 76.0 & 100.0 \\
\hline & Total & 50 & 100.0 & 100.0 & \\
\hline
\end{tabular}

Elaboración propia (2020) - Extraído del SPSS 26 


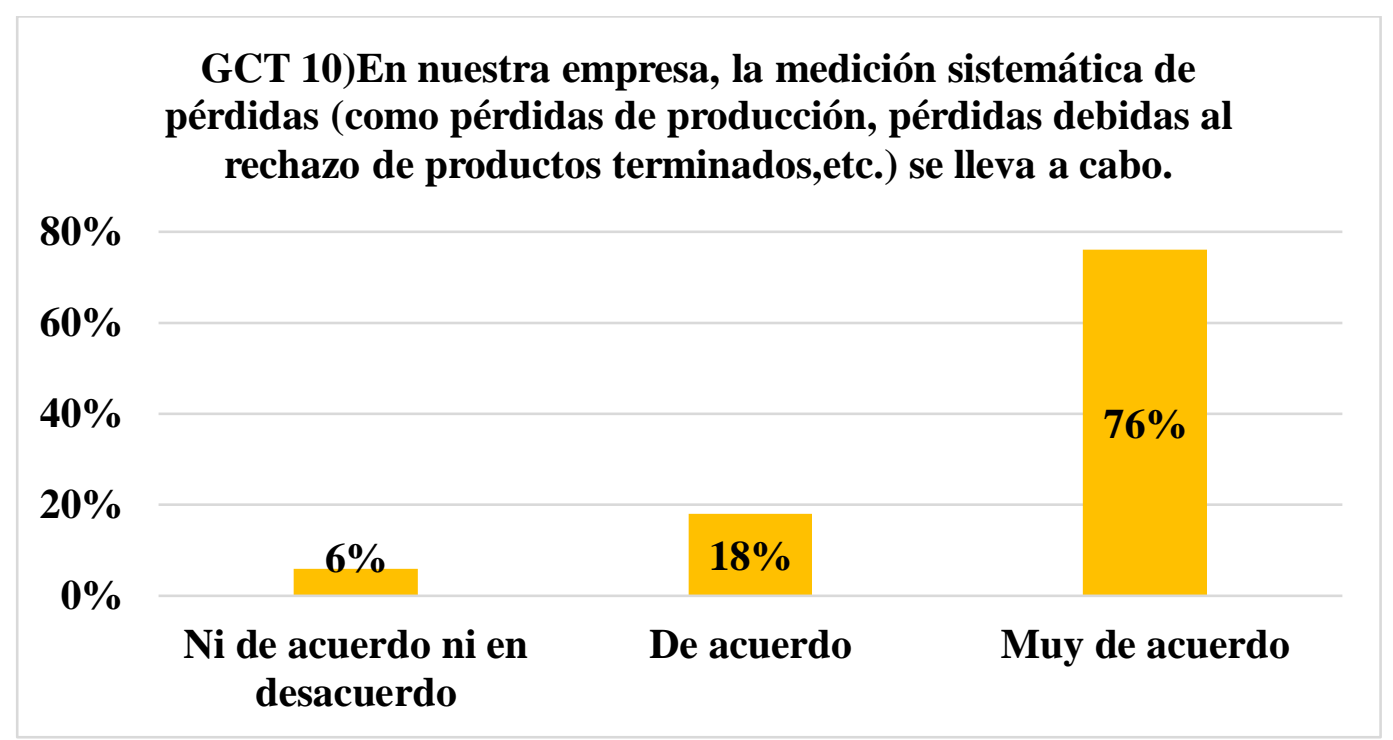

Figura 18. Gráfico Medición de pérdidas

Interpretación:

En la décima afirmación solo se mostró que un 6\% de los representantes estuvieron ni de cuerdo ni en desacuerdo, el $18 \%$ de los representantes de toda la muestra si estaba de acuerdo y el $76 \%$ de los representantes estuvieron muy de acuerdo. Podemos concluir que la mayoría de sus representantes están de acuerdos con que la medición sistemática de perdidas ya sea de producción o por rechazo de productos terminados se lleva a cabo.

Tabla 16

Captura de información sobre clientes y mercados

GCT 11) En nuestra empresa, existen sistemas de información para capturar información sobre clientes y mercados

\begin{tabular}{llcccc}
\hline & Frequency & Percent & $\begin{array}{c}\text { Valid } \\
\text { Percent }\end{array}$ & $\begin{array}{c}\text { Cumulative } \\
\text { Percent }\end{array}$ \\
\hline \multirow{2}{*}{ Valid } & $\begin{array}{l}\text { En desacuerdo } \\
\text { Ni de acuerdo ni en }\end{array}$ & 1 & 2.0 & 2.0 & 2.0 \\
& desacuerdo & 8 & 16.0 & 16.0 & 18.0 \\
& De acuerdo & 25 & 50.0 & 50.0 & 68.0 \\
& Muy de acuerdo & 16 & 32.0 & 32.0 & 100.0 \\
\cline { 2 - 5 } & Total & 50 & 100.0 & 100.0 & \\
\hline
\end{tabular}

Elaboración propia (2020) - Extraído del SPSS 26 


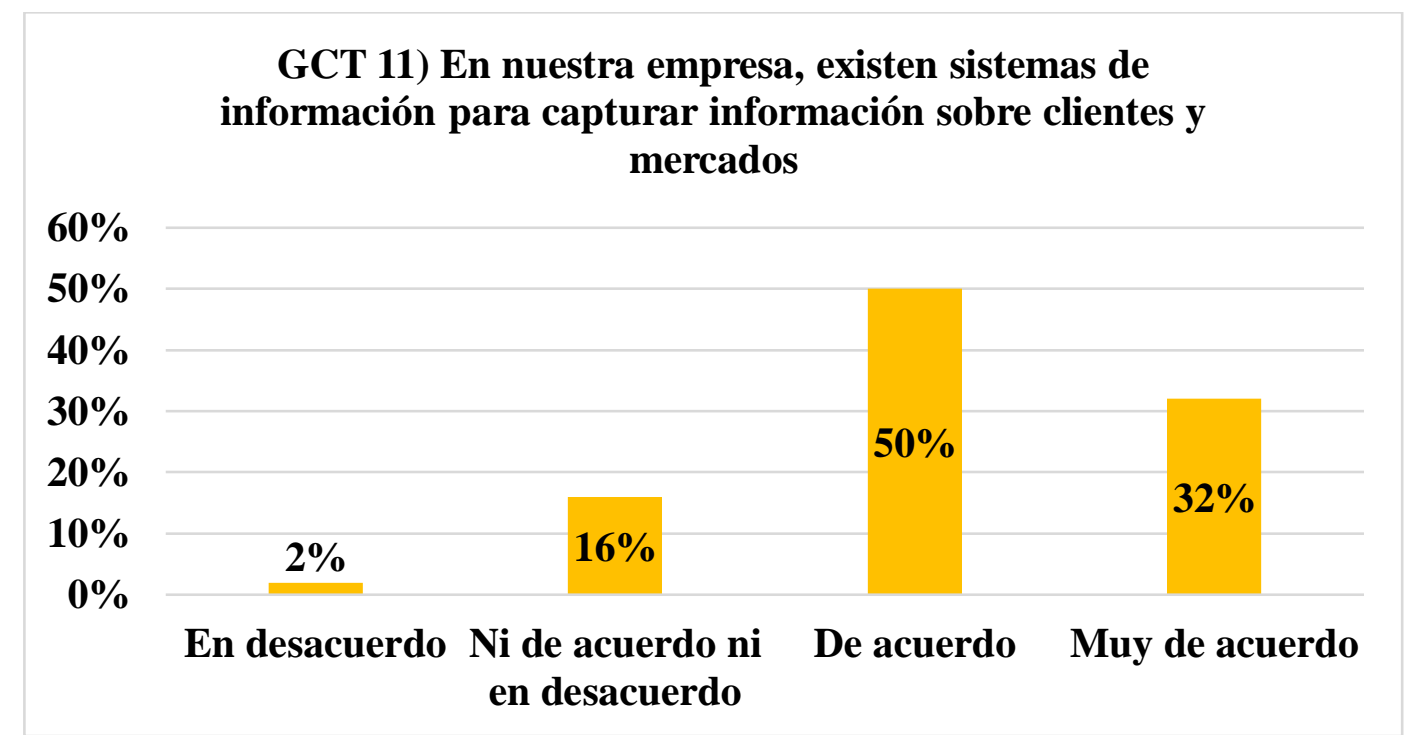

Figura 19. Gráfico Captura de información sobre clientes y mercados

Interpretación:

De los 50 representantes, el $82 \%$ están de acuerdo o muy de acuerdo con que en su empresa exista sistemas de información que capturen la información de clientes y mercados, sin embargo, el 16\% están ni de acuerdo ni en desacuerdo y únicamente un $2 \%$ se encuentra en desacuerdo indicando que no cuentan con el sistema de información consultado.

Tabla 17

Evaluación del desempeño organizacional contra objetivos y metas

GCT 12) En nuestra empresa, periódicamente (por ejemplo, cada tres meses, seis meses o un año), se evalúa el desempeño organizacional contra los objetivos y metas establecidos.

\begin{tabular}{|c|c|c|c|c|c|}
\hline & & Frequency & Percent & $\begin{array}{c}\text { Valid } \\
\text { Percent }\end{array}$ & $\begin{array}{c}\text { Cumulative } \\
\text { Percent }\end{array}$ \\
\hline \multirow[t]{4}{*}{ Valid } & $\begin{array}{l}\text { Ni de acuerdo ni en } \\
\text { desacuerdo }\end{array}$ & 1 & 2.0 & 2.0 & 2.0 \\
\hline & De acuerdo & 5 & 10.0 & 10.0 & 12.0 \\
\hline & Muy de acuerdo & 44 & 88.0 & 88.0 & 100.0 \\
\hline & Total & 50 & 100.0 & 100.0 & \\
\hline
\end{tabular}

Elaboración propia (2020) - Extraído del SPSS 26 


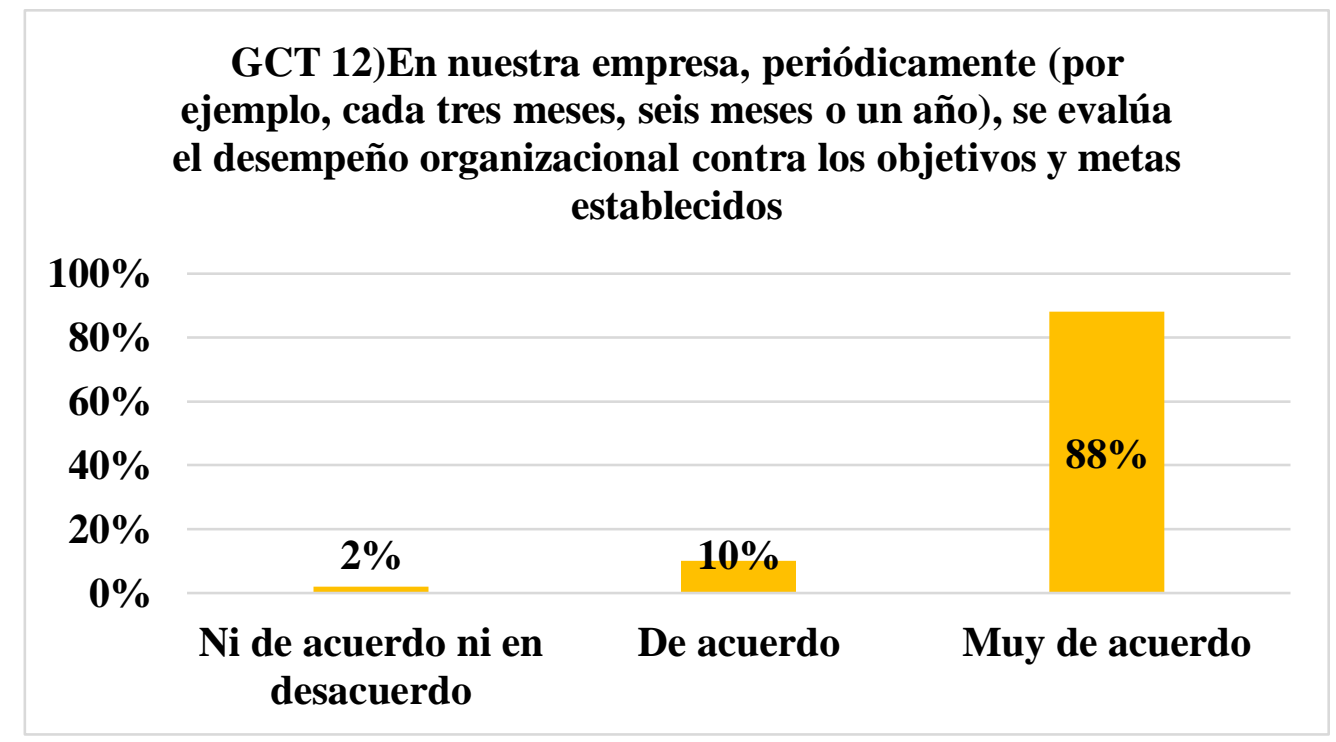

Figura 20. Gráfico Evaluación del desempeño organizacional

Interpretación:

Para esta doceava afirmación al evaluar sobre el desempeño organizacional contra los objetivos y metas establecidas periódicamente, la mayor cantidad de los representantes de las empresas exportadoras MYPE de cacao en grano indicaron que están muy de acuerdo, el $10 \%$ de acuerdo y solo el $2 \%$ están en una posición neutral indicando que no estaban ni de acuerdo ni en desacuerdo. Podemos concluir que los exportadores periódicamente se evalúa el desempeño organizacional contra los objetivos y metas establecidas por la empresa.

Tabla 18

Procesos formales para conocer opiniones de empleados

GCT 13) En nuestra empresa, los procesos formales se utilizan regularmente (encuestas de actitud, información de los empleados, etc.) para conocer las opiniones y puntos de vista de los empleados.

\begin{tabular}{|c|c|c|c|c|c|}
\hline & & Frequency & Percent & $\begin{array}{c}\text { Valid } \\
\text { Percent }\end{array}$ & $\begin{array}{c}\text { Cumulative } \\
\text { Percent }\end{array}$ \\
\hline \multirow[t]{4}{*}{ Valid } & $\begin{array}{l}\text { Ni de acuerdo ni en } \\
\text { desacuerdo }\end{array}$ & 5 & 10.0 & 10.0 & 10.0 \\
\hline & De acuerdo & 28 & 56.0 & 56.0 & 66.0 \\
\hline & Muy de acuerdo & 17 & 34.0 & 34.0 & 100.0 \\
\hline & Total & 50 & 100.0 & 100.0 & \\
\hline
\end{tabular}

Elaboración propia (2020) - Extraído del SPSS 26 


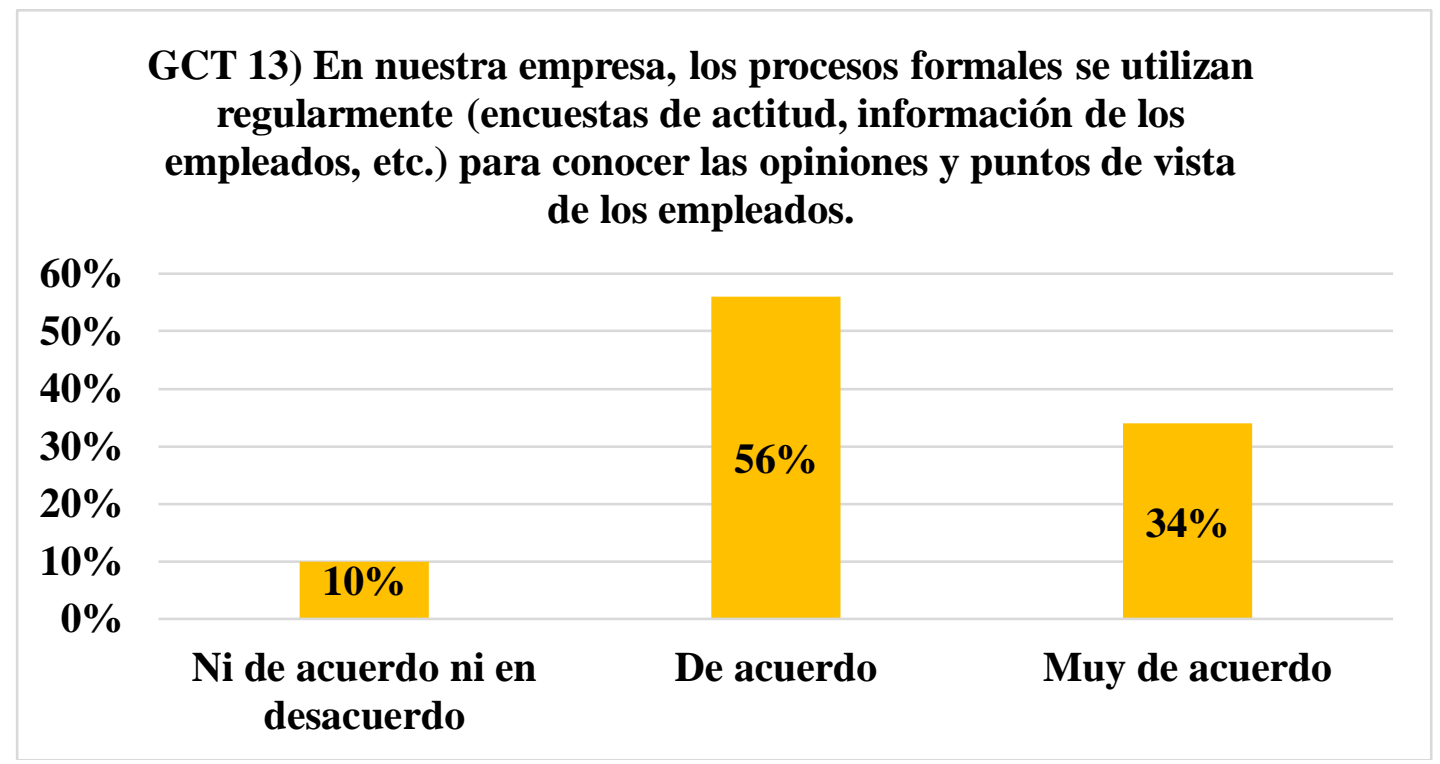

Figura 21. Procesos formales para conocer opiniones de empleados

Interpretación:

Como se observa en la tabla 18 , del total de los representantes, el $10 \%$ estuvieron ni de acuerdo ni en desacuerdo y el 56\% si estuvieron de acuerdo con que los procesos formales como encuestas de actitud o información de empleados para conocer las opiniones y puntos de vista de los empleados y un $34 \%$ de acuerdo con la afirmación. Podemos concluir que el 90\% de las MYPES exportadoras utilizan estos procesos para obtener opiniones y puntos de vista de sus colaboradores.

Tabla 19

Capacitación de calidad a empleados

GCT 14) En nuestra empresa, se ofrece capacitación específica de calidad a los

\begin{tabular}{|c|c|c|c|c|c|}
\hline & & Frequency & Percent & $\begin{array}{c}\text { Valid } \\
\text { Percent }\end{array}$ & $\begin{array}{c}\text { Cumulative } \\
\text { Percent }\end{array}$ \\
\hline \multirow[t]{4}{*}{ Valid } & $\begin{array}{l}\text { Ni de acuerdo ni en } \\
\text { desacuerdo }\end{array}$ & 8 & 16.0 & 16.0 & 16.0 \\
\hline & De acuerdo & 25 & 50.0 & 50.0 & 66.0 \\
\hline & Muy de acuerdo & 17 & 34.0 & 34.0 & 100.0 \\
\hline & Total & 50 & 100.0 & 100.0 & \\
\hline
\end{tabular}

Elaboración propia (2020) - Extraído del SPSS 26 


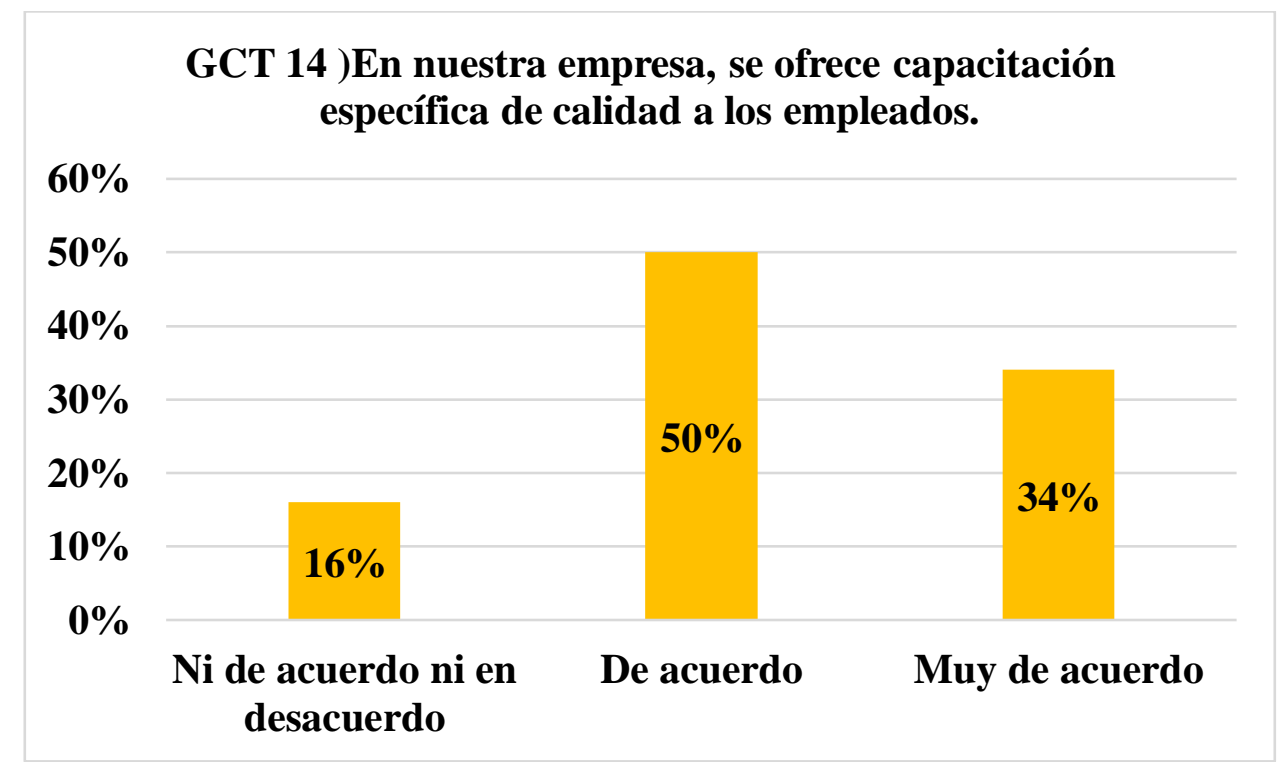

Figura 22 .Gráfico Capacitación de calidad a empleados

Interpretación:

De los 50 representantes, el $50 \%$ están satisfechos con la capacitación especifica de calidad a los empleados, el $16 \%$ no están ni de acuerdo ni en desacuerdo y el $34 \%$ de los gerentes o administradores estuvieron muy de acuerdo con la afirmación llegando a concluir que en la mayoría de las empresas MYPE exportadoras se capacita a los empleados específicamente sobre calidad.

Tabla 20

Actualización de conocimiento y habilidades a empleados

GCT 15) En nuestra empresa, se alienta a los empleados a actualizar sus conocimientos y habilidades.

\begin{tabular}{|c|c|c|c|c|c|}
\hline & & Frequency & Percent & $\begin{array}{c}\text { Valid } \\
\text { Percent }\end{array}$ & $\begin{array}{c}\text { Cumulative } \\
\text { Percent }\end{array}$ \\
\hline \multirow[t]{4}{*}{ Valid } & $\begin{array}{l}\text { Ni de acuerdo ni en } \\
\text { desacuerdo }\end{array}$ & 4 & 8.0 & 8.0 & 8.0 \\
\hline & De acuerdo & 29 & 58.0 & 58.0 & 66.0 \\
\hline & Muy de acuerdo & 17 & 34.0 & 34.0 & 100.0 \\
\hline & Total & 50 & 100.0 & 100.0 & \\
\hline
\end{tabular}

Elaboración propia (2020) - Extraído del SPSS 26. 


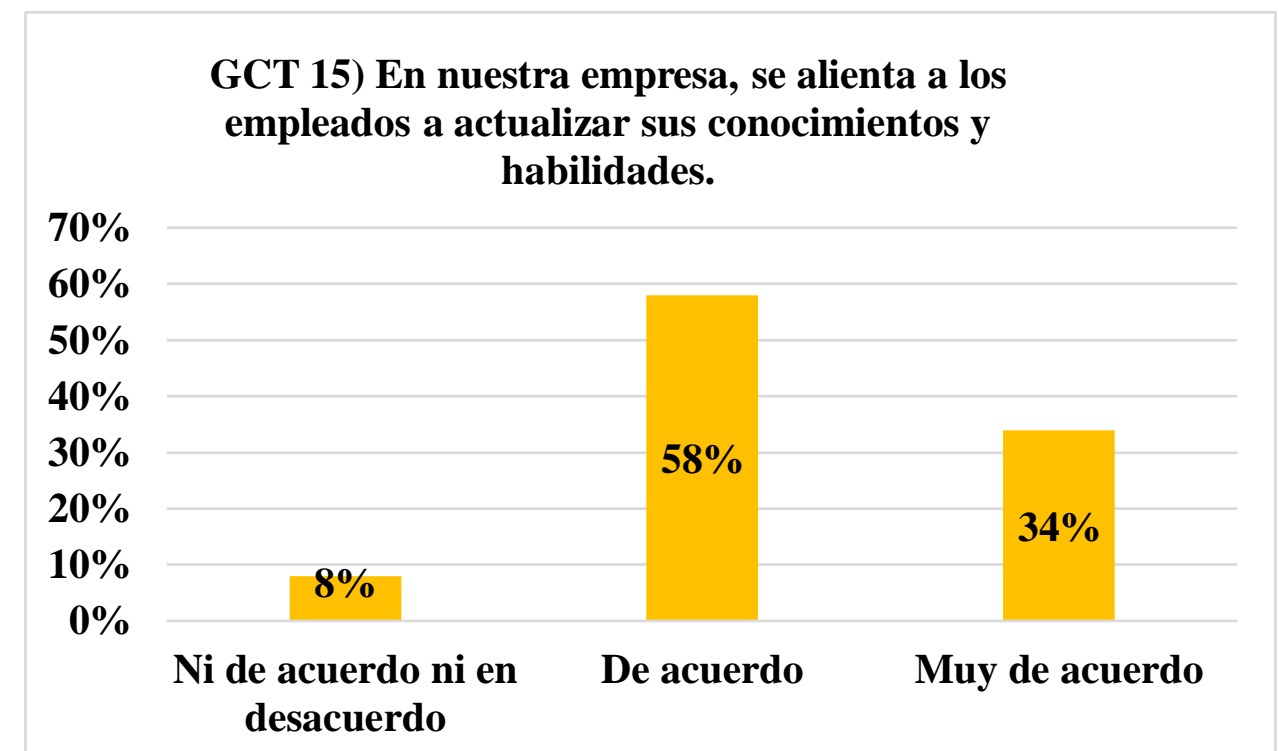

Figura 23.Grafico Actualización de conocimiento y habilidades a empleados

Interpretación:

Como se observa en la tabla 20, del total de los representantes, el $58 \%$ estuvieron de acuerdo y el $34 \%$ muy de acuerdo con que se aliente a los empleados a actualizar sus conocimientos y habilidades. Sin embargo, hubo un $8 \%$ de los representantes que estuvieron ni de acuerdo ni en desacuerdo por lo que podemos concluir que hay más empresas exportadoras de cacao en grano en las que se los conocimientos y habilidades de los empleados son actualizados.

Tabla 21

Trabajo en equipo

GCT 16) En nuestra empresa, el trabajo en equipo es una práctica común dentro de la organización.

\begin{tabular}{|c|c|c|c|c|c|}
\hline & & Frequency & Percent & $\begin{array}{c}\text { Valid } \\
\text { Percent }\end{array}$ & $\begin{array}{c}\text { Cumulative } \\
\text { Percent }\end{array}$ \\
\hline \multirow[t]{4}{*}{ Valid } & $\begin{array}{l}\text { Ni de acuerdo ni en } \\
\text { desacuerdo }\end{array}$ & 9 & 18.0 & 18.0 & 18.0 \\
\hline & De acuerdo & 25 & 50.0 & 50.0 & 68.0 \\
\hline & Muy de acuerdo & 16 & 32.0 & 32.0 & 100.0 \\
\hline & Total & 50 & 100.0 & 100.0 & \\
\hline
\end{tabular}

Elaboración propia (2020) - Extraído del SPSS 26 


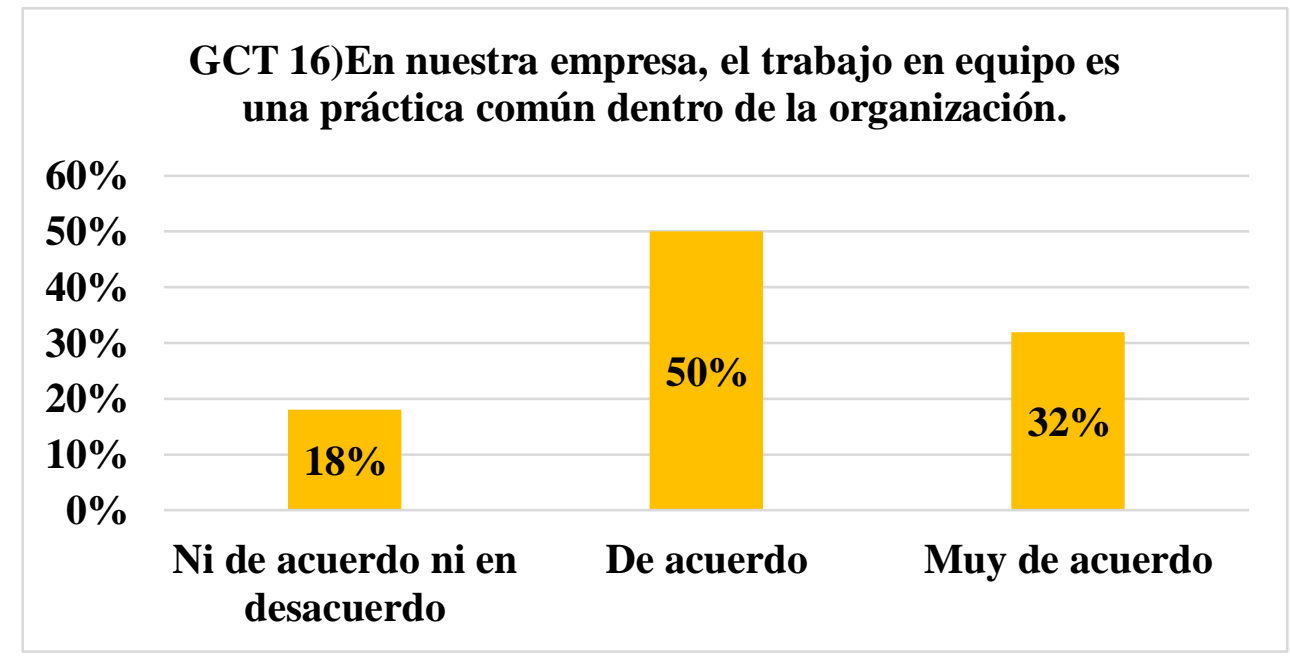

Figura 24. Gráfico Trabajo en equipo

Interpretación:

Para esta afirmación, de todos los representantes de las empresas encuestadas, el $82 \%$ se encuentra de acuerdo o muy de acuerdo con que el trabajo en equipo es una práctica común dentro de la empresa sin embargo el $18 \%$ de los representantes tomo una posición neutral indicando que no estaban ni de acuerdo ni en desacuerdo.

Tabla 22

Fácil acceso para empleados a información relevante

GCT 17) En nuestra empresa, los empleados tienen fácil acceso a la información relevante.

\begin{tabular}{|c|c|c|c|c|c|}
\hline & & Frequency & Percent & $\begin{array}{c}\text { Valid } \\
\text { Percent }\end{array}$ & $\begin{array}{c}\text { Cumulative } \\
\text { Percent }\end{array}$ \\
\hline \multirow{5}{*}{ Valid } & En desacuerdo & 7 & 14.0 & 14.0 & 14.0 \\
\hline & $\begin{array}{l}\text { Ni de acuerdo ni en } \\
\text { desacuerdo }\end{array}$ & 19 & 38.0 & 38.0 & 52.0 \\
\hline & De acuerdo & 19 & 38.0 & 38.0 & 90.0 \\
\hline & Muy de acuerdo & 5 & 10.0 & 10.0 & 100.0 \\
\hline & Total & 50 & 100.0 & 100.0 & \\
\hline
\end{tabular}

Elaboración propia (2020) - Extraído del SPSS 26 


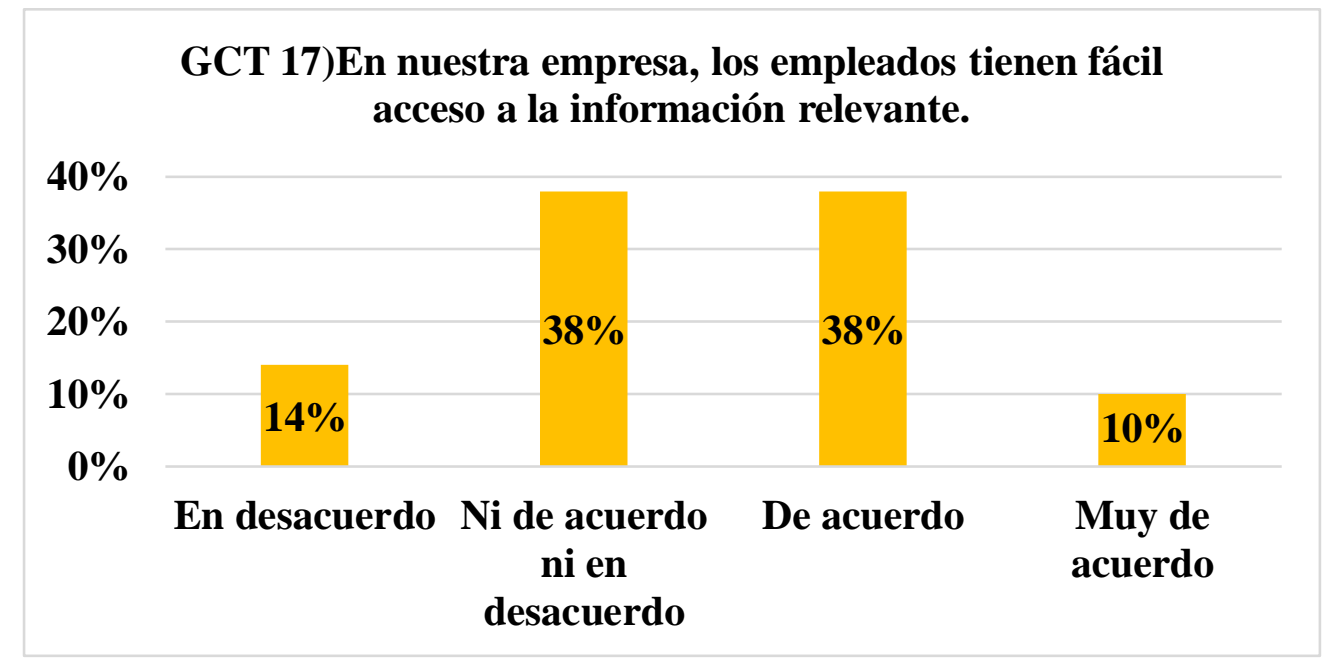

Figura 25.Gráfico Fácil acceso para empleados a información relevante

Interpretación:

En este caso, de los 50 representantes de las empresas, 38 exportadoras MYPE de cacao en grano estuvieron de acuerdo y ni de acuerdo ni en desacuerdo con que los empleados tienen fácil acceso a información relevante de la empresa obteniendo un $76 \%$ de toda la muestra, también existe un 14\% en desacuerdo y un 10\% muy de acuerdo. En conclusión, el $48 \%$ de exportadores están de acuerdo y muy de acuerdo facilitando información relevante a sus empleados y el $38 \%$ en posición neutral.

Tabla 23

Opiniones y sugerencias

GCT 18) En nuestra empresa, fomente las opiniones y sugerencias de los empleados sobre cualquiera de las actividades de la organización.

\begin{tabular}{|c|c|c|c|c|c|}
\hline & & Frequency & Percent & $\begin{array}{c}\text { Valid } \\
\text { Percent }\end{array}$ & $\begin{array}{c}\text { Cumulative } \\
\text { Percent }\end{array}$ \\
\hline \multirow{5}{*}{ Valid } & En desacuerdo & 3 & 6.0 & 6.0 & 6.0 \\
\hline & $\begin{array}{l}\text { Ni de acuerdo ni en } \\
\text { desacuerdo }\end{array}$ & 6 & 12.0 & 12.0 & 18.0 \\
\hline & De acuerdo & 34 & 68.0 & 68.0 & 86.0 \\
\hline & Muy de acuerdo & 7 & 14.0 & 14.0 & 100.0 \\
\hline & Total & 50 & 100.0 & 100.0 & \\
\hline
\end{tabular}

Elaboración propia (2020) - Extraído del SPSS 26 


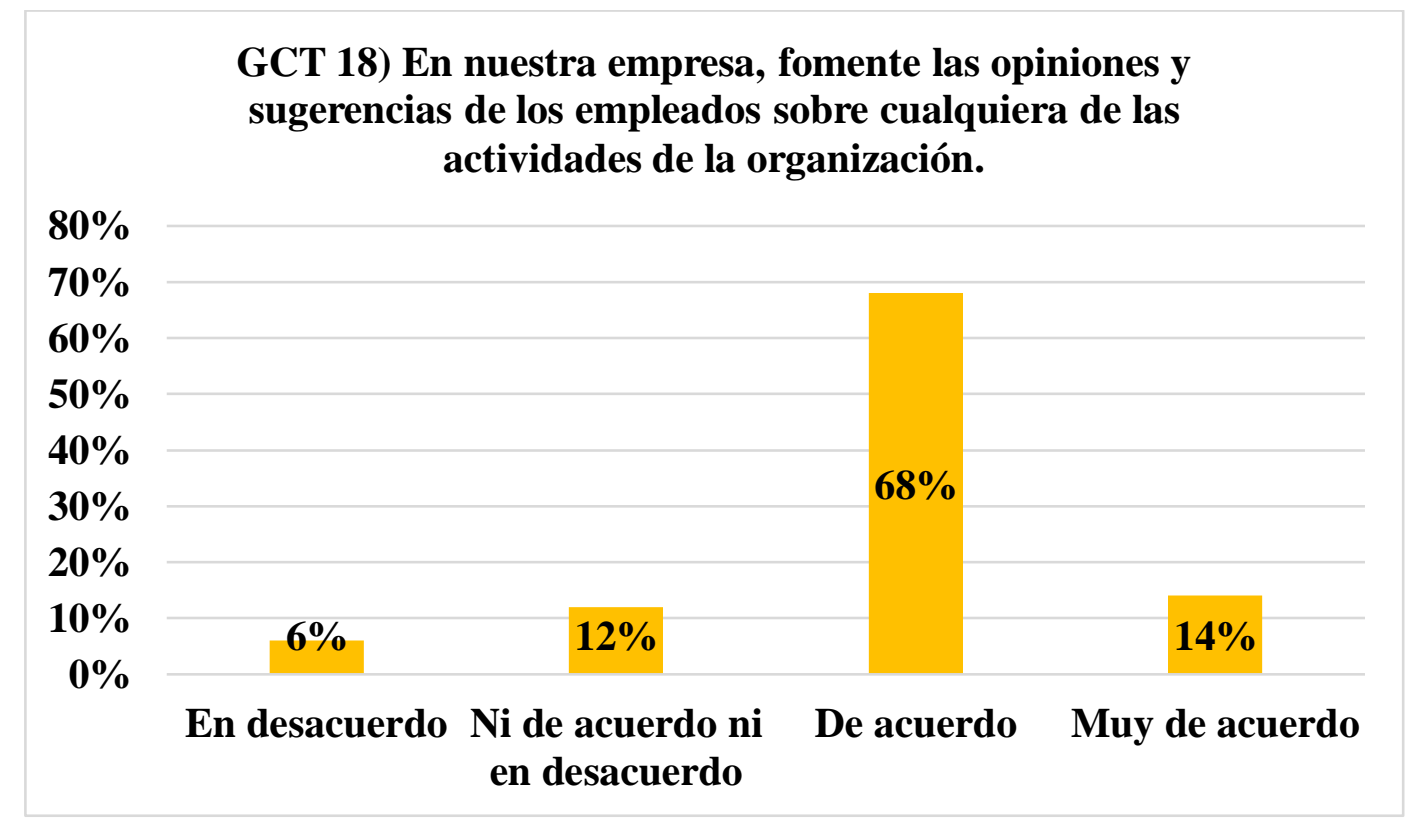

Figura 26. Gráfico Opiniones y sugerencias

Interpretación:

En esta tabla podemos visualizar que hay mayor parte de los representantes de las empresas de acuerdo y muy de acuerdo considerando que ambos forman parte de un $82 \%$ de la muestra y por otro lado tenemos el $6 \%$ de los representantes de las empresas que votaron en desacuerdo y el $12 \%$ de los representantes de las empresas que no están ni de acuerdo ni en desacuerdo adoptando un lado neutral.

Tabla 24

Asociaciones a largo plazo con la organización

GCT 19) En nuestra empresa, se alienta a los proveedores a desarrollar asociaciones a largo plazo con la organización.

\begin{tabular}{|c|c|c|c|c|c|}
\hline & & Frequency & Percent & $\begin{array}{c}\text { Valid } \\
\text { Percent }\end{array}$ & $\begin{array}{c}\text { Cumulative } \\
\text { Percent }\end{array}$ \\
\hline \multirow[t]{4}{*}{ Valid } & $\begin{array}{l}\text { Ni de acuerdo ni en } \\
\text { desacuerdo }\end{array}$ & 5 & 10.0 & 10.0 & 10.0 \\
\hline & De acuerdo & 20 & 40.0 & 40.0 & 50.0 \\
\hline & Muy de acuerdo & 25 & 50.0 & 50.0 & 100.0 \\
\hline & Total & 50 & 100.0 & 100.0 & \\
\hline
\end{tabular}

Elaboración propia (2020) - Extraído del SPSS 26 


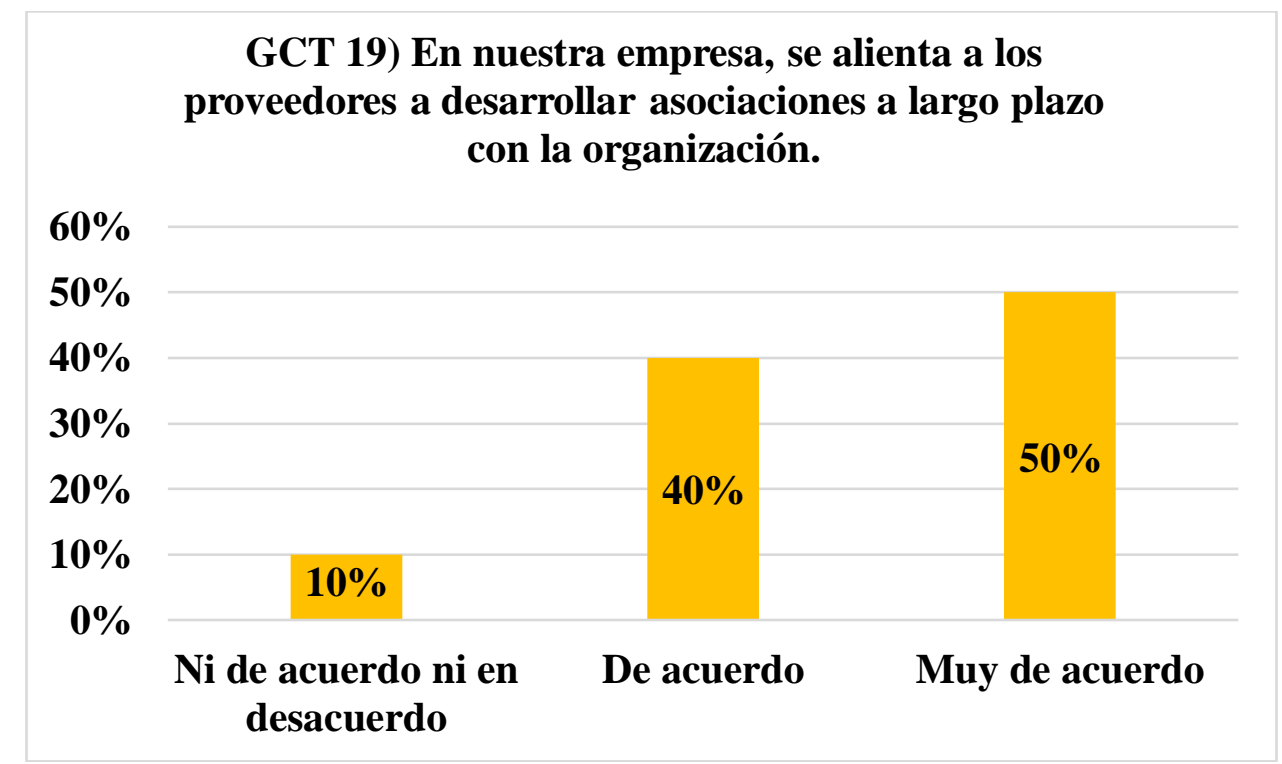

Figura 27.Gráfico Asociaciones a largo plazo con la organización

Interpretación:

Para esta tabla 24, podemos decir que, del total de los representantes, el 50\% se encuentra muy de acuerdo y el $40 \%$ de acuerdo, pero también se debe considerar que hay un $10 \%$ de representantes que no están ni de acuerdo ni en desacuerdo con que se aliente a los proveedores a desarrollar posiciones a largo plazo con la organización. Podemos concluir que 45 exportadores se encuentran a favor.

\section{Tabla 25}

\section{Acuerdos de compra con proveedores}

GCT 20) En nuestra empresa no se da preferencia a la calidad sobre el costo al hacer

\begin{tabular}{|c|c|c|c|c|c|}
\hline & & Frequency & Percent & $\begin{array}{c}\text { Valid } \\
\text { Percent }\end{array}$ & $\begin{array}{c}\text { Cumulative } \\
\text { Percent }\end{array}$ \\
\hline \multirow{5}{*}{ Valid } & En desacuerdo & 2 & 4.0 & 4.0 & 4.0 \\
\hline & $\begin{array}{l}\text { Ni de acuerdo ni en } \\
\text { desacuerdo }\end{array}$ & 10 & 20.0 & 20.0 & 24.0 \\
\hline & De acuerdo & 24 & 48.0 & 48.0 & 72.0 \\
\hline & Muy de acuerdo & 14 & 28.0 & 28.0 & 100.0 \\
\hline & Total & 50 & 100.0 & 100.0 & \\
\hline
\end{tabular}

Elaboración propia (2020) - Extraído del SPSS 26. 


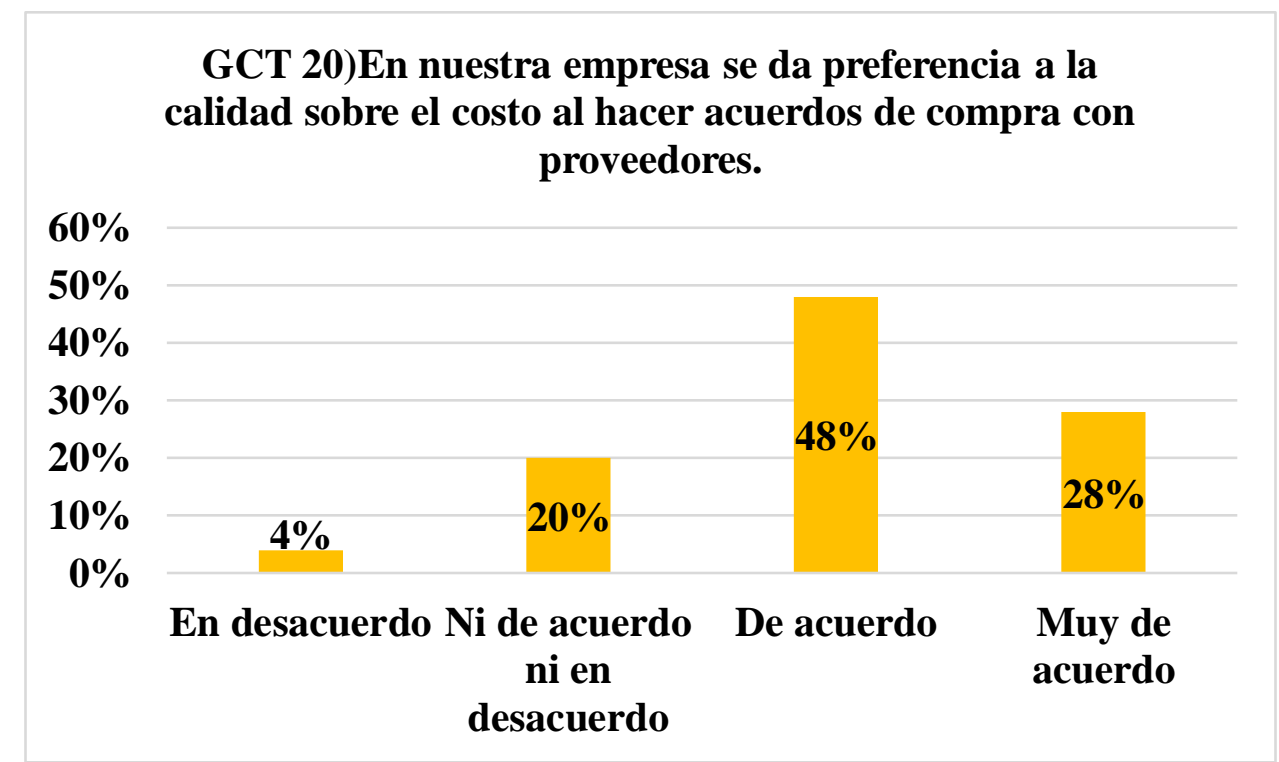

Figura 28.Gráfico Acuerdos de compra con proveedores

Interpretación:

Esta afirmación obtuvo como resultados que el $76 \%$ de la muestra indicó que están de acuerdo y muy de acuerdo, sin embargo, el $20 \%$ no está ni de acuerdo nie s desacuerdo y el únicamente el $4 \%$ se encuentra en desacuerdo. Podemos concluir que la mayoría de las exportadoras MYPES de cacao en grano da preferencia a la calidad sobre el costo cuando se realizan acuerdos de compra con proveedores.

Tabla 26

Evaluación de desempeño de proveedores

GCT 21) En nuestra empresa, el desempeño de los proveedores se evalúa periódicamente.

\begin{tabular}{|c|c|c|c|c|c|}
\hline & & Frequency & Percent & $\begin{array}{c}\text { Valid } \\
\text { Percent }\end{array}$ & $\begin{array}{c}\text { Cumulative } \\
\text { Percent }\end{array}$ \\
\hline \multirow[t]{4}{*}{ Valid } & $\begin{array}{l}\text { Ni de acuerdo ni en } \\
\text { desacuerdo }\end{array}$ & 3 & 6.0 & 6.0 & 6.0 \\
\hline & De acuerdo & 20 & 40.0 & 40.0 & 46.0 \\
\hline & Muy de acuerdo & 27 & 54.0 & 54.0 & 100.0 \\
\hline & Total & 50 & 100.0 & 100.0 & \\
\hline
\end{tabular}

Elaboración propia (2020) - Extraído del SPSS 26 


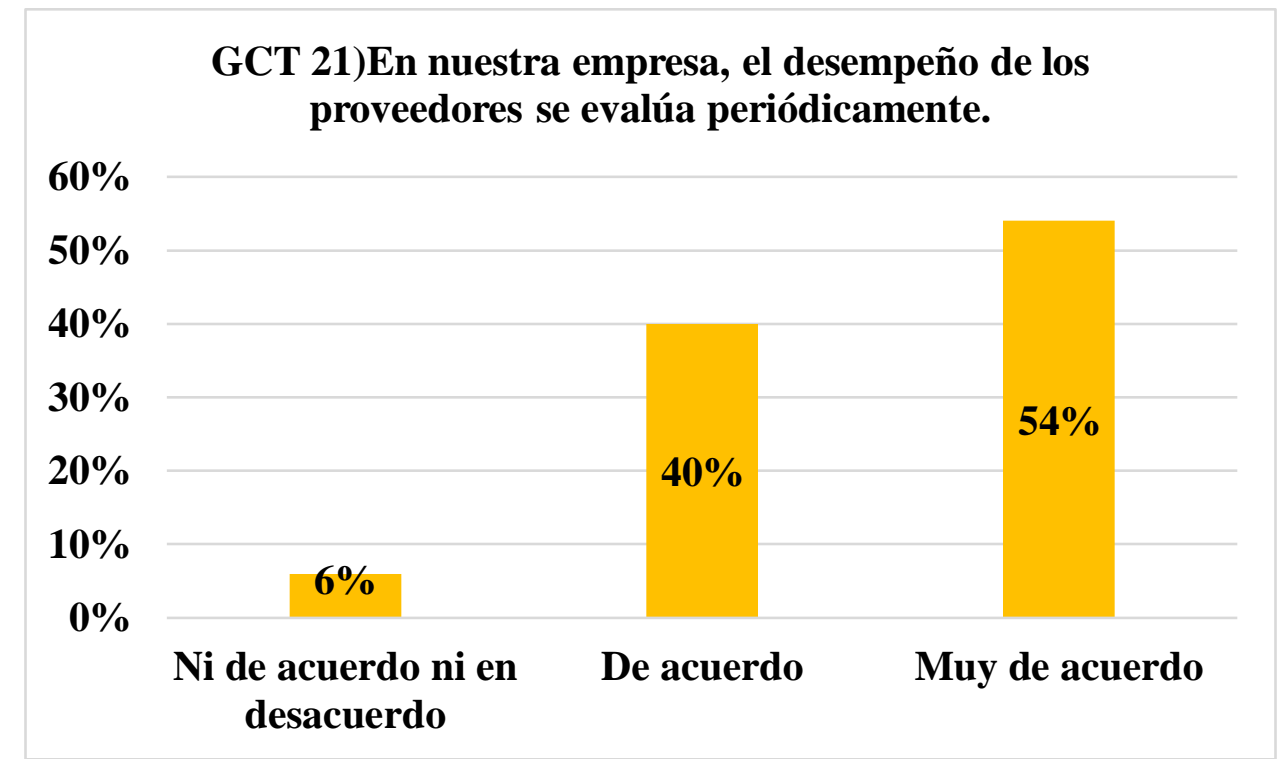

Figura 29. Gráfico Evaluación de desempeño de proveedores

Interpretación:

Como se observa en la tabla 26 , solo el $6 \%$ de los representantes tienen una posición neutral, el $40 \%$ se encuentra de acuerdo y el $54 \%$ muy de acuerdo con que el desempeño de los proveedores se evalúe periódicamente. Como conclusión obtenemos que la mayoría de los exportadores de cacao en grano están a favor de la evaluación periódica de los proveedores.

Tabla 27

Información y recursos actualizados a los empleados

GCT 22) En nuestra empresa, se proporciona información y recursos actualizados a todos los empleados para realizar sus trabajos.

\begin{tabular}{|c|c|c|c|c|c|}
\hline & & Frequency & Percent & $\begin{array}{c}\text { Valid } \\
\text { Percent }\end{array}$ & $\begin{array}{c}\text { Cumulative } \\
\text { Percent }\end{array}$ \\
\hline \multirow[t]{4}{*}{ Valid } & $\begin{array}{l}\text { Ni de acuerdo ni en } \\
\text { desacuerdo }\end{array}$ & 3 & 6.0 & 6.0 & 6.0 \\
\hline & De acuerdo & 22 & 44.0 & 44.0 & 50.0 \\
\hline & Muy de acuerdo & 25 & 50.0 & 50.0 & 100.0 \\
\hline & Total & 50 & 100.0 & 100.0 & \\
\hline
\end{tabular}

Elaboración propia (2020) - Extraído del SPSS 26 


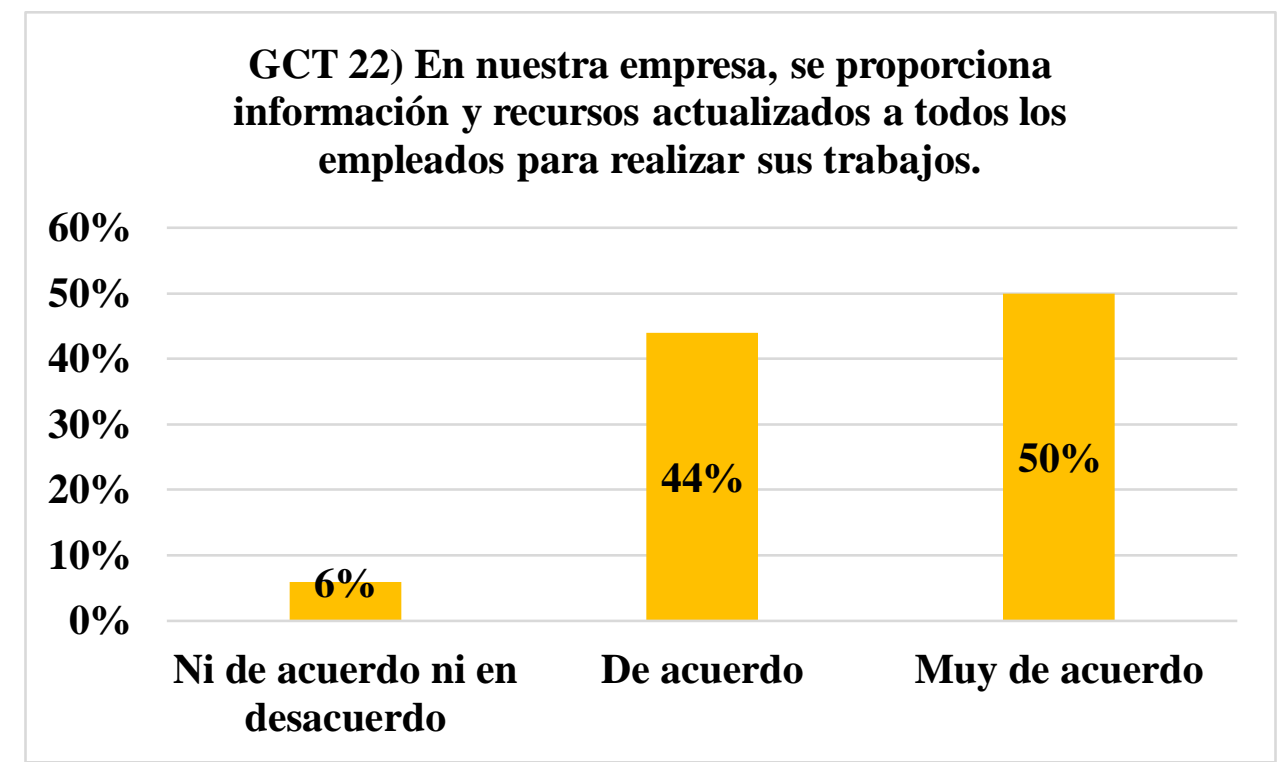

Figura 30. Gráfico Información y recursos actualizados a los empleados Interpretación:

Para este vigésimo segundo afirmación, al evaluar sobre la proporción y recursos actualizados que se brinda a todos los empleados para realizar sus trabajos las empresas exportadoras votaron el equivalente de un $44 \%$ de la muestra que están de acuerdo y solo el $6 \%$ no están ni de acuerdo ni en desacuerdo pero también hubo un 50\% de los representantes de la empresa muy de acuerdo .Podemos concluir que las exportadoras MYPE peruanas e cacao en grano brindan información y recursos actualizados a todos sus trabajadores para realizar sus trabajos.

Tabla 28

Reducción de efectos nocivos en el medio ambiente

GCT 23) Nuestra empresa trata de reducir el efecto nocivo de sus actividades en el

\begin{tabular}{|c|c|c|c|c|c|}
\hline & & Frequency & Percent & $\begin{array}{c}\text { Valid } \\
\text { Percent }\end{array}$ & $\begin{array}{c}\text { Cumulative } \\
\text { Percent }\end{array}$ \\
\hline \multirow[t]{4}{*}{ Valid } & $\begin{array}{l}\text { Ni de acuerdo ni en } \\
\text { desacuerdo }\end{array}$ & 4 & 8.0 & 8.0 & 8.0 \\
\hline & De acuerdo & 21 & 42.0 & 42.0 & 50.0 \\
\hline & Muy de acuerdo & 25 & 50.0 & 50.0 & 100.0 \\
\hline & Total & 50 & 100.0 & 100.0 & \\
\hline
\end{tabular}

Elaboración propia (2020) - Extraído del SPSS 26 


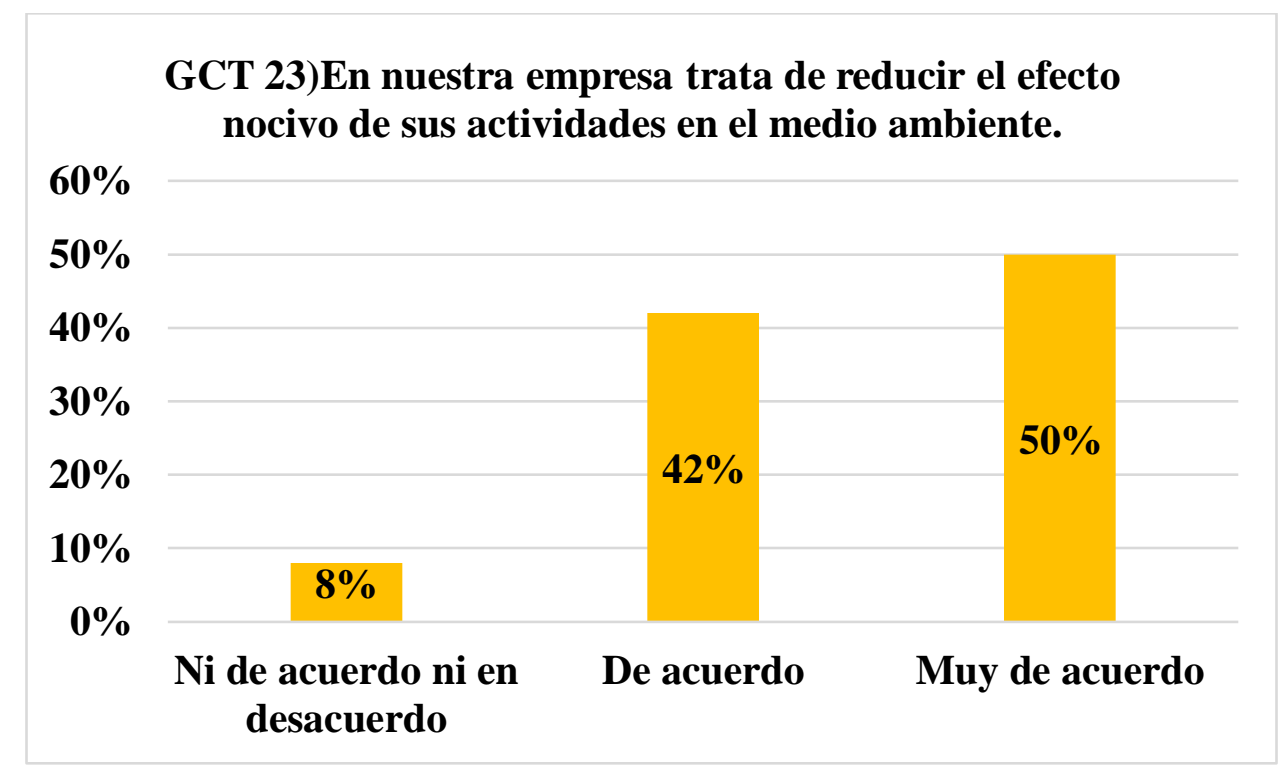

Figura 31.Gráfico Reducción de efectos nocivos en el medio ambiente

Interpretación:

De los 50 representantes, el 50\% está muy de acuerdo con que la empresa trate de reducir el efecto nocivo de sus actividades en el medio ambiente, sin embargo ,4 empresas exportadoras indicaron que no estaban ni de acuerdo ni en desacuerdo y el $42 \%$ de los representantes se mostraron de acuerdo con la afirmación es decir que las exportadoras MYPE de cacao en grano están tratando de reducir su efecto nocivo de sus actividades para no dañar el medio ambiente.

Tabla 29

\section{Procedimientos para diferentes trabajos}

GCT 24) En nuestra empresa, se establecen procedimientos adecuados para realizar diferentes trabajos.

\begin{tabular}{|c|c|c|c|c|c|}
\hline & & Frequency & Percent & $\begin{array}{c}\text { Valid } \\
\text { Percent }\end{array}$ & $\begin{array}{c}\text { Cumulative } \\
\text { Percent }\end{array}$ \\
\hline \multirow{5}{*}{ Valid } & En desacuerdo & 2 & 4.0 & 4.0 & 4.0 \\
\hline & $\begin{array}{l}\text { Ni de acuerdo ni en } \\
\text { desacuerdo }\end{array}$ & 3 & 6.0 & 6.0 & 10.0 \\
\hline & De acuerdo & 21 & 42.0 & 42.0 & 52.0 \\
\hline & Muy de acuerdo & 24 & 48.0 & 48.0 & 100.0 \\
\hline & Total & 50 & 100.0 & 100.0 & \\
\hline
\end{tabular}

Elaboración propia (2020) - Extraído del SPSS 26 


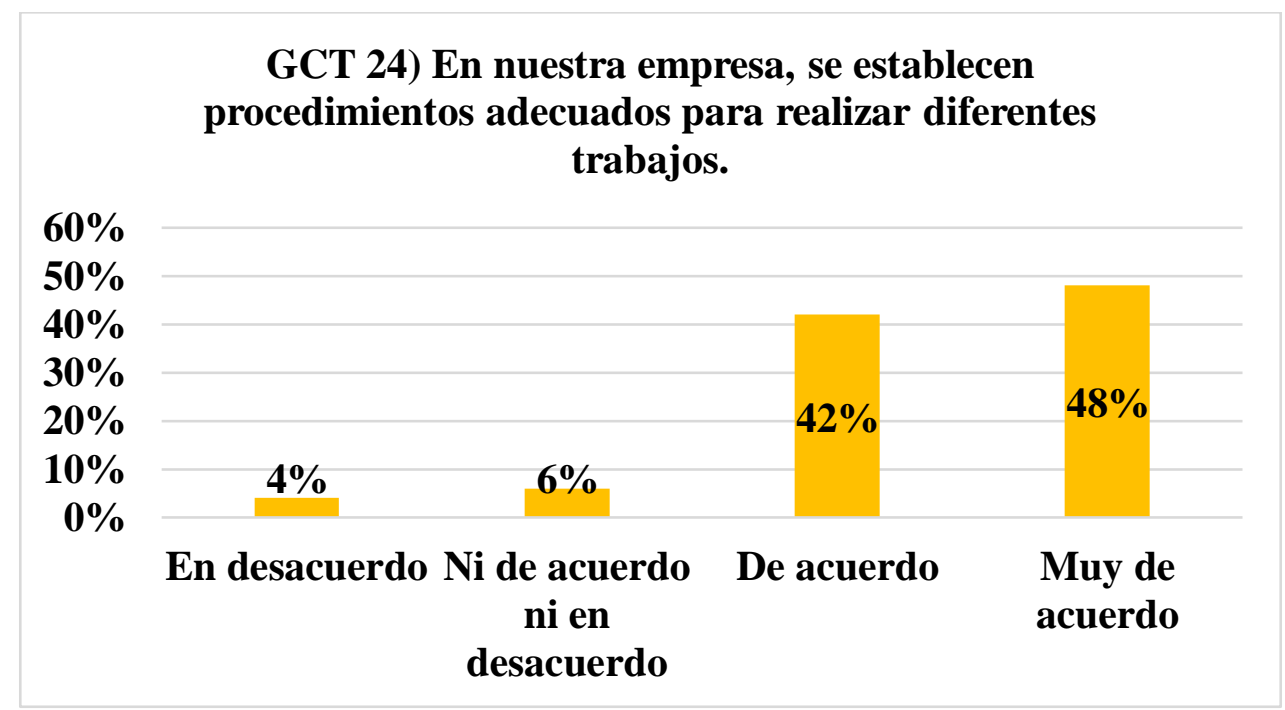

Figura 32. Gráfico Procedimientos para diferentes trabajos

Interpretación:

En este caso, $48 \%$ de los representantes votaron por una posición positiva es decir que se encontraban muy de acuerdo con esta afirmación, también hubo un $42 \%$ de los representantes de las empresas se encuentran de acuerdo. Por otro lado, solo el 10\% de los representantes de las empresas exportadoras encuestadas se encontraron en desacuerdo o ni de acuerdo ni en desacuerdo con que se establezcan procedimientos adecuados para realizar diferentes trabajos.

Tabla 30

Conocimiento de los parámetros de los diferentes procesos

GCT 25) En nuestra empresa, los empleados conocen los parámetros (temperatura, presión, etc.) de los diferentes procesos, que son necesarios.

\begin{tabular}{|c|c|c|c|c|c|}
\hline & & Frequency & Percent & $\begin{array}{c}\text { Valid } \\
\text { Percent }\end{array}$ & $\begin{array}{c}\text { Cumulative } \\
\text { Percent }\end{array}$ \\
\hline & $\begin{array}{l}\text { Totalmente en } \\
\text { desacuerdo }\end{array}$ & 2 & 4.0 & 4.0 & 4.0 \\
\hline \multirow[t]{5}{*}{ Valid } & En desacuerdo & 1 & 2.0 & 2.0 & 6.0 \\
\hline & $\begin{array}{l}\text { Ni de acuerdo ni en } \\
\text { desacuerdo }\end{array}$ & 3 & 6.0 & 6.0 & 12.0 \\
\hline & De acuerdo & 22 & 44.0 & 44.0 & 56.0 \\
\hline & Muy de acuerdo & 22 & 44.0 & 44.0 & 100.0 \\
\hline & Total & 50 & 100.0 & 100.0 & \\
\hline
\end{tabular}

Elaboración propia (2020) - Extraído del SPSS 26 


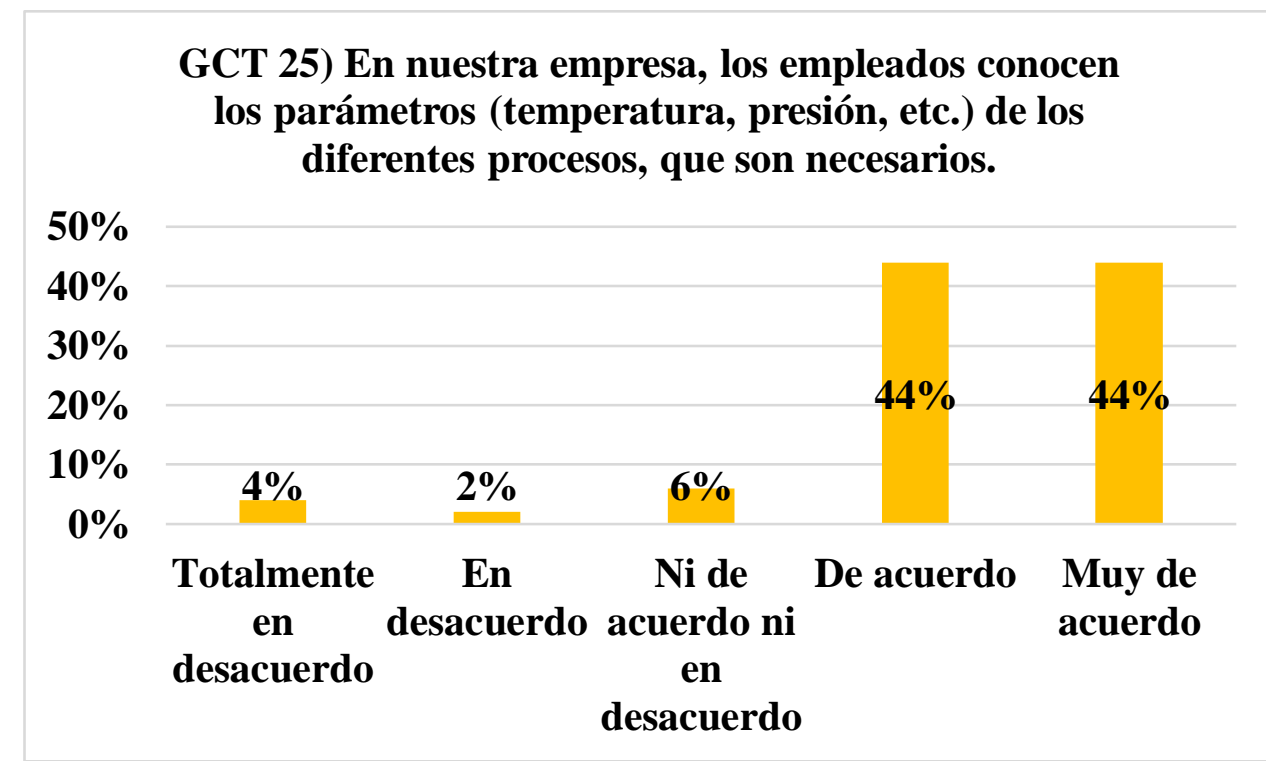

Figura 33. Conocimiento de los parámetros de los diferentes procesos

Interpretación:

Para esta afirmación hubo el 6\% de los representantes de las empresas que tuvieron una posición neutral al no estar ni de acuerdo ni en desacuerdo, 2 personas en totalmente en desacuerdo y 1 empresa exportadora en desacuerdo equivalente a $6 \%$. Al obtener por parte de los representantes un $88 \%$ de votación en donde se encuentran de acuerdo y muy de acuerdo se concluye que los empleados conocen los parámetros de los diferentes procesos que son necesarios.

\section{Tabla 31}

Monitoreo del desempeño de los procesos de producción

GCT 26) En nuestra empresa, se monitorea el desempeño de los procesos de producción.

\begin{tabular}{llcccc}
\hline & Frequency & Percent & $\begin{array}{r}\text { Valid } \\
\text { Percent }\end{array}$ & $\begin{array}{c}\text { Cumulative } \\
\text { Percent }\end{array}$ \\
\hline \multirow{2}{*}{ Valid } & En desacuerdo & 4 & 8.0 & 8.0 & 8.0 \\
& Ni de acuerdo ni en & 2 & 4.0 & 4.0 & 12.0 \\
& desacuerdo & & & & \\
& De acuerdo & 18 & 36.0 & 36.0 & 48.0 \\
Muy de acuerdo & 26 & 52.0 & 52.0 & 100.0 \\
\cline { 2 - 5 } & Total & 50 & 100.0 & 100.0 & \\
\hline
\end{tabular}

Elaboración propia (2020) - Extraído del SPSS 26 


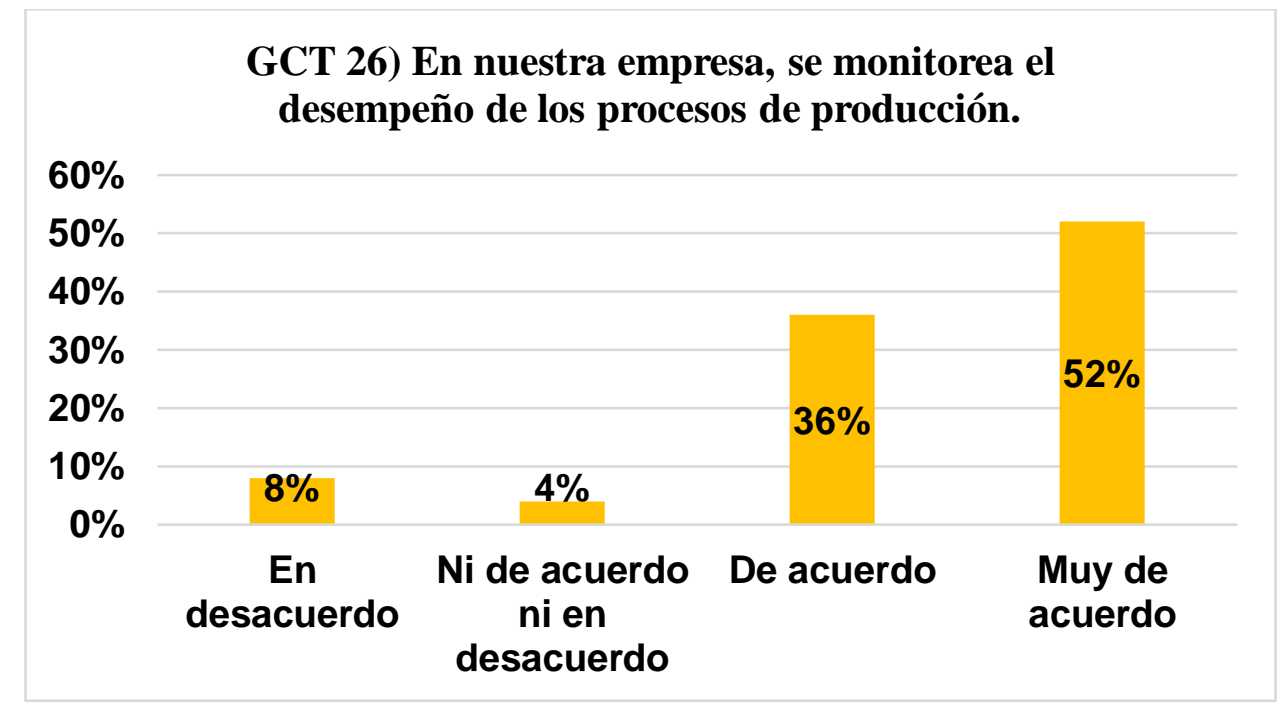

Figura 34. Gráfico Monitoreo del desempeño de los procesos de producción

Interpretación:

La tabla 31 afirma que el $52 \%$ de los representantes encuestados se encuentran muy de acuerdo y un $36 \%$ de acuerdo con que en las empresas exportadoras se monitoree el desempeño de los procesos de producción, sin embargo, existe un $8 \%$ en desacuerdo y un $4 \%$ ni de acuerdo ni en desacuerdo.

Tabla 32

Desarrollo y mejora de la empresa

GCT 27) En nuestra empresa, el departamento de investigación y desarrollo (I + D) está trabajando continuamente en el desarrollo y la mejora.

\begin{tabular}{|c|c|c|c|c|c|}
\hline & & Frequency & Percent & $\begin{array}{c}\text { Valid } \\
\text { Percent }\end{array}$ & $\begin{array}{c}\text { Cumulative } \\
\text { Percent }\end{array}$ \\
\hline \multirow{6}{*}{ Valid } & En desacuerdo & 3 & 6.0 & 6.0 & 6.0 \\
\hline & Ni de acuerdo ni en & 7 & 14.0 & 14.0 & 20.0 \\
\hline & desacuerdo & & & & \\
\hline & De acuerdo & 13 & 26.0 & 26.0 & 46.0 \\
\hline & Muy de acuerdo & 27 & 54.0 & 54.0 & 100.0 \\
\hline & Total & 50 & 100.0 & 100.0 & \\
\hline
\end{tabular}

Elaboración propia (2020) - Extraído del SPSS 26 


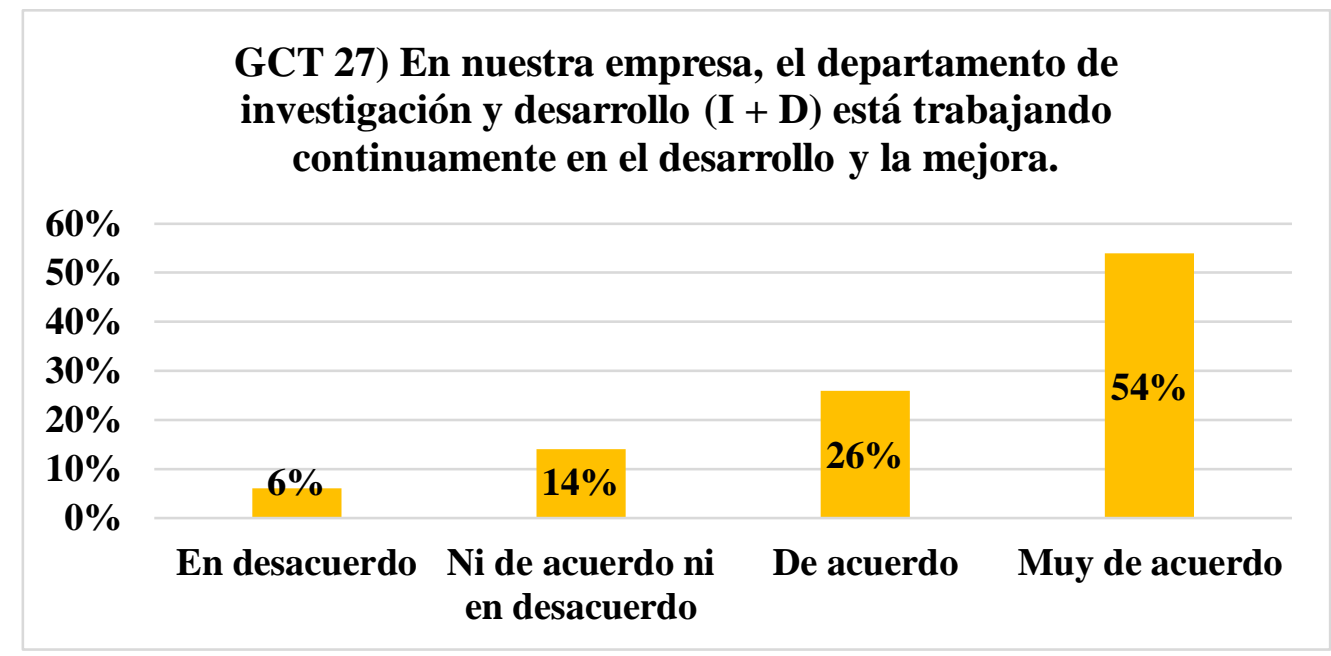

Figura 35. Desarrollo y mejora de la empresa

Interpretación:

Con respecto al desarrollo y mejora de las empresas, los representantes arrojaron que solo un $6 \%$ de los representantes están en desacuerdo con que el departamento de investigación y desarrollo trabaje continuamente en el desarrollo y la mejora .Así mismo, el 14\% de las personas encuestadas no están ni de acuerdo ni en desacuerdo y la mayoría de los representantes (gerentes o administradores ) están muy de acuerdo representando un $54 \%$ de la muestra donde el departamento de I+D trabaja continuamente en el desarrollo y la mejora

Tabla 33

Desarrollo e innovación de los procesos de producción

GCT 28) En nuestra empresa, se enfatiza el desarrollo y la innovación de los procesos de producción

\begin{tabular}{llccc}
\hline & Frequency & Percent & $\begin{array}{c}\text { Valid } \\
\text { Percent }\end{array}$ & $\begin{array}{c}\text { Cumulative } \\
\text { Percent }\end{array}$ \\
\hline En desacuerdo & 4 & 8.0 & 8.0 & 8.0 \\
Valid de acuerdo ni en & 5 & 10.0 & 10.0 & 18.0 \\
desacuerdo & & & & \\
De acuerdo & 20 & 40.0 & 40.0 & 58.0 \\
Muy de acuerdo & 21 & 42.0 & 42.0 & 100.0 \\
\cline { 2 - 5 } Total & 50 & 100.0 & 100.0 & \\
\hline
\end{tabular}

Elaboración propia (2020) - Extraído del SPSS 26 


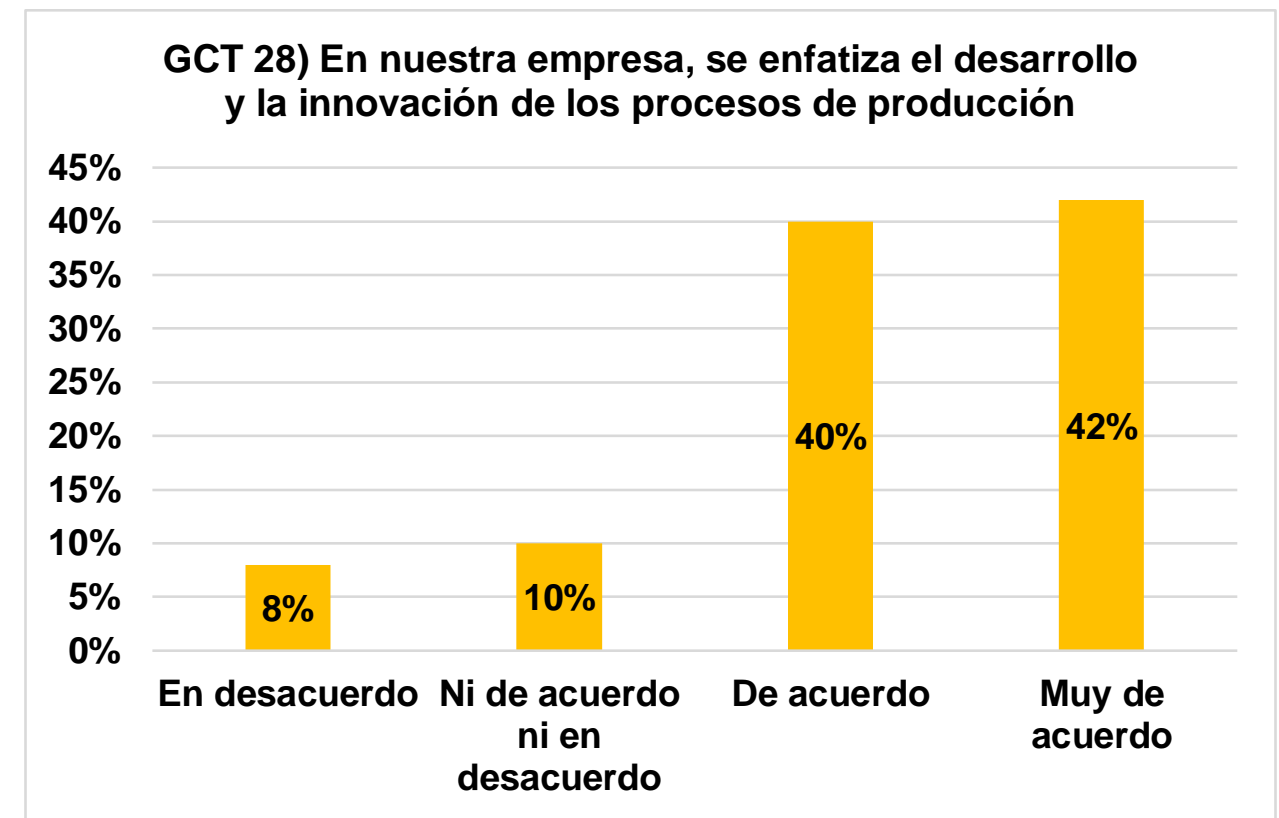

Figura 36.Gráfico Desarrollo e innovación de los procesos de producción Interpretación:

Para esta afirmación, 21 de los representantes de las empresas estuvieron muy de acuerdo, 20 de ellos de acuerdo indicando que ellos como empresa si enfatizan el desarrollo y la innovación de los procesos de producción, por otro lado, hubo solo un $8 \%$ de gerentes o administradores que se encuentran en desacuerdo y un $10 \%$ en una posición neutral indicando que no están ni de acuerdo ni en desacuerdo.

\section{Tabla 34}

Producción de acuerdo a especificaciones de diseño

GCT 29) En nuestra empresa, los procesos de producción son capaces de producir productos de acuerdo con las especificaciones de diseño.

\begin{tabular}{llcccc}
\hline & Frequency & Percent & $\begin{array}{c}\text { Valid } \\
\text { Percent }\end{array}$ & $\begin{array}{c}\text { Cumulative } \\
\text { Percent }\end{array}$ \\
\hline \multirow{2}{*}{ Valid } & En desacuerdo & 2 & 4.0 & 4.0 & 4.0 \\
Ni de acuerdo ni en & 6 & 12.0 & 12.0 & 16.0 \\
& desacuerdo & 17 & 34.0 & 34.0 & 50.0 \\
& De acuerdo & 25 & 50.0 & 50.0 & 100.0 \\
\cline { 2 - 5 } & Muy de acuerdo & 50 & 100.0 & 100.0 & \\
\hline
\end{tabular}

Elaboración propia (2020) - Extraído del SPSS 26 


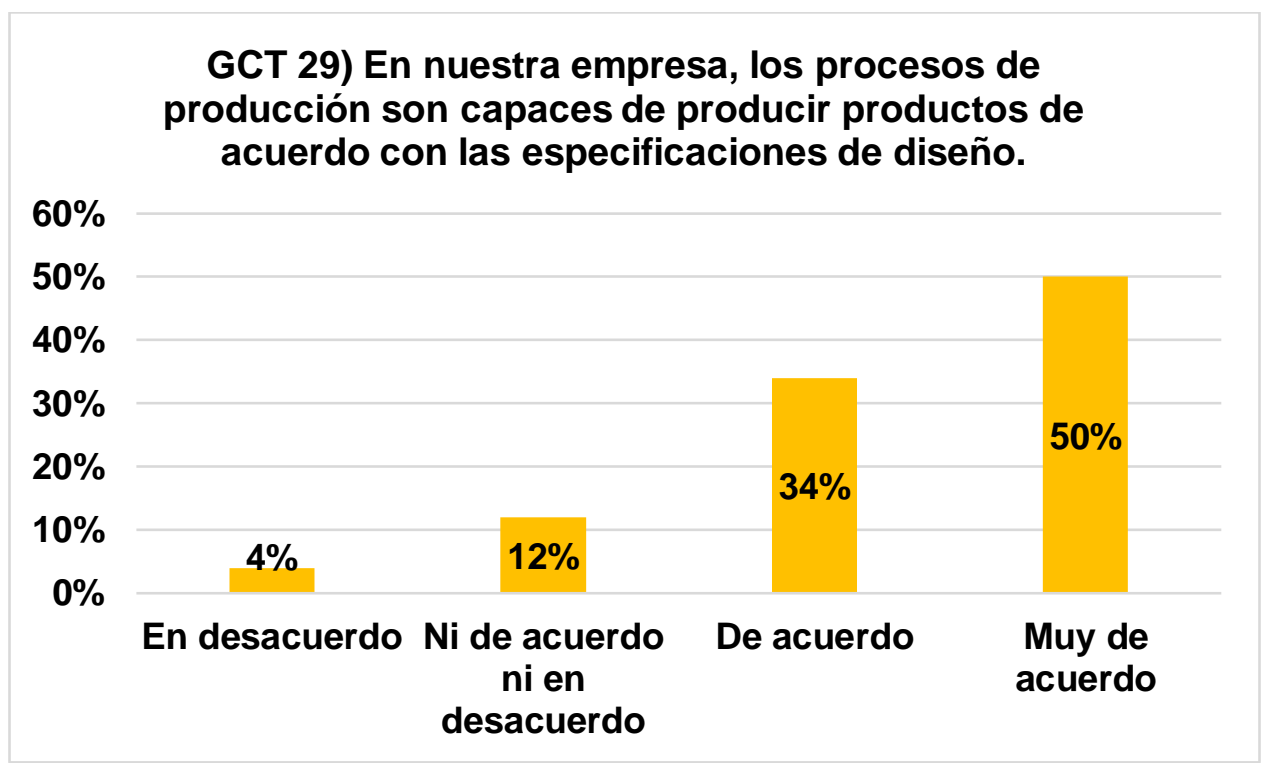

Figura 37.Gráfico Producción de acuerdo a especificaciones de diseño

Interpretación:

Para la vigésima novena afirmación, el resultado arrojo que, de los 50 representantes, el $50 \%$ se encuentran muy de acuerdo con que los procesos de producción de las exportadoras son capaces de producir productos de acuerdo a las especificaciones de diseño y un $34 \%$ que se encuentran de acuerdo, sin embargo, también obtuvimos $12 \%$ que no estaban ni de acuerdo ni en desacuerdo además de tener 2 representantes en desacuerdo con la afirmación.

Tabla 35

Sistema de atención de quejas

GCT 30) En nuestra empresa, existen sistemas adecuados para atender las quejas de los clientes.

\begin{tabular}{|c|c|c|c|c|c|}
\hline & & Frequency & Percent & $\begin{array}{c}\text { Valid } \\
\text { Percent }\end{array}$ & $\begin{array}{c}\text { Cumulative } \\
\text { Percent }\end{array}$ \\
\hline \multirow{5}{*}{ Valid } & En desacuerdo & 3 & 6.0 & 6.0 & 6.0 \\
\hline & $\begin{array}{l}\text { Ni de acuerdo ni en } \\
\text { desacuerdo }\end{array}$ & 4 & 8.0 & 8.0 & 14.0 \\
\hline & De acuerdo & 17 & 34.0 & 34.0 & 48.0 \\
\hline & Muy de acuerdo & 26 & 52.0 & 52.0 & 100.0 \\
\hline & Total & 50 & 100.0 & 100.0 & \\
\hline
\end{tabular}

Elaboración propia (2020) - Extraído del SPSS 26 


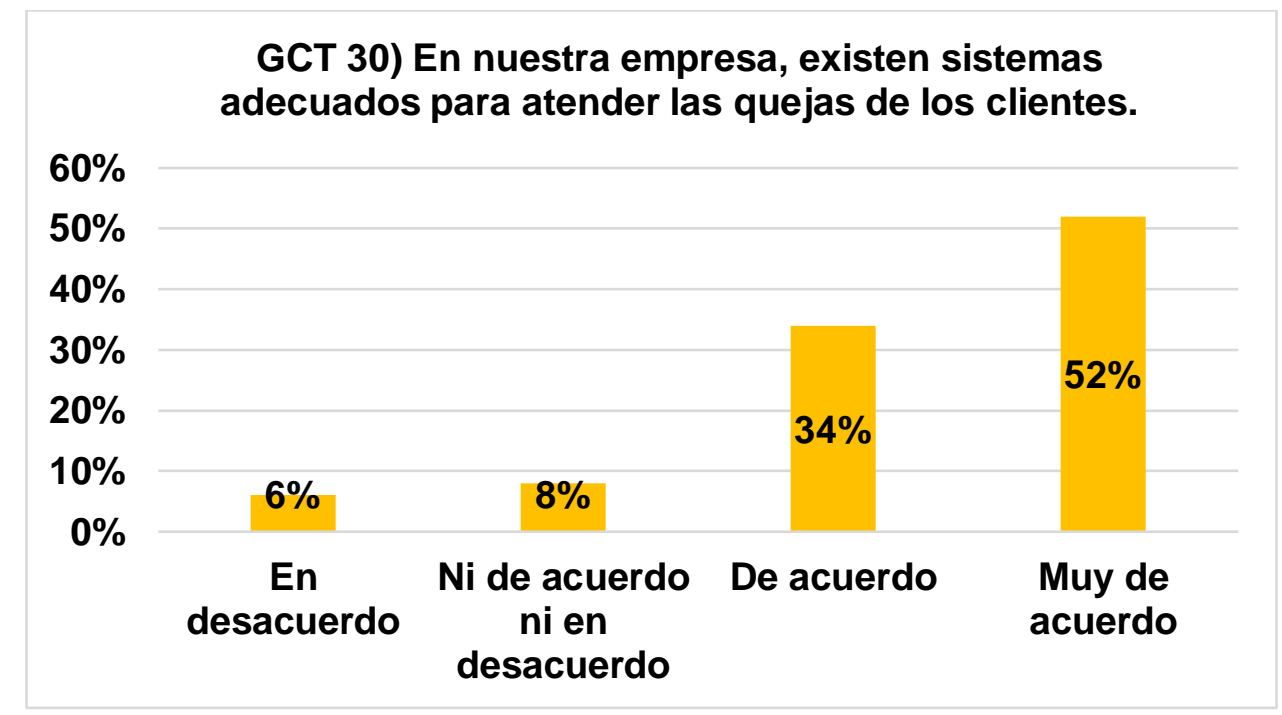

Figura 38. Gráfico Sistema de atención de quejas

Interpretación:

Para este caso, de las 50 empresas exportadoras de cacao en grano, solo el 6\% respondieron que se encontraban en desacuerdo con que en su empresa existan sistemas adecuados para atender las quejas de sus clientes, un $8 \%$ respondió de manera neutral en el que estaba ni de acuerdo ni en desacuerdo, pero también hay un 34\% de acuerdo y un 52\% muy de acuerdo que confirma tener los sistemas adecuados para atender quejas.

\subsubsection{Análisis de las encuestas de Desempeño exportador.}

Tabla 36

Firma de exportación rentable

DEXP1) Nuestra firma de exportación ha sido muy rentable.

\begin{tabular}{llccc}
\hline & Frequency & Percent & $\begin{array}{c}\text { Valid } \\
\text { Percent }\end{array}$ & $\begin{array}{c}\text { Cumulative } \\
\text { Percent }\end{array}$ \\
\hline En desacuerdo & 4 & 8.0 & 8.0 & 8.0 \\
Ni de acuerdo ni en & 9 & 18.0 & 18.0 & 26.0 \\
Valid & & & & \\
desacuerdo & 26 & 52.0 & 52.0 & 78.0 \\
De acuerdo & 11 & 22.0 & 22.0 & 100.0 \\
Muy de acuerdo & 50 & 100.0 & 100.0 & \\
\hline Total & & & & \\
\hline
\end{tabular}

Elaboración propia (2020) - Extraído del SPSS 26 


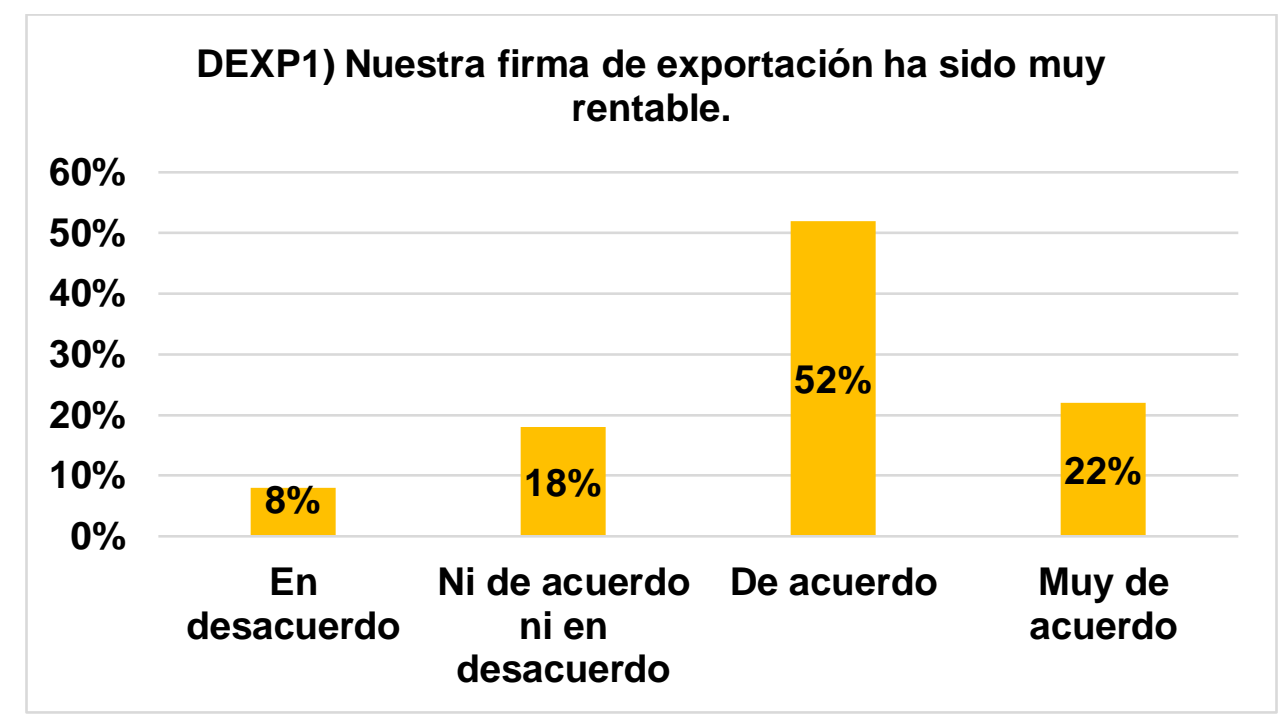

Figura 39. Gráfico Firma de exportación rentable

Interpretación:

Como se puede observar en la tabla 36 , de los 50 representantes de las empresas el $8 \%$ está en desacuerdo, el 74\% está de acuerdo y muy de acuerdo, pero también hubo el 18\% de representantes de las exportadoras que se encontraron ni de acuerdo ni en desacuerdo frente a esta afirmación. Por ello, podemos concluir que la gran mayoría de los representantes de las empresas exportadoras de cacao en grano consideran que su firma de exportación ha sido muy rentable.

Tabla 37

Alto volumen de ventas

DEXP2) Nuestra firma de exportación ha generado un alto volumen de ventas.

\begin{tabular}{|c|c|c|c|c|c|}
\hline & & Frequency & Percent & $\begin{array}{c}\text { Valid } \\
\text { Percent }\end{array}$ & $\begin{array}{c}\text { Cumulative } \\
\text { Percent }\end{array}$ \\
\hline \multirow{5}{*}{ Valid } & En desacuerdo & 4 & 8.0 & 8.0 & 8.0 \\
\hline & $\begin{array}{l}\text { Ni de acuerdo ni en } \\
\text { desacuerdo }\end{array}$ & 10 & 20.0 & 20.0 & 28.0 \\
\hline & De acuerdo & 24 & 48.0 & 48.0 & 76.0 \\
\hline & Muy de acuerdo & 12 & 24.0 & 24.0 & 100.0 \\
\hline & Total & 50 & 100.0 & 100.0 & \\
\hline
\end{tabular}

Elaboración propia (2020) - Extraído del SPSS 26 


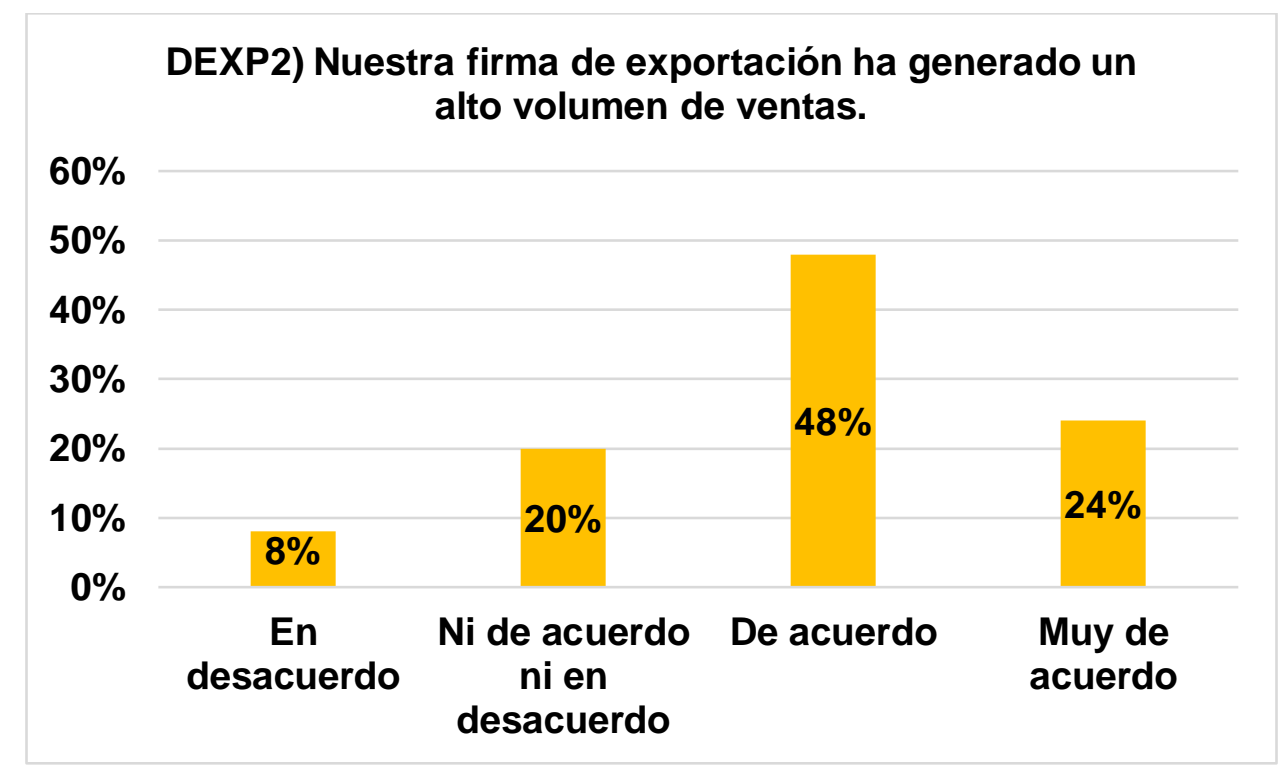

Figura 40. Gráfico Alto volumen en ventas

Interpretación:

Para este caso de los 50 representantes arrojo como resultado que la mayoría de ellos están de acuerdo y muy de acuerdo con que su firma de exportación ha generado un alto volumen de ventas, representó un porcentaje de $72 \%$ y solo el $8 \%$ de los gerente o administradores encuestados están en desacuerdo, sin embargo, también hay un $20 \%$ que no están ni de acuerdo ni en desacuerdo con la afirmación.

Tabla 38

Rápido crecimiento

DEXP3) Nuestra firma de exportación ha logrado un rápido crecimiento.

\begin{tabular}{llcccc}
\hline & Frequency & Percent & $\begin{array}{c}\text { Valid } \\
\text { Percent }\end{array}$ & $\begin{array}{c}\text { Cumulative } \\
\text { Percent }\end{array}$ \\
\hline \multirow{2}{*}{ Valid } & En desacuerdo & 1 & 2.0 & 2.0 & 2.0 \\
& Ni de acuerdo ni en & 4 & 8.0 & 8.0 & 10.0 \\
& desacuerdo & & & & \\
De acuerdo & 15 & 30.0 & 30.0 & 40.0 \\
Muy de acuerdo & 30 & 60.0 & 60.0 & 100.0 \\
\cline { 2 - 5 } & Total & 50 & 100.0 & 100.0 & \\
\hline
\end{tabular}

Elaboración propia (2020) - Extraído del SPSS 26 


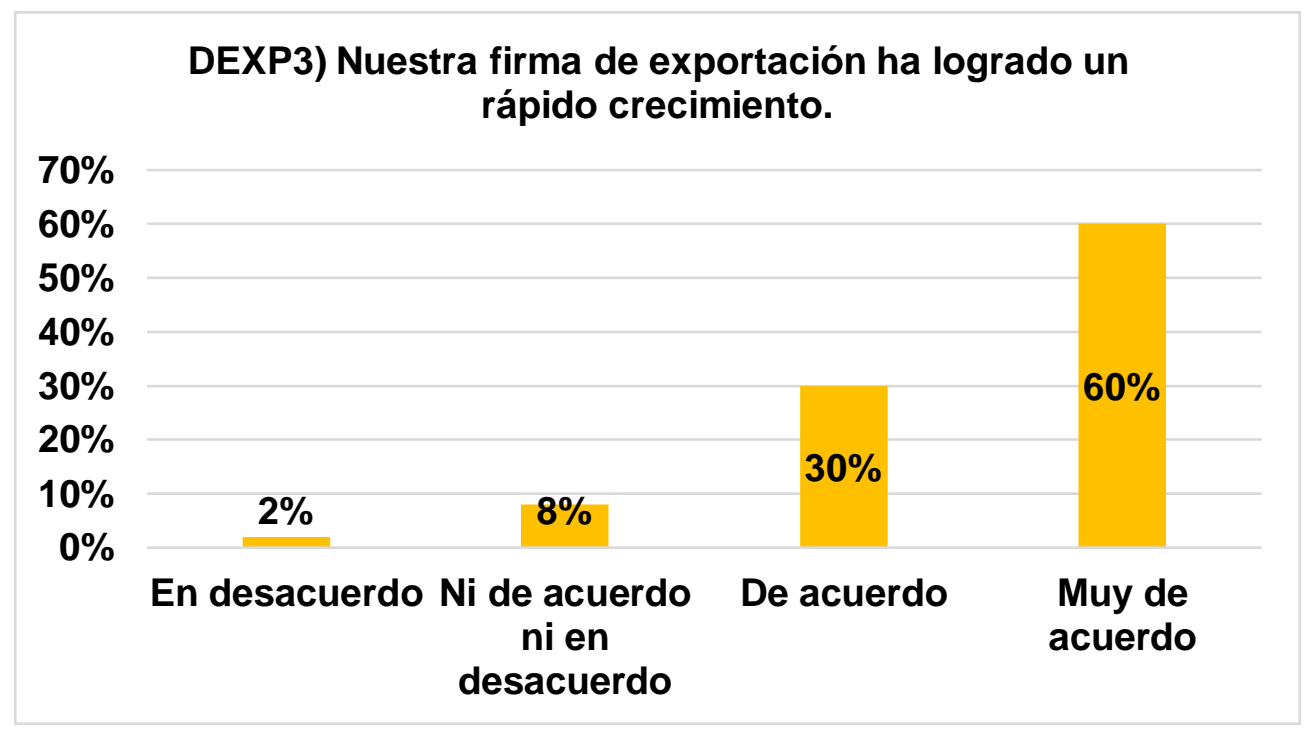

Figura 41. Gráfico Rápido Crecimiento

Interpretación:

Para la tercera afirmación de la dimensión de gestión de calidad, obtuvimos como resultado que, de los 50 representantes, el $60 \%$ están de acuerdo con que la firma de exportación ha logrado un rápido crecimiento y también hay un 30\% que se encuentran de acuerdo, pero por otro lado hay un $10 \%$ que se encuentra en desacuerdo y ni de acuerdo ni en desacuerdo con la afirmación.

Tabla 39

Mejora de competitividad global

DEXP4) Nuestra firma de exportación ha mejorado nuestra competitividad global.

\begin{tabular}{llcccc}
\hline & Frequency & Percent & $\begin{array}{c}\text { Valid } \\
\text { Percent }\end{array}$ & $\begin{array}{c}\text { Cumulative } \\
\text { Percent }\end{array}$ \\
\hline En desacuerdo & 1 & 2.0 & 2.0 & 2.0 \\
Valid & Ni de acuerdo ni en & 11 & 22.0 & 22.0 & 24.0 \\
& desacuerdo & & & & \\
& De acuerdo & 30 & 60.0 & 60.0 & 84.0 \\
& Muy de acuerdo & 8 & 16.0 & 16.0 & 100.0 \\
\cline { 2 - 5 } & Total & 50 & 100.0 & 100.0 & \\
\hline
\end{tabular}

Elaboración propia (2020) - Extraído del SPSS 26 


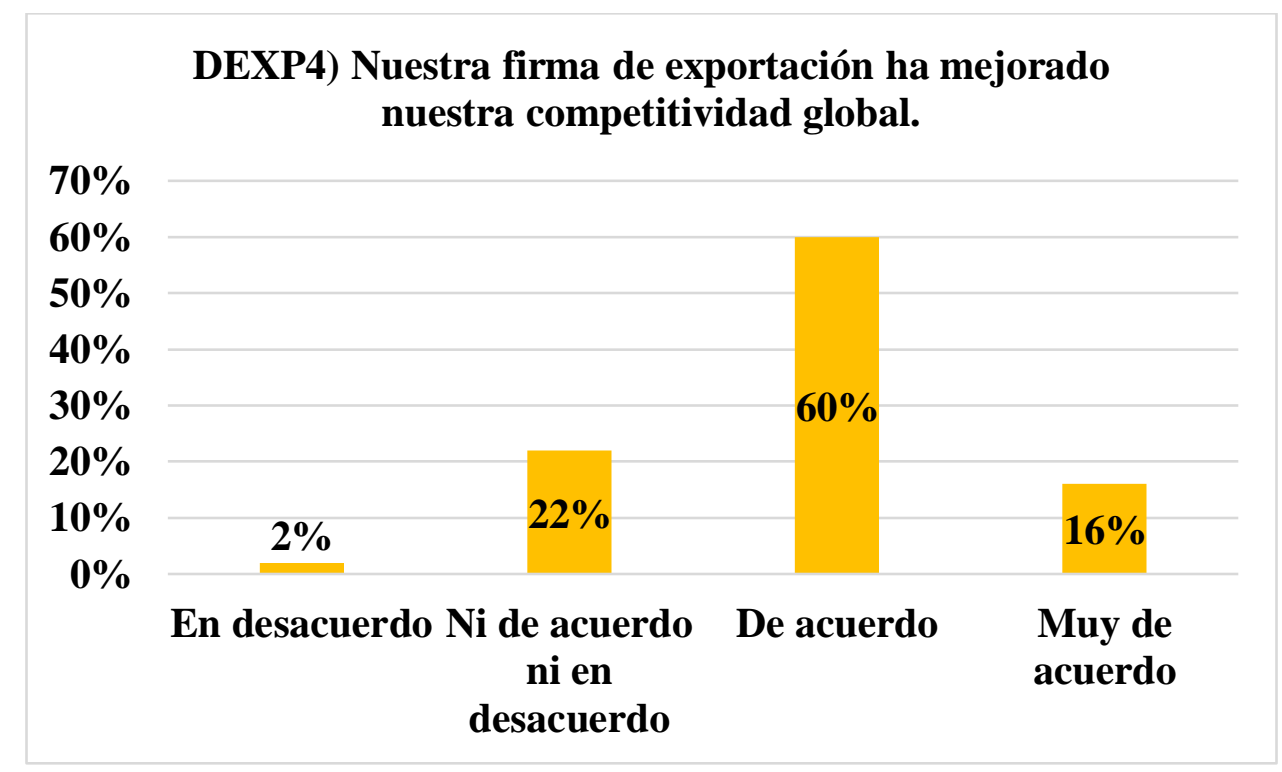

Figura 42.Gráfico Mejora de competitividad global

Interpretación:

Para esta afirmación, 38 de los representantes de las empresas estuvieron de acuerdo y muy de acuerdo obteniendo un equivalente a $76 \%$ de la muestra que dijeron que su firma exportadora ha mejorado su competitividad global, por otro lado, hubo solo un representante en desacuerdo que es equivalente solo al $2 \%$ de la muestra y también hay un $22 \%$ de representantes que no están ni de acuerdo ni en desacuerdo frente a esa afirmación.

Tabla 40

Posición estratégica

DEXP5) Nuestra firma de exportación ha fortalecido nuestra posición estratégica.

\begin{tabular}{|c|c|c|c|c|c|}
\hline & & Frequency & Percent & $\begin{array}{c}\text { Valid } \\
\text { Percent }\end{array}$ & $\begin{array}{c}\text { Cumulative } \\
\text { Percent }\end{array}$ \\
\hline \multirow{5}{*}{ Valid } & En desacuerdo & 2 & 4.0 & 4.0 & 4.0 \\
\hline & $\begin{array}{l}\text { Ni de acuerdo ni en } \\
\text { desacuerdo }\end{array}$ & 10 & 20.0 & 20.0 & 24.0 \\
\hline & De acuerdo & 27 & 54.0 & 54.0 & 78.0 \\
\hline & Muy de acuerdo & 11 & 22.0 & 22.0 & 100.0 \\
\hline & Total & 50 & 100.0 & 100.0 & \\
\hline
\end{tabular}

Elaboración propia (2020) - Extraído del SPSS 26 


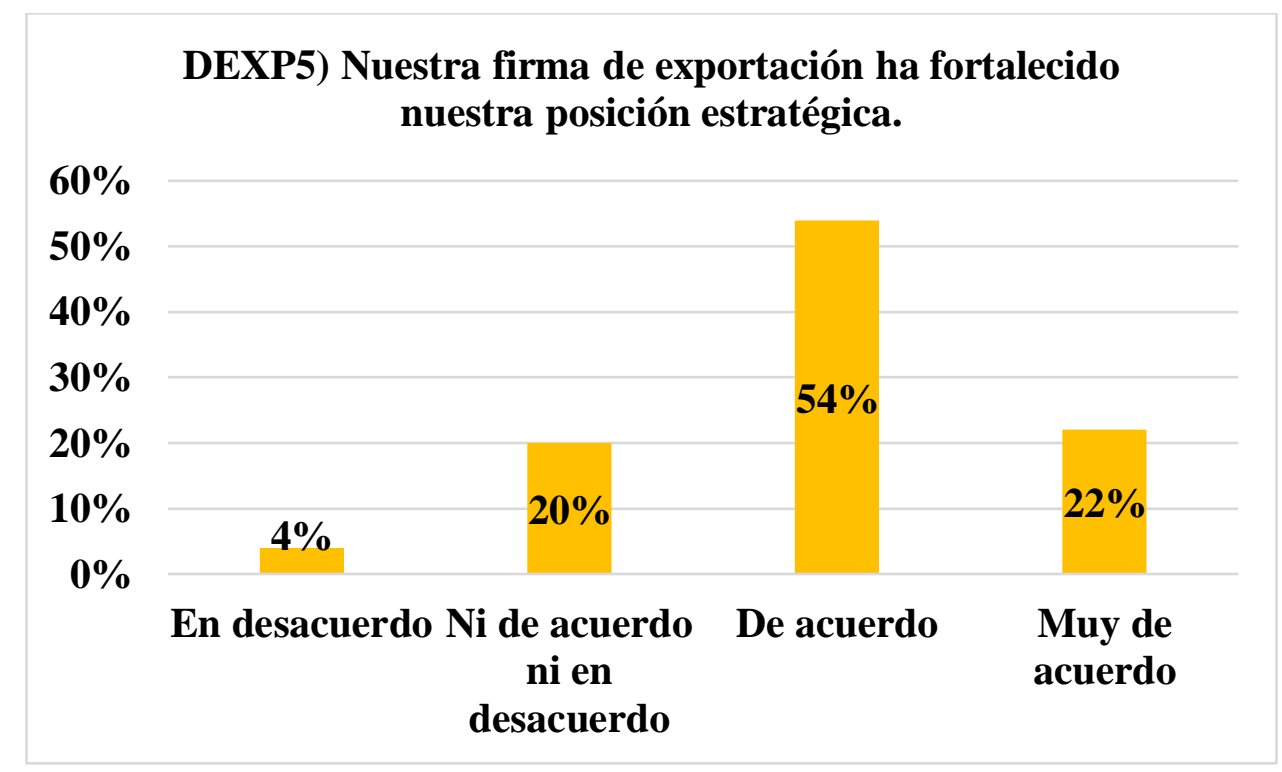

Figura 43.Gráfico Posición estratégica

Interpretación:

Para esta afirmación hubo el $20 \%$ de los representantes de las empresas que no estuvieron ni de acuerdo ni en desacuerdo y sol el $4 \%$ de los representantes de las empresas estuvieron en desacuerdo, pero el $76 \%$ de los representantes si estuvieron de acuerdo y muy de acuerdo con que su firma de exportación ha fortalecido su posición estratégica.

\section{Tabla 41}

Aumento de participación en el mercado global

DEXP6) Nuestra firma de exportación ha aumentado significativamente nuestra participación en el mercado global.

\begin{tabular}{|c|c|c|c|c|c|}
\hline & & Frequency & Percent & $\begin{array}{c}\text { Valid } \\
\text { Percent }\end{array}$ & $\begin{array}{c}\text { Cumulative } \\
\text { Percent }\end{array}$ \\
\hline \multirow[t]{4}{*}{ Valid } & $\begin{array}{l}\text { Ni de acuerdo ni en } \\
\text { desacuerdo }\end{array}$ & 4 & 8.0 & 8.0 & 8.0 \\
\hline & De acuerdo & 16 & 32.0 & 32.0 & 40.0 \\
\hline & Muy de acuerdo & 30 & 60.0 & 60.0 & 100.0 \\
\hline & Total & 50 & 100.0 & 100.0 & \\
\hline
\end{tabular}

Elaboración propia (2020) - Extraído del SPSS 26 


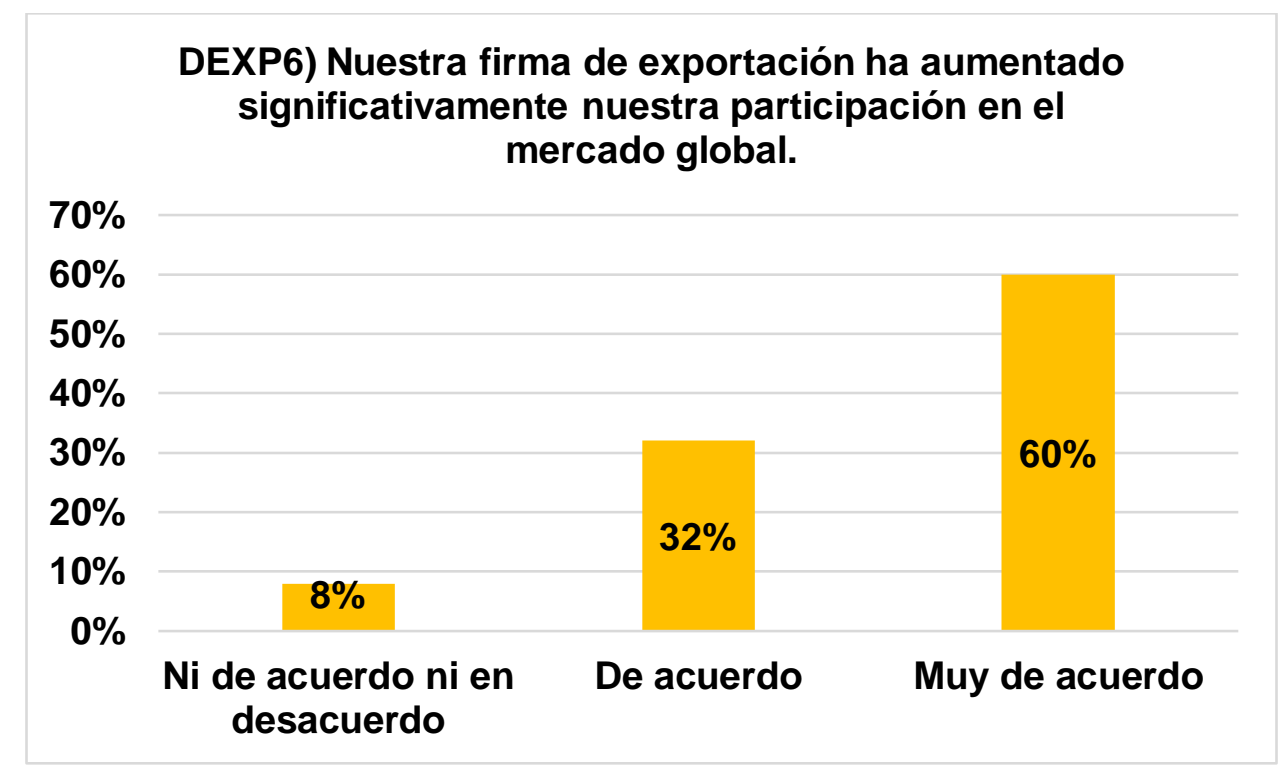

Figura 44 . Gráfico Aumento de participación en el mercado global

Interpretación:

En este caso, $8 \%$ de los representantes votaron por una posición neutral en el que no están ni de acuerdo ni en desacuerdo con la afirmación sin embargo obtuvimos un $92 \%$ de acuerdo y muy de acuerdo con que su firma de exportación aumento significativamente su participación en el mercado global.

Tabla 42

Desempeño exportador satisfactorio

DEXP7) El desempeño exportador de nuestra firma ha sido satisfactorio.

\begin{tabular}{|c|c|c|c|c|c|}
\hline & & Frequency & Percent & $\begin{array}{c}\text { Valid } \\
\text { Percent }\end{array}$ & $\begin{array}{c}\text { Cumulative } \\
\text { Percent }\end{array}$ \\
\hline \multirow{5}{*}{ Valid } & En desacuerdo & 1 & 2.0 & 2.0 & 2.0 \\
\hline & $\begin{array}{l}\text { Ni de acuerdo ni en } \\
\text { desacuerdo }\end{array}$ & 7 & 14.0 & 14.0 & 16.0 \\
\hline & De acuerdo & 18 & 36.0 & 36.0 & 52.0 \\
\hline & Muy de acuerdo & 24 & 48.0 & 48.0 & 100.0 \\
\hline & Total & 50 & 100.0 & 100.0 & \\
\hline
\end{tabular}

Elaboración propia (2020) - Extraído del SPSS 26 


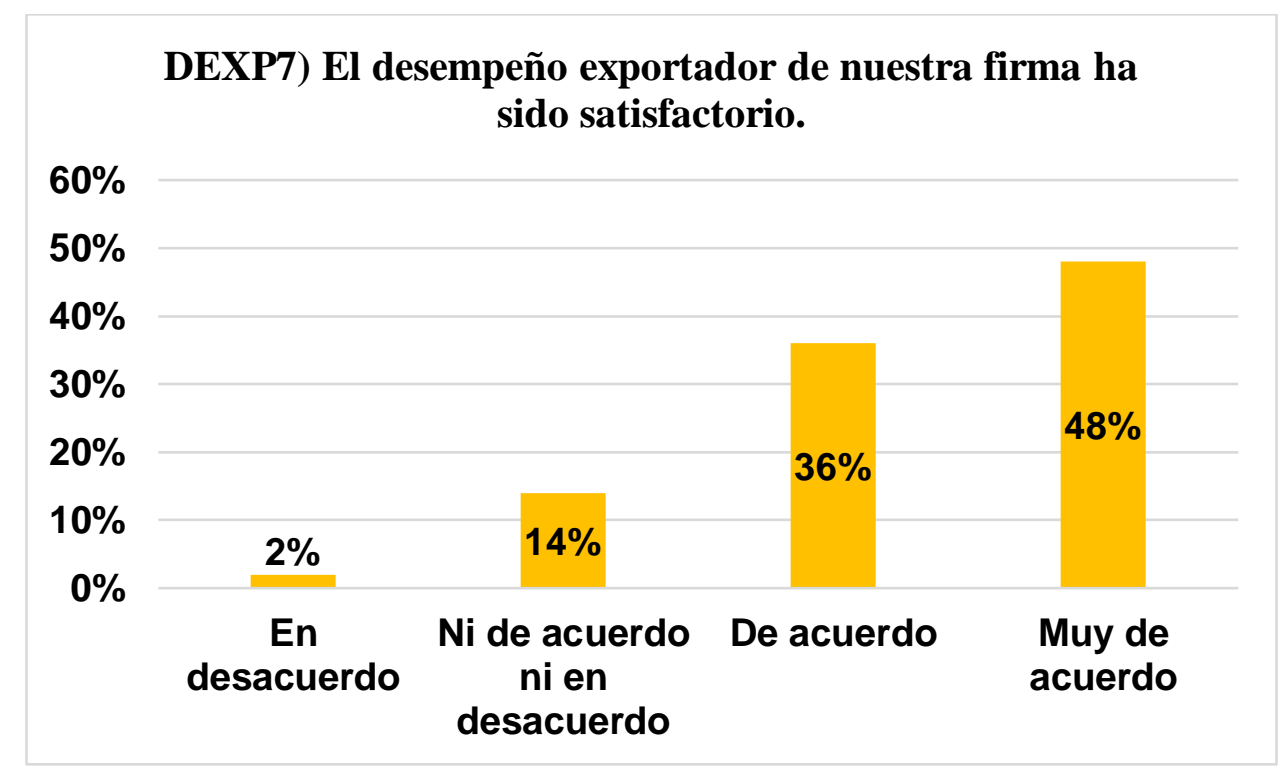

Figura 45. Gráfico Desempeño exportador satisfactorio

Interpretación:

En la tabla 42 solo se mostró que un $2 \%$ de los representantes estuvieron insatisfechos, el $84 \%$ de los representantes de toda la nuestra si estaban de acuerdo y muy de acuerdo y también el 14\% de ellos tuvieron una posición neutral en donde expusieron que no estaban ni de acuerdo ni en desacuerdo. Podemos concluir que la mayoría de los exportadores de cacao en grano ha tenido un desempeño exportador satisfactorio.

Tabla 43

Firma de exportación exitosa

DEXP8) Nuestra firma de exportación ha sido exitosa

\begin{tabular}{lcccc}
\hline & Frequency & Percent & $\begin{array}{c}\text { Valid } \\
\text { Percent }\end{array}$ & $\begin{array}{c}\text { Cumulative } \\
\text { Percent }\end{array}$ \\
\hline $\begin{array}{l}\text { Totalmente en } \\
\text { desacuerdo }\end{array}$ & 1 & 2.0 & 2.0 & 2.0 \\
Valid & & & & \\
En desacuerdo & 4 & 8.0 & 8.0 & 10.0 \\
Ni de acuerdo ni en & 5 & 10.0 & 10.0 & 20.0 \\
desacuerdo & 24 & 48.0 & 48.0 & 68.0 \\
De acuerdo & 16 & 32.0 & 32.0 & 100.0 \\
Muy de acuerdo & 50 & 100.0 & 100.0 & \\
\hline \multicolumn{1}{c}{ Total } & & & & \\
\hline
\end{tabular}

Elaboración propia (2020) - Extraído del SPSS 26 


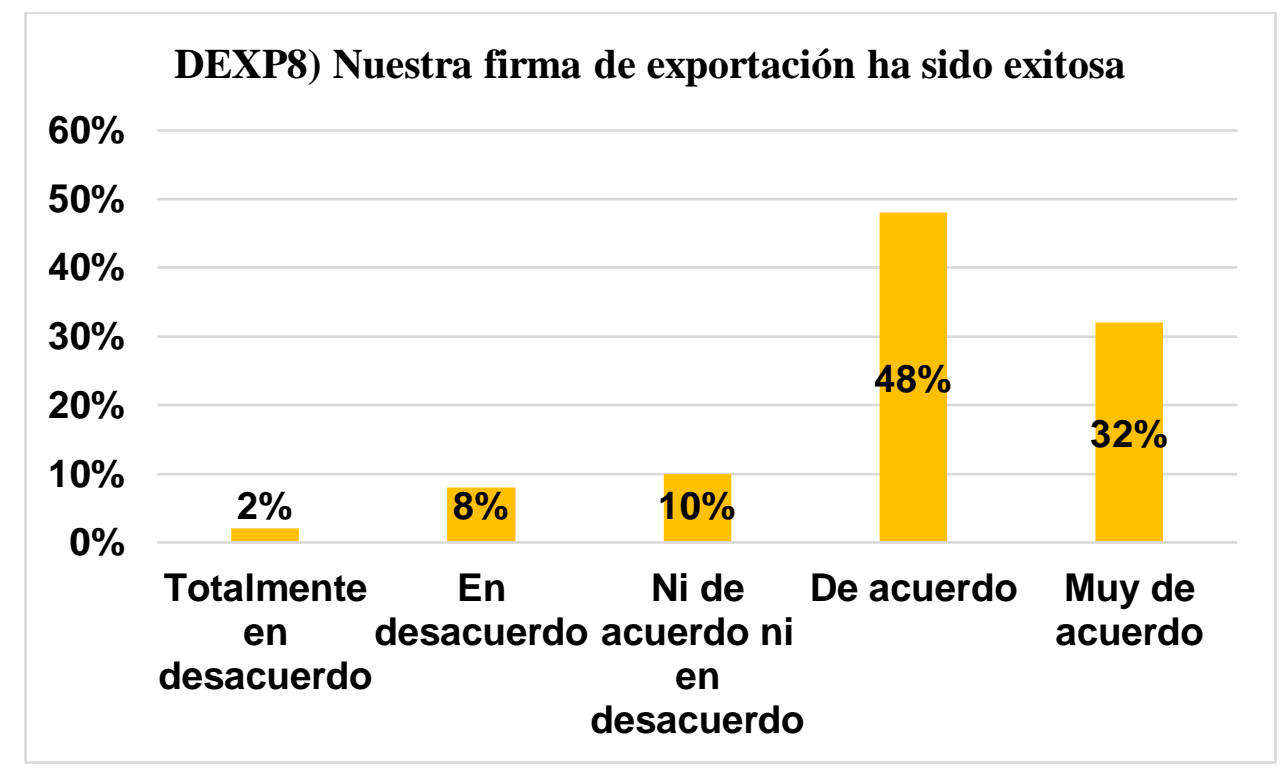

Figura 46.Gráfico Firma de exportación exitosa

Interpretación:

De los 50 representantes, el $80 \%$ estás de acuerdo y muy de acuerdo con que su firma de exportación ha sido exitosa, obtuvimos también un $10 \%$ que estaba ni de acuerdo ni en desacuerdo, el $10 \%$ se encontró totalmente en desacuerdo y en desacuerdo con que su firma de exportación haya sido exitosa.

Tabla 44

Cumplimiento de expectativas

DEXP9) Nuestra empresa de exportación ha cumplido plenamente nuestras expectativas.

\begin{tabular}{llccc}
\hline & Frequency & Percent & $\begin{array}{c}\text { Valid } \\
\text { Percent }\end{array}$ & $\begin{array}{c}\text { Cumulative } \\
\text { Percent }\end{array}$ \\
\hline En desacuerdo & 1 & 2.0 & 2.0 & 2.0 \\
Ni de acuerdo ni en & 8 & 16.0 & 16.0 & 18.0 \\
Valid desacuerdo & & & & \\
De acuerdo & 26 & 52.0 & 52.0 & 70.0 \\
Muy de acuerdo & 15 & 30.0 & 30.0 & 100.0 \\
\hline Total & 50 & 100.0 & 100.0 & \\
\hline
\end{tabular}

Elaboración propia (2020) - Extraído del SPSS 26 


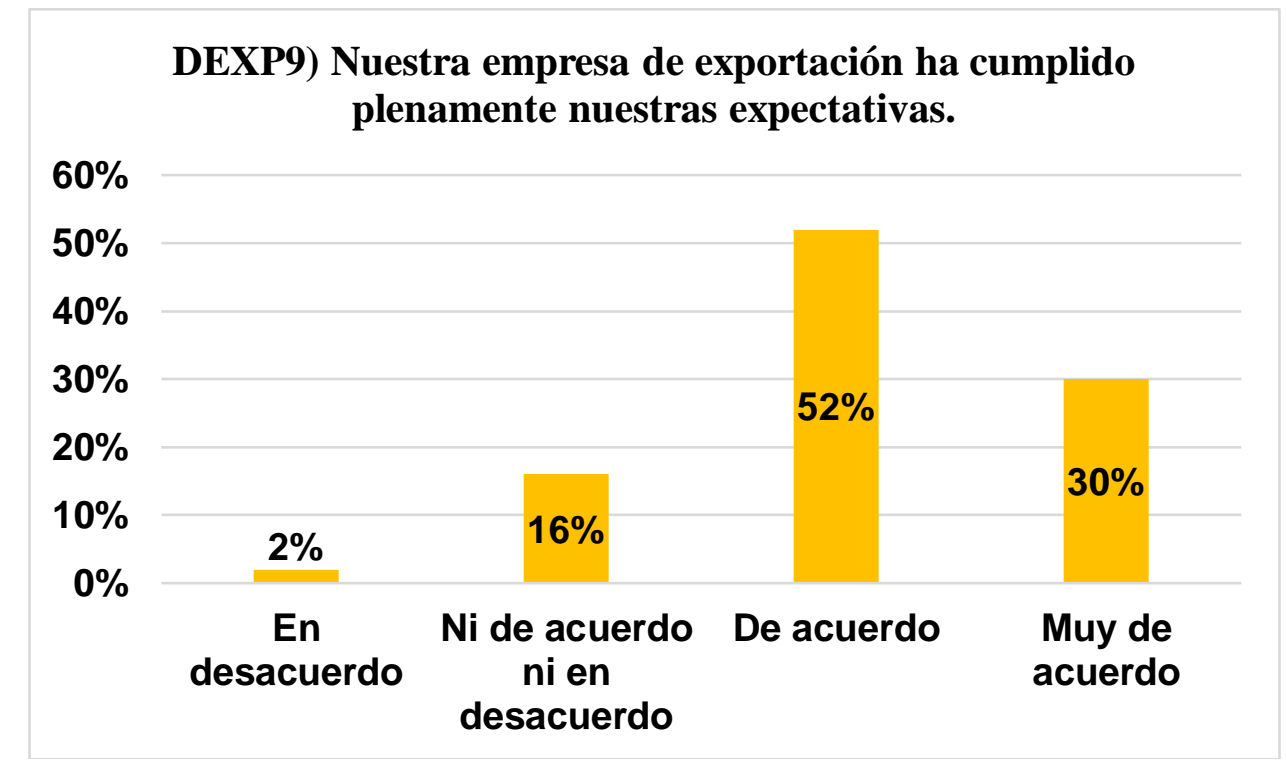

Figura 47. Gráfico Cumplimiento de expectativas

Interpretación:

La tabla 44, al evaluar sobre si ha cumplido las expectativas, la mayor cantidad de los representantes de las empresas exportadoras de cacao en grano votaron el equivalente de un $52 \%$ de la muestra que están de acuerdo y $30 \%$ muy de acuerdo. Sin embargo, el $2 \%$ están en desacuerdo y un $16 \%$ ni de acuerdo ni en desacuerdo por lo que podemos concluir que su empresa ha cumplido plenamente con sus expectativas.

\subsection{Contrastación de Hipótesis}

\subsubsection{Prueba de normalidad de Shapiro-Wilk.}

Se realiza la prueba de normalidad de Shapiro- Wilk con el fin de comprender de una mejor manera los datos y poder verificar si tienen o no una distribución normal. En los anexos 3 y 4 se puede observar que en ningún resultado de los cuestionarios tiene normalidad por lo que se puede concluir que no tienen una distribución normal debiéndose ejecutar pruebas no paramétricas. Es por este motivo que se usara el coeficiente de correlación de Rho Spearman para poder ver la demostración de las hipótesis que se han planteado para esta investigación.

El Rho Spearman se utilizó para medir la correlación de las variables en un nivel ordinal pudiendo de esta manera que los componentes analizados se puedan ordenar por categorías, 
así como también dichos coeficientes son utilizados para que las escalas tipo Likert sean vinculadas. Hernández, R., Fernández, C., \& Baptista, L. (2014).

\subsubsection{Análisis Factorial exploratorio.}

EL análisis factorial exploratorio (AFE), es definida como un método multivariado de interdependencia el cual se realiza con la intención de confirmar la cantidad de dimensiones que tienen las variables de esta investigación corroborando también la agrupación de las preguntas (Pérez y Medrano, 2010).Utilizando este método se puede extraer las preguntas utilizando también el método de Varimax para la rotación que tiene esto como propósito redistribuir la varianza de los componentes de la matriz.

El índice de Kaiser indique si a la muestra elegida se le puede aplicar el análisis factorial .En caso los valores de este indie se encuentren entre el rango de 0.5 y 1 , eso significa que es apropiada al aplicación del análisis, el resultado obtenido es de 0.719 por lo que sí es significativo .Por otro lado , la prueba de esfericidad de esfericidad de Barlett se usó con el din de comprobar la hipótesis nula ,la cual se fundamente que las variables no están correlacionas en la población. Para este caso se eligió la prueba de esfericidad de Barlett en donde el valor fue de $0.000<5 \%$, lo cual indica que las variables están relacionadas.

En cuanto a los resultados, en la tabla 43 se puede observar que la variable gestión de calidad total arrojo un 0.719 para la medida Kaiser-Meyer-Olkin (KMO), 1566.291para el Chi-cuadrado y 0.000 en la significancia. Estos resultados indican que el AFE es correcto y que después de desarrollar el análisis, se obtiene 2 variables, que se llegan a explicar el $76.054 \%$ de la varianza total. (Ver tabla 43 y 44 ). 


\section{Tabla 45}

Prueba de KMO y Bartlett-Gestión de calidad total

\begin{tabular}{|c|c|c|}
\hline \multicolumn{3}{|c|}{ KMO y prueba de Bartlett } \\
\hline Medida de adecuación muestral d & ser-Meyer-Olkin. & 0.675 \\
\hline \multirow{3}{*}{ Prueba de esfericidad de Bartlett } & Chi-cuadrado aproximado & 1566.291 \\
\hline & gl & 435 \\
\hline & Sig. & 0 \\
\hline
\end{tabular}

Elaboración propia (2020). Extraído de SPSS.

El factor 1 que viene a ser en este caso procesos posee una varianza de $26.039 \%$, liderazgo que viene a ser el factor 2 obtiene una varianza de $16.113 \%$, estrategia que es el factor 3 representa una varianza de $13.713 \%$, además de ello tenemos al factor 4 personas con una varianza de $10.79 \%$; por último, el factor 5 es recursos el cual posee una varianza de $8.500 \%$.

Tabla 46

Varianza total explicada-Gestión de calidad total

\begin{tabular}{|c|c|c|c|c|c|c|c|c|c|}
\hline \multirow[t]{2}{*}{ Factor } & \multicolumn{3}{|c|}{ Autovalores iniciales } & \multicolumn{3}{|c|}{$\begin{array}{l}\text { Sumas de las saturaciones } \\
\text { al } \\
\text { cuadrado de la extracción }\end{array}$} & \multicolumn{3}{|c|}{$\begin{array}{c}\text { Suma de las saturaciones al } \\
\text { cuadrado de la rotación }\end{array}$} \\
\hline & Total & $\begin{array}{c}\% \text { de la } \\
\text { varianza }\end{array}$ & $\begin{array}{c}\% \\
\text { acumulado }\end{array}$ & Total & $\begin{array}{l}\% \text { de la } \\
\text { varianza }\end{array}$ & $\begin{array}{c}\% \\
\text { acumulado }\end{array}$ & Total & $\begin{array}{c}\% \text { de la } \\
\text { varianza }\end{array}$ & $\begin{array}{c}\% \\
\text { acumulado }\end{array}$ \\
\hline 1 & 8.082 & 26.939 & 26.939 & 8.082 & 26.939 & 26.939 & 5.519 & 18.396 & 18.396 \\
\hline 2 & 4.834 & 16.113 & 43.052 & 4.834 & 16.113 & 43.052 & 4.639 & 15.463 & 33.859 \\
\hline 3 & 4.114 & 13.713 & 56.765 & 4.114 & 13.713 & 56.765 & 4.498 & 14.994 & 48.853 \\
\hline 4 & 3.237 & 10.79 & 67.554 & 3.237 & 10.79 & 67.554 & 4.276 & 14.254 & 63.107 \\
\hline 5 & 2.55 & 8.5 & 76.054 & 2.55 & 8.5 & 76.054 & 3.884 & 12.947 & 76.054 \\
\hline 6 & 0.995 & 3.317 & 79.371 & & & & & & \\
\hline 7 & 0.884 & 2.945 & 82.316 & & & & & & \\
\hline 8 & 0.725 & 2.415 & 84.731 & & & & & & \\
\hline 9 & 0.648 & 2.159 & 86.89 & & & & & & \\
\hline 10 & 0.587 & 1.957 & 88.848 & & & & & & \\
\hline 11 & 0.521 & 1.735 & 90.583 & & & & & & \\
\hline 12 & 0.49 & 1.632 & 92.215 & & & & & & \\
\hline
\end{tabular}




\begin{tabular}{lccc}
13 & 0.374 & 1.248 & 93.463 \\
14 & 0.325 & 1.083 & 94.546 \\
15 & 0.297 & 0.99 & 95.536 \\
16 & 0.234 & 0.779 & 96.315 \\
17 & 0.195 & 0.65 & 96.965 \\
18 & 0.174 & 0.579 & 97.543 \\
19 & 0.119 & 0.397 & 97.94 \\
20 & 0.115 & 0.382 & 98.323 \\
21 & 0.109 & 0.362 & 98.685 \\
22 & 0.102 & 0.34 & 99.025 \\
23 & 0.086 & 0.287 & 99.312 \\
24 & 0.059 & 0.195 & 99.507 \\
25 & 0.049 & 0.165 & 99.672 \\
26 & 0.03 & 0.101 & 99.773 \\
27 & 0.026 & 0.088 & 99.861 \\
28 & 0.018 & 0.061 & 99.923 \\
29 & 0.016 & 0.053 & 99.976 \\
30 & 0.007 & 0.024 & 100 \\
\hline
\end{tabular}

Fuente: Elaboración propia en base a los resultados extraídos del SPSS 26

La rotación Varimax permite simplificar todas las expresiones de los subgrupos donde abarcan pocos componentes principales, con normalización Kaiser, la matriz de componentes rotados, con las preguntas agrupadas del 24 al 30 son de la variable procesos el cual es el factor 1 , mientras que las preguntas agrupadas del 1 al 6 son el factor 2 de la variable "liderazgo", las preguntas del 7 al 12 agrupadas pertenecen al factor 3 y a la variable estrategia ;por último, las preguntas agrupadas del 19 al 23 son del factor 5 "recursos".

Tabla 47

Matriz de factores rotados-Gestión de calidad total

\begin{tabular}{llllll}
\hline Matriz de factores rotados \\
\cline { 2 - 6 } & \multicolumn{5}{c}{ Factor } \\
\hline
\end{tabular}

GCT 29) En nuestra empresa, los procesos de producción son capaces de producir productos de $\quad 0.926$ acuerdo con las especificaciones de diseño. 
GCT 24) En nuestra empresa, se establecen

procedimientos adecuados para realizar diferentes $\quad 0.924$

trabajos.

GCT 28) En nuestra empresa, se enfatiza el desarrollo y la innovación de los procesos de

producción

GCT 26) En nuestra empresa, se monitorea el desempeño de los procesos de producción.

GCT 27) En nuestra empresa, el departamento de investigación y desarrollo (I + D) está trabajando continuamente en el desarrollo y la mejora.

GCT 25) En nuestra empresa, los empleados conocen los parámetros (temperatura, presión, etc.) 0.798 de los diferentes procesos, que son necesarios.

GCT 30) En nuestra empresa, existen sistemas adecuados para atender las quejas de los clientes.

GCT 1) Los gerentes de nuestra empresa consideran que el costo es más importante en comparación con la calidad de los productos.

GCT 5) Los gerentes de nuestra empresa adquieren y actualizan continuamente su conocimiento que es valioso para la organización.

GCT 2) Los gerentes de nuestra empresa se presentan como modelos a seguir para los empleados.

GCT 3) Los gerentes de nuestra empresa se aseguran de que los empleados conozcan los planes a largo plazo de la empresa.

GCT 4) Los gerentes de nuestra empresa no desean otorgar autoridad a los empleados para que tomen decisiones sobre sus trabajos.

GCT 6) Los gerentes de nuestra empresa fomentan y participan en iniciativas de mejora continua.

GCT 12) En nuestra empresa, periódicamente (por ejemplo, cada tres meses, seis meses o un año), se evalúa el desempeño organizacional contra los objetivos y metas establecidos. 
GCT 7) En nuestra empresa, las opiniones de los clientes (las personas / empresas que compran o desean comprar los productos de su empresa) se consideran importantes al diseñar nuevos productos.

GCT 10) En nuestra empresa, la medición sistemática de pérdidas (como pérdidas de producción, pérdidas debidas al rechazo de productos terminados, etc.) se lleva a cabo. GCT 8) En nuestra empresa, se consideran las opiniones de los proveedores al configurar los objetivos de la empresa.

GCT 11) En nuestra empresa, existen sistemas de información para capturar información sobre clientes y mercados GCT 9) En nuestra empresa, se evalúa y analiza el desempeño de los competidores y las mejores compañías de su clase.

GCT 14) En nuestra empresa, se ofrece capacitación específica de calidad a los empleados.

GCT 13) En nuestra empresa, los procesos formales se utilizan regularmente (encuestas de actitud, información de los empleados, etc.) para conocer las opiniones y puntos de vista de los empleados.

GCT 15) En nuestra empresa, se alienta a los empleados a actualizar sus conocimientos y habilidades.

GCT 16) En nuestra empresa, el trabajo en equipo es una práctica común dentro de la organización.

GCT 17) En nuestra empresa, los empleados tienen fácil acceso a la información relevante.

GCT 18) En nuestra empresa, fomente las opiniones y sugerencias de los empleados sobre cualquiera de las actividades de la organización.

GCT 19) En nuestra empresa, se alienta a los proveedores a desarrollar asociaciones a largo plazo con la organización.

GCT 21) En nuestra empresa, el desempeño de los proveedores se evalúa periódicamente.

GCT 23) En nuestra empresa trata de reducir el efecto nocivo de sus actividades en el medio ambiente. 
GCT 22) En nuestra empresa, se proporciona información y recursos actualizados a todos los empleados para realizar sus trabajos.

GCT 20) En nuestra empresa no da preferencia a la calidad sobre el costo al hacer acuerdos de compra con proveedores.

Fuente: Elaboración propia en base a los resultados extraídos del SPSS 26

Además, tenemos los resultados para la variable desempeño exportador, primero arrojo que hay un 0.719 para la medida de KMO (Kaiser- Meyer-Oklin) en cuanto al chicuadrado arrojo 253.797 y un 0.000 en la significancia mostrados en la tabla 46. A través de estos resultados se visualiza la capacidad del SPSS para mostrar la información estadística del KMO (0.719) permitiendo que a la muestra se le pueda realizar un análisis factorial que aporta a esta investigación para la dimensión de satisfacción donde explica el $80.210 \%$ de la varianza total.

Tabla 48

Prueba de Bartlett y KMO -Desempeño exportador

\begin{tabular}{llc}
\hline \multicolumn{3}{c}{ KMO y prueba de Bartlett } \\
\hline Medida de adecuación muestral de Kaiser-Meyer-Olkin. & 0.719 \\
& Chi-cuadrado & 253.797 \\
Prueba de esfericidad de Bartlett & aproximado & 36 \\
& Gl & 0 \\
\hline
\end{tabular}

Fuente: Elaboración propia en base a los resultados extraídos del SPSS 26.

Para poder analizar la varianza total de las variables desempeño exportador contamos con 3 dimensiones las cuales son satisfacción, finanzas, y estrategias van representadas por factor 1, factor 2 y factor 3 en el orden mencionado. El factor 1 "satisfacción" arrojó una varianza de $37.653 \%$, el factor 2 "finanzas "con $27.899 \%$ y por último estrategias representando al factor 3 con una varianza de $14.658 \%$. 
Tabla 49

Varianza total explicada - Desempeño exportador

\begin{tabular}{|c|c|c|c|c|c|c|c|c|c|}
\hline \multirow{2}{*}{ Factor } & \multicolumn{3}{|c|}{ Autovalores iniciales } & \multicolumn{3}{|c|}{$\begin{array}{l}\text { Sumas de las saturaciones al } \\
\text { cuadrado de la extracción }\end{array}$} & \multicolumn{3}{|c|}{$\begin{array}{l}\text { Suma de las saturaciones al } \\
\text { cuadrado de la rotación }\end{array}$} \\
\hline & Total & $\begin{array}{c}\% \text { de la } \\
\text { varianza }\end{array}$ & $\begin{array}{c}\% \\
\text { acumulado }\end{array}$ & Total & $\begin{array}{c}\% \text { de la } \\
\text { varianza }\end{array}$ & $\begin{array}{c}\% \\
\text { acumulado }\end{array}$ & Total & $\begin{array}{c}\% \text { de la } \\
\text { varianza }\end{array}$ & $\begin{array}{c}\% \\
\text { acumulado }\end{array}$ \\
\hline 1 & 3.389 & 37.653 & 37.653 & 3.389 & 37.653 & 37.653 & 2.557 & 28.411 & 28.411 \\
\hline 2 & 2.511 & 27.899 & 65.552 & 2.511 & 27.899 & 65.552 & 2.543 & 28.251 & 56.661 \\
\hline 3 & 1.319 & 14.658 & 80.210 & 1.319 & 14.658 & 80.210 & 2.119 & 23.548 & 80.210 \\
\hline 4 & 0.494 & 5.486 & 85.695 & & & & & & \\
\hline 5 & 0.417 & 4.632 & 90.327 & & & & & & \\
\hline 6 & 0.351 & 3.900 & 94.227 & & & & & & \\
\hline 7 & 0.235 & 2.607 & 96.833 & & & & & & \\
\hline 8 & 0.178 & 1.973 & 98.807 & & & & & & \\
\hline 9 & 0.107 & 1.193 & 100.000 & & & & & & \\
\hline
\end{tabular}

Fuente: Elaboración propia en base a los resultados extraídos del SPSS 26

En el caso de la Matriz Factorial cruzada para la variable desempeño exportador en donde se enfoca en 3 dimensiones. En la tabla 48, las afirmaciones que abarcan desde el numero 7 al 9 representa a la dimensión satisfacción, el factor 2 con las preguntas agrupadas del 1 al 3 variable "finanzas", por último, las variables "estrategias" está compuesta por las preguntas agrupadas del 4 al 6.

Tabla 50

Matrix Factorial-Desempeño exportador

\begin{tabular}{|c|c|c|c|}
\hline & \multicolumn{3}{|c|}{ Factores } \\
\hline & 1 & 2 & 3 \\
\hline $\begin{array}{l}\text { DEXP7) El desempeño exportador de nuestra firma } \\
\text { ha sido satisfactorio. }\end{array}$ & 0.911 & & \\
\hline $\begin{array}{l}\text { DEXP9) Nuestra empresa de exportación ha } \\
\text { cumplido plenamente nuestras expectativas. }\end{array}$ & 0.904 & & \\
\hline $\begin{array}{l}\text { DEXP8) Nuestra firma de exportación ha sido } \\
\text { exitosa }\end{array}$ & 0.896 & & \\
\hline $\begin{array}{l}\text { DEXP2) Nuestra firma de exportación ha generado } \\
\text { un alto volumen de ventas. }\end{array}$ & & 0.915 & \\
\hline $\begin{array}{l}\text { DEXP3) Nuestra firma de exportación ha logrado } \\
\text { un rápido crecimiento. }\end{array}$ & & 0.884 & \\
\hline $\begin{array}{l}\text { DEXP1) Nuestra firma de exportación ha sido muy } \\
\text { rentable. }\end{array}$ & & 0.883 & \\
\hline
\end{tabular}


DEXP6) Nuestra firma de exportación ha

aumentado significativamente nuestra participación

en el mercado global.

DEXP4) Nuestra firma de exportación ha mejorado $\quad 0.806$

nuestra competitividad global.

DEXP5) Nuestra firma de exportación ha

0.786

fortalecido nuestra posición estratégica.

Fuente: Elaboración propia en base a los resultados extraídos del SPSS 26

\subsubsection{Correlaciones Rho Spearman.}

Obtenido ya las respuestas de las encuestas, se procedió a realizar la tabulación donde se utilizó el software estadístico SPSS por lo cual se agrupo a través de la suma de puntajes ya que según n Hernández, R., Fernández, C., \& Baptista, L. (2014) la escala de Likert se construye en base a un grupo de afirmaciones en donde se califica cada ítem con el fin de obtener puntuaciones y estas mismas se correlacionan a través de la suma de los puntajes para el total de las afirmaciones.

De igual manera, el proceso para poder conseguir la correlación en el SPSS se seleccionó en el botón analizar luego en correlaciones y por último clic en la opción bivariada con el fin de obtener la correlación entre ambas variables donde la gestión de calidad total representa desde las afirmaciones 1 al 30 en donde las preguntas de la 1 a la 6 pertenecen a liderazgo , estrategia abarca de la pregunta 7 a la 12 , además de ellos tenemos a la dimensión personas que abarca de la pregunta 13 a la 18,la dimensión recursos de la pregunta 19 a la 23 y por último la dimensión procesos de la pregunta 24 a la 30 .Por otro lado ,la variable desempeño exportador con 3 dimensiones las cuales inicia con la dimensión finanzas que abarca de la pregunta 1 a 3 ,estrategias de la pregunta 4 a la 6 y por último la dimensión satisfacción que abarca de la pregunta 7 a la 9.

Para concluir se obtuvo los resultados de correlación, es decir el error de Rho Spearman. Seguido a ello, se procede a mostrar en la tabla 49 las relaciones que se llegaron a encontrar ente la gestión de calidad total y el desempeño exportador, enfocados en los cuestionarios 
que fueron respondidos por los gerentes o representantes de las empresas exportadoras MYPE de cacao en grano en el país.

Tabla 51

Correlaciones Rho Spearman para hipótesis general.

\begin{tabular}{|c|c|c|c|c|}
\hline & & & GCT & DEX \\
\hline \multirow{6}{*}{$\begin{array}{c}\text { Rho de } \\
\text { Spearman }\end{array}$} & & Coeficiente de correlación & 1.000 & $.754^{* *}$ \\
\hline & GCT & Sig. (bilateral) & & 0.000 \\
\hline & & $\mathrm{N}$ & 50 & 50 \\
\hline & & Coeficiente de correlación & $.754^{* *}$ & 1.000 \\
\hline & DEX & Sig. (bilateral) & 0.000 & \\
\hline & & $\mathrm{N}$ & 50 & 50 \\
\hline
\end{tabular}

Fuente: Elaboración propia en base a los resultados extraídos del SPSS 26

Tabla 52

Correlaciones Rho Spearman para hipótesis específicas.

\begin{tabular}{|c|c|c|c|c|c|c|c|c|}
\hline & & & Lid & Est & Pers & $\operatorname{Rec}$ & Proc & DEX \\
\hline \multirow{10}{*}{$\begin{array}{c}\text { Rho } \\
\text { Spearman }\end{array}$} & \multirow{3}{*}{ Lid } & $\begin{array}{l}\text { Coeficiente } \\
\text { de } \\
\text { correlación }\end{array}$ & 1.000 & $.368^{* *}$ & $.313^{*}$ & 0.165 & 0.168 & $.530^{* *}$ \\
\hline & & $\begin{array}{l}\text { Sig. } \\
\text { (bilateral) }\end{array}$ & & 0.008 & 0.027 & 0.252 & 0.243 & 0.000 \\
\hline & & $\mathrm{N}$ & 50 & 50 & 50 & 50 & 50 & 50 \\
\hline & \multirow{3}{*}{ Est } & $\begin{array}{l}\text { Coeficiente } \\
\text { de } \\
\text { correlación }\end{array}$ & $.368^{* *}$ & 1.000 & 0.269 & $\begin{array}{c}- \\
0.124\end{array}$ & 0.199 & $.349^{*}$ \\
\hline & & $\begin{array}{l}\text { Sig. } \\
\text { (bilateral) }\end{array}$ & 0.008 & & 0.059 & 0.390 & 0.166 & 0.013 \\
\hline & & $\mathrm{N}$ & 50 & 50 & 50 & 50 & 50 & 50 \\
\hline & \multirow{3}{*}{ Pers } & $\begin{array}{l}\text { Coeficiente } \\
\text { de } \\
\text { correlación }\end{array}$ & $.313^{*}$ & 0.269 & 1.000 & $\begin{array}{c}- \\
0.051\end{array}$ & 0.203 & $.292^{*}$ \\
\hline & & $\begin{array}{l}\text { Sig. } \\
\text { (bilateral) }\end{array}$ & 0.027 & 0.059 & & 0.724 & 0.158 & 0.040 \\
\hline & & $\mathrm{N}$ & 50 & 50 & 50 & 50 & 50 & 50 \\
\hline & Rec & $\begin{array}{l}\text { Coeficiente } \\
\text { de } \\
\text { correlación }\end{array}$ & 0.165 & $0 . \overline{124}$ & -0.051 & 1.000 & 0.197 & $.291^{*}$ \\
\hline
\end{tabular}




\begin{tabular}{|c|c|c|c|c|c|c|c|}
\hline \multirow{2}{*}{\multicolumn{2}{|c|}{$\begin{array}{l}\text { Sig. } \\
\text { (bilateral) } \\
\mathrm{N} \\
\end{array}$}} & 0.252 & 0.390 & 0.724 & & 0.171 & 0.040 \\
\hline & & 50 & 50 & 50 & 50 & 50 & 50 \\
\hline \multirow{3}{*}{ Proc } & $\begin{array}{l}\text { Coeficiente } \\
\text { de } \\
\text { correlación }\end{array}$ & 0.168 & 0.199 & 0.203 & 0.197 & 1.000 & $.541^{* *}$ \\
\hline & $\begin{array}{l}\text { Sig. } \\
\text { (bilateral) }\end{array}$ & 0.243 & 0.166 & 0.158 & 0.171 & & 0.000 \\
\hline & $\mathrm{N}$ & 50 & 50 & 50 & 50 & 50 & 50 \\
\hline \multirow{3}{*}{ DEX } & $\begin{array}{l}\text { Coeficiente } \\
\text { de } \\
\text { correlación }\end{array}$ & $.530^{* *}$ & $.349^{*}$ & $.292^{*}$ & $.291^{*}$ & $.541^{* *}$ & 1.000 \\
\hline & $\begin{array}{l}\text { Sig. } \\
\text { (bilateral) }\end{array}$ & 0.000 & 0.013 & 0.040 & 0.040 & 0.000 & \\
\hline & $\mathrm{N}$ & 50 & 50 & 50 & 50 & 50 & 50 \\
\hline
\end{tabular}

Fuente: Elaboración propia en base a los resultados extraídos del SPSS 26.

La correlación de Rho de Spearman en esta investigación tuvo como finalidad confirmar las hipótesis y a su vez saber si existe o no la relación entre la ca gestión de calidad total y el desempeño exportador .Acorde a los resultados para esta investigación se obtuvo como resultado que si existe una relación entre gestión de calidad total y sus dimensiones liderazgo , estrategia, personas, recursos y procesos y por otro lado está el desempeño exportador de modo que a mayor gestión de calidad total, el desempeño exportador será mayor.

\subsubsection{Contrastación de Hipótesis.}

La contrastación de la hipótesis que se desarrolló en esta investigación se explicara a través de la prueba Rho Spearman donde se confirman los resultados logrados para obtener la información precisa.

\subsubsection{Hipótesis General.}

La gestión de calidad total se relaciona con el desempeño exportador de las empresas MYPE exportadoras de cacao en grano peruanas en el 2020.

\section{a. Hipótesis nula}


$\mathrm{H}_{0}: \rho=0$, (La gestión de calidad total NO se relaciona con el desempeño exportador de las MYPE exportadoras peruanas de cacao en grano en el 2020.

\section{b. Hipótesis alterna}

$\mathrm{H}_{1}: \rho \neq 0$ (La gestión de calidad total SI se relaciona con el desempeño exportador de las MYPE exportadoras peruanas de cacao en grano en el 2020.

\section{c. Nivel de significancia $(\alpha)$}

El nivel de significancia se considera $\alpha=5 \%$.

\section{d. Cálculo de la prueba estadística}

\section{Tabla 53}

Resultado de Rho de Spearman - Hipótesis General

\begin{tabular}{ccc}
\hline Significancia & Coeficiente de correlación & Conclusión \\
\hline 0.000 & 0.754 & $<5 \%$ se rechaza la hipótesis \\
nula
\end{tabular}

Fuente: Elaboración propia en base a los resultados extraídos del SPSS 26.

\section{e. Toma de decisiones}

Con el nivel de significancia de 5\% ( $\mathrm{r}=0.754$; p_valor $=0.000<0.05)$, RH0. Por lo tanto, se rechaza la hipótesis nula y se llega a la conclusión que la gestión de calidad total si se relaciona significativamente de forma positiva con el desempeño exportador de las empresas MYPE exportadoras peruanas de cacao en grano 2020.

\subsubsection{Primera Hipótesis Especifica.}

El liderazgo se relaciona positivamente con el desempeño exportador de las empresas MYPE exportadoras peruanas de cacao en grano 2020.

\section{a. Hipótesis nula}

$\mathrm{H}_{0}: \rho=0$, (Liderazgo NO se relaciona con el desempeño exportador de las MYPE exportadoras peruanas de cacao en grano 2020. 


\section{b. Hipótesis alterna}

$\mathrm{H}_{1}: \rho \neq 0$, (Liderazgo SI se relaciona con el desempeño exportador de las MYPE exportadoras peruanas de cacao en grano 2020).

c. Nivel de significancia $(\alpha)$

El nivel de significancia se considera $\alpha=5 \%$

\section{d. Cálculo de la prueba estadística}

Tabla 54

Resultado de Rho de Spearman - Primera Hipótesis Especifica.

\begin{tabular}{ccc}
\hline Significancia & $\begin{array}{c}\text { Coeficiente de } \\
\text { correlación }\end{array}$ & Conclusión \\
\hline 0.000 & 0.530 & $<5 \%$ se rechaza la hipótesis nula \\
\hline
\end{tabular}

Fuente: Elaboración propia en base a los resultados extraídos del SPSS

\section{e. Toma de decisiones}

Con el nivel de significancia de $5 \%\left(\mathrm{r}=0.530 ; \mathrm{p} \_\right.$valor $\left.=0.000<0.05\right)$ RH0. Por lo tanto, se rechaza la hipótesis nula y se llega a la conclusión que liderazgo si se relaciona de una forma positiva con el desempeño exportador de las MYPE exportadoras peruanas de cacao en grano 2020.

\subsubsection{Segunda Hipótesis Especifica.}

La conformidad de estrategia se relaciona de manera efectiva con el desempeño exportador de las MYPE exportadoras peruanas de cacao en grano 2020.

\section{a. Hipótesis nula}

$\mathrm{H}_{0}: \rho=0$, (Estrategia NO se relaciona con el desempeño exportador de las MYPE exportadoras peruanas de cacao en grano 2020).

\section{b. Hipótesis alterna}


$\mathrm{H}_{1}: \rho \neq 0$, (Estrategia SI se relaciona con el desempeño exportador de las MYPE exportadoras peruanas de cacao en grano 2020).

\section{c. Nivel de significancia}

El nivel de significancia se considera $\alpha=5 \%$.

\section{d. Cálculo de la prueba estadística}

Tabla 55

Resultado de Rho de Spearman - Segunda Hipótesis Especifica.

\begin{tabular}{ccc}
\hline Significancia & $\begin{array}{c}\text { Coeficiente de } \\
\text { correlación }\end{array}$ & Conclusión \\
\hline 0.013 & 0.349 & $<5 \%$ se rechaza la hipótesis nula \\
\hline
\end{tabular}

Fuente: Elaboración propia en base a los resultados extraídos del SPSS 26

e. Toma de decisiones

Con el nivel de significancia de 5\% ( $\mathrm{r}=0.349 ; \mathrm{p} \_$valor $\left.=0.013<0.05\right)$ RH0. Por lo tanto, se rechaza la hipótesis nula y se llega a la conclusión que la estrategia si se relaciona con el desempeño exportador de las MYPE exportadoras peruanas de cacao en grano 2020.

\subsubsection{Tercera Hipótesis Especifica.}

Las personas se relacionan de manera eficiente con el desempeño exportador de las MYPE exportadoras peruanas de cacao en grano 2020.

\section{a. Hipótesis nula}

$\mathrm{H}_{0}: \rho=0$, (Las personas NO se relacionan de manera eficiente con el desempeño exportador de las MYPE exportadoras peruanas de cacao en grano 2020).

\section{b. Hipótesis alterna}

$\mathrm{H}_{1}: \rho \neq 0$, (Las personas SI se relacionan de manera eficiente con el desempeño exportador de las MYPE exportadoras peruanas de cacao en grano 2020). 


\section{c. Nivel de significancia}

El nivel de significancia se considera $\alpha=5 \%$.

\section{d. Cálculo de la prueba estadística}

Tabla 56

Resultado de Rho de Spearman - Tercera Hipótesis Especifica

Coeficiente de

Significancia correlación Conclusión

$0.040<0.292<5 \%$ se rechaza la hipótesis nula

Fuente: Elaboración propia en base a los resultados extraídos del SPSS.

e. Toma de decisiones

Con el nivel de significancia de 5\% $\left(r=0.292 ; \mathrm{p} \_\right.$valor $\left.=0.040<0.05\right)$ RH0. Por lo tanto, se rechaza la hipótesis nula y se llega a la conclusión que las personas si se relacionan de manera eficiente con el desempeño exportador de las MYPE exportadoras peruanas de cacao en grano 2020.

\subsubsection{Cuarta Hipótesis Especifica.}

Los recursos se relacionan positivamente con el desempeño exportador de las MYPE exportadoras peruanas de cacao en grano 2020.

\section{a. Hipótesis nula}

$\mathrm{H}_{0}: \rho=0$, (Los recursos NO se relacionan positivamente con el desempeño exportador de las MYPE exportadoras peruanas de cacao en grano 2020).

\section{b. Hipótesis alterna}

$\mathrm{H}_{1}: \rho \neq 0$, (Los recursos SI se relacionan positivamente con el desempeño exportador de las MYPE exportadoras peruanas de cacao en grano 2020).

\section{c. Nivel de significancia}

El nivel de significancia se considera $\alpha=5 \%$ 


\section{d. Cálculo de la prueba estadística}

Tabla 57

Resultado de Rho de Spearman - Cuarta Hipótesis Especifica.

\begin{tabular}{ccc}
\hline Significancia & Coeficiente de correlación & Conclusión \\
\hline 0.040 & 0.291 & $<5 \%$ se rechaza la hipótesis nula \\
\hline
\end{tabular}

Fuente: Elaboración propia en base a los resultados extraídos del SPSS.

\section{e. Toma de decisiones}

Con el nivel de significancia de $5 \%\left(r=0.291 ; p_{-}\right.$valor $\left.=0.040<0.05\right)$ RH0. Por lo tanto, se rechaza la hipótesis nula y se llega a la conclusión que los recursos si se relacionan positivamente con el desempeño exportador de las MYPE exportadoras peruanas de cacao en grano 2020.

\subsubsection{Quinta Hipótesis Especifica.}

Los procesos se relacionan positivamente con el desempeño exportador de las MYPE exportadoras peruanas de cacao en grano 2020.

\section{a. Hipótesis nula}

$\mathrm{H}_{0}: \rho=0$, (Los procesos NO se relacionan positivamente con el desempeño exportador de las MYPE exportadoras peruanas de cacao en grano 2020).

\section{b. Hipótesis alterna}

$\mathrm{H}_{1}: \rho \neq 0$, (Los procesos SI se relacionan positivamente con el desempeño exportador de las MYPE exportadoras peruanas de cacao en grano 2020).

\section{c. Nivel de significancia}

El nivel de significancia se considera $\alpha=5 \%$

\section{d. Cálculo de la prueba estadística}




\section{Tabla 58}

Resultado de Rho de Spearman - Quinta Hipótesis Especifica.

\begin{tabular}{ccc}
\hline Significancia & Coeficiente de correlación & Conclusión \\
\hline 0.000 & 0.541 & $<5 \%$ se rechaza la hipótesis nula \\
\hline
\end{tabular}

Fuente: Elaboración propia en base a los resultados extraídos del SPSS.

\section{f. Toma de decisiones}

Con el nivel de significancia de $5 \%\left(r=0.541 ; p_{-}\right.$valor $\left.=0.000<0.05\right)$ RH0. Por lo tanto, se rechaza la hipótesis nula y se llega a la conclusión que los recursos si se relacionan positivamente con el desempeño exportador de las MYPE exportadoras peruanas de cacao en grano 2020.

\subsection{Discusión}

Para esta investigación titulada la relación entre la gestión de calidad total y el desempeño exportador de MYPE exportadoras peruanas de cacao en grano 2020 se utilizaron dos cuestionarios dirigidos específicamente a los gerentes o dueños llamados también en nuestra investigación representantes de las empresas MYPE exportadoras peruanas de cacao en grano. Adicional a ello, considerando las variables que se asignaron para el desarrollo de esta investigación se menciona a los investigadores Imran, M., Hamid, S y Aziz, A. (2018) a quienes les pertenece ambos cuestionarios tanto de gestión de calidad total como de desempeño exportador. Por consiguiente, ambos cuestionarios fueron utilizados con el único objetivo de determinar o analizar la relación que hay entre ambas variables para las empresas MYPE exportadoras de cacao en grano 2020. Por último, los resultados obtenidos en baso a los cuestionarios tienen una semejanza con otros resultados obtenidos por otros autores como se muestra a continuación:

\section{Hipótesis General}

Conforme a los resultados mostrados en la hipótesis general que tiene el presente trabajo de investigación con título la relación entre la gestión de calidad total y el desempeño exportador de MYPE exportadoras peruanas de cacao en grano 2020 tiene validación porque 
la gestión de calidad total tiene un coeficiente de correlación de Spearman de $\mathrm{r}=0.754, \mathrm{p}$ $<0.00$, esto quiere decir que la gestión de calidad total si se relaciona de manera positiva con el desempeño exportador de las empresas MYPE exportadoras de cacao en grano 2020 por ello es posible aseverar que la hipótesis si tiene validación.

En cuanto a la relación que hay entre las variables asignadas para la presente investigación, se procede a realizar una comparación con otros investigadores que llegaron a los mismos resultados:

- Según Imran, M., Hamid, S y Aziz, A. (2018) se hallaron resultados alto impacto en donde existe una relación entre la gestión de calidad total y el desempeño exportador indicando que las empresas que cuenten con una implementación de alto nivel de gestión de calidad total tendrán más éxito en el mercado internacional y podrán lograr un mejor rendimiento de exportación.

- Según los investigadores Bruce Barringer,S. Thomas Foster Jr. \& Granger Macy (1999) indican que si existe una relación positive entre la calidad del producto que se exporta con el éxito de la exportación que desea la empresa indicando que los gerentes de operaciones deben priorizar los recursos de su empresa para lograr mejores resultados al ingresar a los mercados extranjeros.

- Según Corredor, Pilar \& Goñi, Salomé (2011) los resultados de su investigación indican que, en ausencia de evidencia para confirmar la hipótesis universal, los pioneros de la gestión de calidad experimentan ganancias de rendimiento, debido a la implementación temprana del sistema; sin embargo, los adoptadores tardíos no experimentan resultados similares.

- Según, Abeykoon, M., \& de Alwis, A. (2016) existe relación entre la gestión de calidad total y el desempeño exportador ya que los resultados del estudio indicaron que todas las dimensiones evaluadas, excepto información y análisis, se correlacionaron significativamente con el desempeño exportador. 
- Según, Gamal Abdualmajed Ali, Haim hilman Abdullah,Abdullahi Hassan Gorondutse (2017) llegan a la conclusión con su investigación de que si existe relación entre la gestión de calidad total y el desempeño exportador .

\section{Primera Hipótesis especifica}

En relaciona a los resultados arrojados en la primera hipótesis especifica de esta investigación liderazgo se relaciona positivamente con el desempeño exportador de las empresas ya que liderazgo tiene un coeficiente de correlación de Spearman de $\mathrm{r}=0.530 ; \mathrm{p}<$ 0.05 esto quiere decir que liderazgo si se relaciona de manera positiva con el desempeño exportador de las empresas MYPE exportadoras de cacao en grano 2020 y por ella la hipótesis planteada es validada.

Con respecto a la relación que hay entre las variables asignadas para la investigación , se inicia a realizar una comparación con otros investigadores que obtuvieron los mismos resultados ,por ejemplo los autores Abeykoon \& de Alwis, 2016; Lages et al., 2009; Masakure et al.(2009) indicaron que la gestión de calidad con sus dimensiones entre ellas liderazgo, se encuentran ligadas directamente en las operaciones comerciales se interrelacionan con todos los componentes de gestión de calidad total y estos elementos deber ser considerados a si vez para la toma de decisiones. Adicionalmente, Abeykoon, M., \& de Alwis, A. (2016) realizaron un estudio en donde tuvieron por resultado que la dimensión liderazgo si se relaciona de manera positiva con el desempeño exportador, sin embargo, no es la más importante ya que el autor considera que el enfoque en el cliente, la mejora continua y la gestión de proveedores impactan más en el desempeño exportador.

\section{Segunda Hipótesis Especifica}

Conforme a los resultados mostrados en la segunda hipótesis especifica que tiene este trabajo de investigación la conformidad de estrategia se relaciona de manera efectiva con el desempeño exportador de las MYPE exportadoras peruanas de cacao en grano 2020 tiene validación ya que la estrategia tiene un coeficiente de correlación de Spearman de $\mathrm{r}=0.349$ $2, \mathrm{p}<0.05$, esto quiere decir que estrategia si se relaciona de manera positiva con el desempeño exportador y es por ello que podemos indicar que la hipótesis si tiene validación. 
En cuanto a la relación que hay entre las variables asignadas se procede a realizar una comparación con otros investigadores que llegaron a resultados similares como, por ejemplo Marina Godinho Antunes, Joaquín Texeira Quirós, Maria do Rosário Fernandes Justino (2017) indica que las empresas que optan por estrategias de innocacion de procesos logran mejoras en su desempeño además de que con el estudio realizado se encontró que solo las empresas que adoptan estrategias de innovación de sus procesos promueven la adopción de prácticas de gestión de calidad total. Asimismo, los investigadores Bruce Barringer,S. Thomas Foster Jr. \& Granger Macy (1999) tuvieron como resultado de su estudio que las estrategias de mercado de la fijación de precios, promoción y distribución tienen una relación positiva entre la calidad del producto de exportación y el rendimiento de la exportación. Este resultado es convincente y los gerentes de producto tienen el desafío de desarrollar estrategias para competir en mercados de exportación desconocidos ya que el desarrollo de productos de alta calidad es un antecedente importante para el éxito de las exportaciones.

\section{Tercera Hipótesis Especifica}

De acuerdo, con los resultados mostrados en la tercera hipótesis especifica que tiene esta investigación las personas se relacionan de manera positiva con el desempeño exportador de las MYPE exportadoras peruanas de cacao en grano 2020 ya que tiene un coeficiente de correlación de Spearman de $\mathrm{r}=0.292$ p $<0.05$, lo cual indica que las personas si se relacionan positivamente con el desempeño exportador logrando que indiquemos que la hipótesis es válida.

Con relación a las variables asignadas se procede a realizar una comparación con otros investigadores los cuales no llegaron a obtener resultados similares como en el caso de Jabeen, R. y Mahmood, R. (2014) que sugieren que los representantes deberían ser más proactivos en la implementación de la gestión de calidad total para preparar a sus empresas para enfrentar los desafíos del futuro. Indican también que deben estar actualizados y equipados con conocimientos, habilidades y habilidades actuales que podrían beneficiar su negocio. Los resultados también indicaron que es muy importante para las PYME 
implementar estrategias como la gestión de calidad y dar a conocer como estos actuarían como un sistema de apoyo para responder al entorno competitivo además de conducir con el tiempo por un camino con un mayor rendimiento. Esto se puede hacer ofreciendo productos de calidad o nuevos productos mejorados en el mercado utilizando los recursos disponibles en el mercado. Es importante indicar que, en este caso, los resultados están basados en una muestra limitada específicamente en Rawalpindi y la región de Islamabad, por lo que no representa a todo el sector de las PYME en Pakistán

\section{Cuarta Hipótesis Especifica}

Los resultados mostrados en la cuarta hipótesis especifican de la presente investigación indican que los recursos se relacionan positivamente con el desempeño exportador de las MYPE exportadoras peruanas de cacao en grano 2020 ya que cuentan con un coeficiente de correlación de Spearman de r =0.291, p < 0.05 lo cual indica que los recursos si se relacionan positivamente con el desempeño exportador y la hipótesis mencionada logre ser válida.

Con relación a las variables asignadas se comparó con otros investigadores hallando como resultado que Sui \& Baum (2014) llegaron a obtener similar resultado a la presente investigación indicando que varios estudios informaron que los recursos de la empresa podrían utilizarse para mejorar el desempeño de las MYPES exportadoras. Asimismo, Imran y col. $(2016,2017)$ enfatizaron que el desempeño exportador de las Pymes depende también de los recursos estratégicos firmes. Por otro lado, algunos de los investigadores encontraron un resultado positivo vínculo entre la gestión de calidad total y el desempeño de las exportaciones de la empresa y sugirieron además que la gestión de calidad total podría ser un recurso influenciado para el desempeño de las exportaciones de las MY`PE según Abeykoon \& de Alwis, (2016); Lages et al., 2009; Masakure et al (2009).

\section{Quinta Hipótesis especifica}

Los resultados mostrados en la cuarta hipótesis especifican de la presente investigación indican que los recursos se relacionan positivamente con el desempeño exportador de las MYPE exportadoras peruanas de cacao en grano 2020 ya que cuentan con un coeficiente de correlación de Spearman de $\mathrm{r}=0.541, \mathrm{p}<0.000$ lo cual indica que los procesos si se 
relacionan positivamente con el desempeño exportador y la hipótesis mencionada logre ser válida.

Con relación a las variables asignadas se comparó con otros investigadores hallando como resultado que Marina Godinho Antunes, Joaquín Texeira Quirós, Maria do Rosário Fernandes Justino (2017) opinan que si existe relación entre los procesos y el desempeño exportador .Además de ello ,los investigadores Muhammad Imran, Azelin binti Aziz, Siti Norasyikin binti Abdul Hamid, Muhammad Salman Shabbir, Rabia Salman, Zhaoquan Jian (2018) encontraron un resultado positivo vínculo entre los procesos y el desempeño exportador ya que permite tomar mejores decisiones a desarrollar al implementar una gestión de calidad total.

\subsection{Conclusiones}

Respecto a los resultados que se lograron obtener para esta investigación en base a los cuestionarios de la gestión de calidad total y desempeño exportador, se llegó a concluir lo siguiente:

1. Para la presente investigación enfocada en las empresas peruanas MYPE exportadoras de cacao en grano se obtuvo como resultados que la gestión de calidad total de las empresas exportadoras es de mucha importancia para poder obtener un desempeño exportador favorable .Por consiguiente podemos afirmar que la gestión de calidad total si se relaciona de manera positiva y también significativa con el desempeño exportador, pudiendo confirmar que en cuanto mayor nivel de gestión de calidad total la empresa podrá lograr tener mucho más éxito en el mercado internacional además de un mejor rendimiento de exportación. Con respecto a los cuestionarios que se efectuaron y los resultados obtenidos mediante los estadígrafos (Shapiro-Wilk, Kaiser-MeyerOlkin (KMO) y Rho Spearman) se pudieron llegar a reafirmar si existe relación entre la gestión de calidad y el desempeño exportador para las MYPES peruanas exportadoras de cacao en grano teniendo como resultado que la hipótesis planteada es comprobada. 
2. Para la presente investigación enfocada en las empresas peruanas MYPE exportadoras de cacao en grano se obtuvo como resultados que el liderazgo de las empresas exportadoras es esencial para poder lograr tener un desempeño exportador favorable .Por ende, en esta investigación podemos afirmar que liderazgo si se relaciona de manera positiva y significativa con el desempeño exportador ,permitiendo confirmar que a mayor liderazgo tenga una empresa exportadora mejor desempeño exportador tendrá .Respecto a los cuestionarios , logramos obtener resultados mediante estadígrafos (Shapiro-Wilk, Kaiser-MeyerOlkin (KMO) y Rho Spearman),llegando así a constatar nuevamente que si existe relación entre el liderazgo y el desempeño exportador de las empresas MYPE exportadoras peruanas y de modo que la hipótesis planteada es comprobada.

3. Para la presente investigación enfocada en las empresas peruanas MYPE exportadoras de cacao en grano se obtuvo como resultados que las estrategias de las empresas exportadoras son de mucha importancia para poder obtener un desempeño exportador favorable. Por consiguiente, podemos afirmar que estrategia si se relaciona de manera positiva y significativa con desempeño exportador, ello permite confirmar que a cuanto sea mejor las estrategias planteadas por las empresas, aumentara el desempeño exportador de las empresas peruanas MYPE exportadoras de cacao en grano. Con respecto a los cuestionarios que se ejecutaron y los resultados que se obtuvieron mediante estadígrafos (Shapiro-Wilk, KaiserMeyerOlkin (KMO) y Rho Spearman), llegando así a reconfirmar que si existe relación entre las estrategias y el desempeño exportador de las empresas peruanas MYPE exportadoras de cacao en grano de modo que la hipótesis planteada es comprobada.

4. Para la presente investigación enfocada en las empresas peruanas MYPE exportadoras de cacao en grano se obtuvo como resultados que las personas de las empresas exportadoras son de mucha importancia para poder obtener un desempeño exportador favorable. Por consiguiente, podemos afirmar que las personas de la empresa si se relacionan de manera positiva y significativa con desempeño 
exportador, ello permite confirmar que a cuanto mejor estén actualizados y equipados con conocimientos y habilidades este su personal, lograra incrementar su desempeño exportador de las empresas peruanas MYPE exportadoras de cacao en grano. Con respecto a los cuestionarios que se ejecutaron y los resultados que se obtuvieron mediante estadígrafos (Shapiro-Wilk, Kaiser-MeyerOlkin (KMO) y Rho Spearman), se llagó a reconfirmar que si existe relación entre las personas y el desempeño exportador de las empresas peruanas MYPE exportadoras de cacao en grano de modo que la hipótesis planteada es comprobada.

5. Para la presente investigación enfocada en las empresas peruanas MYPE exportadoras de cacao en grano se obtuvo como resultados que los recursos de las empresas exportadoras son de mucha importancia para poder obtener un desempeño exportador favorable. Por consiguiente, podemos afirmar que los recursos de la empresa si se relacionan de manera positiva y significativa con desempeño exportador, ello permite confirmar que a mayor recurso tenga la empresa ésta logra incrementar su desempeño exportador de las empresas peruanas MYPE exportadoras de cacao en grano. Con respecto a los cuestionarios que se ejecutaron y los resultados que se obtuvieron mediante estadígrafos (Shapiro-Wilk, KaiserMeyerOlkin (KMO) y Rho Spearman), se llagó a reconfirmar que si existe relación entre los recursos y el desempeño exportador de las empresas peruanas MYPE exportadoras de cacao en grano de modo que la hipótesis planteada es comprobada.

6. Para la presente investigación enfocada en las empresas peruanas MYPE exportadoras de cacao en grano se obtuvo como resultados que los procesos de las empresas exportadoras son de mucha importancia para poder obtener un desempeño exportador favorable. Por consiguiente, es posible afirmar que los procesos de las empresas exportadoras MYPES de cacao en grano son esenciales para poder lograr un desempeño exportador favorable al ser estos los responsables de una buena implementación de prácticas de gestión de calidad total permitiendo controlar el desempeño de la organización en general incrementando la posición competitiva de la empresa. Con respecto a los cuestionarios que se ejecutaron y los resultados que 
se obtuvieron mediante estadígrafos (Shapiro-Wilk, Kaiser-MeyerOlkin (KMO) y Rho Spearman), se llagó a reconfirmar que si existe relación entre los procesos y el desempeño exportador de las empresas peruanas MYPE exportadoras de cacao en grano de modo que la hipótesis planteada es comprobada.

\subsection{Recomendaciones}

Los gerentes o dueños denominados en nuestra investigación como representantes de las empresas exportadoras peruanas MYPE de cacao en grano podrán considerar las siguientes recomendaciones acorde a su conveniencia en relación a la gestión de calidad total y el desempeño exportador:

1. Para que los representantes de las empresas exportadoras peruanas MYPE de cacao en grano en relación con la gestión de calidad total tengan un alto grado y significativo aumento en su desempeño exportador se les recomienda implementar sus procesos, su personal, sus estrategias y su liderazgo en la toma de decisiones como empresa ya que al implementar este proceso van a mejorar el desempeño de exportación al tener vínculo directo. El personal de la empresa debería actualizarse y equiparse con los conocimientos, habilidades y capacidades actuales que podrían beneficiar a su compañía. Además de ello, con el fin de poder ser líder se debe proyectar como empresa una imagen honesta hacia sus colaboradores y hacia su mercado objetivo para motivarlos. Realizar estrategias corporativas de estabilidad con el fin de que las empresas se encuentren en etapa de madurez por mayor tiempo, realizar estrategias corporativas de crecimiento para lograr cooperación, diversificación e integración. Utilizar sus recursos financieros propios, así como portaciones de socios para poder desarrollar sus actividades de forma óptima, igual forma se recomienda usar sus bienes tangibles como instalaciones o equipas para brindar un mejor producto a su mercado objetivo. 
2. Principalmente a los dueños de las empresas, brindar voz y voto a los encargados del área logística y comercial para poder tomar decisiones ya sea de procesos, compra de materia prima o venta del producto en el que trabajan. Con esta acción se les brindará la opción de tomar decisiones sobre sus labores diarias identificándose el empleado con la empresa y a la vez logra motivarlos para poder tener un mejor desempeño. Lo que se busca con liderazgo es que la empresa sea líder en el mercado brindando una buena imagen tanto para los colaboradores como los clientes.

3. En cuanto a las estrategias, realizar evaluaciones de desempeño de los competidores directos para saber a qué se enfrentan como empresa en el amplio mercado que tienen. De igual manera una medición automatizada de las perdidas cada cierto periodo es recomendable para tener conocimiento de la situación financiera en la que se encuentran actualmente. Adicionalmente, desarrollar un adecuado desempeño organizacional es crucial para estar al tanto de si el personal tiene conocimiento de las metas y objetivos que tiene la empresa en la que laboran pudiendo así dar un beneficio mediante su trabajo, para este caso se utilizará herramientas como evaluaciones de disposición, necesidades, puntos fuertes y débiles al igual que escenarios que describan situaciones futuras. Tomar en cuenta la opinión de los clientes es signo de una estrategia inteligente para la empresa ya que se puede conocer mediante estudios lo que el mercado objetivo desea y gracias a eso se puede iniciar la creación de nuevos productos.

4. Los colaboradores son parte esencial en una gestión de calidad total porque a través de ellos se puede lograr vincular todas las áreas operaciones de la empresa involucradas en una mejora de un producto para ser ofrecido, es por este motivo que deben enfatizar mucho interés en ellos. Brindarles capacitaciones virtuales o presenciales de manera constantes sobre temas relacionados a su área de trabajo y desarrollo personal los motivará a cumplir sus funciones con un mejor desempeño, que puedan dar su opinión en todo 
momento sobre sus funciones hará que estén motivados al sentirse parte de la compañía. No olvidar que también es importante recaudar la mayor información de ellos al igual que realizarle encuestas de actitud eventualmente con el fin de lograr un conocimiento de hacía que camino se está yendo y poder plantear una estrategia a futuro como organización.

5. Se les recomienda desarrollar asociaciones a largo plazo con otra empresa que les brinde algún insumo importante para su core business, por otro lado, es recomendable también tener acuerdos de compra con los proveedores con el fin de siempre tener un precio fijo del insumo que se requerirá para así no afectar la calidad sobre el costo de lo requerido. Adicional a ello, es importante que se evalúe la manera de producir sin afectar el medio ambiente minimizando el uso de plástico o bolsas.

6. En cuanto a procesos, se recomienda establecer implementar un control estadístico de procesos ya que esta herramienta tiene como objetivo hacer predecible un proceso en el tiempo que ayudara a tomar decisiones y facilitar el proceso de mejora constante en la empresa mediante graficas de control para lograr distinguir las causas especiales de las causas comunes de variación. Además de ello, es recomendable la medición de procesos planteando objetivos y un plan correctamente definidos ajustándose a las acciones que su organización necesita. Mediante un sistema de administración o ERP que contenga un módulo de producción podrá facilitar a el control de procesos de su empresa generando reportes en tiempo real y atomizando las tareas administrativas. Con la ayuda del ISO 10002 la alta dirección de cada organización debe evaluar la necesidad de recursos y proporcionarlos para así lograr asegurar una operación eficaz y eficiente del proceso de tratamiento de las quejas incluyendo recursos como personal, hardware y software informáticos y financieros. 


\section{Referencias Bibliográficas}

Abeykoon, M., \& amp:amp, de Alwis,A.(2016).The impact of Total Quality Management Practices on Export Performance of Apparel Exporters of Sri.Lanka.Kelaniya Journal of Human Resources Management ,10(1).

Abeykoon, M., \& de Alwis, A. (2016). The Impact of Total Quality Management Practices on Export Performance of Apparel Exporters of Sri Lanka. Kelaniya Journal of Human Resource Management, 10(1)

Amit, R., y Schoemaker, P. (1993). Strategic Assets and Organizational Rent. Strategic management journal, 14, 33-46

Autio, E., Sapienza, H., y Almeida, J. (2000). Effects of age at entry, knowledge intensity and imitability on international growth. Academy of Management Journal, 909-924.

Bruce Barringer, S. Thomas Foster Jr. \&amp; Granger Macy (1999) The Role of Quality in Determining Export Success, Quality Management Journal, 6:4, 55-70

Christina Sichtmann, Maren von Selasinsky, Adamantios Diamantopoulos (2011)."Service Quality and Export Performance of Business-to-Business Service Providers: The Role of Service Employee- and Customer-Oriented Quality Control Initiatives"

Concepto de calidad total y su evolución. Recuperado de http://www.cyta.com.ar/biblioteca/bddoc/bdlibros/tqm/1 conceptos/1 conceptos.ht $\underline{\mathrm{m}}$

Contenido de cadmio en el cacao: Preocupación mundial. Recuperdo de http://www.naturalezainterior.org.pe/index.php/mundo-forestal/item/527-contenidode-cadmio-en-el-cacao-preocupacion-mundial

Corredor, Pilar \&amp; Goñi, Salomé, 2011. \&quot;TQM and performance: Is the relationship so obvious?,\&quot; Journal of Business Research, Elsevier, vol. 64(8), pages $830-838$. 
Haahti, A., Madupu, V., Yavas, U., y Babakus, E. (2005). Cooperative Strategy, Knowledge Intensity and Export Performance of Small and Medium Sized Enterprises. Journal of World Business, 40, 124-138.

Hablemos del cadmio en el cacao andino. Recuperado de https://blog.ciat.cgiar.org/es/hablemos-del-cadmio-en-el-cacaoandino/\#: :text=A\%20pesar\%20de\%20ser\%20productor,de\%20cacao\%20y\%20que \%20tiene

Hillman, A., Whithers, M., y Collins, B. (2009). Resource Dependence Theory: A Review. Journal of Management, 1404-1427.

Implementación del programa Seis Sigma para desarrollo sostenible en consumo de químicos en procesos litográficos. Recuperado de file:///C:/Users/JOHA/Downloads/DialnetImplementacionDelProgramaSeisSigmaParaDesarrolloSo-5012127.pdf

Imran, M., binti Abdul Hamid, S. N., \&amp; binti Aziz, A. (2017). Total quality management, export market orientation and firm export performance: A Conceptual Framework. International Journal of Academic Research in Business and Social Sciences, 7(9), 591-601.

Imran, M., Hamid, S \& Aziz, A. (2018). The influence of TQM on export performance of SMEs: Empirical evidence from manufacturing sector in Pakistan using PLSSEM.Management Science Letters , 8(5), 483-496.

Jabeen, R., \& Mahmood, R. (2014). The Effects of Total Quality Management and Market Orientation on Business Performance of Small and Medium Enterprises in Pakistan. Journal of Economics, Management and Trade, 5(4), 408-418.

Kanji, G. K. (1990). Total quality management: the second industrial revolution. Total quality management, 1(1), 3-12.

Leonidou, L., y Theodosiou, M. (2004). The export marketing information system: an integration of the extant knowledge. Journal of World Business, 39(1), 12-36. 
Marina Godinho Antunes, Joaquín Texeira Quirós, Maria do Rosário Fernandes Justino (2017). "The relationship between innovation and total quality management and the innovation effects on organizational performance"

Memoria de reunión. "Presencia de cadmio en cacao". Recuperado de https://redcacaoychocolateperu.blogspot.pe/2015_11_01_archive.html

Minagri. (2019). Sector Agrario. Recuperado de http://minagri.gob.pe/portal/datero/58sector-agrario/sector-agrario

Muhammad Imran, Siti Norasyikin, Azelin binti Aziz,(2018) .The mediating role of total quality management between entrepreneurial orientation and SMEs export performance.

Perú ingresa al top 10 de exportadores de cacao en grano. Recuperado de https://www.diariodelexportador.com/2017/03/peru-ingresa-al-top-10-deexportadores.html

Pfeffer, J., y Salancik, G. (1978). The External Control of Organizations: A resource dependence perspective. New York: Harper \& Row.

Porter, M. (1981). The Contributions of Industrial Organization to Strategic Management. The Academy of Management Review, 6(4), 609-620.

Prévot, F., Brulhart, F., y Gilles, G. (2010). Perspectives fondées sur les ressources. Revue française de gestion(204), 87-103.

Rankin (2018), Hablemos del cadmio en el cacao andino. Recuperado de https://blog.ciat.cgiar.org/es/hablemos-del-cadmio-en-el-cacaoandino/\#: :text=Los\%20niveles\%20de\%20cadmio\%20en,y\%201as\%20capacidades \%20de\%20asimilaci\%C3\%B3n 
RONCALLI SILVA MARANHÃO (2011) la calidad total en organizaciones y entornos complejos: análisis en una aerolínea de bandera. Universidad Autónoma de Madrid, España.

Rosales, S. (25 de marzo de 2019). Cacao peruano: crecimiento de exportaciones caería de $18 \%$ a $6 \%$ por restricciones de la UE. Gestión.

Siicex. (2019). Ficha comercial del cacao. Recuperado en http://www.siicex.gob.pe/siicex/portal5ES.asp?_page_=160.00000

The effect of information, communication and technology (ICT) and quality management to export performance of Malaysian's SME in manufacturing sector.Journal of scientific research and development 2(14):146-157,2015.

Trade Map (2019), Principales paises exportadores de cacao. Recuperado de https://www.trademap.org/Index.aspx

Unión Europea pone en jaque al cacao peruano por la presencia del cadmio. Recuperado de https://gestion.pe/economia/union-europea-pone-jaque-cacao-peruano-presenciacadmio-240787-noticia/

Zou, S., y Stan, S. (1998). The Determinants of Export Performance: A Review of the Empirical Literature between 1987 and 1997. International Marketing Review, 15(5), $333-356$ 
Anexos

Anexo 1. Matriz de consistencia

\begin{tabular}{|c|c|c|c|c|}
\hline Problema & Objetivo & Hipótesis & Variables & Metodología \\
\hline $\begin{array}{l}\text { Problema general } \\
\text { ¿Cuál es la relación entre la } \\
\text { gestión de calidad total y el } \\
\text { desempeño exportador de } \\
\text { empresas MYPE } \\
\text { exportadoras peruanas de } \\
\text { cacao en grano 2020? } \\
\text { Problemas específicos } \\
\text { ¿Existe relación entre el } \\
\text { liderazgo y el desempeño } \\
\text { exportador? } \\
\text { ¿Existe relación entre la } \\
\text { estrategia y el desempeño } \\
\text { exportador? } \\
\text { ¿Existe relación entre las } \\
\text { personas y el desempeño } \\
\text { exportador? }\end{array}$ & $\begin{array}{l}\text { Objetivo general } \\
\text { Determinar la relación } \\
\text { que existe entre la gestión } \\
\text { de calidad total y el } \\
\text { desempeño exportador de } \\
\text { empresas MYPE } \\
\text { exportadoras peruanas de } \\
\text { cacao en grano. } \\
\text { Objetivos específicos } \\
\text { Determinar la relación } \\
\text { que existe entre el } \\
\text { liderazgo y el desempeño } \\
\text { exportador. } \\
\text { Analizar la relación que } \\
\text { existe entre la estrategia y } \\
\text { el desempeño exportador. }\end{array}$ & $\begin{array}{l}\text { Hipótesis general } \\
\text { La gestión de calidad total } \\
\text { tiene relación positiva con } \\
\text { el desempeño exportador } \\
\text { de las empresas MYPE } \\
\text { exportadoras peruanas de } \\
\text { cacao en grano. } \\
\text { Hipótesis especificas } \\
\text { El liderazgo se relaciona } \\
\text { positivamente con el } \\
\text { desempeño exportador. } \\
\text { La conformidad de } \\
\text { estrategia se relaciona de } \\
\text { manera efectiva con el } \\
\text { desempeño exportador. }\end{array}$ & $\begin{array}{l}\text { X: Gestión de } \\
\text { calidad total } \\
\text { X1: Liderazgo } \\
\text { X2: Estrategia } \\
\text { X3: Personas } \\
\text { X4: Recursos } \\
\text { X5: Procesos } \\
\text { Y: Desempeño } \\
\text { Exportador } \\
\text { Y1: Finanzas } \\
\text { Y2: Estrategias }\end{array}$ & $\begin{array}{l}\text { Método de investigación } \\
\text { El método es de enfoque } \\
\text { cuantitativo. } \\
\text { Tipo de investigación } \\
\text { Esta investigación es de } \\
\text { tipo correlacional. } \\
\text { Diseño de investigación } \\
\text { El diseño de esta } \\
\text { investigación es no } \\
\text { experimental transversal. } \\
\text { Muestra } \\
\text { Son } 50 \text { empresas MYPES } \\
\text { exportadoras de cacao en } \\
\text { grano. }\end{array}$ \\
\hline
\end{tabular}




\begin{tabular}{|c|c|c|c|c|}
\hline $\begin{array}{l}\text { ¿Existe relación entre los } \\
\text { recursos en el desempeño } \\
\text { exportador? } \\
\text { ¿Existe relación entre los } \\
\text { procesos y el desempeño } \\
\text { exportador? }\end{array}$ & $\begin{array}{l}\text { Analizar cómo se } \\
\text { relacionan las personas en } \\
\text { el desempeño exportador. } \\
\text { Determinar la relación } \\
\text { que existe entre los } \\
\text { recursos y el desempeño } \\
\text { exportador. } \\
\text { Determinar la relación } \\
\text { que existe entre procesos } \\
\text { y el desempeño } \\
\text { exportador. }\end{array}$ & $\begin{array}{l}\text { Las personas se relacionan } \\
\text { de manera eficiente con el } \\
\text { desempeño exportador. } \\
\text { Los recursos se relacionan } \\
\text { positivamente con el } \\
\text { desempeño exportador. } \\
\text { Los procesos se relacionan } \\
\text { de manera positiva con el } \\
\text { desempeño exportador. }\end{array}$ & Y3: Satisfacción & $\begin{array}{l}\text { Instrumento } \\
\text { investigación } \\
\text { El cuestionario cuenta con } \\
39 \text { ítems, los cuales fueron } \\
\text { propuestos por los } \\
\text { investigadores Imran, } \\
\text { Hamid y Aziz (2018) }\end{array}$ \\
\hline
\end{tabular}

Elaboración Propia 


\section{Anexo 2. Cuestionario de Gestión de calidad total y desempeño exportador}

El diseño del cuestionario se elaboró en base a las preguntas propuestas por los investigadores Imran, M., Hamid, S y Aziz, A. (2018), los cuales aplicaron las variables mencionadas para lograr el cuestionario final. La finalidad de este es determinar la relación entre la gestión de calidad total de las MYPES peruanas exportadoras de cacao con su desempeño exportador. Agradeceremos su gentil apoyo con el desarrollo de la presente encuesta, marcar con "X" la mejor opción que refleje el estado de su empresa. Tener presente la asignación correspondiente: 1 es totalmente en desacuerdo, 2 es parcialmente en desacuerdo, 3 es indiferente, 4 es parcialmente de acuerdo y 5 es totalmente de acuerdo.

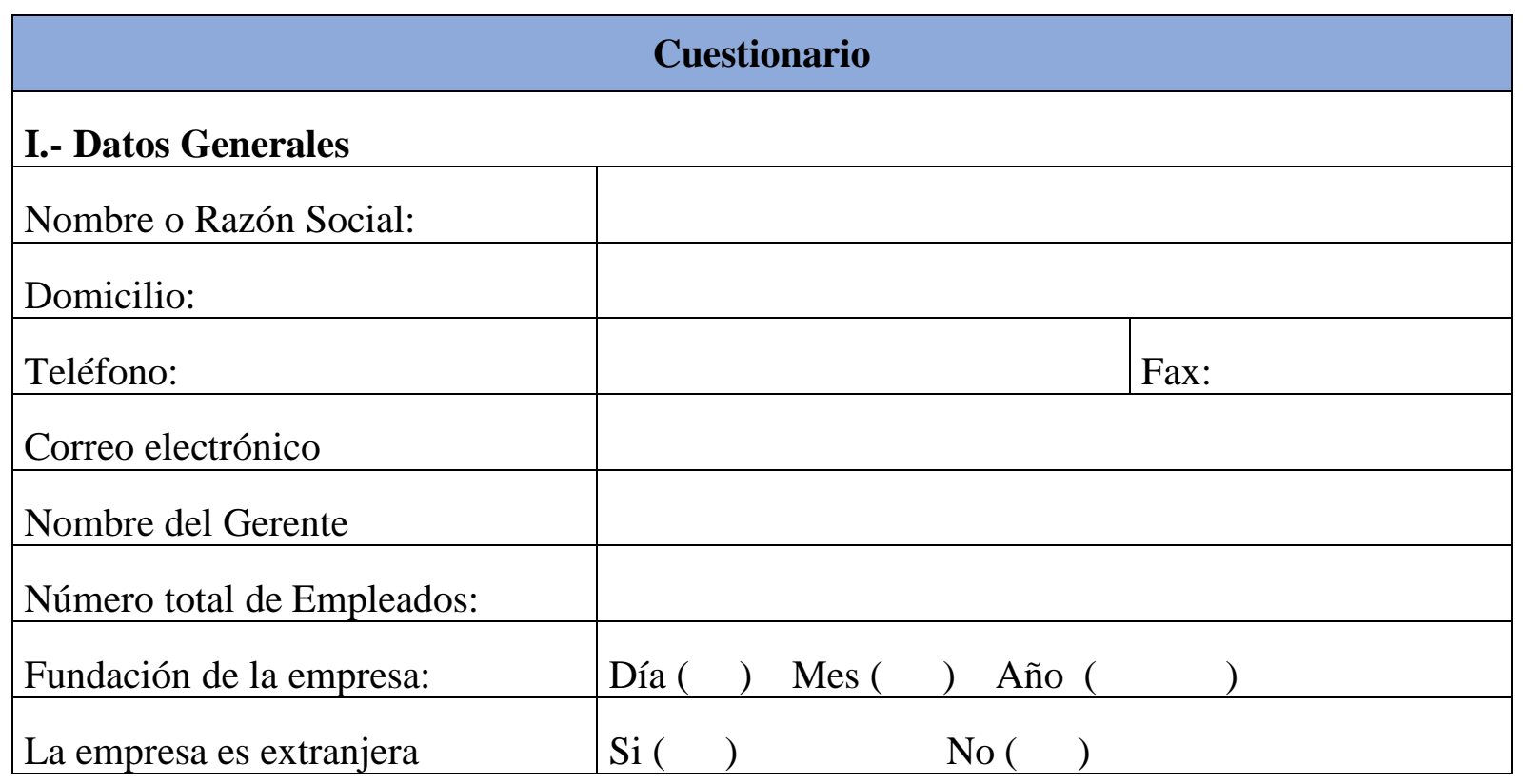

\begin{tabular}{|l|c|c|c|c|c|}
\hline \multirow{2}{*}{ Dimensiones /Preguntas } & \multicolumn{5}{|c|}{ Puntuación } \\
\cline { 2 - 6 } & $\mathbf{1}$ & $\mathbf{2}$ & $\mathbf{3}$ & $\mathbf{4}$ & $\mathbf{5}$ \\
\cline { 2 - 6 } & $\begin{array}{c}\text { Muy en } \\
\text { desacuerdo }\end{array}$ & $\begin{array}{c}\text { En } \\
\text { desacuerdo }\end{array}$ & $\begin{array}{c}\text { Ni de } \\
\text { acuerdo ni } \\
\text { en } \\
\text { desacuerdo }\end{array}$ & De acuerdo & $\begin{array}{c}\text { Muy de } \\
\text { acuerdo }\end{array}$ \\
\hline $\begin{array}{l}\text { I) GESTION DE CALIDAD TOTAL } \\
\begin{array}{l}\text { 1) Los gerentes de nuestra } \\
\text { empresa consideran que el } \\
\text { costo es más importante en } \\
\text { comparación con la calidad } \\
\text { de los productos. }\end{array}\end{array}$ & & & & \\
\hline
\end{tabular}




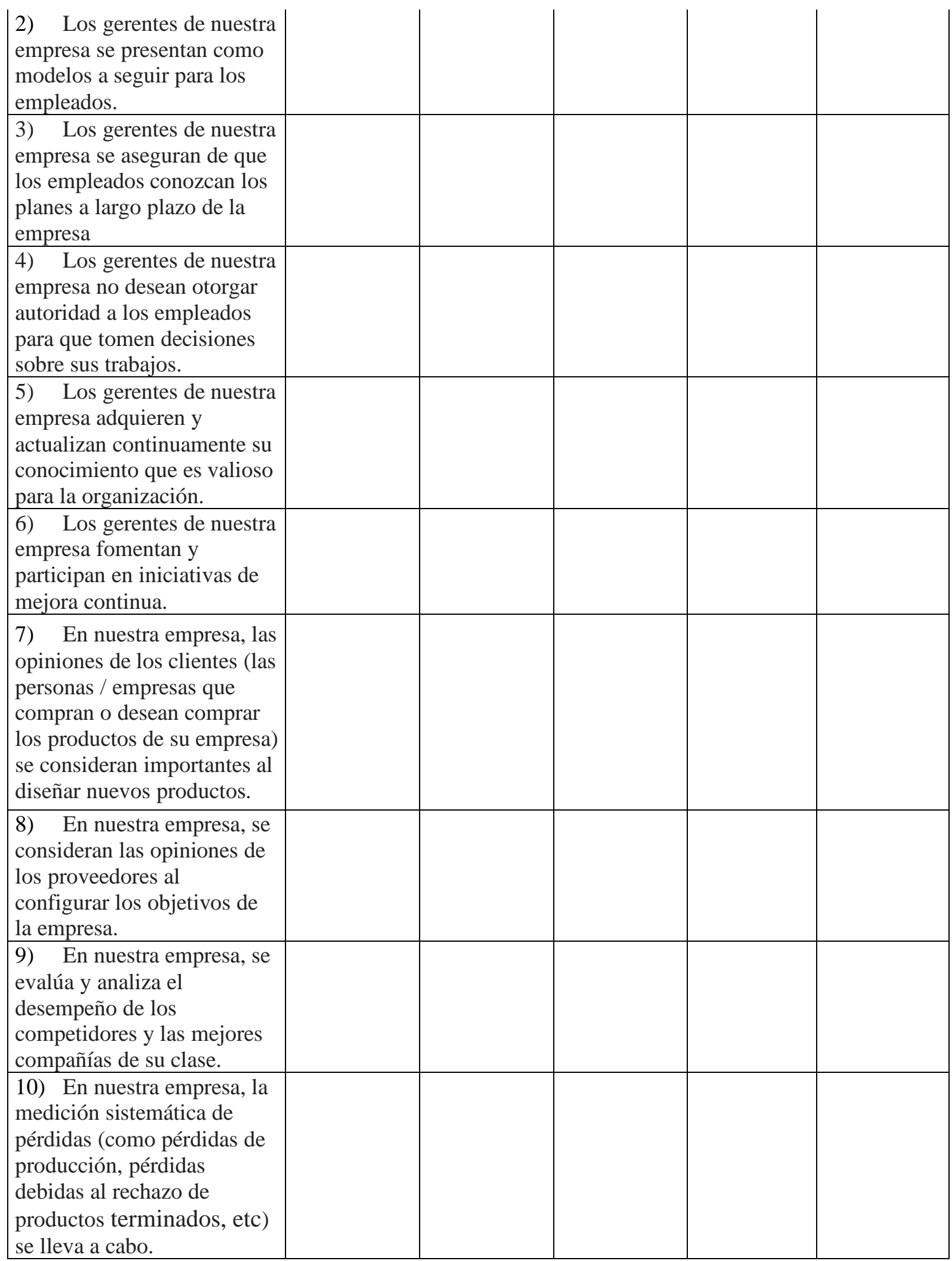




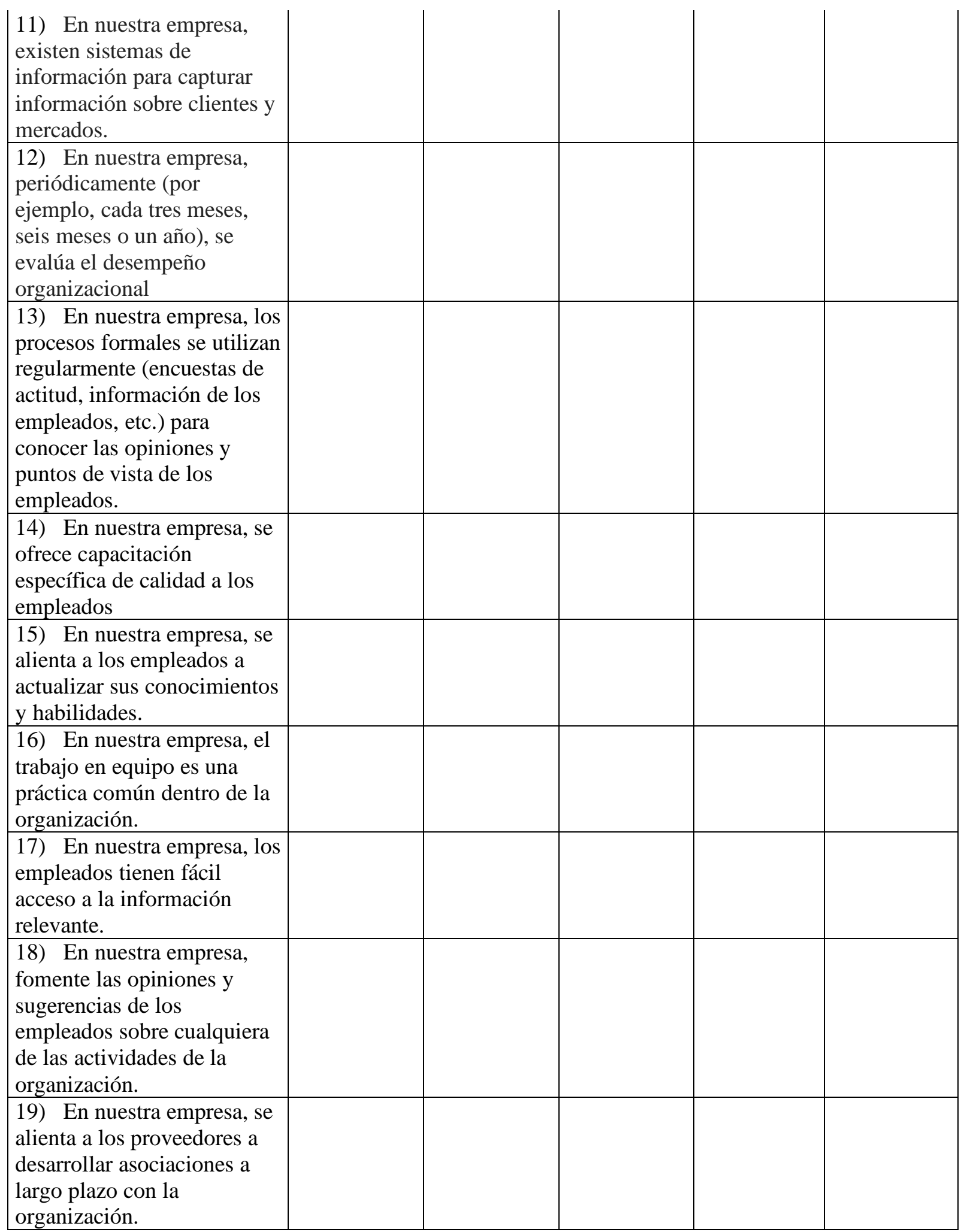




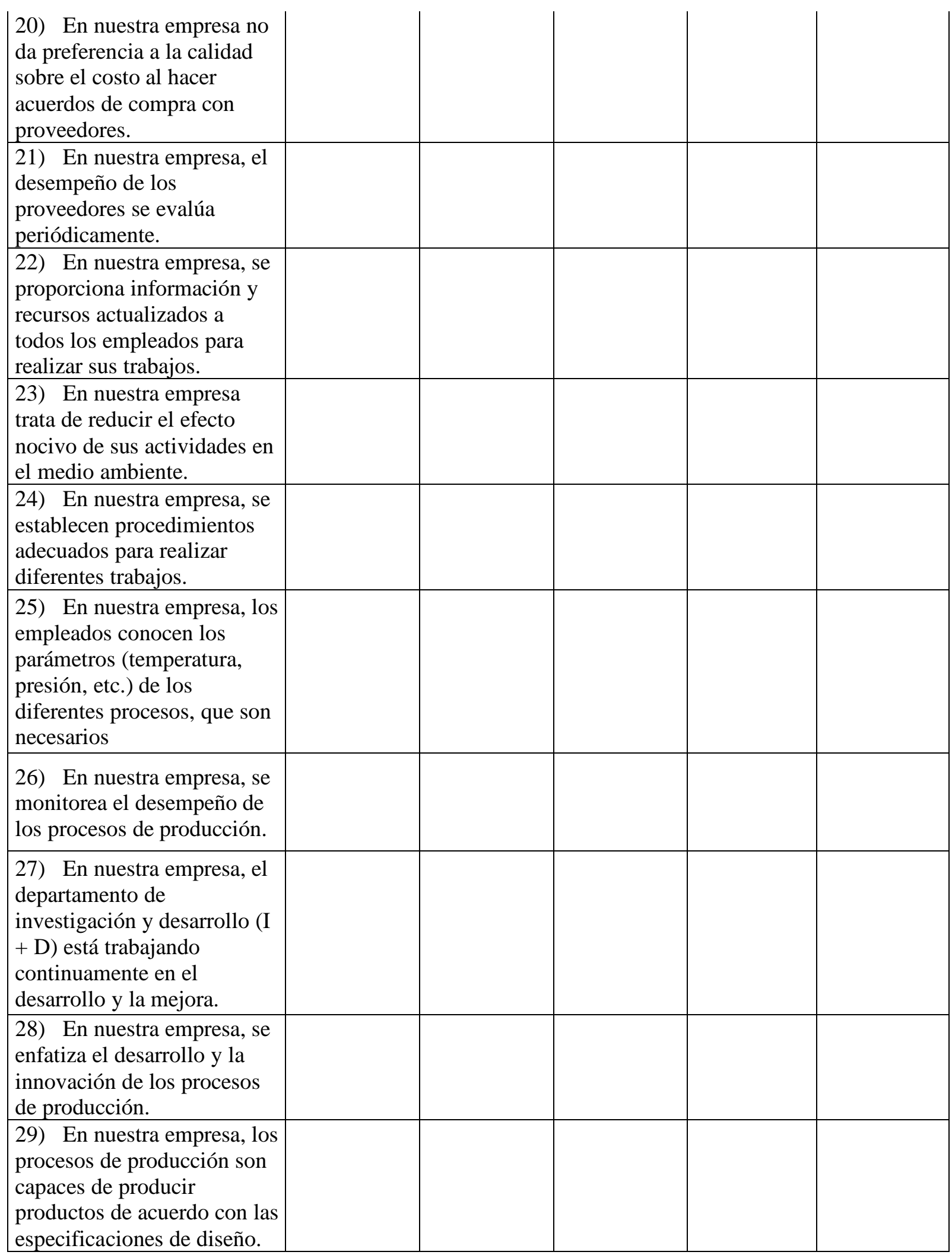




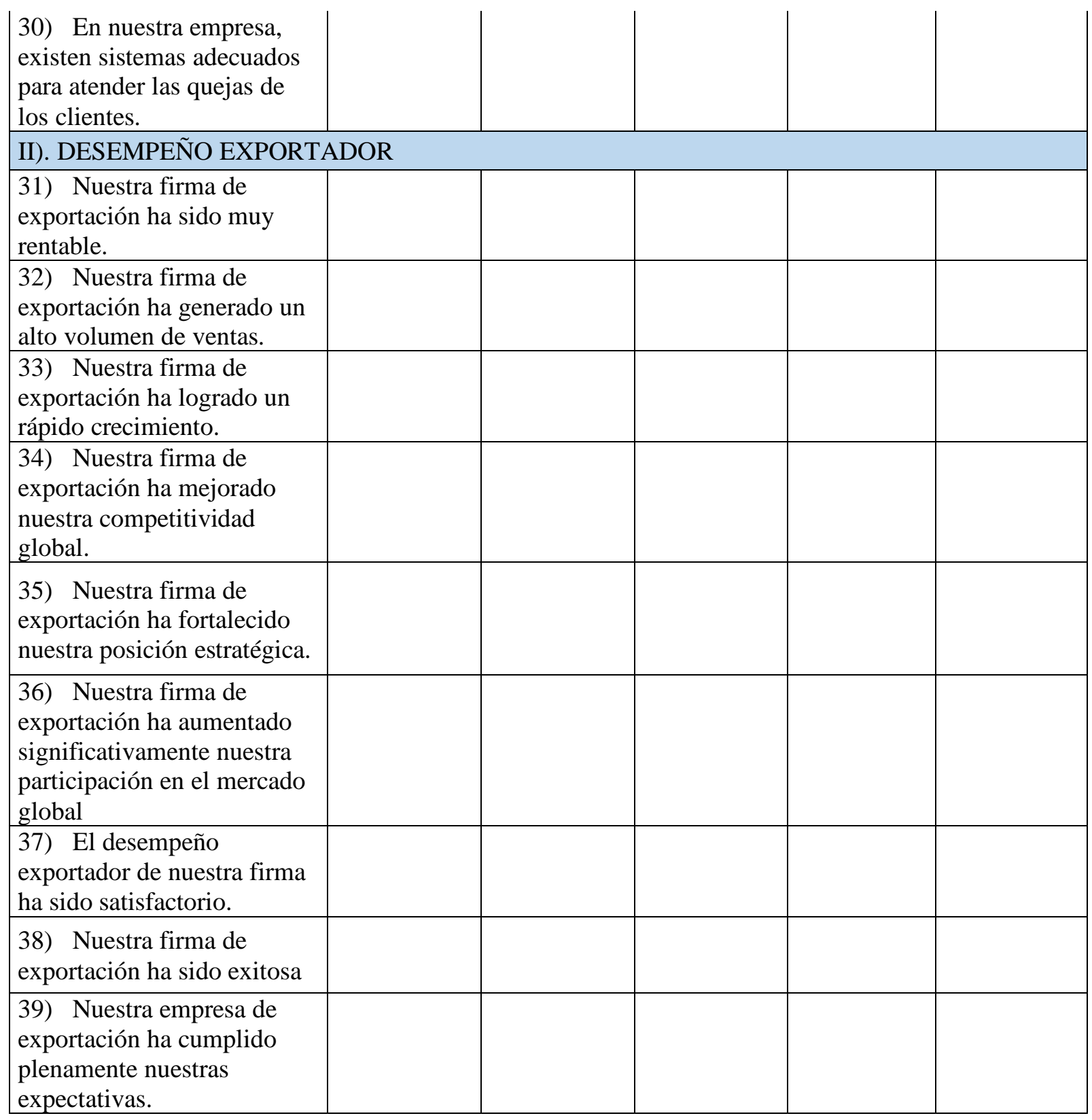




\section{Anexo 3. Prueba de Shapiro-Wilk-Gestión de calidad total}

Prueba de normalidad

\begin{tabular}{|c|c|c|c|c|c|c|}
\hline & \multicolumn{3}{|c|}{ Kolmogorov-Smirnov $^{\mathrm{a}}$} & \multicolumn{3}{|c|}{ Shapiro-Wilk } \\
\hline & Estadistico & Gl & Sig. & Estadístico & Gl & Sig. \\
\hline $\begin{array}{l}\text { GCT 1) Los gerentes de nuestra empresa consideran que el costo es más } \\
\text { importante en comparación con la calidad de los productos. }\end{array}$ & 0.221 & 50 & 0 & 0.879 & 50 & 0 \\
\hline $\begin{array}{l}\text { GCT 2) Los gerentes de nuestra empresa se presentan como modelos a seguir } \\
\text { para los empleados. }\end{array}$ & 0.363 & 50 & 0 & 0.706 & 50 & 0 \\
\hline $\begin{array}{l}\text { GCT 3) Los gerentes de nuestra empresa se aseguran de que los empleados } \\
\text { conozcan los planes a largo plazo de la empresa. }\end{array}$ & 0.201 & 50 & 0 & 0.852 & 50 & 0 \\
\hline $\begin{array}{l}\text { GCT 4) Los gerentes de nuestra empresa no desean otorgar autoridad a los } \\
\text { empleados para que tomen decisiones sobre sus trabajos. }\end{array}$ & 0.295 & 50 & 0 & 0.782 & 50 & 0 \\
\hline $\begin{array}{l}\text { GCT 5) Los gerentes de nuestra empresa adquieren y actualizan continuamente } \\
\text { su conocimiento que es valioso para la organización. }\end{array}$ & 0.358 & 50 & 0 & 0.716 & 50 & 0 \\
\hline $\begin{array}{l}\text { GCT 6) Los gerentes de nuestra empresa fomentan y participan en iniciativas } \\
\text { de mejora continua. }\end{array}$ & 0.339 & 50 & 0 & 0.765 & 50 & 0 \\
\hline $\begin{array}{l}\text { GCT 7) En nuestra empresa, las opiniones de los clientes (las personas / } \\
\text { empresas que compran o desean comprar los productos de su empresa) se } \\
\text { consideran importantes al diseñar nuevos productos. }\end{array}$ & 0.262 & 50 & 0 & 0.792 & 50 & 0 \\
\hline $\begin{array}{l}\text { GCT 8) En nuestra empresa, se consideran las opiniones de los proveedores al } \\
\text { configurar los objetivos de la empresa. }\end{array}$ & 0.439 & 50 & 0 & 0.604 & 50 & 0 \\
\hline $\begin{array}{l}\text { GCT 9) En nuestra empresa, se evalúa y analiza el desempeño de los } \\
\text { competidores y las mejores compañías de su clase. }\end{array}$ & 0.457 & 50 & 0 & 0.563 & 50 & 0 \\
\hline $\begin{array}{l}\text { GCT 10) En nuestra empresa, la medición sistemática de pérdidas (como } \\
\text { pérdidas de producción, pérdidas debidas al rechazo de productos } \\
\text { terminados,etc.) se lleva a cabo. }\end{array}$ & 0.457 & 50 & 0 & 0.563 & 50 & 0 \\
\hline $\begin{array}{l}\text { GCT 11) En nuestra empresa, existen sistemas de información para capturar } \\
\text { información sobre clientes y mercados }\end{array}$ & 0.256 & 50 & 0 & 0.822 & 50 & 0 \\
\hline $\begin{array}{l}\text { GCT 12) En nuestra empresa, periódicamente (por ejemplo, cada tres meses, } \\
\text { seis meses o un año), se evalúa el desempeño organizacional contra los } \\
\text { objetivos y metas establecidos. }\end{array}$ & 0.515 & 50 & 0 & 0.389 & 50 & 0 \\
\hline
\end{tabular}


GCT 13) En nuestra empresa, los procesos formales se utilizan regularmente (encuestas de actitud, información de los empleados, etc.) para conocer las opiniones y puntos de vista de los empleados.

GCT 14) En nuestra empresa, se ofrece capacitación específica de calidad a los empleados.

GCT 15) En nuestra empresa, se alienta a los empleados a actualizar sus conocimientos y habilidades.

GCT 16) En nuestra empresa, el trabajo en equipo es una práctica común dentro de la organización.

GCT 17) En nuestra empresa, los empleados tienen fácil acceso a la información relevante.

GCT 18) En nuestra empresa, fomente las opiniones y sugerencias de los empleados sobre cualquiera de las actividades de la organización.

GCT 19) En nuestra empresa, se alienta a los proveedores a desarrollar asociaciones a largo plazo con la organización.

GCT 20) En nuestra empresa no da preferencia a la calidad sobre el costo al hacer acuerdos de compra con proveedores.

GCT 21) En nuestra empresa, el desempeño de los proveedores se evalúa periódicamente.

GCT 22) En nuestra empresa, se proporciona información y recursos actualizados a todos los empleados para realizar sus trabajos.

GCT 23) En nuestra empresa trata de reducir el efecto nocivo de sus actividades en el medio ambiente.

GCT 24) En nuestra empresa, se establecen procedimientos adecuados para realizar diferentes trabajos.

GCT 25) En nuestra empresa, los empleados conocen los parámetros (temperatura, presión, etc.) de los diferentes procesos, que son necesarios.

GCT 26) En nuestra empresa, se monitorea el desempeño de los procesos de producción.

GCT 27) En nuestra empresa, el departamento de investigación y desarrollo (I + D) está trabajando continuamente en el desarrollo y la mejora.

GCT 28) En nuestra empresa, se enfatiza el desarrollo y la innovación de los procesos de producción

\begin{tabular}{l|l|l|l|l|l|}
0.31 & 50 & 0 & 0.769 & 50 & 0 \\
0.263 & 50 & 0 & 0.796 & 50 & 0 \\
0.328 & 50 & 0 & 0.755 & 50 & 0 \\
0.259 & 50 & 0 & 0.801 & 50 & 0 \\
0.222 & 50 & 0 & 0.875 & 50 & 0 \\
0.376 & 50 & 0 & 0.748 & 50 & 0 \\
0.315 & 50 & 0 & 0.751 & 50 & 0 \\
0.26 & 50 & 0 & 0.844 & 50 & 0 \\
0.341 & 50 & 0 & 0.723 & 50 & 0 \\
0.32 & 50 & 0 & 0.735 & 50 & 0 \\
0.317 & 50 & 0 & 0.745 & 50 & 0 \\
0.284 & 50 & 0 & 0.749 & 50 & 0 \\
0.289 & 50 & 0 & 0.721 & 50 & 0 \\
0.297 & 50 & 0 & 0.72 & 50 & 0 \\
0.321 & 50 & 0 & 0.755 & 50 & 0 \\
0.25 & 50 & 0 & 0.791 & 50 & 0
\end{tabular}


GCT 29) En nuestra empresa, los procesos de producción son capaces de producir productos de acuerdo con las especificaciones de diseño.

GCT 30) En nuestra empresa, existen sistemas adecuados para atender las quejas de los clientes.

Elaboración propia - Extraído del SPSS

\section{Anexo 4. Prueba de Shapiro-Wilk-Desempeño exportador}

\section{Prueba de normalidad}

\begin{tabular}{|c|c|c|c|c|c|c|}
\hline & \multicolumn{3}{|c|}{ Kolmogorov-Smirnov $^{\mathrm{a}}$} & \multicolumn{3}{|c|}{ Shapiro-Wilk } \\
\hline & Estadístico & Gl & Sig. & Estadístico & Gl & Sig. \\
\hline $\begin{array}{l}\text { DEXP1) Nuestra firma de exportación ha sido muy } \\
\text { rentable. }\end{array}$ & 0.296 & 50 & 0.000 & 0.840 & 50 & 0.000 \\
\hline $\begin{array}{l}\text { DEXP2) Nuestra firma de exportación ha generado un } \\
\text { alto volumen de ventas. }\end{array}$ & 0.275 & 50 & 0.000 & 0.852 & 50 & 0.000 \\
\hline $\begin{array}{l}\text { DEXP3) Nuestra firma de exportación ha logrado un } \\
\text { rápido crecimiento. }\end{array}$ & 0.360 & 50 & 0.000 & 0.707 & 50 & 0.000 \\
\hline $\begin{array}{l}\text { DEXP4) Nuestra firma de exportación ha mejorado } \\
\text { nuestra competitividad global. }\end{array}$ & 0.319 & 50 & 0.000 & 0.811 & 50 & 0.000 \\
\hline $\begin{array}{l}\text { DEXP5) Nuestra firma de exportación ha fortalecido } \\
\text { nuestra posición estratégica. }\end{array}$ & 0.291 & 50 & 0.000 & 0.837 & 50 & 0.000 \\
\hline $\begin{array}{l}\text { DEXP6) Nuestra firma de exportación ha aumentado } \\
\text { significativamente nuestra participación en el mercado } \\
\text { global. }\end{array}$ & 0.371 & 50 & 0.000 & 0.700 & 50 & 0.000 \\
\hline $\begin{array}{l}\text { DEXP7) El desempeño exportador de nuestra firma ha } \\
\text { sido satisfactorio. }\end{array}$ & 0.293 & 50 & 0.000 & 0.784 & 50 & 0.000 \\
\hline DEXP8) Nuestra firma de exportación ha sido exitosa & 0.300 & 50 & 0.000 & 0.810 & 50 & 0.000 \\
\hline $\begin{array}{l}\text { DEXP9) Nuestra empresa de exportación ha cumplido } \\
\text { plenamente nuestras expectativas. }\end{array}$ & 0.266 & 50 & 0.000 & 0.822 & 50 & 0.000 \\
\hline
\end{tabular}




\section{Anexo 5. Alfa de Cronbach}

\section{Liderazgo}

Resumen del procesamiento de los casos

\begin{tabular}{|c|c|c|c|}
\hline \multicolumn{2}{|c|}{} & $\mathrm{N}$ & $\%$ \\
\hline \multirow{3}{*}{ Casos } & Válidos & 50 & 100.0 \\
\cline { 2 - 4 } & Excluidos & 0 & 0.0 \\
\cline { 2 - 4 } & Total & 50 & 100.0 \\
\hline
\end{tabular}

Estadísticos de fiabilidad

\begin{tabular}{|c|c|}
\hline $\begin{array}{c}\text { Alfa de } \\
\text { Cronbach }\end{array}$ & $\begin{array}{c}\mathrm{N}^{\mathrm{a}} \mathrm{de} \\
\text { elementos }\end{array}$ \\
\hline 0.965 & 6 \\
\hline
\end{tabular}

Estadísticos total-elemento

\begin{tabular}{|l|c|c|c|c|}
\hline & $\begin{array}{c}\text { Media de } \\
\text { la escala si } \\
\text { se elimina } \\
\text { el } \\
\text { elemento }\end{array}$ & $\begin{array}{c}\text { Varianza } \\
\text { de la } \\
\text { escala si } \\
\text { se elimina } \\
\text { el } \\
\text { elemento }\end{array}$ & $\begin{array}{c}\text { Correlación } \\
\text { elemento } \\
\text { total } \\
\text { corregido }\end{array}$ & $\begin{array}{c}\text { Alfa de } \\
\text { Cronbach } \\
\text { si se } \\
\text { elimina el } \\
\text { elemento }\end{array}$ \\
\hline $\begin{array}{l}\text { GCT 1) Los gerentes de nuestra empresa } \\
\text { consideran que el costo es más importante } \\
\text { en comparación con la calidad de los } \\
\text { productos. }\end{array}$ & 18.36 & 22.684 & 0.867 & 0.961 \\
$\begin{array}{l}\text { GCT 2) Los gerentes de nuestra empresa se } \\
\text { presentan como modelos a seguir para los } \\
\text { empleados. } \\
\text { GCT 3) Los gerentes de nuestra empresa se } \\
\text { aseguran de que los empleados conozcan } \\
\text { los planes a largo plazo de la empresa. } \\
\begin{array}{l}\text { GCT 4) Los gerentes de nuestra empresa no } \\
\text { desean otorgar autoridad a los empleados } \\
\text { para que tomen decisiones sobre sus } \\
\text { trabajos. }\end{array}\end{array}$ & 18.24 & 21.451 & 0.876 & 0.960 \\
$\begin{array}{l}\text { GCT 5) Los gerentes de nuestra empresa } \\
\text { adquieren y actualizan continuamente su } \\
\text { conocimiento que es valioso para la } \\
\text { organización. }\end{array}$ & 17.60 & 23.510 & 0.911 & 0.985 \\
\end{tabular}


GCT 6) Los gerentes de nuestra empresa fomentan y participan en iniciativas de mejora continua.

\section{Estrategia}

Resumen del procesamiento de los casos

\begin{tabular}{|c|c|c|c|}
\hline \multicolumn{2}{|c|}{} & $\mathrm{N}$ & $\%$ \\
\hline \multirow{3}{*}{ Casos } & Válidos & 50 & 100.0 \\
\cline { 2 - 4 } & Excluidos & 0 & 0.0 \\
\cline { 2 - 4 } & Total & 50 & 100.0 \\
\hline
\end{tabular}

Estadísticos de fiabilidad

\begin{tabular}{|c|c|}
\hline $\begin{array}{c}\text { Alfa de } \\
\text { Cronbach }\end{array}$ & $\begin{array}{c}\mathrm{N}^{\mathrm{a}} \text { de } \\
\text { elementos }\end{array}$ \\
\hline 0.849 & 6 \\
\hline
\end{tabular}

Estadísticos total-elemento

\begin{tabular}{|l|c|c|c|c|}
\hline & $\begin{array}{c}\text { Media de } \\
\text { 1a escala si } \\
\text { se elimina } \\
\text { el } \\
\text { elemento }\end{array}$ & $\begin{array}{c}\text { Varianza } \\
\text { de la } \\
\text { escala si } \\
\text { se elimina } \\
\text { el } \\
\text { elemento }\end{array}$ & $\begin{array}{c}\text { Correlación } \\
\text { elemento } \\
\text { total } \\
\text { corregido }\end{array}$ & $\begin{array}{c}\text { Alfa de } \\
\text { Cronbach } \\
\text { si se } \\
\text { elimina el } \\
\text { elemento }\end{array}$ \\
\hline $\begin{array}{l}\text { GCT 7) En nuestra empresa, las opiniones de los } \\
\text { clientes (las personas / empresas que compran o } \\
\text { desean comprar los productos de su empresa) se } \\
\text { consideran importantes al diseñar nuevos } \\
\text { productos. }\end{array}$ & 23.06 & 5.445 & 0.807 & 0.860 \\
\hline $\begin{array}{l}\text { GCT 8) En nuestra empresa, se consideran las } \\
\text { opiniones de los proveedores al configurar los } \\
\text { objetivos de la empresa. }\end{array}$ & 22.60 & 6.531 & 0.632 & 0.887 \\
\hline $\begin{array}{l}\text { GCT 9) En nuestra empresa, se evalúa y analiza el } \\
\text { desempeño de los competidores y las mejores } \\
\text { compañías de su clase. }\end{array}$ & 22.58 & 6.412 & 0.635 & 0.887 \\
\hline $\begin{array}{l}\text { GCT 10) En nuestra empresa, la medición } \\
\text { sistemática de pérdidas (como pérdidas de } \\
\text { producción, pérdidas debidas al rechazo de } \\
\text { productos terminados,etc.) se lleva a cabo. }\end{array}$ & 22.58 & 6.167 & 0.732 & 0.872 \\
\hline
\end{tabular}




\begin{tabular}{|l|c|c|c|c|}
$\begin{array}{l}\text { GCT 11) En nuestra empresa, existen sistemas de } \\
\text { información para capturar información sobre } \\
\text { clientes y mercados }\end{array}$ & 23.16 & 5.484 & 0.736 & 0.876 \\
\hline $\begin{array}{l}\text { GCT 12) En nuestra empresa, periódicamente (por } \\
\text { ejemplo, cada tres meses, seis meses o un año), se } \\
\text { evalúa el desempeño organizacional contra los } \\
\text { objetivos y metas establecidos. }\end{array}$ & 22.42 & 6.616 & 0.881 & 0.865 \\
\hline
\end{tabular}

\section{Personas}

Resumen del procesamiento de los casos

\begin{tabular}{|c|c|c|c|}
\hline \multicolumn{2}{|c|}{} & $\mathrm{N}$ & $\%$ \\
\hline \multirow{3}{*}{ Casos } & Válidos & 50 & 100.0 \\
\cline { 2 - 4 } & Excluidos & 0 & 0.0 \\
\cline { 2 - 4 } & Total & 50 & 100.0 \\
\hline
\end{tabular}

Estadísticos de fiabilidad

\begin{tabular}{|c|c|}
\hline $\begin{array}{c}\text { Alfa de } \\
\text { Cronbach }\end{array}$ & $\begin{array}{c}\mathrm{N}^{\mathrm{a}} \text { de } \\
\text { elementos }\end{array}$ \\
\hline 0.898 & 6 \\
\hline
\end{tabular}

Estadísticos total-elemento

\begin{tabular}{|l|c|c|c|c|}
\hline & $\begin{array}{c}\text { Media de la } \\
\text { escala si se } \\
\text { elimina el } \\
\text { elemento }\end{array}$ & $\begin{array}{c}\text { Varianza } \\
\text { de la } \\
\text { escala si } \\
\text { se } \\
\text { elimina } \\
\text { el } \\
\text { elemento }\end{array}$ & $\begin{array}{c}\text { Correlación } \\
\text { elemento } \\
\text { total } \\
\text { corregido }\end{array}$ & $\begin{array}{c}\text { Alfa de } \\
\text { Cronbach } \\
\text { si se } \\
\text { elimina el } \\
\text { elemento }\end{array}$ \\
\hline $\begin{array}{l}\text { GCT 13) En nuestra empresa, los procesos } \\
\text { formales se utilizan regularmente (encuestas } \\
\text { de actitud, información de los empleados, etc.) } \\
\text { para conocer las opiniones y puntos de vista de } \\
\text { los empleados. }\end{array}$ & 19.92 & 8.279 & 0.862 & 0.862 \\
\hline $\begin{array}{l}\text { GCT 14) En nuestra empresa, se ofrece } \\
\text { capacitación específica de calidad a los } \\
\text { empleados. }\end{array}$ & 19.98 & 7.734 & 0.926 & 0.849 \\
\hline $\begin{array}{l}\text { GCT 15) En nuestra empresa, se alienta a los } \\
\text { empleados a actualizar sus conocimientos y } \\
\text { habilidades. }\end{array}$ & 19.90 & 8.622 & 0.792 & 0.873 \\
\hline
\end{tabular}




\begin{tabular}{|c|c|c|c|c|}
\hline $\begin{array}{l}\text { GCT 16) En nuestra empresa, el trabajo en } \\
\text { equipo es una práctica común dentro de la } \\
\text { organización. }\end{array}$ & 20.02 & 8.428 & 0.701 & 0.884 \\
\hline $\begin{array}{l}\text { GCT 17) En nuestra empresa, los empleados } \\
\text { tienen fácil acceso a la información relevante. }\end{array}$ & 20.72 & 7.798 & 0.672 & 0.895 \\
\hline $\begin{array}{l}\text { GCT 18) En nuestra empresa, fomente las } \\
\text { opiniones y sugerencias de los empleados } \\
\text { sobre cualquiera de las actividades de la } \\
\text { organización. }\end{array}$ & 20.26 & 9.176 & 0.489 & 0.915 \\
\hline
\end{tabular}

\section{Recursos}

Resumen del procesamiento de los casos

\begin{tabular}{|c|c|c|c|}
\hline \multicolumn{2}{|c|}{} & $\mathrm{N}$ & $\%$ \\
\hline \multirow{3}{*}{ Casos } & Válidos & 50 & 100.0 \\
\cline { 2 - 4 } & Excluidos & 0 & 0.0 \\
\cline { 2 - 4 } & Total & 50 & 100.0 \\
\hline
\end{tabular}

Estadísticos de fiabilidad

\begin{tabular}{|c|c|}
\hline $\begin{array}{c}\text { Alfa de } \\
\text { Cronbach }\end{array}$ & $\begin{array}{c}\mathrm{N}^{\mathrm{a}} \text { de } \\
\text { elementos }\end{array}$ \\
\hline 0.919 & 5 \\
\hline
\end{tabular}

Estadísticos total-elemento

\begin{tabular}{|l|c|c|c|c|}
\hline & $\begin{array}{c}\text { Media de } \\
\text { la escala si } \\
\text { se elimina } \\
\text { el } \\
\text { elemento }\end{array}$ & $\begin{array}{c}\text { Varianza } \\
\text { de la } \\
\text { escala si } \\
\text { se elimina } \\
\text { el } \\
\text { elemento }\end{array}$ & $\begin{array}{c}\text { Correlación } \\
\text { elemento } \\
\text { total } \\
\text { corregido }\end{array}$ & $\begin{array}{c}\text { Alfa de } \\
\text { Cronbach } \\
\text { si se } \\
\text { elimina el } \\
\text { elemento }\end{array}$ \\
\hline $\begin{array}{l}\text { GCT 19) En nuestra empresa, se } \\
\text { alienta a los proveedores a } \\
\text { desarrollar asociaciones a largo } \\
\text { plazo con la organización. }\end{array}$ & 17.34 & 5.331 & 0.900 & 0.879 \\
\hline $\begin{array}{l}\text { GCT 20) En nuestra empresa no } \\
\text { da preferencia a la calidad sobre } \\
\text { el costo al hacer acuerdos de } \\
\text { compra con proveedores. }\end{array}$ & 17.74 & 5.298 & 0.702 & 0.928 \\
\hline $\begin{array}{l}\text { GCT 21) En nuestra empresa, el } \\
\text { desempeño de los proveedores se } \\
\text { evalúa periódicamente. }\end{array}$ & 17.26 & 5.666 & 0.862 & 0.889 \\
\hline
\end{tabular}




\begin{tabular}{|l|c|c|c|c|}
$\begin{array}{l}\text { GCT 22) En nuestra empresa, se } \\
\text { proporciona información y } \\
\text { recursos actualizados a todos los } \\
\text { empleados para realizar sus } \\
\text { trabajos. }\end{array}$ & 17.30 & 5.969 & 0.743 & 0.911 \\
\hline $\begin{array}{l}\text { GCT 23) En nuestra empresa } \\
\text { trata de reducir el efecto nocivo } \\
\text { de sus actividades en el medio } \\
\text { ambiente. }\end{array}$ & 17.32 & 5.691 & 0.804 & 0.899 \\
\hline
\end{tabular}

\section{Procesos}

Resumen del procesamiento de los casos

\begin{tabular}{|c|c|c|c|}
\hline \multicolumn{2}{|c|}{} & $\mathrm{N}$ & $\%$ \\
\hline \multirow{3}{*}{ Casos } & Válidos & 50 & 100.0 \\
\cline { 2 - 4 } & Excluidos & 0 & 0.0 \\
\cline { 2 - 4 } & Total & 50 & 100.0 \\
\hline
\end{tabular}

Estadísticos de fiabilidad

\begin{tabular}{|c|c|}
\hline $\begin{array}{c}\text { Alfa de } \\
\text { Cronbach }\end{array}$ & $\begin{array}{c}\mathrm{N}^{\mathrm{a}} \mathrm{de} \\
\text { elementos }\end{array}$ \\
\hline 0.947 & 7 \\
\hline
\end{tabular}

Estadísticos total-elemento

\begin{tabular}{|l|c|c|c|c|}
\hline & $\begin{array}{c}\text { Media de la } \\
\text { escala si se } \\
\text { elimina el } \\
\text { elemento }\end{array}$ & $\begin{array}{c}\text { Varianza de } \\
\text { la escala si } \\
\text { se elimina el } \\
\text { elemento }\end{array}$ & $\begin{array}{c}\text { Correlación } \\
\text { elemento total } \\
\text { corregido }\end{array}$ & $\begin{array}{c}\text { Alfa de } \\
\text { Cronbach si } \\
\text { se elimina el } \\
\text { elemento }\end{array}$ \\
\hline $\begin{array}{l}\text { GCT 24) En nuestra empresa, se } \\
\text { establecen procedimientos adecuados } \\
\text { para realizar diferentes trabajos. }\end{array}$ & 25.60 & 21.796 & 0.882 & 0.933 \\
\hline $\begin{array}{l}\text { GCT 25) En nuestra empresa, los } \\
\text { empleados conocen los parámetros } \\
\text { (temperatura, presión, etc.) de los } \\
\text { diferentes procesos, que son necesarios. }\end{array}$ & 25.72 & 21.512 & 0.715 & 0.947 \\
\hline $\begin{array}{l}\text { GCT 26) En nuestra empresa, se } \\
\text { monitorea el desempeño de los procesos } \\
\text { de producción. }\end{array}$ & 25.62 & 20.975 & 0.856 & 0.934 \\
\hline
\end{tabular}




\begin{tabular}{|c|c|c|c|c|}
\hline $\begin{array}{l}\text { GCT 27) En nuestra empresa, el } \\
\text { departamento de investigación y } \\
\text { desarrollo (I + D) está trabajando } \\
\text { continuamente en el desarrollo y la } \\
\text { mejora. }\end{array}$ & 25.66 & 20.841 & 0.833 & 0.936 \\
\hline $\begin{array}{l}\text { GCT 28) En nuestra empresa, se enfatiza } \\
\text { el desarrollo y la innovación de los } \\
\text { procesos de producción }\end{array}$ & 25.78 & 20.869 & 0.847 & 0.935 \\
\hline $\begin{array}{l}\text { GCT 29) En nuestra empresa, los } \\
\text { procesos de producción son capaces de } \\
\text { producir productos de acuerdo con las } \\
\text { especificaciones de diseño. }\end{array}$ & 25.64 & 21.011 & 0.915 & 0.929 \\
\hline $\begin{array}{l}\text { GCT 30) En nuestra empresa, existen } \\
\text { sistemas adecuados para atender las } \\
\text { quejas de los clientes. }\end{array}$ & 25.62 & 22.200 & 0.709 & 0.946 \\
\hline
\end{tabular}

\section{Finanzas}

\section{Resumen del procesamiento de los casos}

\begin{tabular}{|c|c|c|c|}
\hline \multirow{3}{*}{ Casos } & $\mathrm{N}$ & $\%$ \\
\hline \multirow{3}{*}{} & Válidos & 50 & 100.0 \\
\cline { 2 - 4 } & Excluidos & 0 & 0.0 \\
\cline { 2 - 4 } & Total & 50 & 100.0 \\
\hline
\end{tabular}

Estadísticos de fiabilidad

\begin{tabular}{|c|c|}
\hline $\begin{array}{c}\text { Alfa de } \\
\text { Cronbach }\end{array}$ & $\begin{array}{c}\mathrm{N}^{\mathrm{a}} \text { de } \\
\text { elementos }\end{array}$ \\
\hline 0.879 & 3 \\
\hline
\end{tabular}

Estadísticos total-elemento

\begin{tabular}{|l|c|c|c|c|}
\hline & $\begin{array}{c}\text { Media de la } \\
\text { escala si se } \\
\text { elimina el } \\
\text { elemento }\end{array}$ & $\begin{array}{c}\text { Varianza de la } \\
\text { escala si se } \\
\text { elimina el } \\
\text { elemento }\end{array}$ & $\begin{array}{c}\text { Correlación } \\
\text { elemento total } \\
\text { corregido }\end{array}$ & $\begin{array}{c}\text { Alfa de } \\
\text { Cronbach si } \\
\text { se elimina el } \\
\text { elemento }\end{array}$ \\
\hline $\begin{array}{l}\text { DEXP1) Nuestra firma de } \\
\text { exportación ha sido muy } \\
\text { rentable. } \\
\begin{array}{l}\text { DEXP2) Nuestra firma de } \\
\text { exportación ha generado un } \\
\text { alto volumen de ventas. }\end{array}\end{array}$ & 8.36 & 2.235 & 0.759 & 0.836
\end{tabular}


DEXP3) Nuestra firma de exportación ha logrado un rápido crecimiento.

\section{Estrategias}

\section{Resumen del procesamiento de los casos}

\begin{tabular}{|c|c|c|c|}
\hline \multicolumn{2}{|c|}{} & $\mathrm{N}$ & $\%$ \\
\hline \multirow{3}{*}{ Casos } & Válidos & 50 & 100.0 \\
\cline { 2 - 4 } & Excluidos & 0 & 0.0 \\
\cline { 2 - 4 } & Total & 50 & 100.0 \\
\hline
\end{tabular}

Estadísticos de fiabilidad

\begin{tabular}{|c|c|}
\hline $\begin{array}{c}\text { Alfa de } \\
\text { Cronbach }\end{array}$ & $\begin{array}{c}\mathrm{N}^{\mathrm{a}} \mathrm{de} \\
\text { elementos }\end{array}$ \\
\hline 0.770 & 3 \\
\hline
\end{tabular}

\section{Estadísticos total-elemento}

\begin{tabular}{|l|c|c|c|c|}
\hline & $\begin{array}{c}\text { Media de la } \\
\text { escala si se } \\
\text { elimina el } \\
\text { elemento }\end{array}$ & $\begin{array}{c}\text { Varianza de } \\
\text { la escala si } \\
\text { se elimina el } \\
\text { elemento }\end{array}$ & $\begin{array}{c}\text { Correlación } \\
\text { elemento total } \\
\text { corregido }\end{array}$ & $\begin{array}{c}\text { Alfa de } \\
\text { Cronbach } \\
\text { si se } \\
\text { elimina el } \\
\text { elemento }\end{array}$ \\
\hline $\begin{array}{l}\text { DEXP4) Nuestra firma de } \\
\text { exportación ha mejorado nuestra } \\
\text { competitividad global. } \\
\text { DEXP5) Nuestra firma de } \\
\text { exportación ha fortalecido nuestra } \\
\text { posición estratégica. } \\
\text { DEXP6) Nuestra firma de } \\
\text { exportación ha aumentado } \\
\text { significativamente nuestra } \\
\text { participación en el mercado global. }\end{array}$ & 8.46 & 1.478 & 0.652 & 0.638 \\
\hline
\end{tabular}




\section{Satisfacción}

Resumen del procesamiento de los casos

\begin{tabular}{|c|c|c|c|}
\hline \multicolumn{2}{|c|}{} & $\mathrm{N}$ & $\%$ \\
\hline \multirow{3}{*}{ Casos } & Válidos & 50 & 100.0 \\
\cline { 2 - 4 } & Excluidos & 0 & 0.0 \\
\cline { 2 - 4 } & Total & 50 & 100.0 \\
\hline
\end{tabular}

Estadísticos de fiabilidad

\begin{tabular}{|c|c|}
\hline $\begin{array}{c}\text { Alfa de } \\
\text { Cronbach }\end{array}$ & $\begin{array}{c}\mathrm{N}^{\mathrm{a}} \text { de } \\
\text { elementos }\end{array}$ \\
\hline 0.891 & 3 \\
\hline
\end{tabular}

Estadísticos total-elemento

\begin{tabular}{|l|c|c|c|c|}
\hline & $\begin{array}{c}\text { Media de } \\
\text { la escala si } \\
\text { se elimina } \\
\text { el } \\
\text { elemento }\end{array}$ & $\begin{array}{c}\text { Varianza } \\
\text { de la } \\
\text { escala si } \\
\text { se elimina } \\
\text { el } \\
\text { elemento }\end{array}$ & $\begin{array}{c}\text { Correlación } \\
\text { elemento } \\
\text { total } \\
\text { corregido }\end{array}$ & $\begin{array}{c}\text { Alfa de } \\
\text { Cronbach } \\
\text { si se } \\
\text { elimina el } \\
\text { elemento }\end{array}$ \\
\hline $\begin{array}{l}\text { DEXP7) El desempeño } \\
\text { exportador de nuestra firma } \\
\text { ha sido satisfactorio. }\end{array}$ & 6.96 & 2.202 & 0.795 & 0.836 \\
\hline $\begin{array}{l}\text { DEXP8) Nuestra firma de } \\
\text { exportación ha sido exitosa }\end{array}$ & 7.74 & 1.992 & 0.840 & 0.795 \\
\hline $\begin{array}{l}\text { DEXP9) Nuestra empresa de } \\
\text { exportación ha cumplido } \\
\text { plenamente nuestras } \\
\text { expectativas. }\end{array}$ & 7.82 & 2.396 & 0.728 & 0.893 \\
\hline
\end{tabular}


Anexo 6. Coeficiente de Aiken

Variables: Gestión de calidad total y desempeño exportador

\begin{tabular}{|c|c|c|c|c|c|c|c|c|c|c|c|c|c|c|}
\hline \multirow[b]{2}{*}{ ITEM } & \multicolumn{4}{|c|}{ JUEZ 1} & \multicolumn{4}{|c|}{ JUEZ 2} & \multicolumn{4}{|c|}{ JUEZ 3} & \multirow[b]{2}{*}{ SUMA } & \multirow[b]{2}{*}{ V AIKEN } \\
\hline & $\mathbf{C}$ & $\mathrm{CON}$ & $\mathrm{CON}$ & DC & $\mathbf{C}$ & $\mathrm{CON}$ & $\mathrm{CON}$ & DC & $\mathbf{C}$ & $\mathrm{CON}$ & $\mathrm{CON}$ & DC & & \\
\hline GCT1 & 5 & 4 & 5 & 4 & 5 & 5 & 5 & 5 & 5 & 5 & 5 & 5 & 58 & 0.97 \\
\hline GCT2 & 5 & 4 & 4 & 5 & 4 & 5 & 4 & 5 & 5 & 4 & 4 & 5 & 54 & 0.90 \\
\hline GCT3 & 5 & 4 & 5 & 5 & 5 & 4 & 4 & 5 & 5 & 4 & 5 & 5 & 56 & 0.93 \\
\hline GCT4 & 5 & 4 & 5 & 4 & 5 & 5 & 5 & 4 & 5 & 5 & 5 & 4 & 56 & 0.93 \\
\hline GCT5 & 5 & 4 & 4 & 4 & 4 & 5 & 5 & 5 & 5 & 5 & 5 & 5 & 56 & 0.93 \\
\hline GCT6 & 5 & 4 & 4 & 5 & 4 & 5 & 4 & 5 & 5 & 4 & 5 & 5 & 55 & 0.92 \\
\hline GCT7 & 5 & 4 & 4 & 4 & 5 & 4 & 4 & 4 & 5 & 4 & 5 & 4 & 52 & 0.87 \\
\hline GCT8 & 5 & 4 & 4 & 4 & 5 & 4 & 5 & 5 & 5 & 4 & 5 & 4 & 54 & 0.90 \\
\hline GCT9 & 5 & 4 & 4 & 4 & 4 & 5 & 4 & 4 & 4 & 5 & 4 & 4 & 51 & 0.85 \\
\hline GCT10 & 5 & 4 & 4 & 5 & 5 & 4 & 4 & 5 & 4 & 5 & 4 & 5 & 54 & 0.90 \\
\hline GCT11 & 5 & 4 & 4 & 4 & 5 & 4 & 5 & 4 & 5 & 4 & 4 & 5 & 53 & 0.88 \\
\hline GCT12 & 5 & 4 & 5 & 4 & 5 & 4 & 5 & 4 & 4 & 5 & 5 & 5 & 55 & 0.92 \\
\hline GCT13 & 5 & 4 & 5 & 4 & 5 & 5 & 5 & 4 & 4 & 5 & 5 & 4 & 55 & 0.92 \\
\hline GCT14 & 5 & 4 & 5 & 4 & 5 & 4 & 5 & 4 & 4 & 4 & 5 & 4 & 53 & 0.88 \\
\hline GCT15 & 5 & 5 & 4 & 4 & 4 & 5 & 5 & 4 & 4 & 5 & 5 & 5 & 55 & 0.92 \\
\hline GCT16 & 5 & 5 & 4 & 4 & 5 & 4 & 4 & 5 & 5 & 4 & 4 & 5 & 54 & 0.90 \\
\hline GCT17 & 5 & 4 & 5 & 4 & 5 & 4 & 4 & 5 & 5 & 4 & 4 & 4 & 53 & 0.88 \\
\hline GCT18 & 5 & 4 & 5 & 4 & 4 & 4 & 5 & 4 & 5 & 4 & 5 & 4 & 53 & 0.88 \\
\hline GCT19 & 5 & 4 & 4 & 4 & 4 & 5 & 5 & 4 & 5 & 4 & 4 & 4 & 52 & 0.87 \\
\hline GCT20 & 4 & 5 & 5 & 4 & 4 & 5 & 5 & 5 & 4 & 5 & 5 & 5 & 56 & 0.93 \\
\hline GCT21 & 5 & 5 & 5 & 5 & 5 & 5 & 5 & 5 & 5 & 5 & 4 & 5 & 59 & 0.98 \\
\hline GCT22 & 5 & 5 & 5 & 5 & 5 & 5 & 5 & 5 & 5 & 5 & 5 & 5 & 60 & 1.00 \\
\hline GCT23 & 5 & 5 & 5 & 4 & 4 & 5 & 4 & 4 & 5 & 4 & 4 & 4 & 53 & 0.88 \\
\hline
\end{tabular}




\begin{tabular}{|c|c|c|c|c|c|c|c|c|c|c|c|c|c|c|}
\hline GCT24 & 5 & 4 & 5 & 4 & 5 & 5 & 5 & 5 & 5 & 5 & 4 & 5 & 57 & 0.95 \\
\hline GCT25 & 4 & 4 & 4 & 4 & 5 & 4 & 5 & 5 & 4 & 4 & 4 & 5 & 52 & 0.87 \\
\hline GCT26 & 4 & 4 & 4 & 4 & 5 & 4 & 4 & 4 & 4 & 4 & 4 & 5 & 50 & 0.83 \\
\hline GCT27 & 4 & 5 & 4 & 5 & 4 & 4 & 5 & 5 & 4 & 4 & 5 & 5 & 54 & 0.90 \\
\hline GCT28 & 5 & 5 & 5 & 5 & 5 & 5 & 5 & 5 & 5 & 5 & 5 & 5 & 60 & 1.00 \\
\hline GCT29 & 4 & 4 & 4 & 5 & 4 & 5 & 4 & 4 & 5 & 4 & 4 & 4 & 51 & 0.85 \\
\hline GCT30 & 4 & 5 & 5 & 4 & 5 & 5 & 5 & 5 & 5 & 5 & 4 & 5 & 57 & 0.95 \\
\hline DEXP1 & 4 & 5 & 5 & 4 & 5 & 5 & 5 & 5 & 5 & 5 & 4 & 5 & 57 & 0.95 \\
\hline DEXP2 & 4 & 5 & 5 & 4 & 4 & 5 & 4 & 4 & 5 & 5 & 4 & 5 & 54 & 0.90 \\
\hline DEXP3 & 5 & 4 & 5 & 4 & 5 & 5 & 4 & 4 & 4 & 5 & 5 & 5 & 55 & 0.92 \\
\hline DEXP4 & 5 & 4 & 5 & 5 & 4 & 4 & 5 & 4 & 4 & 4 & 5 & 4 & 53 & 0.88 \\
\hline DEXP5 & 4 & 4 & 5 & 5 & 4 & 5 & 5 & 4 & 4 & 5 & 5 & 5 & 55 & 0.92 \\
\hline DEXP6 & 5 & 5 & 4 & 5 & 4 & 5 & 4 & 5 & 5 & 4 & 4 & 4 & 54 & 0.90 \\
\hline DEXP7 & 5 & 5 & 4 & 5 & 5 & 4 & 5 & 5 & 4 & 5 & 5 & 4 & 56 & 0.93 \\
\hline DEXP8 & 4 & 4 & 5 & 5 & 4 & 5 & 5 & 5 & 5 & 5 & 5 & 5 & 57 & 0.95 \\
\hline \multirow[t]{2}{*}{ DEXP9 } & 5 & 5 & 4 & 5 & 5 & 5 & 4 & 4 & 4 & 5 & 5 & 5 & 56 & 0.93 \\
\hline & & & & & & & & & & & & & $\begin{array}{c}\text { V } \\
\text { AIKEN }\end{array}$ & 0.91 \\
\hline
\end{tabular}

$\mathrm{C}=\mathrm{CLARIDAD}, \mathrm{CO}=\mathrm{CONGRUENCIA}, \mathrm{CON}=\mathrm{CONTEXTO}, \mathrm{DC}=$ DOMINIO DE CONSTRUCTO 


\section{Anexo 7. Juicio de expertos}

\section{Juez $N^{\circ}$ 1: Carla Arriola Alvarado}

\section{INSTRUMENTO PARA LA VALIDEZ DE CONTENIDO}

\section{(JUICIO DE EXPERTOS)}

El presente instrumento tiene como finalidad validar la encuesta de Gestión de Calidad Total y Desempeño Exportador, el mismo que será aplicado a los agentes de carga que forman parte del estudio "RELACIÓN ENTRE LA GESTIÓN DE CALIDAD TOTAL Y EL DESEMPEN̈O EXPORTADOR DE MYPES EXPORTADORAS PERUANAS DE CACAO $2020^{\prime \prime}$ que corresponde a un diseño de investigación no experimental y transversal.

\section{Instrucciones}

La evaluación requiere una lectura detallada y completa de cada ítem propuesto a fin de comparar de manera cualitativa con los criterios propuestos relativos a: Claridad de la redacción, Contexto correcto de ítem, Congruencia con el contenido y Dominio del Constructo. Para tal fin, deberá asignar una valoración si el ítem presenta o no los criterios propuestos, y caso contrario se ofrece un espacio para las observaciones si las hubiera.

\begin{tabular}{|l|l|}
\hline Juez $\mathrm{N}^{\circ}$ : & 1 \\
\hline Fecha actual: & 1 de junio de 2020 \\
\hline Nombres y Apellidos de Juez: & Carla Arriola Alvarado \\
\hline Grado Académico: & Magister \\
\hline Puesto de trabajo: & Coordinadora académica \\
\hline Institución donde labora: & USIL \\
\hline $\begin{array}{l}\text { Años de experiencia } \\
\text { profesional/cientifica: }\end{array}$ & 7 \\
\hline
\end{tabular}

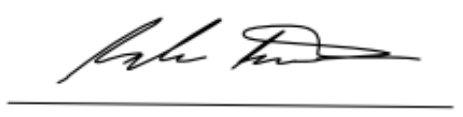

Firma y/o Sello 


\subsection{INVENTARIO DE LA ENCUESTA DE GESTION DE CALIDAD TOTAL Y DESEMPEÑO EXPORTADOR}

\section{INSTRUMENTO PARA FINES ESPECIFICOS DE LA VALIDACION DE CONTENIDO (JUICIO DE EXPERTO)}

Calificación: Muy aceptable (5) Aceptable (4) Regular (3) Poco aceptable (2) Inaceptable

(1)

\begin{tabular}{|c|c|c|c|c|c|c|c|c|c|c|c|c|c|c|c|c|}
\hline \multirow{2}{*}{$\mathbf{N}^{\circ} \mid$} & \multirow{2}{*}{ İtems (afirmaciones) } & \multicolumn{3}{|c|}{ Claridad $^{1}$} & \multicolumn{4}{|c|}{ Congruencia $^{2}$} & \multicolumn{3}{|c|}{ Contexto ${ }^{3}$} & \multicolumn{4}{|c|}{$\begin{array}{l}\begin{array}{l}\text { Dominio del } \\
\text { constructo }^{4}\end{array} \\
\end{array}$} & \multirow[t]{2}{*}{ Sugerencias } \\
\hline & & 5 & 43 & $\begin{array}{ll}2 & 1\end{array}$ & 5 & \begin{tabular}{l|l}
4 & 3
\end{tabular} & 32 & 1 & 5 & 43 & 32 & \begin{tabular}{|l|l|} 
& 5 \\
\end{tabular} & 4 & \begin{tabular}{|l|l|}
3 & 2 \\
\end{tabular} & 1 & \\
\hline 1 & $\begin{array}{l}\text { Los gerentes de nuestra empresa } \\
\text { consideran que el costo es más } \\
\text { importante en comparación con la calidad } \\
\text { de los productos. }\end{array}$ & $\mathrm{x}$ & & & & $\mathrm{x}$ & & & $\mathrm{x}$ & & & & $\mathrm{x}$ & & & \\
\hline 2 & $\begin{array}{l}\text { Los gerentes de nuestra empresa se } \\
\text { presentan como modelos a seguir para } \\
\text { los empleados }\end{array}$ & $\mathrm{x}$ & & & & $\mathrm{X}$ & & & & $\mathrm{x}$ & & $\mathrm{x}$ & & & & \\
\hline 3 & $\begin{array}{l}\text { Los gerentes de nuestra empresa se } \\
\text { aseguran de que los empleados } \\
\text { conozcan los planes a largo plazo de la } \\
\text { empresa }\end{array}$ & & & & & $\mathrm{x}$ & & & & & & $\mathrm{X}$ & & & & \\
\hline
\end{tabular}

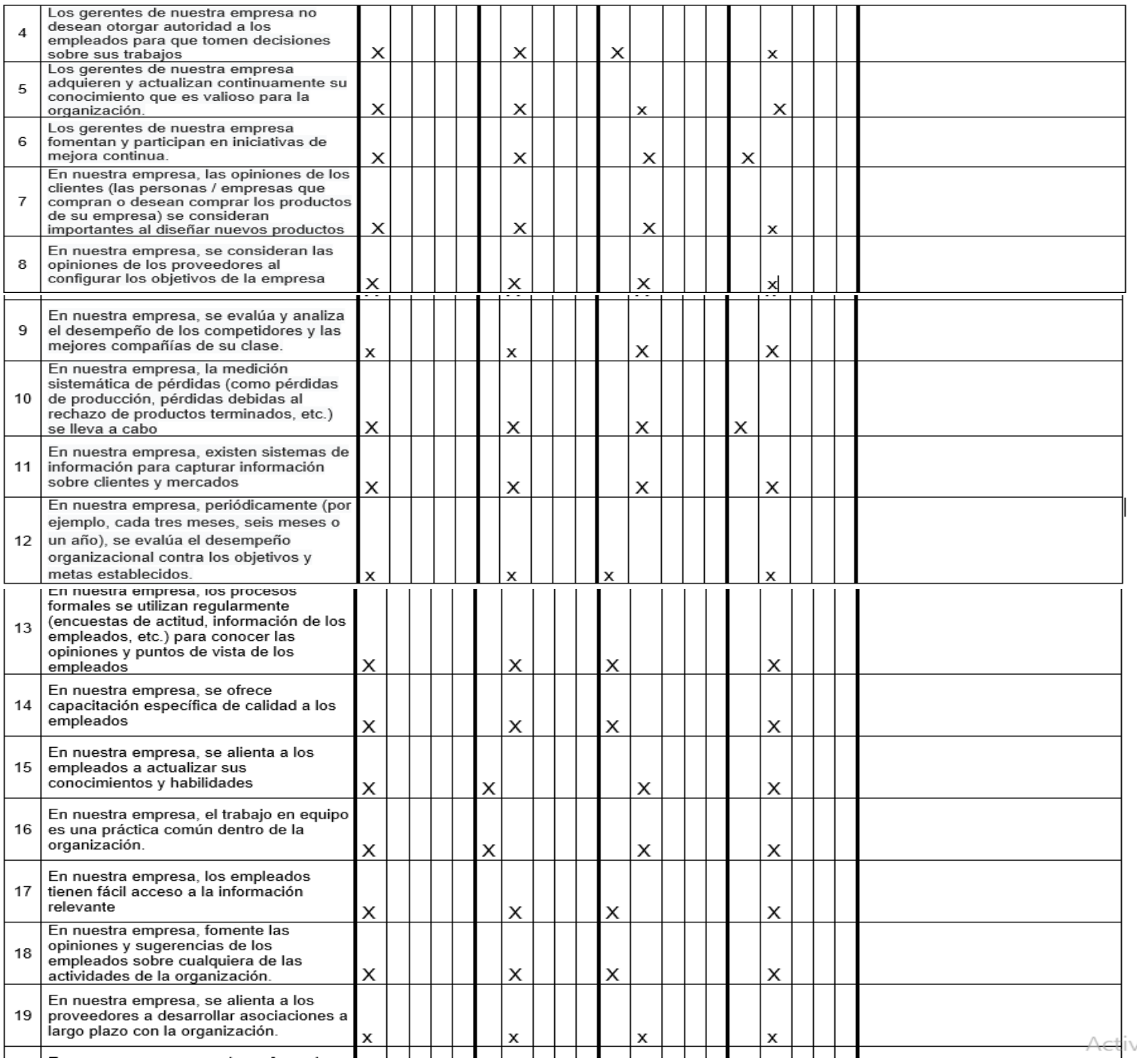




\begin{tabular}{|c|c|c|c|c|c|c|c|c|c|c|c|c|c|c|c|}
\hline 20 & $\begin{array}{l}\text { En nuestra empresa no da preferencia a } \\
\text { la calidad sobre el costo al hacer } \\
\text { acuerdos de compra con proveedores. }\end{array}$ & & $\mathrm{X}$ & & & $\mathrm{X}$ & & & $X$ & & & & $x$ & & \\
\hline 21 & $\begin{array}{l}\text { En nuestra empresa, el desempeño de } \\
\text { los proveedores se evalúa } \\
\text { periódicamente. }\end{array}$ & $x$ & & & & $x$ & & & $x$ & & & $x$ & & & \\
\hline 22 & $\begin{array}{l}\text { En nuestra empresa, se proporciona } \\
\text { información y recursos actualizados a } \\
\text { todos los empleados para realizar sus } \\
\text { trabajos. }\end{array}$ & $x$ & & & & $x$ & & & $X$ & & & $\mathrm{x}$ & & & \\
\hline 23 & $\begin{array}{l}\text { En nuestra empresa trata de reducir el } \\
\text { efecto nocivo de sus actividades en el } \\
\text { medio ambiente. }\end{array}$ & $x$ & & & & $\mathrm{x}$ & & & $x$ & & & & $x$ & & \\
\hline 24 & $\begin{array}{l}\text { En nuestra empresa, se establecen } \\
\text { procedimientos adecuados para realizar } \\
\text { diferentes trabajos. }\end{array}$ & $x$ & & & & & $X$ & & $x$ & & & & $x$ & & \\
\hline 25 & $\begin{array}{l}\text { En nuestra empresa, los empleados } \\
\text { conocen los parámetros (temperatura, } \\
\text { presión, etc.) de los diferentes procesos, } \\
\text { que son necesarios. }\end{array}$ & & $x$ & & & & $x$ & & & $x$ & & & $x$ & & \\
\hline 26 & $\begin{array}{l}\text { En nuestra empresa, se monitorea el } \\
\text { desempeño de los procesos de } \\
\text { producción. }\end{array}$ & & $x$ & & & & $X$ & & & $\mathrm{X}$ & & & $x$ & & \\
\hline 27 & $\begin{array}{l}\text { En nuestra empresa, el departamento de } \\
\text { investigación y desarrollo }(I+D) \text { está } \\
\text { trabajando continuamente en el } \\
\text { desarrollo y la mejora. }\end{array}$ & & $x$ & & & $x$ & & & & $x$ & & $\mathrm{x}$ & & & \\
\hline 28 & $\begin{array}{l}\text { En nuestra empresa, se enfatiza el } \\
\text { desarrollo y la innovación de los } \\
\text { procesos de producción. }\end{array}$ & $x$ & & & & $x$ & & & $x$ & & & $x$ & & & \\
\hline 29 & $\begin{array}{l}\text { En nuestra empresa, los procesos de } \\
\text { producción son capaces de producir } \\
\text { productos de acuerdo con las } \\
\text { especificaciones de diseño. }\end{array}$ & & $\mathrm{x}$ & & & & $X$ & & $x$ & & & $x$ & & & \\
\hline 30 & $\begin{array}{l}\text { En nuestra empresa, existen sistemas } \\
\text { adecuados para atender las quejas de } \\
\text { los clientes. }\end{array}$ & & $\mathrm{X}$ & & & $\mathrm{X}$ & & & & $\mathrm{X}$ & & $x$ & & & \\
\hline 31 & $\begin{array}{l}\text { Nuestra firma de exportación ha sido } \\
\text { muy rentable. }\end{array}$ & & $x$ & & & $x$ & & & & $x$ & & $X$ & & & \\
\hline 32 & $\begin{array}{l}\text { Nuestra firma de exportación ha } \\
\text { generado un alto volumen de ventas. }\end{array}$ & & $\mathrm{x}$ & & & $\mathrm{x}$ & & & & $\mathrm{X}$ & & $\mathrm{x}$ & & & \\
\hline 33 & $\begin{array}{l}\text { Nuestra firma de exportación ha logrado } \\
\text { un rápido crecimiento. }\end{array}$ & $x$ & & & & $\mathrm{x}$ & & & & $\mathrm{X}$ & & $x$ & & & \\
\hline 34 & $\begin{array}{l}\text { Nuestra firma de exportación ha } \\
\text { mejorgdo nuestra competitividad globsl. }\end{array}$ & $x$ & & & & $\mathrm{x}$ & & & $x$ & & & & $x$ & & \\
\hline 35 & $\begin{array}{l}\text { Nuestra firma de exportación ha } \\
\text { fortalecido nuestra posición estratégica. }\end{array}$ & & $x$ & & & $\mathrm{x}$ & & & $x$ & & & & $x$ & & \\
\hline 36 & \begin{tabular}{|l|} 
Nuestra firma de exportación ha \\
aumentado significativamente nuestra \\
participación en el mercado global.
\end{tabular} & $\mathrm{x}$ & & & & & $\mathrm{X}$ & & $x$ & & & & $x$ & & \\
\hline 37 & $\begin{array}{l}\text { El desempeño exportador de nuestra } \\
\text { firma ha sido satisfactorio. }\end{array}$ & $x$ & & & & & 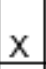 & & $x$ & & & & $x$ & & \\
\hline 38 & $\begin{array}{l}\text { Nuestra firma de exportación ha sido } \\
\text { exitosa. }\end{array}$ & & $x$ & & & $\mathrm{x}$ & & & $x$ & & & $x$ & & & \\
\hline 39 & $\begin{array}{l}\text { Nuestra empresa de exportación ha } \\
\text { cumplido plenamente nuestras } \\
\text { expectativas. }\end{array}$ & $\mathrm{x}$ & & & & & $\mathrm{x}$ & & $\mathrm{X}$ & & & $\mathrm{x}$ & & & \\
\hline
\end{tabular}




\section{Juez N 2: Carlos Alberto Pereira Luza}

\section{IN STRUMENTO PARA LA VALIDEZ DE CONTENIDO}

\section{(JUICIO DE EXPERTOS)}

El presente instrumento tiene como finalidad validar la encuesta de Gestión de Calidad Total y Desempeño Exportador, el mismo que será aplicado a los agentes de carga que forman parte del estudio 'RELACIÓN ENTRE LA GESTIÓN DE CALIDAD TOTAL Y EL DESEMPEÑO EXPORTADOR DE MYPES EXPORTADORAS PERUANAS DE CACAO $2020^{*}$ que corresponde $\mathrm{a}$ un diseño de investigación no experimental y transversal.

Instrucciones

La evaluación requiere una lectura detallada y completa de cada ítem propuesto a fin de comparar de manera cualitativa con los criterios propuestos relativos a: Claridad de la redacción, Contexto correcto de ítem, Congruencia con el contenido y Dominio del Constructo. Para tal fin, deberá asignar una valoración si el ítem presenta o no los criterios propuestos, y caso contrario se ofrece un espacio para las observaciones si las hubiera.

\begin{tabular}{|l|l|}
\hline Juez N : & 2 \\
\hline Fecha actual: & 3 de junio de 2020 \\
\hline Nombres y Apellidos de Juez: & Carlos Alberto Pereira Luza \\
\hline Grado Académico: & Doctor en Derecho \\
\hline Puesto de trabajo: & Especialista en Aduanas SUNAT \\
\hline Institución donde labora: & SUNAT \\
\hline $\begin{array}{l}\text { Años de experiencia } \\
\text { profesional/cientifica: }\end{array}$ & 25 \\
\hline
\end{tabular}

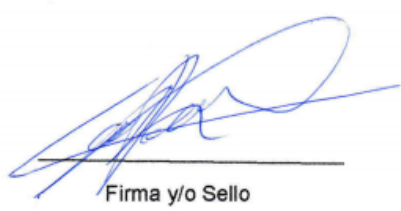




\subsection{INVENTARIO DE LA ENCUESTA DE GESTION DE CALIDAD TOTAL Y DESEMPEÑO EXPORTADOR}

\section{INSTRUMENTO PARA FINES ESPECIFICOS DE LA VALIDACION DE CONTENIDO (JUICIO DE EXPERTO)}

Calificación: Muy aceptable (5) Aceptable (4) Regular (3) Poco aceptable (2) Inaceptable (1)

\begin{tabular}{|c|c|c|c|c|c|c|c|c|c|c|c|c|c|c|c|c|c|}
\hline \multirow{2}{*}{$\mathbf{N}^{\circ}$} & \multirow{2}{*}{ Ítems (afirmaciones) } & \multicolumn{4}{|c|}{ Claridad $^{1}$} & \multicolumn{4}{|c|}{ Congruencia ${ }^{2}$} & \multicolumn{3}{|c|}{ Contexto ${ }^{2}$} & & \multicolumn{3}{|c|}{$\begin{array}{l}\text { Dominio del } \\
\text { constructo }^{4}\end{array}$} & \multirow[t]{2}{*}{ Sugerencias } \\
\hline & & 5 & 4 & 32 & 1 & 5 & 43 & 32 & 1 & 5 & \begin{tabular}{l|l}
4 & 3
\end{tabular} & 2 & \begin{tabular}{|l|l}
1 & 5
\end{tabular} & \begin{tabular}{l|l}
5 & 4
\end{tabular} & 3 & 21 & \\
\hline 1 & $\begin{array}{l}\text { Los gerentes de nuestra empress } \\
\text { consideran que el costo es más } \\
\text { importante en comparación con la } \\
\text { calidad de los productos. }\end{array}$ & $\mathrm{x}$ & & & & $\mathrm{x}$ & & & & $\mathrm{x}$ & & & & $\mathrm{x}$ & & & \\
\hline 2 & $\begin{array}{l}\text { Los gerentes de nuestra empresa se } \\
\text { presentan como modelos a seguir para } \\
\text { los empleados }\end{array}$ & & $\mathrm{x}$ & & & $x$ & & & & & $\mathrm{x}$ & & & $\mathrm{x}$ & & & \\
\hline 3 & $\begin{array}{l}\text { Los gerentes de nuestra empresa se } \\
\text { aseguran de que los empleados } \\
\text { conozcan los planes a largo plazo de la } \\
\text { empresa }\end{array}$ & $x$ & & & & & $\mathrm{x}$ & & & & $\mathrm{x}$ & & $\underline{x}$ & $x$ & & & \\
\hline
\end{tabular}

\begin{tabular}{|c|c|c|c|c|c|c|c|c|c|c|c|c|c|c|}
\hline 4 & \begin{tabular}{|l|} 
Los gerentes de nuestra empresa no \\
desean otorgar autoridad a los \\
empleados para que tomen decisiones \\
sobre sus trabaios
\end{tabular} & $\mathrm{x}$ & & & $X$ & & & $\mathrm{X}$ & & & & $x$ & & \\
\hline 5 & $\begin{array}{l}\text { Los gerentes de nuestra empresa } \\
\text { adquieren y actualizan continuamente } \\
\text { su conocimiento que es valioso para la } \\
\text { organización. }\end{array}$ & & $x$ & & $\mathrm{X}$ & & & $\mathrm{X}$ & & & $\mathrm{X}$ & & & \\
\hline 6 & $\begin{array}{l}\text { Los gerentes de nuestra empresa } \\
\text { fomentan y participan en iniciativas de } \\
\text { mejora continua. }\end{array}$ & & $x$ & & $\mathrm{X}$ & & & & $\mathrm{X}$ & & $\mathrm{X}$ & & & \\
\hline 7 & \begin{tabular}{|l} 
En nuestra empress, las opiniones de \\
los clientes (las personas / empresas \\
que compran o desean comprar los \\
productos de su empresa) se \\
consideran importantes al diseñar \\
nuevos productos
\end{tabular} & $\mathrm{x}$ & & & & $x$ & & & $x$ & & & $x$ & & \\
\hline 8 & $\begin{array}{l}\text { En nuestra empresa, se consideran las } \\
\text { opiniones de los proveedores al } \\
\text { configurar los objetivos de la empresa }\end{array}$ & $\mathrm{X}$ & & & & $x$ & & $\mathrm{X}$ & & & $\mathrm{X}$ & & & \\
\hline 8 & \begin{tabular}{|l|} 
En nuestra empresa, se evalúa y \\
analiza el desempeño de los \\
competidores y las mejores compañías \\
de su clase.
\end{tabular} & & $X$ & & $x$ & & & & $x$ & & & $\mathrm{x}$ & & \\
\hline 10 & $\begin{array}{l}\text { En nuestra empresa, la medición } \\
\text { sistemática de pérdidas (como pérdidas } \\
\text { de producción, pérdidas debidas al } \\
\text { rechazo de productos terminados, etc.) } \\
\text { se lleva a cabo }\end{array}$ & $X$ & & & & $x$ & & & $x$ & & $x$ & & & \\
\hline 11 & $\begin{array}{l}\text { En nuestra empresa, existen sistemas } \\
\text { de información para capturar } \\
\text { información sobre clientes y mercados }\end{array}$ & IX & & & & $X$ & & $X$ & & & & $|x|$ & & \\
\hline 12 & $\begin{array}{l}\text { En nuestra empresa, periódicamente } \\
\text { (por ejemplo, cada tres meses, seis } \\
\text { meses o un año), se evalúa el } \\
\text { desempeño organizacional contra los } \\
\text { objetivos y metas establecidos. }\end{array}$ & & & & & $\mathrm{X}$ & & X & & & & $\mathrm{X}$ & & \\
\hline
\end{tabular}




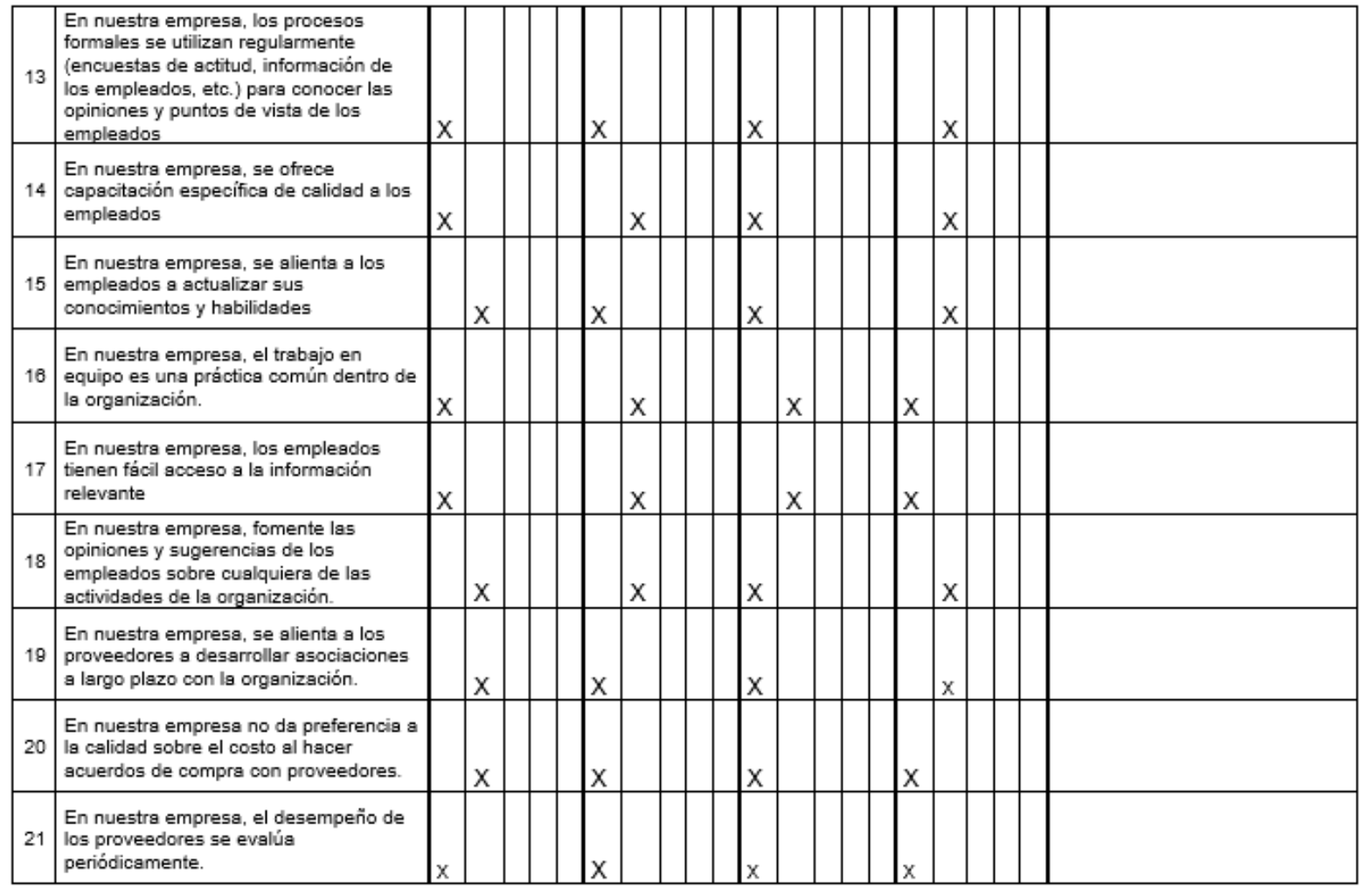

\begin{tabular}{|c|c|c|c|c|c|c|c|c|c|c|c|c|c|c|}
\hline 22 & $\begin{array}{l}\text { En nuestra empresa, se proporcions } \\
\text { información y recursos actualizados a } \\
\text { todos los empleados para realizar sus } \\
\text { trabaios. }\end{array}$ & $\mathrm{X}$ & & & $\mathrm{x}$ & & & $\mathrm{x}$ & & & $x$ & & & \\
\hline 23 & $\begin{array}{l}\text { En nuestra empresa trata de reducir el } \\
\text { efecto nocivo de sus actividades en el } \\
\text { medio ambiente. }\end{array}$ & & $\mathrm{X}$ & & $\mathrm{x}$ & & & & $X$ & & & $\mathrm{X}$ & & \\
\hline 24 & $\begin{array}{l}\text { En nuestra empresa, se establecen } \\
\text { procedimientos adecuados para realizar } \\
\text { diferentes trabajos. }\end{array}$ & $x$ & & & $\mathrm{x}$ & & & & $x$ & & $x$ & & & \\
\hline 25 & $\begin{array}{l}\text { En nuestra empresa, los empleados } \\
\text { conocen los parámetros (temperatura, } \\
\text { presión, etc.) de los diferentes procesos, } \\
\text { que son hecesarios. }\end{array}$ & $x$ & & & & $x$ & & & $\mathrm{x}$ & & $x$ & & & \\
\hline 28 & $\begin{array}{l}\text { En nuestra empresa, se monitorea el } \\
\text { desempeño de los procesos de } \\
\text { producción. }\end{array}$ & 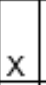 & & & & $x$ & & & $\mathrm{x}$ & & & $\mathrm{X}$ & & \\
\hline 27 & $\begin{array}{l}\text { En nuestra empresa, el departamento } \\
\text { de investigación y desarrollo }(I+D) \text { está } \\
\text { trabajando continuamente en el } \\
\text { desarrollo y la mejorg. }\end{array}$ & & $X$ & & & $x$ & & $x$ & & & $x$ & & & \\
\hline 28 & $\begin{array}{l}\text { En nuestra empresa, se enfatiza el } \\
\text { desarrollo y la innovación de los } \\
\text { procesos de producción. }\end{array}$ & $x$ & & & $\mathrm{X}$ & & & $x$ & & & $x$ & & & \\
\hline 29 & $\begin{array}{l}\text { En nuestra empresa, los procesos de } \\
\text { producción son capaces de producir } \\
\text { productos de acuerdo con las } \\
\text { especificaciones de diseño. }\end{array}$ & & X & & $x$ & & & $\mathrm{X}$ & & & & $\mathrm{X}$ & & \\
\hline 30 & $\begin{array}{l}\text { En nuestra empresa, existen sistemas } \\
\text { adecuados para atender las quejas de } \\
\text { los clientes. }\end{array}$ & $\mathrm{X}$ & & & $X$ & & & $\mathrm{X}$ & & & $x$ & & & \\
\hline 31 & $\begin{array}{l}\text { Nuestra firma de exportación ha sido } \\
\text { muy rentable. }\end{array}$ & $X$ & & & $x$ & & & & & & & & & \\
\hline
\end{tabular}




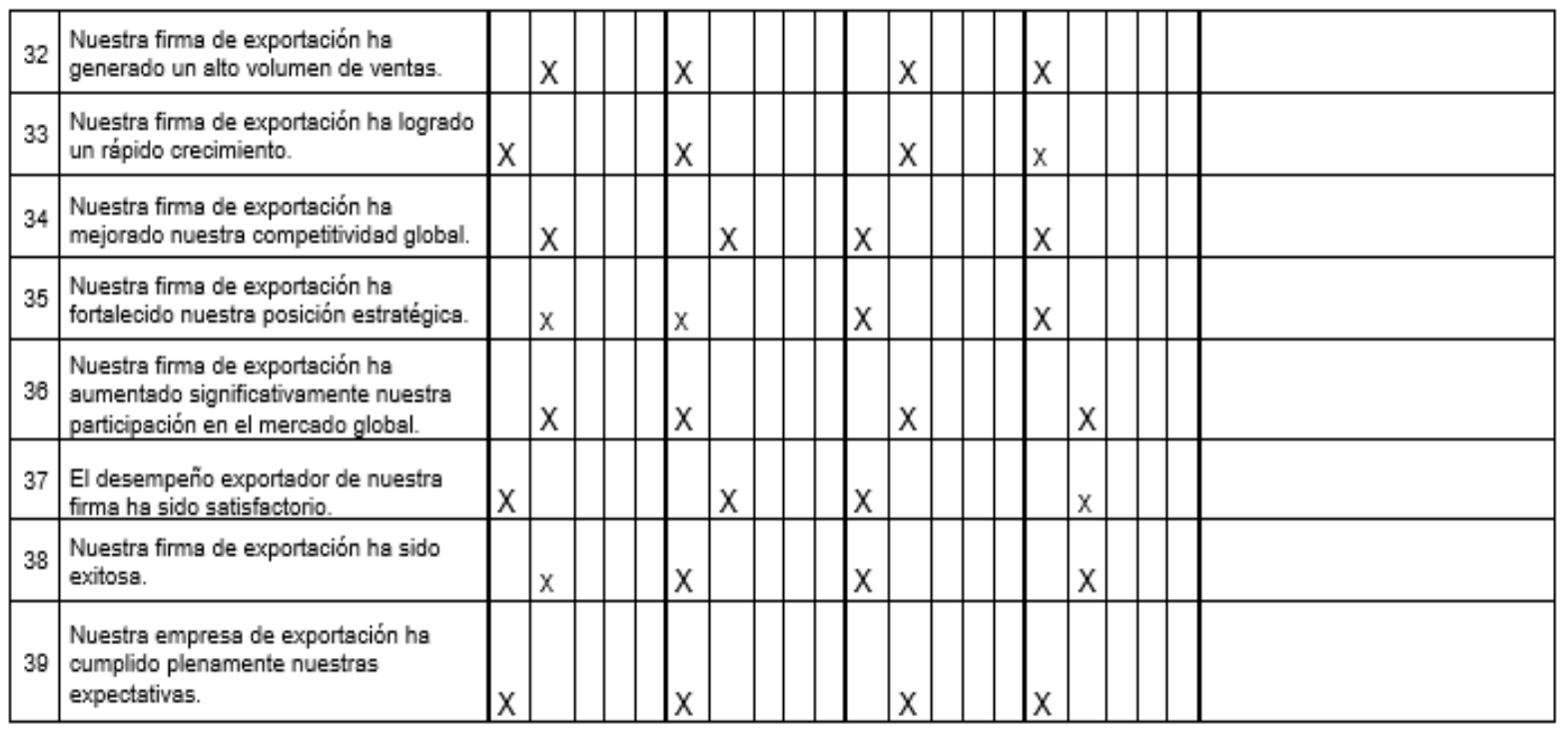




\section{Juez N’3: Alberto Valdez Barboza}

\section{IN STRUMENTO PARA LA VALIDEZ DE CONTENIDO}

\section{(JUICIO DE EXPERTOS)}

El presente instrumento tiene como finalidad validar la encuesta de Gestión de Calidad Total y Desempeño Exportador, el mismo que será aplicado a los agentes de carga que forman parte del estudio 'RELACIÓN ENTRE LA GESTIÓN DE CALIDAD TOTAL Y EL DESEMPEÑO EXPORTADOR DE MYPES EXPORTADORAS PERUANAS DE CACAO $2020^{\circ}$ que corresponde a un diseño de investigación no experimental y transversal.

\section{Instrucciones}

La evaluación requiere una lectura detallada y completa de cada ítem propuesto a fin de comparar de manera cualitativa con los criterios propuestos relativos a: Claridad de la redacción, Contexto correcto de ítem, Congruencia con el contenido y Dominio del Constructo. Para tal fin, deberá asignar una valoración si el ítem presenta o no los criterios propuestos, y caso contrario se ofrece un espacio para las observaciones si las hubiera.

\begin{tabular}{|c|c|}
\hline Juez $N$ : & 3 \\
\hline Fecha actual: & 5 de junio de 2020 \\
\hline Nombres y Apellidos de Juez: & Alberto Valdez Barboza \\
\hline Grado Académico: & MgSc Economía \\
\hline Puesto de trabajo: & $\begin{array}{l}\text { Docente universitario, asesor de la escuela de } \\
\text { economía de la universidad Ricardo Palma y } \\
\text { consultor de empresas en el área de ventas y } \\
\text { finanzas. }\end{array}$ \\
\hline Institución donde labora: & Universidad San Ignacio de Loyola \\
\hline $\begin{array}{l}\text { Años de experiencia } \\
\text { profesional/científica: }\end{array}$ & $\begin{array}{l}35 \text { años de experiencia profesional entre la } \\
\text { docencia universitaria y la actividad industrial. }\end{array}$ \\
\hline
\end{tabular}

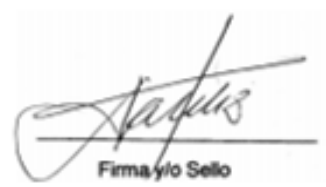




\subsection{INVENTARIO DE LA ENCUESTA DE GESTION DE CALIDAD TOTAL Y DESEMPEÑO EXPORTADOR}

\section{INSTRUMENTO PARA FINES ESPECIFICOS DE LA VALIDACION DE CONTENIDO (JUICIO DE EXPERTO)}

Calificación: Muy aceptable (5) Aceptable (4) Regular (3) Poco aceptable (2) Inaceptable

(1)

\begin{tabular}{|c|c|c|c|c|c|c|c|c|c|c|c|c|c|c|c|c|c|c|}
\hline \multirow{2}{*}{$\mathbf{N}^{\circ}$} & \multirow{2}{*}{ İtems (afirmaciones) } & \multicolumn{4}{|c|}{ Claridad $^{1}$} & \multicolumn{4}{|c|}{ Congruencia ${ }^{2}$} & \multicolumn{4}{|c|}{ Contexto $^{2}$} & \multicolumn{4}{|c|}{$\begin{array}{l}\text { Dominio del } \\
\text { constructo }\end{array}$} & \multirow[t]{2}{*}{ Sugerencias } \\
\hline & & 5 & 4 & 32 & 1 & 5 & 4 & \begin{tabular}{l|l}
3 & 2 \\
4
\end{tabular} & 1 & 5 & 4 & 32 & 1 & 5 & $4: 3$ & \begin{tabular}{ll|}
3 & 2 \\
\end{tabular} & 1 & \\
\hline 1 & $\begin{array}{l}\text { Los gerentes de nuestra empresa } \\
\text { consideran que el costo es más } \\
\text { importante en comparación con la } \\
\text { calidad de los productos. } \\
\end{array}$ & $x$ & & & & $x$ & & & & $x$ & & & & $x$ & & & & \\
\hline 2 & $\begin{array}{l}\text { Los gerentes de nuestra empresa se } \\
\text { presentan como modelos a seguir para } \\
\text { los empleados }\end{array}$ & $x$ & & & & & $x$ & & & & $\mathrm{x}$ & & & $x$ & & & & \\
\hline 3 & $\begin{array}{l}\text { Los gerentes de nuestra empresa se } \\
\text { aseguran de que los empleados } \\
\text { conozosn los planes a largo plazo de la } \\
\text { empresa }\end{array}$ & $x$ & & & & & $x$ & & & $x$ & & & & $\mathrm{x}$ & & & & \\
\hline 4 & $\begin{array}{l}\text { Los gerentes de nuestra empresa no } \\
\text { desean otorgar autoridad a los } \\
\text { empleados para que tomen decisiones } \\
\text { sobre sus trabajos }\end{array}$ & $\mathrm{X}$ & & & & $x$ & & & & $x$ & & & & & $x$ & & & \\
\hline 5 & \begin{tabular}{|l|} 
Los gerentes de nuestra empresa \\
adquieren y actualizan continuamente su \\
conocimiento que es valioso para la \\
organización.
\end{tabular} & $\mathrm{x}$ & & & & $x$ & & & & $x$ & & & & $x$ & & & & \\
\hline 6 & $\begin{array}{l}\text { Los gerentes de nuestra empresa } \\
\text { fomentan y participan en iniciativas de } \\
\text { mejora continua. }\end{array}$ & $x$ & & & & & $\mathrm{X}$ & & & $x$ & & & & $x$ & & & & \\
\hline 7 & \begin{tabular}{|l|} 
En nuestra empresa, las opiniones de \\
los clientes (las personas / empresas \\
que compran o desean comprar los \\
productos de su empresa) se consideran \\
importantes al diseñar nuevos productos \\
\end{tabular} & $\mathrm{x}$ & & & & & $\mathrm{X}$ & & & $x$ & & & & & $\mathrm{x}$ & & & \\
\hline 8 & $\begin{array}{l}\text { En nuestra empresa, se consideran las } \\
\text { opiniones de los proveedores al } \\
\text { configurar los objetivos de la empresa }\end{array}$ & $x$ & & & & & $\mathrm{x}$ & & & $x$ & & & & & $\mathrm{x}$ & & & \\
\hline 8 & $\begin{array}{l}\text { En nuestra empresa, se evalúa y ansliza } \\
\text { el desempeño de los competidores y las } \\
\text { mejores compañías de su clase. }\end{array}$ & & $x$ & & & $x$ & & & & & $x$ & & & & $x$ & & & \\
\hline 10 & $\begin{array}{l}\text { En nuestra empresa, la medición } \\
\text { sistemática de pérdidas (como pérdidas } \\
\text { de producción, pérdidas debidas al } \\
\text { rechazo de productos terminados, etc.) } \\
\text { se lleva a cabo }\end{array}$ & & $x$ & & & $\mathrm{x}$ & & & & & $x$ & & & $x$ & & & & \\
\hline 11 & $\begin{array}{l}\text { En nuestra empresa, existen sistemas } \\
\text { de información para capturar } \\
\text { información sobre clientes y mercados }\end{array}$ & $x$ & & & & & $x$ & & & & $x$ & & & X & & & & \\
\hline 12 & $\begin{array}{l}\text { En nuestra empresa, periódicamente } \\
\text { (por ejemplo, cada tres meses, seis } \\
\text { meses o un año), se evalúa el } \\
\text { desempeño organizacional contra los } \\
\text { objetivos y metas establecidos. }\end{array}$ & & $|x|$ & & & $\mid x$ & & & & $x$ & & & & $x$ & & & & \\
\hline 13 & \begin{tabular}{|l|} 
En nuestra empresa, los procesos \\
formales se utilizan regularmente \\
(encuestas de actitud, información de los \\
empleados, etc.) para conocer las \\
opiniones y puntos de vista de los \\
empleados
\end{tabular} & & $\mathrm{x}$ & & & $\mathrm{x}$ & & & & $x$ & & & & & $x$ & & & \\
\hline 14 & $\begin{array}{l}\text { En nuestra empresa, se ofrece } \\
\text { capacitación especifica de calidad a los } \\
\text { empleados }\end{array}$ & & $x$ & & & & $x$ & & & $\mathrm{X}$ & & & & & $x$ & & & \\
\hline
\end{tabular}




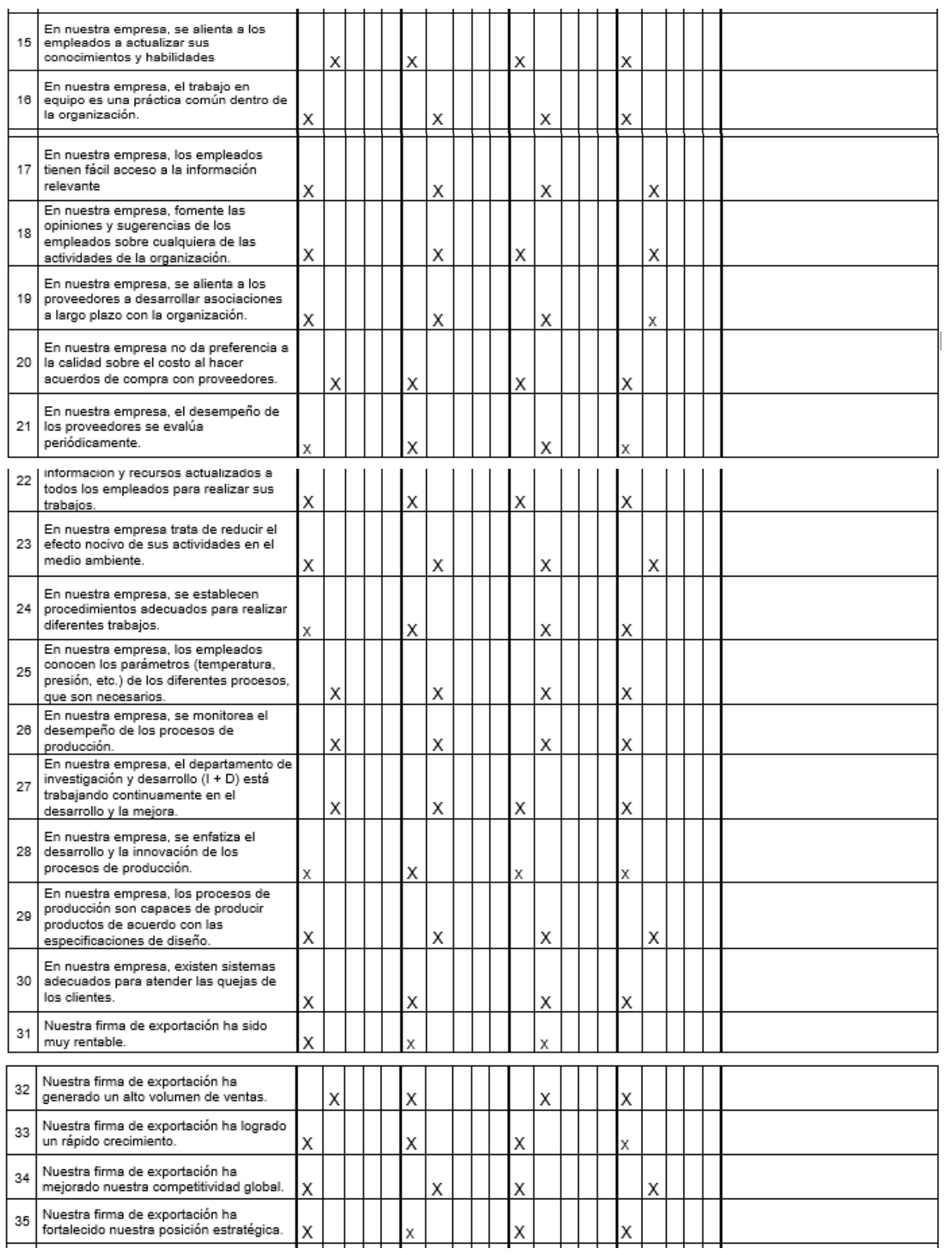




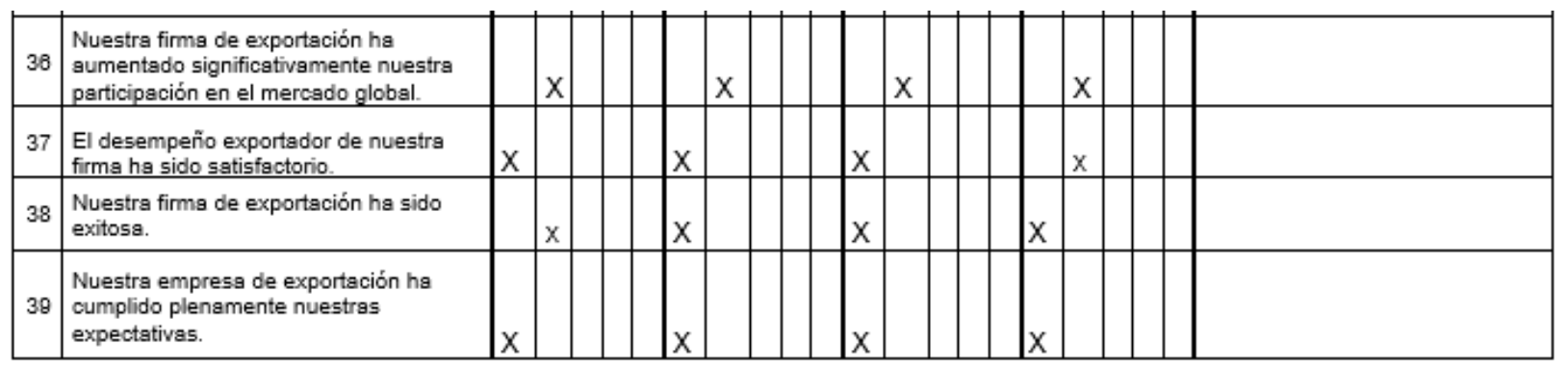

